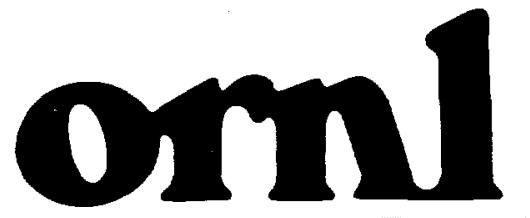

OAK RIDGE

NATIONAL

LABORATORY

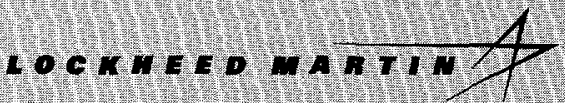

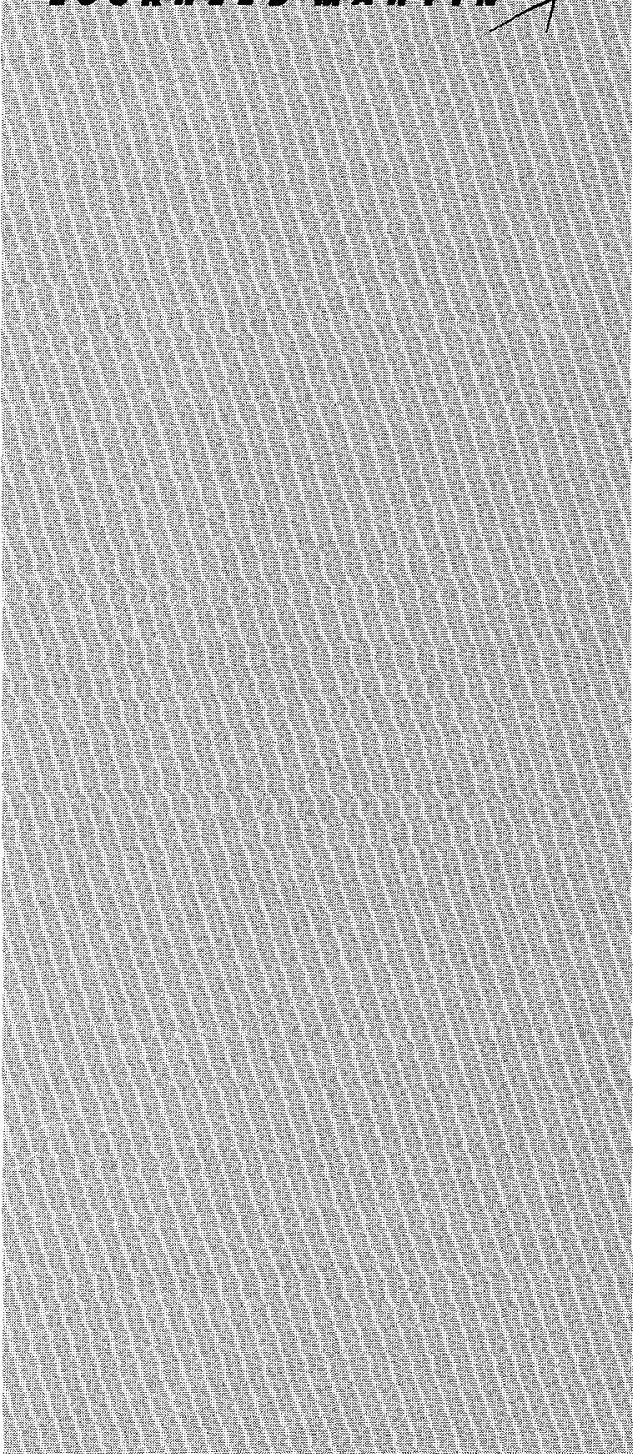

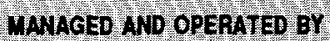

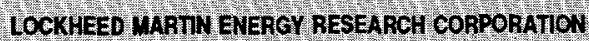
FOA HILUTIEOSTATES

DERARTEN OF EXEG

\section{Criticality Safety Scoping Study for the Transport of Weapons- Grade Mixed-Oxide Fuel Using the MO-1 Shipping Package}


This report has been reproduced directly from the best available copy.

Available to DOE and DOE contractors form the Office of Scientific and Technical Information, P.O. Box 62, Oak Ridge, TN 37831; prices available from (615) 576-8401.

Available to the public from the National Technical Information Service, U.S. Department of Commerce, 5285 Port Royal Rd., Springfield, VA 22161.

This report was prepared as an account of work sponsored by an agency of the United States Government. Neither the United States nor any agency thereof, nor any of their employees, makes any warranty, express or implied, or assumes any legal liability or responsibility for the accuracy, completeness, or usefulness of any information, apparatus, product, or process disclosed, or represents that its use would not infringe privately owned rights. Reference herein to any specific commercial product, process, or service by trade name, trademark, manufacturer, or otherwise, does not necessarily constitute or imply its endorsement, recommendation, or favoring by the United States Government or any agency thereof. The views and opinions of authors expressed herein do not necessarily state or reflect those of the United States Government or any agency thereof. 


\section{DISCLAIMER}

Portions of this document may be illegible in electronic image products. Images are produced from the best available original document. 
Computational Physics and Engineering Division

Criticality Safety Scoping Study for the Transport of WeaponsGrade Mixed-Oxide Fuel Using the MO-1 Shipping Package

M. E. Dunn

P. B. Fox

Date Published: May 1999

Prepared by the

Oak Ridge National Laboratory

Oak Ridge, Tennessee 37831-6370

Managed by

LOCKHEED MARTIN ENERGY RESEARCH CORP.

for the

U. S. DEPARTMENT OF ENERGY

under contract DE-AC05-96OR22464 



\begin{abstract}
This report provides the criticality safety information needed for obtaining certification for the shipment of mixed-oxide (MOX) fuel using the MO-1 [USA/9069/B( )F] shipping package. Specifically, this report addresses the shipment of non-weapons-grade MOX fuel as certified under Certificate of Compliance 9069, Revision 10. The report further addresses the shipment of weapons-grade MOX fuel using a possible Westinghouse fuel design. Criticality safety analysis information is provided to demonstrate that the requirements of 10 CFR $\S 71.55$ and 71.59 are satisfied for the MO-1 package. Using NUREG/CR-5661 as a guide, a transport index (TI) for criticality control is determined for the shipment of non-weapons-grade MOX fuel as specified in Certificate of Compliance 9069, Revision 10. A TI for criticality control is also determined for the shipment of weapons-grade MOX fuel. Since the possible weapons-grade fuel design is preliminary in nature, this report is considered to be a scoping evaluation and is not intended as a substitute for the final criticality safety analysis of the MO-1 shipping package.

However, the criticality safety evaluation information that is presented in this report does demonstrate the feasibility of obtaining certification for the transport of weapons-grade MOX lead test fuel using the MO-1 shipping package.
\end{abstract}





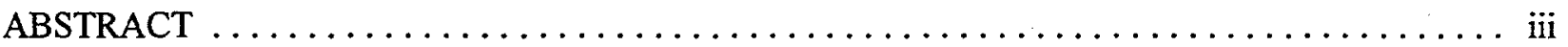

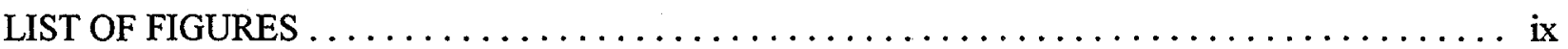

LIST OF TABLES $\ldots \ldots \ldots \ldots \ldots \ldots \ldots \ldots \ldots \ldots \ldots \ldots \ldots \ldots \ldots \ldots \ldots \ldots \ldots$

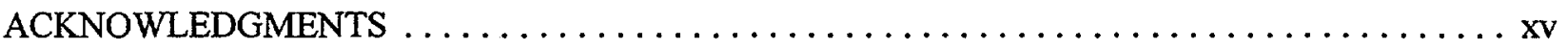

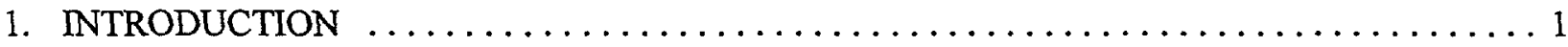

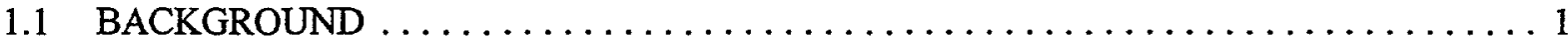

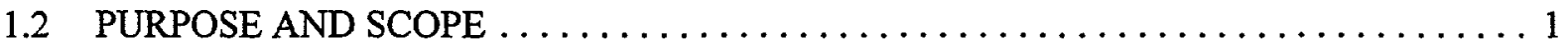

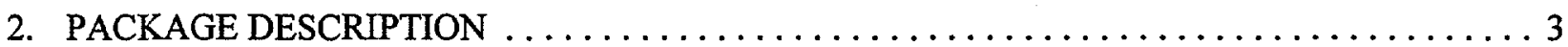

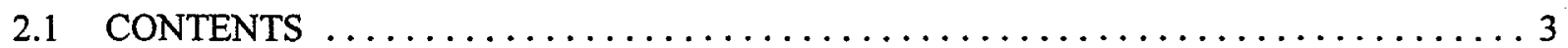

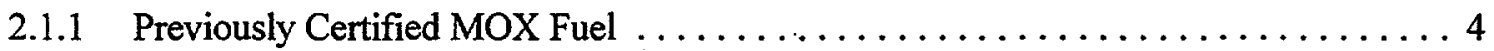

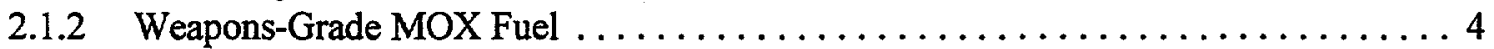

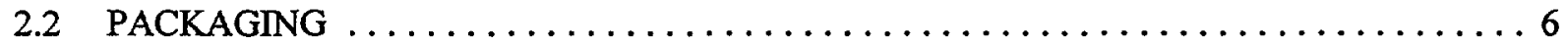

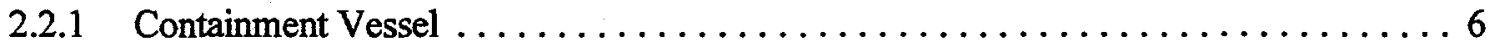

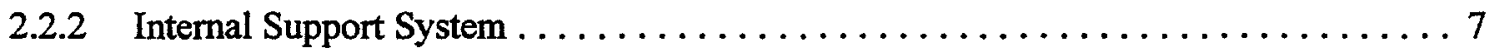

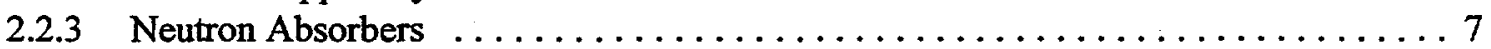

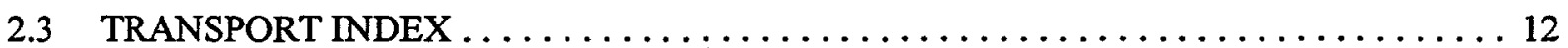

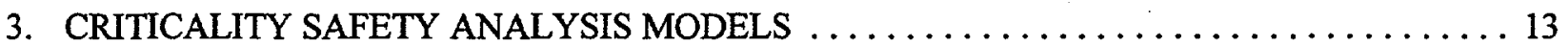

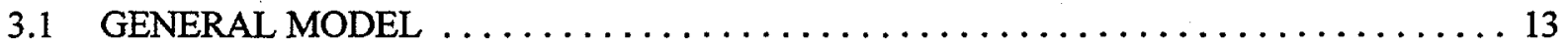

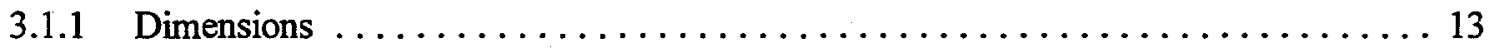

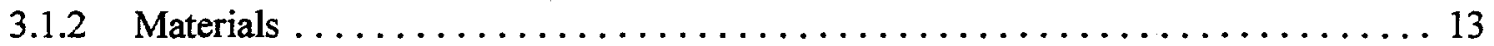

3.1.3 Models—Actual Package Differences $\ldots \ldots \ldots \ldots \ldots \ldots \ldots \ldots \ldots \ldots \ldots \ldots$

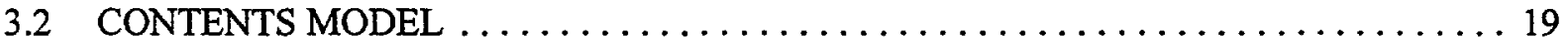

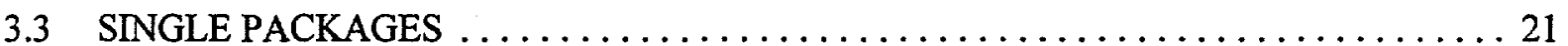

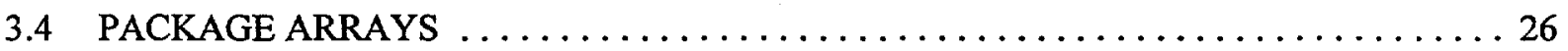

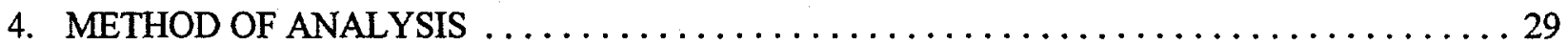

4.1 OVERVIEW OF CRITICALITY SAFETY EVALUATION $\ldots \ldots \ldots \ldots \ldots \ldots \ldots \ldots 29$

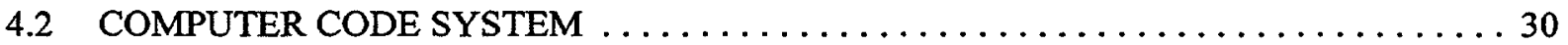

4.3 CROSS SECTIONS AND CROSS-SECTION PROCESSING $\ldots \ldots \ldots \ldots \ldots \ldots \ldots . \ldots . \ldots 1$

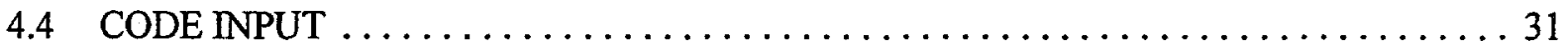

4.5 CONVERGENCE OF CALCULATIONS $\ldots \ldots \ldots \ldots \ldots \ldots \ldots \ldots \ldots \ldots \ldots \ldots \ldots \ldots \ldots \ldots$

5. VALIDATION OF CALCULATIONAL METHOD $\ldots \ldots \ldots \ldots \ldots \ldots \ldots \ldots \ldots \ldots \ldots \ldots$

5.1 SELECTION OF CRITICAL EXPERIMENTS $\ldots \ldots \ldots \ldots \ldots \ldots \ldots \ldots \ldots \ldots \ldots \ldots \ldots \ldots$

5.2 ESTABLISHMENT OF BIAS, UNCERTAINTY AND ACCEPTANCE CRITERIA … 37

5.3 ESTABLISHMENT OF RANGE OF APPLICABILITY $\ldots \ldots \ldots \ldots \ldots \ldots \ldots \ldots . \ldots \ldots$ 


\section{CONTENTS (continued)}

6. CRITICALITY CALCULATIONS AND RESULTS FOR SHIPMENT OF ASSEMBLIES $\ldots \ldots 77$

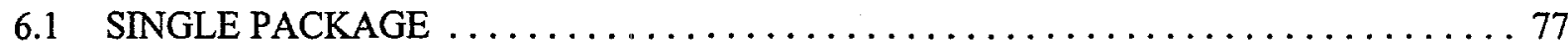

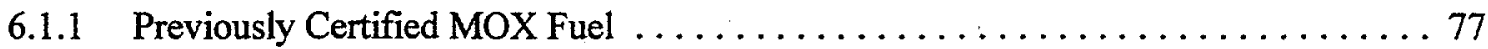

6.1.1.1 Undamaged Package Configurations . . . . . . . . . . . . 77

6.1.1.2 Damaged Package Configurations $\ldots \ldots \ldots \ldots \ldots \ldots \ldots \ldots \ldots \ldots$

6.1 .2 Weapons-Grade MOX Fuel . . . . . . . . . . . . . . . . . . . 89

6.1.2.1 Undamaged Package Configurations . . . . . . . . . . . . . 89

6.1.2.2 Damaged Package Configurations . . . . . . . . . . . . 93

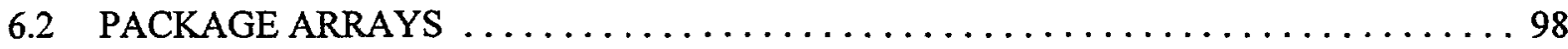

6.2 .1 Previously Certified MOX Fuel $\ldots \ldots \ldots \ldots \ldots \ldots \ldots \ldots \ldots \ldots \ldots \ldots \ldots$

6.2.1.1 Undamaged Package Configurations . . . . . . . . . . . . . 98

6.2.1.2 Damaged Package Configurations . . . . . . . . . . . . . . . 99

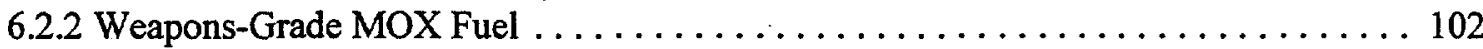

6.2.2.1 Undamaged Package Configurations .................... 102

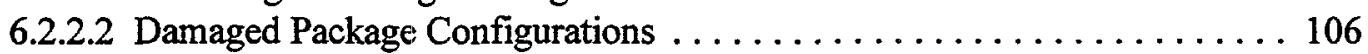

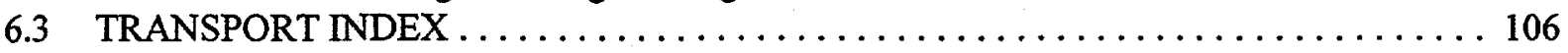

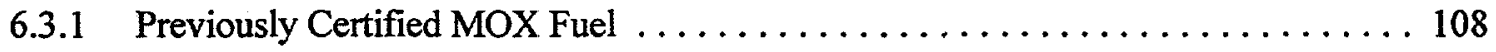

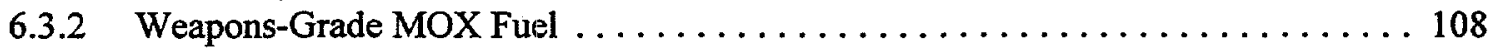

7. CRITICALITY CALCULATIONS AND RESULTS FOR SHIPMENT OF FUEL PINS $\ldots \ldots 109$

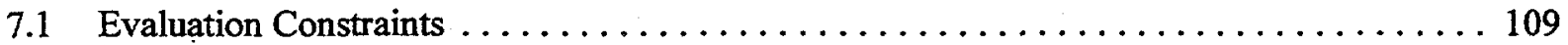

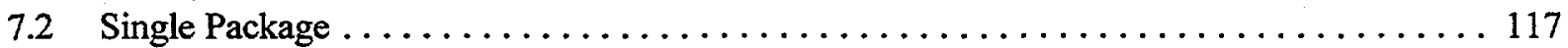

7.2.1 Previously Certified MOX Fuel $\ldots \ldots \ldots \ldots \ldots \ldots \ldots \ldots \ldots \ldots \ldots \ldots \ldots \ldots$

7.2.1.1 Undamaged Package Configurations . . . . . . . . . . . . 117

7.2.1.2 Damaged Package Configurations . . . . . . . . . . . . 119

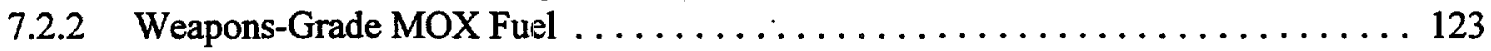

7.2.2.1 Undamaged Package Configurations ................... 123

7.2.2.2 Damaged Package Configurations . . . . . . . . . . . . . . 124

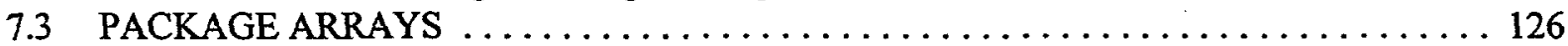

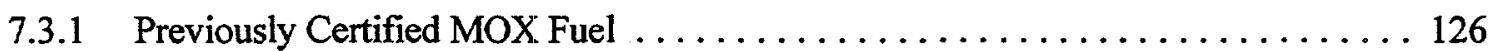

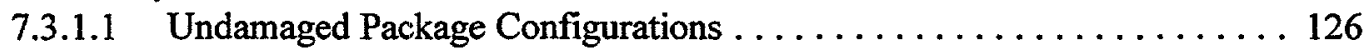

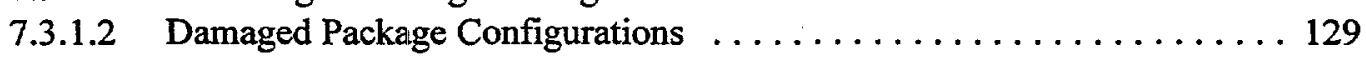

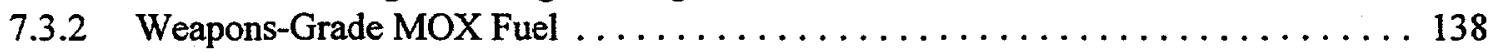

7.3.2.1 Undamaged Package Configurations . . . . . . . . . . . . . 138

7.3.2.2 Damaged Package Configurations $\ldots \ldots \ldots \ldots \ldots \ldots \ldots \ldots \ldots \ldots$

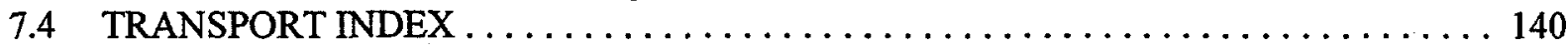

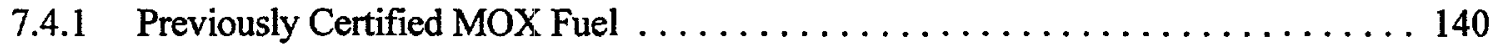

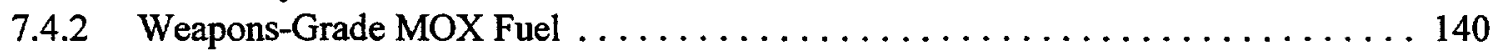

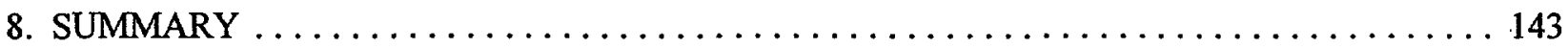

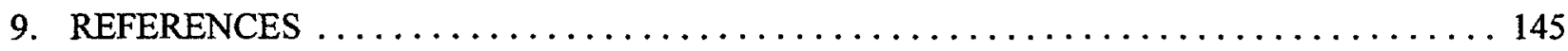


APPENDIX A: SAMPLE CSAS25 INPUT FILES $\ldots \ldots \ldots \ldots \ldots \ldots \ldots \ldots \ldots \ldots \ldots \ldots$

A.1 FUEL-ASSEMBLY CALCULATIONS $\ldots \ldots \ldots \ldots \ldots \ldots \ldots \ldots \ldots \ldots \ldots \ldots \ldots \ldots$

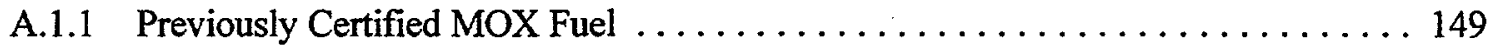

A.1.1.1 Single-Package Model . . . . . . . . . . . . . . . . . . 149

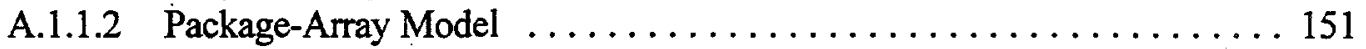

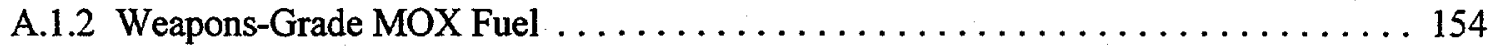

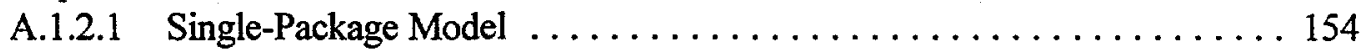

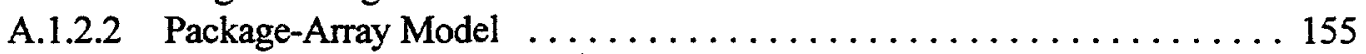

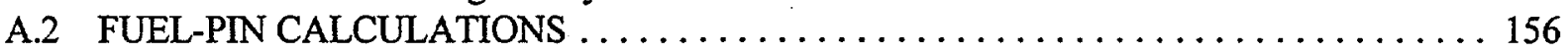

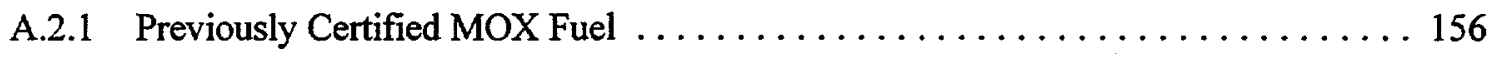

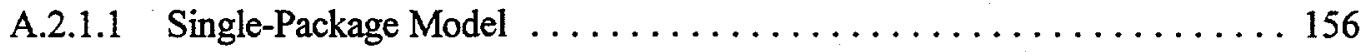

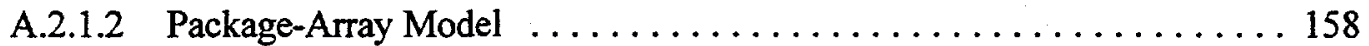

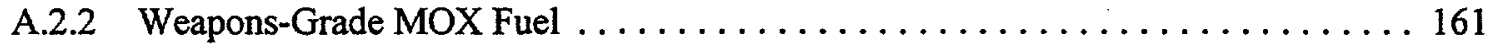

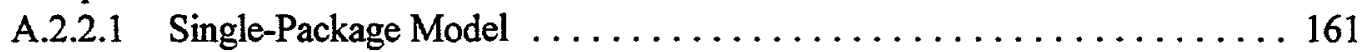

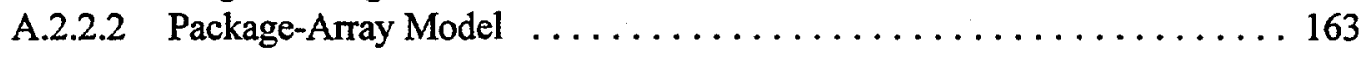

APPENDIX B: VOLUME FRACTION CALCULATION FOR $\mathrm{H}_{2} \mathrm{O} \ldots \ldots \ldots \ldots \ldots \ldots \ldots$ 



\section{LIST OF FIGURES}

Figure

Page

2.1. Isometric view of MO-1 shipping package. $\ldots \ldots \ldots \ldots \ldots \ldots \ldots \ldots \ldots \ldots \ldots$

2.2. Cutaway side view of MO-1 (all dimensions are in inches). $\ldots \ldots \ldots \ldots \ldots \ldots \ldots \ldots \ldots$

2.3. Cross-section view of MO-1 (all dimensions are in inches). $\ldots \ldots \ldots \ldots \ldots \ldots \ldots \ldots \ldots$

2.4. MO-1 cross-section detail A for strongback support structure (all dimensions are in inches). . . 11

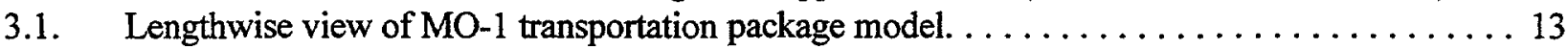

3.2. MO-1 cross-section view A-A (see Fig. 3.1) with two $14 \times 14$

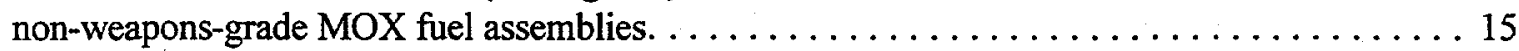

3.3. MO-1 cross-section view A-A (see Fig. 3.1) with two weapons-grade MOX fuel assemblies. . . 16

3.4. Detail of $14 \times 14$ non-weapons-grade MOX fuel assemblies in MO-1 $\ldots \ldots \ldots \ldots \ldots \ldots 17$

3.5. Detail of $17 \times 17$ weapons-grade MOX fuel assemblies in MO-1 $\ldots \ldots \ldots \ldots \ldots \ldots \ldots$

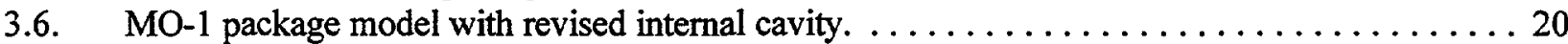

3.7. Damaged MO-1 model with fuel positioned in center of package. $\ldots \ldots \ldots \ldots \ldots \ldots \ldots$

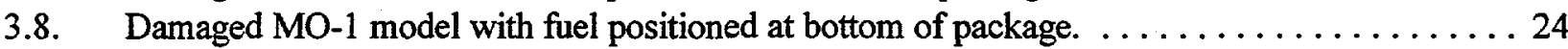

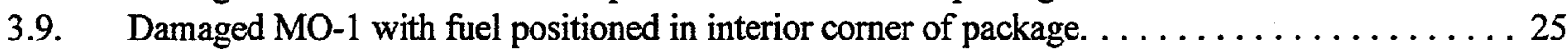

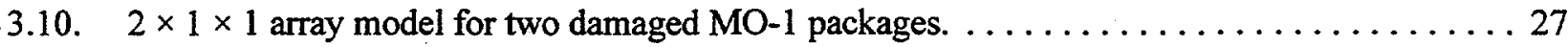

3.11. Alternative $2 \times 1 \times 1$ array model for two damaged MO-1 packages. . . . . . . . . . 28

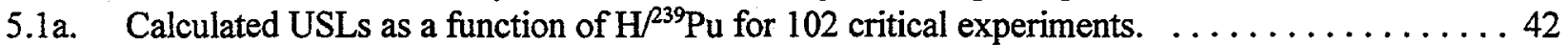

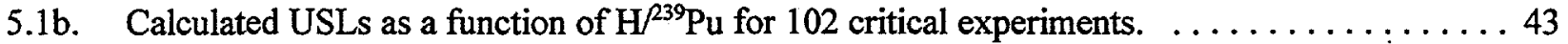

5.2. Calculated USLs as a function of $\mathrm{H}$ atom density for 102 critical experiments. . . . . . . . 44

5.3a. Calculated USLs as a function of $\mathrm{N}$ atom density for 102 critical experiments. . . . . . . . 4 45

5.3b. Calculated USLs as a function of $\mathrm{N}$ atom density for 102 critical experiments. . . . . . . . . 46

5.4. Calculated USLs as a function of ${ }^{241} \mathrm{Pu}{ }^{239} \mathrm{Pu}$ for 102 critical experiments. $\ldots \ldots \ldots \ldots \ldots 4$

5.5. Calculated USLs as a function of ${ }^{240} \mathrm{Pu} /{ }^{239} \mathrm{Pu}$ for 102 critical experiments. . . . . . . . 48

5.6. USLs for 36 critical experiments with $\mathrm{H}^{239} \mathrm{Pu} \leq 126.4 \ldots \ldots \ldots \ldots \ldots \ldots \ldots \ldots \ldots$

5.7a. Calculated USLs as a function of nitrogen atom density

for 63 experiments involving structural steel. . . . . . . . . . . . . . . . . . 62

5.7b. Calculated USLs as a function of nitrogen atom density

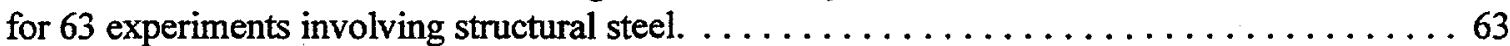

5.8. Calculated USLs as a function of $\mathrm{H}^{239} \mathrm{Pu}$ for $\mathrm{H}_{2} \mathrm{O}$-moderated experiments. $\ldots \ldots \ldots \ldots \ldots 6$

5.9. Calculated USLs as a function of $\mathrm{H}$ atom density for $\mathrm{H}$-moderated experiments. . . . . . . 66

5.10. Calculated USLs as a function of ${ }^{239} \mathrm{Pu}$ atom density for $\mathrm{H}_{2} \mathrm{O}$-reflected experiments. . . . . . 68

5.11. Calculated USLs as a function of ${ }^{240} \mathrm{Pu}$ atom density for $\mathrm{H}_{2} \mathrm{O}$-reflected experiments. . . . . . 69

5.12. Calculated USLs as a function of ${ }^{235} \mathrm{U}$ atom density for $\mathrm{H}_{2} \mathrm{O}$-reflected experiments. . . . . . 70

5.13. Calculated USLs as a function of ${ }^{238} \mathrm{U}$ atom density for $\mathrm{H}_{2} \mathrm{O}$-reflected experiments. $\ldots \ldots \ldots 71$

5.14. Calculated USLs as a function of ${ }^{238} \mathrm{U}$ for 36 experiments with $\mathrm{H}^{239} \mathrm{Pu}$ ratios

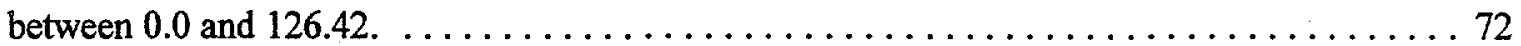

5.15. Calculated USLs as a function of AEF for $\mathrm{H}_{2} \mathrm{O}$-moderated experiments. $\ldots \ldots \ldots \ldots \ldots 73$

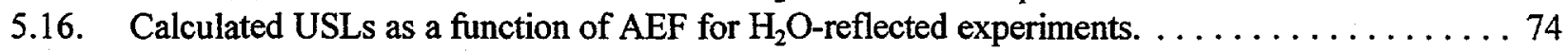

6.1. $\quad k_{\infty}$ as a function of pitch for previously certified MOX fuel. $\ldots \ldots \ldots \ldots \ldots \ldots \ldots \ldots$

6.2. Calculated neutron flux in $6 \mathrm{wt} \% \mathrm{PuO}_{2}$ MOX fuel at $293 \mathrm{~K}$ and $483.15 \mathrm{~K} \ldots \ldots \ldots . \ldots 85$

6.3. Macroscopic total cross section of $6 \mathrm{wt} \% \mathrm{PuO}_{2} \mathrm{MOX}$ fuel at $293 \mathrm{~K}$ and $483.15 \mathrm{~K} \ldots \ldots . \ldots 86$ 


\section{LIST OF' FIGURES (continued)}

6.4. Macroscopic fission cross section for $6 \mathrm{wt} \% \mathrm{PuO}_{2} \mathrm{MOX}$ fuel at $293 \mathrm{~K}$ and $483.15 \mathrm{~K} . \ldots 87$

6.5. $\quad k_{\infty}$ as a function of pitch for weapons-grade $\mathrm{MOX}$ fuel. $\ldots \ldots \ldots \ldots \ldots \ldots \ldots$

6.6. Calculated neutron flux in WG MOX fuel at $293 \mathrm{~K}$ and $483.15 \mathrm{~K} . \ldots \ldots \ldots \ldots . . .95$

6.7. Macroscopic total cross section for WG MOX fuel at $293 \mathrm{~K}$ and $483.15 \mathrm{~K} \ldots \ldots \ldots \ldots$

6.8. Macroscopic fission cross section for WG MOX fuel at $293 \mathrm{~K}$ and $483.15 \mathrm{~K} \ldots \ldots \ldots . \ldots 97$

6.9. Possible loading configuration for one WG assembly in two undamaged $\mathrm{MO}-1$ packages. . . . 105

7.1. $k_{\infty}$ as a function of triangular pitch for previously certified MOX fuel. $\ldots \ldots \ldots \ldots \ldots$

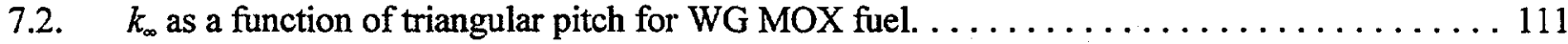

7.3. Arbitrary configuration of $6 \mathrm{wt} \% \mathrm{PuO}_{2} \mathrm{MOX}$ fuel pins. $\ldots \ldots \ldots \ldots \ldots \ldots \ldots \ldots \ldots \ldots$

7.4. Arbitrary configuration of WG MOX fuel pins. $\ldots \ldots \ldots \ldots \ldots \ldots \ldots \ldots \ldots \ldots \ldots$ 


\section{LIST OF TABLES}

Tabile

Page

2.1. Material specifications for MO-1 shipping package $\ldots \ldots \ldots \ldots \ldots \ldots \ldots \ldots \ldots$

2.2. Original certified $\mathrm{MOX}$ isotopic specifications $\ldots \ldots \ldots \ldots \ldots \ldots \ldots \ldots \ldots \ldots \ldots$

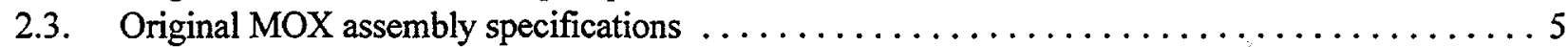

2.4. Westinghouse weapons-grade $\mathrm{MOX}$ isotopic specifications $\ldots \ldots \ldots \ldots \ldots \ldots \ldots \ldots \ldots$

2.5. Westinghouse weapons-grade assembly specifications $\ldots \ldots \ldots \ldots \ldots \ldots \ldots \ldots$

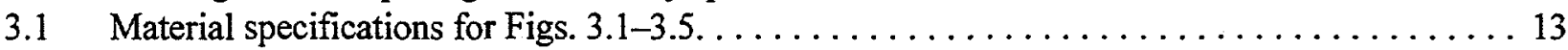

3.2. $\mathrm{H}_{2} \mathrm{O}$ saturation pressures for $\mathrm{MO}-1$ temperature conditions $\ldots \ldots \ldots \ldots \ldots \ldots \ldots \ldots \ldots 26$

5.1. Characterization variables of selected critical experiments $\ldots \ldots \ldots \ldots \ldots \ldots \ldots \ldots \ldots$

5.2. Correlation coefficients for characteristic parameters $\ldots \ldots \ldots \ldots \ldots \ldots \ldots \ldots \ldots \ldots$

5.3. Summary of USL calculations for 102 critical experiments $\ldots \ldots \ldots \ldots \ldots \ldots \ldots \ldots \ldots$

5.4. ${ }^{239} \mathrm{Pu}$ atom densities for different $\mathrm{MOX}$ loadings in $\mathrm{MO}-1 \ldots \ldots \ldots \ldots \ldots \ldots \ldots \ldots$

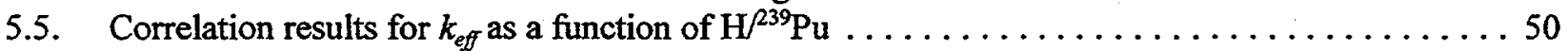

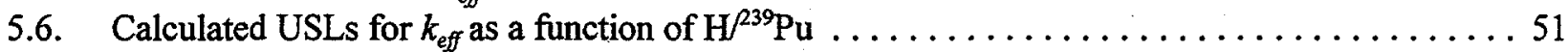

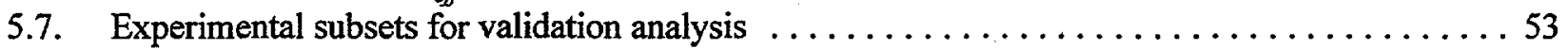

5.8. Summary of correlation study for 102 critical experiments $\ldots \ldots \ldots \ldots \ldots \ldots \ldots \ldots \ldots$

5.9. Summary of USL calculations for experiment subsets $\ldots \ldots \ldots \ldots \ldots \ldots \ldots \ldots \ldots \ldots$

5.10. USL calculations for selected experiment subsets $\ldots \ldots \ldots \ldots \ldots \ldots \ldots \ldots \ldots \ldots \ldots$

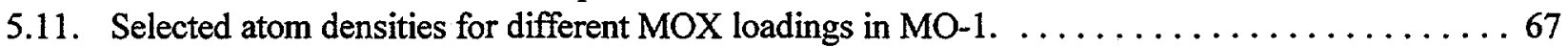

5.12. Hydrogen moderation parameters for different MOX loadings in $\mathrm{MO}-1 . \ldots \ldots \ldots \ldots \ldots$

6.1. Calculated $k_{\text {eff }}$ values for the $\mathrm{MO}-1$ with $6 \mathrm{wt} \% \mathrm{PuO}_{2}$

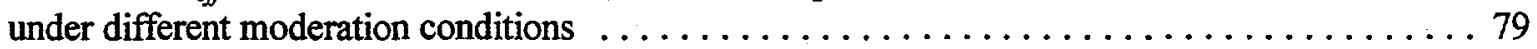

6.2. Calculated results for single package under normal conditions with 6 wt $\% \mathrm{PuO}_{2} \mathrm{MOX} \ldots \ldots 80$

6.3. Calculated $k_{e f f}$ values for the MO-1 under normal conditions with $4.4 \mathrm{wt} \%$ and $3.03 \mathrm{wt} \% \mathrm{PuO}_{2} \mathrm{MOX} \ldots \ldots \ldots \ldots \ldots \ldots \ldots \ldots \ldots \ldots \ldots \ldots \ldots \ldots \ldots \ldots$

6.4. Calculated results for the damaged single package $6 \mathrm{wt} \% \mathrm{PuO}_{2} \mathrm{MOX}_{\ldots} \ldots \ldots \ldots \ldots$

6.5. Calculated $k_{e f f}$ values for a damaged MO- 1 with $4.4 \mathrm{wt} \%$ and $3.03 \mathrm{wt} \% \mathrm{PuO}_{2} \mathrm{MOX}_{2} \ldots \ldots 88$

6.6. Comparison of reactivity between WG MOX assembly and non-weapons-grade MOX assemblies . . . . . . . . . . . . . . . . . . . . 89

6.7. Calculated $k_{\text {eff }}$ values for the MO-1 with WG MOX fuel

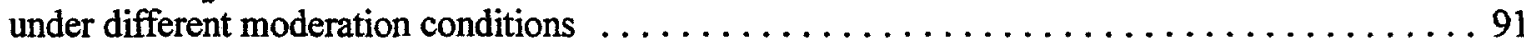

6.8. Calculated results for the MO-1 under normal conditions with a single WG MOX assembly .. 92

6.9. Calculated results for the MO-1 under normal conditions with two WG MOX assemblies .... 93

6.10. Calculated results for the damaged MO-1 with one WG MOX assembly . . . . . . . 94

6.11. Calculated system multiplication for an infinite array of undamaged $\mathrm{MO}-1 \mathrm{~s}$

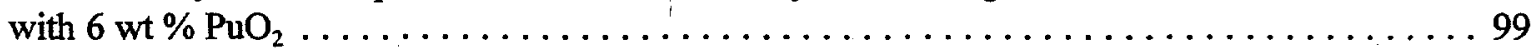

6.12. Calculated system multiplication for an infinite array of undamaged $\mathrm{MO}-1 \mathrm{~s}$

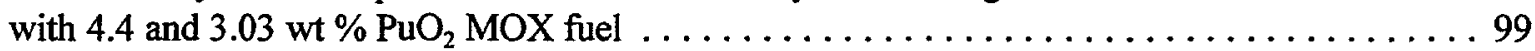

6.13. Calculated system multiplication for an infinite array of damaged $\mathrm{MO}-1 \mathrm{~s}$

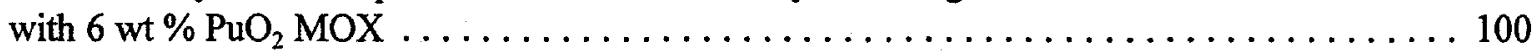

6.14. Calculated $k_{\text {eff }}$ values for finite array of damaged $\mathrm{MO}-1 \mathrm{~s}$ with $6 \mathrm{wt} \% \mathrm{PuO}_{2} \mathrm{MOX} \ldots \ldots \ldots 101$

6.15. Calculated $k_{\text {eff }}$ values for finite array of damaged MO-1s with $4.4 \mathrm{wt} \%$ and $3.03 \mathrm{wt} \% \mathrm{PuO}_{2} \mathrm{MOX}$ fuel 


\section{LIST OF TABLES (continued)}

6.16. Calculated system multiplication for an infinite array of undamaged MO-1s

with one WG MOX assembly . . . . . . . . . . . . . . . . . . . . . . 104

6.17. Calculated system multiplication for an infinite array of undamaged $\mathrm{MO}-1 \mathrm{~s}$

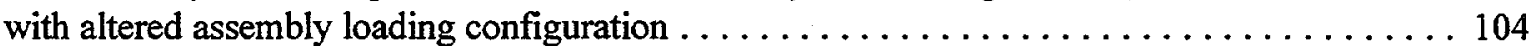

6.18. Calculated $k_{\text {eff }}$ values for finite array of damaged MO-1s with WG MOX $\ldots \ldots \ldots \ldots$

6.19. Previously certified MOX fuel parameters used for TI determination $\ldots \ldots \ldots \ldots \ldots \ldots$

6.20. Weapons-grade MOX fuel parameters used for $\mathrm{TI}$ determination $\ldots \ldots \ldots \ldots \ldots \ldots \ldots$

7.1. Calculated $k_{\text {eff }}$ values for $6 \mathrm{wt} \% \mathrm{PuO}_{2} \mathrm{MOX}$ fuel in rod box fully moderated

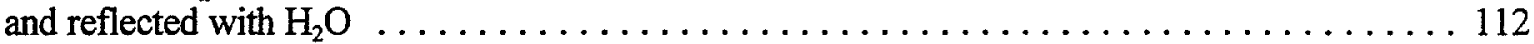

7.2. Calculated $k_{\text {eff }}$ values for $4.4 \mathrm{wt} \% \mathrm{PuO}_{2} \mathrm{MOX}$ fuel in rod box fully moderated

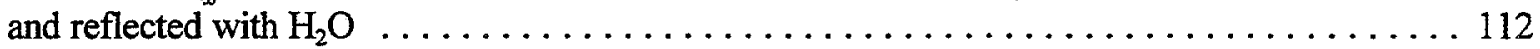

7.3. Calculated $k_{\text {eff }}$ values for $3.03 \mathrm{wt} \% \mathrm{PuO}_{2} \mathrm{MOX}$ fuel in rod box fully moderated

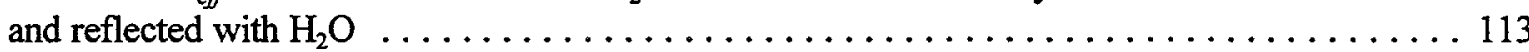

7.4. Calculated $k_{\text {eff }}$ values for WG MOX fuel in rod box fully moderated

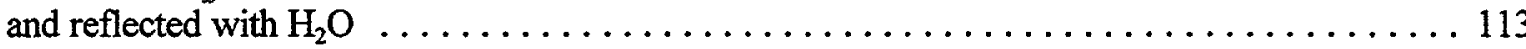

7.5. Calculated results for single package under normal conditions with $6 \mathrm{wt} \%$,

$4.4 \mathrm{wt} \%$ and $3.03 \mathrm{wt} \% \mathrm{PuO}_{2} \mathrm{MOX}$ fuel pins $\ldots \ldots \ldots \ldots \ldots \ldots \ldots \ldots \ldots \ldots \ldots \ldots \ldots$

7.6. Calculated results for the damaged single package with 6 wt $\% \mathrm{PuO}_{2} \mathrm{MOX}$ fuel pins $\ldots \ldots \ldots 120$

7.7. Calculated results for the damaged single package with $4.4 \mathrm{wt} \%$ and $3.03 \mathrm{wt} \%$

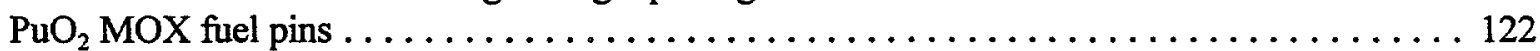

7.8. Calculated results for single package under normal conditions with WG MOX fuel pins . . . . 123

7.9. Calculated results for the damaged single package with WG MOX fuel pins $\ldots \ldots \ldots \ldots 125$

7.10. Calculated system multiplication for an infinite array of undamaged $\mathrm{MO}-1 \mathrm{~s}$

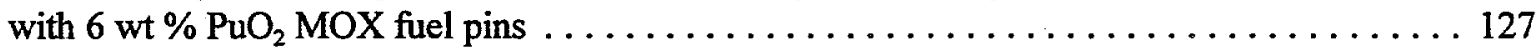

7.11. Calculated system multiplication for an infinite array of undamaged $\mathrm{MO}-1 \mathrm{~s}$

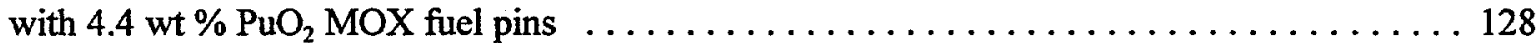

7.12. Calculated system multiplication for an infinite array of undamaged MO-1s

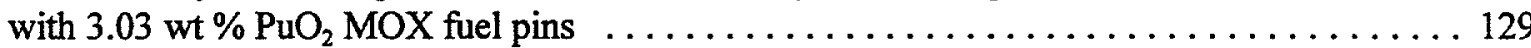

7.13. Calculated $k_{\text {eff }}$ values for two unspaced MO-1s (damaged)

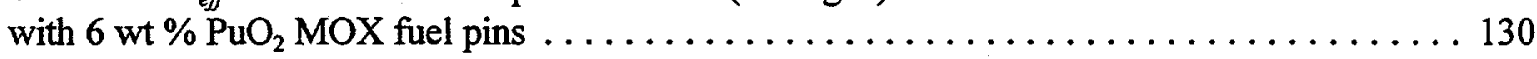

7.14. Calculated $k_{\text {eff }}$ values for two 0.5 in. spaced MO-1s (damaged)

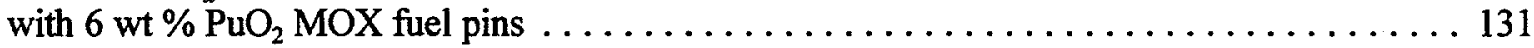

7.15. Calculated $k_{\text {eff }}$ values for two 1.0 in. spaced MO-1s (damaged)

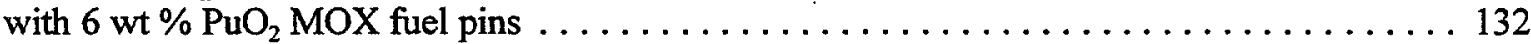

7.16. Calculated $k_{\text {eff }}$ values for two 2.0 in. spaced MO-1s (damaged)

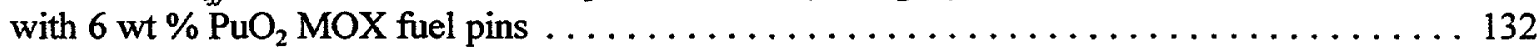

7.17. Calculated $k_{\text {eff }}$ values for two 3.0 in. spaced MO-1s (damaged)

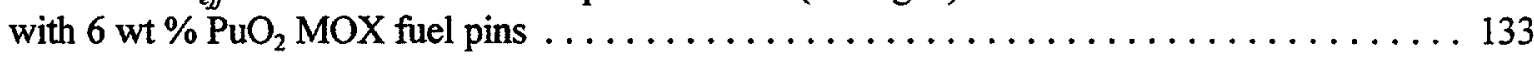

7.18. Calculated $k_{\text {eff }}$ values for two unspaced MO-1s (damaged)

with 4.4 wt \% $\mathrm{PuO}_{2}$ MOX fuel pins

7.19. Calculated $k_{e f f}$ values for two $0.5 \mathrm{in}$. spaced MO-1s (damaged)

with $4.4 \mathrm{wt} \% \mathrm{PuO}_{2} \mathrm{MOX}$ fuel pins 


\section{LIST OF TABLES (continued)}

7.20. Calculated $k_{e f f}$ values for two 1.0-in.-spaced MO-1s (damaged) with 4.4 wt $\% \mathrm{PuO}_{2} \mathrm{MOX}$ fuel pins

7.21. Calculated $k_{e f}$ values for two 2.0-in.-spaced MO-1s (damaged)

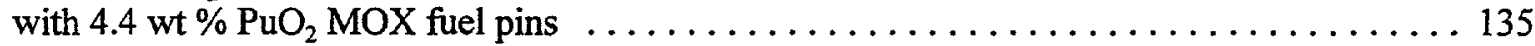

7.22. Calculated $k_{e f f}$ values for two unspaced MO-1s (damaged)

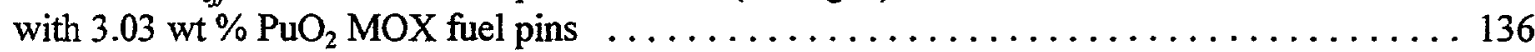

7.23. Calculated $k_{\text {eff }}$ values for two 0.5 -in.-spaced MO-1s (damaged) with 3.03 wt $\% \mathrm{PuO}_{2} \mathrm{MOX}$ fuel pins

7.24. Calculated $k_{\text {eff }}$ values for two 1.0-in.-spaced MO-1s (damaged) with $3.03 \mathrm{wt} \% \mathrm{PuO}_{2} \mathrm{MOX}$ fuel pins

7.25. Calculated $k_{\text {eff }}$ values for two 2.0-in.-spaced MO-1s (damaged) with 3.03 wt $\% \mathrm{PuO}_{2} \mathrm{MOX}$ fuel pins

7.26. Calculated system multiplication for an infinite array of undamaged MO-1s, with WG MOX fuel pins

7.27. Calculated $k_{\text {eff }}$ values for finite array of damaged MO-1s with WG MOX fuel pins 139

7.28. Parameters used for TI determination of previously certified MOX fuel pins 140

7.29. Parameters used for TI determination of weapons-grade MOX fuel pins 



\section{ACKNOWLEDGMENTS}

The authors acknowledge the overall direction and contributions provided by C. V. Parks and S. B. Ludwig during the preparation of this document. In addition, the detailed validation information provided by J. J. Lichtenwalter and R. T. Primm III during the course of the evaluation is greatly appreciated. 



\section{INTRODUCTION}

\subsection{BACKGROUND}

The Fissile Material Disposition Program (FMDP) is tasked with implementing the Department of Energy (DOE) formal Record of Decision for the storage and disposition of surplus weapons-grade (WG) plutonium. One disposition option involves the irradiation of surplus plutonium as mixed-oxide (MOX) fuel in existing light-water reactors (LWR). ${ }^{1}$ An integral part of the MOX fuel disposition approach involves the transportation of MOX assemblies from the fuel fabrication facility to one or more existing commercial LWR sites. These fuel assemblies must be transported in Type B fissile material packages, which must be certified by the Nuclear Regulatory Commission (NRC) in accordance with Title 10 Code of Federal Regulations (CFR) Part 71.2 Until a new package can be designed and certified for transport of WG MOX assemblies, the DOE FMDP is exploring interim use of the existing MO-1 fresh-fuel package for shipment of lead test WG-MOX assemblies.

The MO-1 [USA/9069/B( )F] was originally developed by Westinghouse, a commercial fresh-fuel vendor, and certified by the NRC in 1976 under Certificate of Compliance (CoC) 9069, Revision 0. ${ }^{3}$ Since issuance of the original certificate, the $\mathrm{CoC}$ has been revised various times, with the most recent version being Revision 11 . $^{4}$ Throughout the certification history of the MO-1, only two packages were fabricated by the vendor. Under Revision 10 of the $\mathrm{CoC}$, the MO-1 is certified for the shipment of low-enricheduranium (LEU) fuel, as well as MOX fuel; however, the CoC, Revision 10, expired on January 31, 1997. Currently, the MO-1 is approved solely for the shipment of LEU fuel under Revision 11 of the CoC. Following expiration of Revision 10 of the $\mathrm{CoC}$, the NRC expressed a concern to DOE with regard to the renewal of the MO-1 certificate. Based on a review of the previous criticality safety analysis for MOX fuel shipment, the NRC determined that the "...analysis for hypothetical accident conditions and the transport index are inconsistent." Given the time frame of the original criticality analysis (i.e., late 1970s and early 1980 s), the previous analysis does not completely address the current criticality safety analysis requirements documented in 10 CFR Part 71 . Since the previous analysis is not consistent with current regulatory requirements, the MO-1 package must be reevaluated before certification can be obtained for the shipment of MOX fuel. To fulfill the disposition objectives, the FMDP plans to modify CoC 9069 and obtain re-certification for the shipment of MOX fuel. In addition, the FMDP plans to further extend the approved contents to include WG-MOX fuel.

\subsection{PURPOSE AND SCOPE}

The purpose of this report is to clarify and establish the criticality safety evaluation information that should be included in the criticality safety section of the revised application for approval for the MO-1 shipping package. At the time of evaluation, only preliminary designs of lead test MOX assemblies were available. Three preliminary LWR configurations are considered in the evaluation: two PWR assemblies designed by Westinghouse and Combustion Engineering and a BWR assembly designed by General Electric. However, the Combustion Engineering and General Electric assemblies are too long and cannot fit in the MO-1 package. ${ }^{3}$ As a result, the Westinghouse PWR design is considered to be the most likely candidate for the lead test assembly and is evaluated in this report. In addition to the proposed WG MOX fuel, this report re-evaluates the MOX fuel configurations previously approved under CoC 9069 , Revision 10. This report is considered to be a scoping evaluation and is not intended to substitute for the final criticality safety analysis of the MO-1 shipping package. All calculations in this report were performed in accordance with the guidance of NUREG/CR-5661. 



\section{PACKAGE DESCRIPTION}

\subsection{CONTENTS}

The material specifications for the MO-1 shipping package are provided in Table 2.1. As noted in Table 2.1, the shipping package has neutron-absorbing material in the form of borated stainless steel 304 (SS304). The borated SS304 specification, as documented in CoC 9069, Revision 10, requires the steel to contain $1.3 \mathrm{wt} \%$ (minimum) boron. However, for this criticality safety evaluation, no more than $75 \%$ of the specified neutron absorber concentration should be considered in the criticality evaluation. ${ }^{7}$ The specified neutron absorber content in the criticality evaluation may be increased above $75 \%$ provided a poison control program is in place to verify the presence and uniformity of the neutron absorber material. Consequently, the boron content is reduced to $0.975 \mathrm{wt} \%$ in the evaluation, and the modified isotopics for borated SS304 are presented in Table 2.1.

Table 2.1. Material specifications for MO-1 shipping package

\begin{tabular}{|c|c|c|c|c|}
\hline Material & $\begin{array}{l}\text { Density } \\
\left(\mathrm{g} / \mathrm{cm}^{3}\right)\end{array}$ & $\begin{array}{l}\text { Density } \\
\left(\mathrm{lb} / \mathrm{in}^{3}\right)\end{array}$ & Constituent & $\begin{array}{l}\text { Atomic density } \\
\text { (atoms } / \mathrm{b}-\mathrm{cm} \text { ) }\end{array}$ \\
\hline $\begin{array}{c}\text { Borated stainless } \\
\text { steel } 304^{a}\end{array}$ & 7.74 & 0.28 & $\begin{array}{l}{ }^{10} \mathrm{~B} \\
{ }^{11} \mathrm{~B} \\
\mathrm{Fe} \\
\mathrm{Cr} \\
\mathrm{Ni} \\
\mathrm{Mg}\end{array}$ & $\begin{array}{l}8.37 \times 10^{-4} \\
3.37 \times 10^{-3} \\
5.74 \times 10^{-2} \\
1.69 \times 10^{-2} \\
7.47 \times 10^{-3} \\
3.80 \times 10^{-3}\end{array}$ \\
\hline Polyethylene & 0.92 & 0.03 & $\begin{array}{l}\mathrm{C} \\
\mathrm{H}\end{array}$ & $\begin{array}{l}3.95 \times 10^{-2} \\
7.91 \times 10^{-2}\end{array}$ \\
\hline Water & 0.9982 & 0.0361 & $\begin{array}{l}\mathrm{H} \\
\mathrm{O}\end{array}$ & $\begin{array}{l}6.68 \times 10^{-2} \\
3.34 \times 10^{-2}\end{array}$ \\
\hline $\begin{array}{l}\text { Polyurethane } \\
\text { foam }\end{array}$ & $8.0 \times 10^{-2}$ & $2.9 \times 10^{-3}$ & $\begin{array}{l}\mathrm{H} \\
\mathrm{C} \\
\mathrm{N} \\
\mathrm{O}\end{array}$ & $\begin{array}{l}1.96 \times 10^{-3} \\
2.18 \times 10^{-3} \\
4.17 \times 10^{-4} \\
8.86 \times 10^{-4}\end{array}$ \\
\hline Carbon steel & 7.8212 & 0.2826 & $\begin{array}{l}\mathrm{Fe} \\
\mathrm{C}\end{array}$ & $\begin{array}{l}8.35 \times 10^{-2} \\
3.93 \times 10^{-3}\end{array}$ \\
\hline
\end{tabular}

${ }^{a}$ The density of borated SS304 is a modified density based on the boron content in the steel. The density of SS304 and natural boron is $0.29 \mathrm{lb} / \mathrm{in}^{3}$ and $8.573 \times 10^{-2} \mathrm{lb} / \mathrm{in} .^{3}\left(7.92 \mathrm{~g} / \mathrm{cm}^{3}\right.$ and $2.373 \mathrm{~g} / \mathrm{cm}^{3}$ ), respectively. ${ }^{8}$ If the boron content of the SS304 is $0.975 \mathrm{wt} \%$, the density of the borated SS304 is $0.28 \mathrm{ib} / \mathrm{in}^{3}\left(7.74 \mathrm{~g} / \mathrm{cm}^{3}\right)$. 
Two possible classes of MOX fuel are evaluated for shipment in the MO-1 package. In particular, the evaluation addresses the original MOX fuel configurations as defined in CoC 9069, Revision 10. The original MOX loadings have fissile Pu fractions that are less than $85 \mathrm{wt} \%$ and are not considered to be WG material. The second class of MOX fuel has a fissile Pu fraction of $94 \mathrm{wt} \%$ and is considered to be WG material. The different MOX loadings are further discussed in Sects. 2.1.1 and 2.1.2.

\subsubsection{Previously Certified MOX Fuel}

CoC 9069, Revision 10, specified two forms of MOX fuel and one form of LEU fuel. The original CoC permitted shipment of PWR MOX fuel assemblies or fuel pins. The original MOX isotopics, as specified in $\mathrm{CoC}$ 9069, are provided in Table 2.2. Moreover, the assembly design specifications are given in Table 2.3. As noted in Table 2.2, three possible MOX loadings were certified under CoC 9069, Revision 10.

Table 2.2. Original certified MOX isotopic specifications

\begin{tabular}{|c|c|c|c|}
\hline Parameter & $6 \mathrm{wt} \% \mathrm{PuO}_{2}$ & $4.4 \mathrm{wt} \% \mathrm{PuO}_{2}$ & 3.03 wt $\% \mathrm{PuO}_{2}$ \\
\hline $\mathrm{Pu}$ fissile fraction (wt \%) & 70.97 & 81.18 & 85.607 \\
\hline \multicolumn{4}{|l|}{$\mathrm{Pu}$ isotopics (wt \%): } \\
\hline${ }^{238} \mathrm{Pu}$ & 1.53 & 0.09 & 0.228 \\
\hline${ }^{239} \mathrm{Pu}$ & 57.43 & 78.13 & 81.839 \\
\hline${ }^{240} \mathrm{Pu}$ & 22.45 & 18.27 & 13.575 \\
\hline${ }^{241} \mathrm{Pu}$ & 13.54 & 3.05 & 3.768 \\
\hline${ }^{242} \mathrm{Pu}$ & 5.05 & 0.47 & 0.590 \\
\hline${ }^{241} \mathrm{Pu} /{ }^{239} \mathrm{Pu}$ & 0.23 & 0.04 & 0.05 \\
\hline${ }^{240} \mathrm{Pu} /{ }^{239} \mathrm{Pu}$ & 0.39 & 0.23 & 0.17 \\
\hline \multicolumn{4}{|l|}{$\mathrm{U}$ isotopics (wt \%): } \\
\hline${ }^{234} \mathrm{U}$ & 0.0054 & 0.0054 & 0.0054 \\
\hline${ }^{235} \mathrm{U}$ & 0.71 & 0.71 & 0.71 \\
\hline${ }^{236} \mathrm{U}$ & $-a$ & $-{ }^{a}$ & $-{ }^{a}$ \\
\hline${ }^{238} \mathrm{U}$ & 99.283 & 99.283 & 99.283 \\
\hline
\end{tabular}

${ }^{a}$ No data available.

\subsubsection{Weapons-Grade MOX Fuel}

The proposed isotopics and design specifications of the Westinghouse lead test assemblies are presented in Tables 2.4 and 2.5, respectively. 
Table 2.3. Original MOX assembly specifications ${ }^{a}$

\begin{tabular}{cc}
\hline Parameter & Original MOX certification \\
\hline Rod parameters & \\
& \\
Cladding material & Zirc-4 \\
Pellet OD & 0.365 in. $(0.927 \mathrm{~cm})$ \\
Cladding OD & 0.422 in. $(1.072 \mathrm{~cm})$ \\
Clad thickness & 0.024 in. $(0.061 \mathrm{~cm})$ \\
Fuel length & 144.0 in. $(365.8 \mathrm{~cm})$ \\
Assembly parameters: & \\
& $14 \times 14$ \\
Pattern & 179 \\
No. of fuel rods & 16 \\
No. of guide tubes & 1 \\
No. of instrument tubes & $0.556 \mathrm{in} .(1.412 \mathrm{~cm})$ \\
Pitch & $7.784 \mathrm{in} . \times 7.784 \mathrm{in}$. \\
Assembly envelope & $(19.77 \mathrm{~cm} \times 19.77 \mathrm{~cm})$ \\
\hline
\end{tabular}

${ }^{a}$ Assembly specifications are provided in English units in ref. 10. SI units are obtained by converting from English units using appropriate conversion factors.

Table 2.4. Westinghouse weapons-grade MOX isotopic specifications

\begin{tabular}{cc}
\hline Parameter & FMDP lead test assembly MOX \\
\hline Pu fuel & $4.803 \mathrm{wt} \% \mathrm{Pu}(94)$ \\
(Fissile fraction wt \%) & \\
Pu isotopics (wt \%): & $-^{a}$ \\
${ }^{238} \mathrm{Pu}$ & 93.6 \\
${ }^{239} \mathrm{Pu}$ & 5.9 \\
${ }^{240} \mathrm{Pu}$ & 0.4 \\
${ }^{241} \mathrm{Pu}$ & 0.1 \\
${ }^{242} \mathrm{Pu}$ & \\
${ }^{241} \mathrm{Pu} /{ }^{239} \mathrm{Pu}$ & 0.004 \\
${ }^{240} \mathrm{Pu} /{ }^{239} \mathrm{Pu}$ & 0.06 \\
$\mathrm{U}$ isotopics (wt \%): & \\
${ }^{234} \mathrm{U}$ & 0.002 \\
${ }^{235} \mathrm{U}$ & 0.2 \\
${ }^{236} \mathrm{U}$ & 0.001 \\
${ }^{238} \mathrm{U}$ & 99.797
\end{tabular}

No data available. 
Table 2.5. Westinghouse weapons-grade assembly specifications

\begin{tabular}{cc}
\hline Parameter & Specification $^{a}$ \\
\hline Rod parameters & \\
Cladding material & Zirc-4 \\
Pellet OD & $0.7844 \mathrm{~cm}(0.309 \mathrm{in})$. \\
Cladding OD & $0.9144 \mathrm{~cm}(0.36 \mathrm{in})$. \\
Fuel length & $365.8 \mathrm{~cm}(144.0 \mathrm{in})$. \\
Oxide density & $10.26 \mathrm{~g} / \mathrm{cm}^{3}\left(0.37 \mathrm{lb} / \mathrm{in}^{3}{ }^{3}\right)$ \\
& \\
Assembly parameters: & $17 \times 17$ \\
Pattern & 264 \\
No. of fuel rods & 25 \\
No. of guide tubes & $1.26 \mathrm{~cm}(0.496 \mathrm{in})$. \\
Pitch &
\end{tabular}

${ }^{a}$ Assembly specifications are provided in SI units in ref. 9.

English units are obtained by coverting from SI units using appropriate conversion factors.

\subsection{PACKAGING}

The principal structural members of the MO- 1 which are pertinent for criticality safety include the primary containment vessel and the internal support system. In addition, the MO-1 packaging provides neutron poison plates for reactivity control.

\subsubsection{Containment Vessel}

The external containment vessel or overpack consists of an inner and an outer carbon-steel shell. The exterior shell is constructed of 12-gauge carbon steel and is $47.0 \mathrm{in} . \times 45.0 \mathrm{in} . \times 206.0 \mathrm{in}$. (119.4 cm $\times 114.3 \mathrm{~cm} \times 523.2 \mathrm{~cm}$ ). With regard to the interior, the inner shell is constructed of 10-gauge carbon steel and is 37.0 in. $\times 37.0 \mathrm{in} . \times 186.0 \mathrm{in} .(93.9 \mathrm{~cm} \times 93.9 \mathrm{~cm} \times 472.4 \mathrm{~cm})$. The volume between the shells is filled with a shock and thermal insulating material consisting of rigid polyurethane foam $\left(\rho=2.9 \times 10^{-3}\right.$ $\mathrm{lb} / \mathrm{in}^{3}$ or $8.0 \times 10^{-2} \mathrm{~g} / \mathrm{cm}^{3}$ ). The insulating foam is poured into the cavity between the two shells and allowed to expand, thereby filling the void completely. Moreover, the foam "bonds to the shells and creates a unitized package construction." 10

The internal and external shells are separated into upper and lower sections of the unit. When assembled, the upper and lower sections form a rectangular box with a central separation plane. The upper and lower sections are secured by 12 ratchet binders which are considered to be the primary attachment. The secondary attachment consists of twelve 0.625 -in. $(1.59-\mathrm{cm})$-diam latch pins which are inserted through the lid into the body. The package provides a primary and secondary attachment system to ensure the upper and lower sections remain together during hypothetical accident conditions. 
With regard to accident conditions, the MO-1 structural analysis evaluates various impact orientations (i.e., flat side, long edge, corner and short edge).$^{10}$ Because of the shifting payload during impact, the forces generated by the impact can lead to various reductions in external wall thickness. The most severe deformation leads to a reduced external wall thickness of 0.028 in. $(0.071 \mathrm{~cm})$. During fire conditions, the basis of the thermal analysis is that the MO-1 package is exposed to a source temperature of $1475.0^{\circ} \mathrm{F}(1074.8 \mathrm{~K})$ for $30 \mathrm{~min}$.

\subsubsection{Internal Support System}

The internal support structure is composed of a strongback frame which is used to support two fuel assemblies over the entire assembly length. Figures 2.1 and 2.2 present an isometric view and cutaway side view (lengthwise) of the MO-1 internal support system. As depicted in Fig. 2.2, a series of 8 clamping frames are located every $22.29 \mathrm{in}$. $(56.62 \mathrm{~cm})$ along the entire length of the fuel assemblies. The clamping frames secure the fuel assemblies to the strongback during transport. The entire strongback support frame is attached to the inner shell of the MO-1 by 18 rubber shock absorbers. The shock absorbers suspend the internals within the package and provide shock and vibration isolation for the fuel during transport.

Figures 2.3 and 2.4 depict a cross-sectional view of the internal support system. The internal support structure is constructed of carbon steel, and the assemblies rest on 0.25 -in. (0.64-cm)-thick particle board. The supporting plate beneath the particle board is a carbon-steel plate that is $0.19 \mathrm{in} .(0.48 \mathrm{~cm})$ thick. As shown in Fig. 2.4, the region between the two assemblies is composed of a 1.5-in. (3.8-cm)-thick gap region. On either side of the gap are 0.19-in. $(0.48-\mathrm{cm})$-thick borated SS304 plates that extend the complete length of the fuel assemblies. Each neutron absorber plate is separated from the assembly by an additional 0.19 -in. $(0.48-\mathrm{cm})$ carbon-steel plate, followed by $0.25 \mathrm{in} .(0.64 \mathrm{~cm})$ of particle board. The total separation distance between the two assemblies (i.e., including the gap, neutron absorber, SS304 and particle board) is $2.26 \mathrm{in}$. $(5.74 \mathrm{~cm})$. Note that the internal region of the MO-1 does not have cavities that will preferentially flood before another region. In particular, the gap between the fuel assemblies is open at the bottom and will not fill with water prior to any other region in the package. Moreover, the inleakage of water will be distributed uniformly throughout the package.

As noted above, the assemblies rest on two strongback support plates. The region directly beneath the support plates is void except for seven carbon steel crossbars located $6.44 \mathrm{in}$. $(16.4 \mathrm{~cm})$ below the fuel assemblies. Each crossbar member has a thickness of 0.25 in. $(0.64 \mathrm{~cm})$. Attached to either end of the crossbars is a 0.25 -in. $(0.64-\mathrm{cm})$-thick carbon steel plate which extends the full length of the support frame and serves as the mounting location for the rubber shock mounts. Specifically, nine rubber shock mounts are attached to the carbon-steel plate on either side of the support structure.

Under the impact conditions, the failure of the shock mount system is not considered to be incredible. Consequently, the fuel assemblies including the strongback support frame could shift within the MO-1 during a hypothetical accident scenario. As shown in Fig. 2.4, spacing between the two assemblies is only maintained by a carbon steel spacer bar located at the top of the gap region. If two assemblies are transported, shifting of the assemblies toward the centerline of the package could lead to a loss of spacing between the two assemblies.

\subsubsection{Neutron Absorbers}

The MO-1 strongback assembly contains two borated stainless steel 304 neutron-absorber plates. Each plate has a thickness of $0.19 \mathrm{in} .(0.48 \mathrm{~cm})$ and extends the full length of the strongback support frame. 


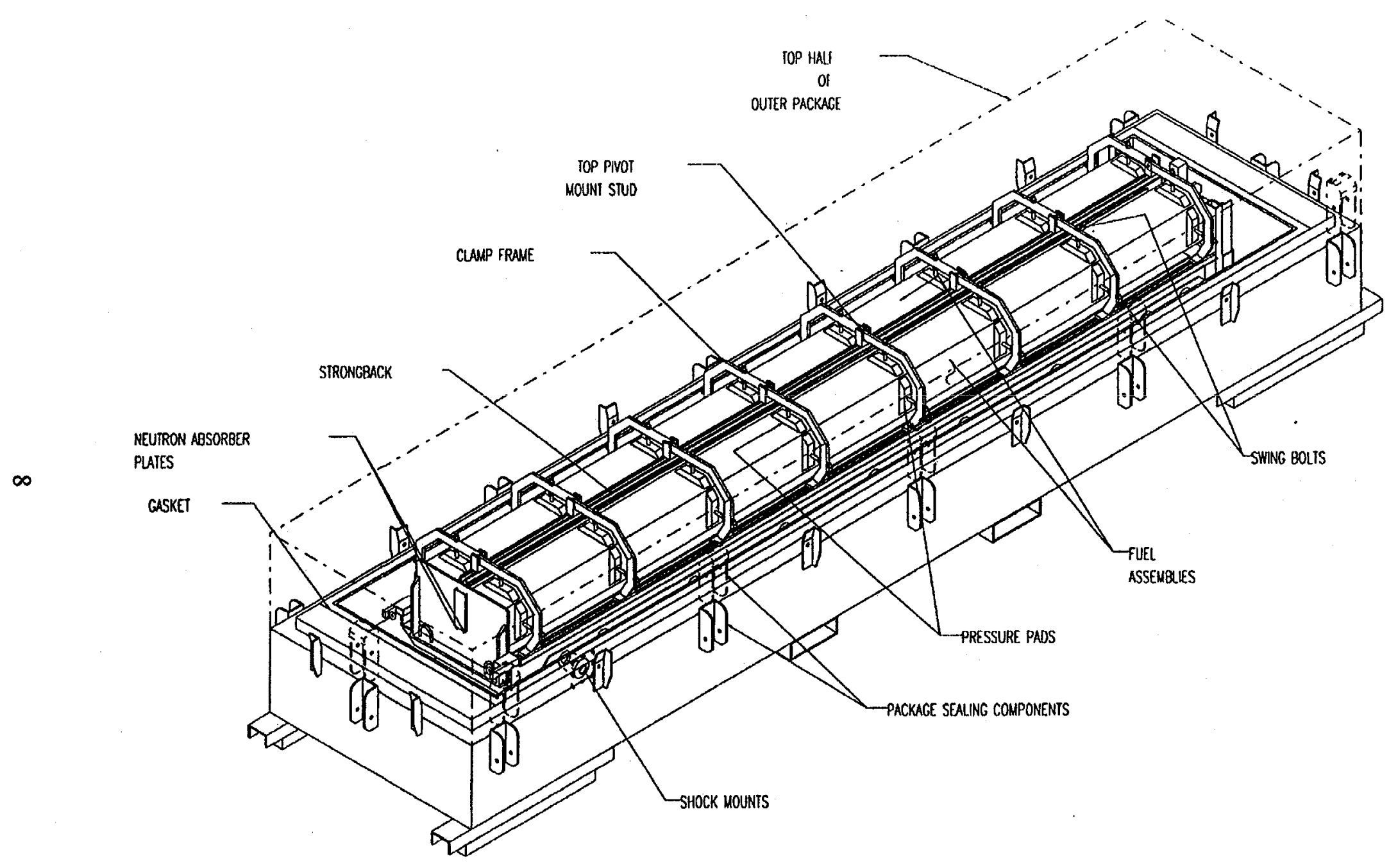

Fig. 2.1. Isometric view of MO-1 shipping package. 


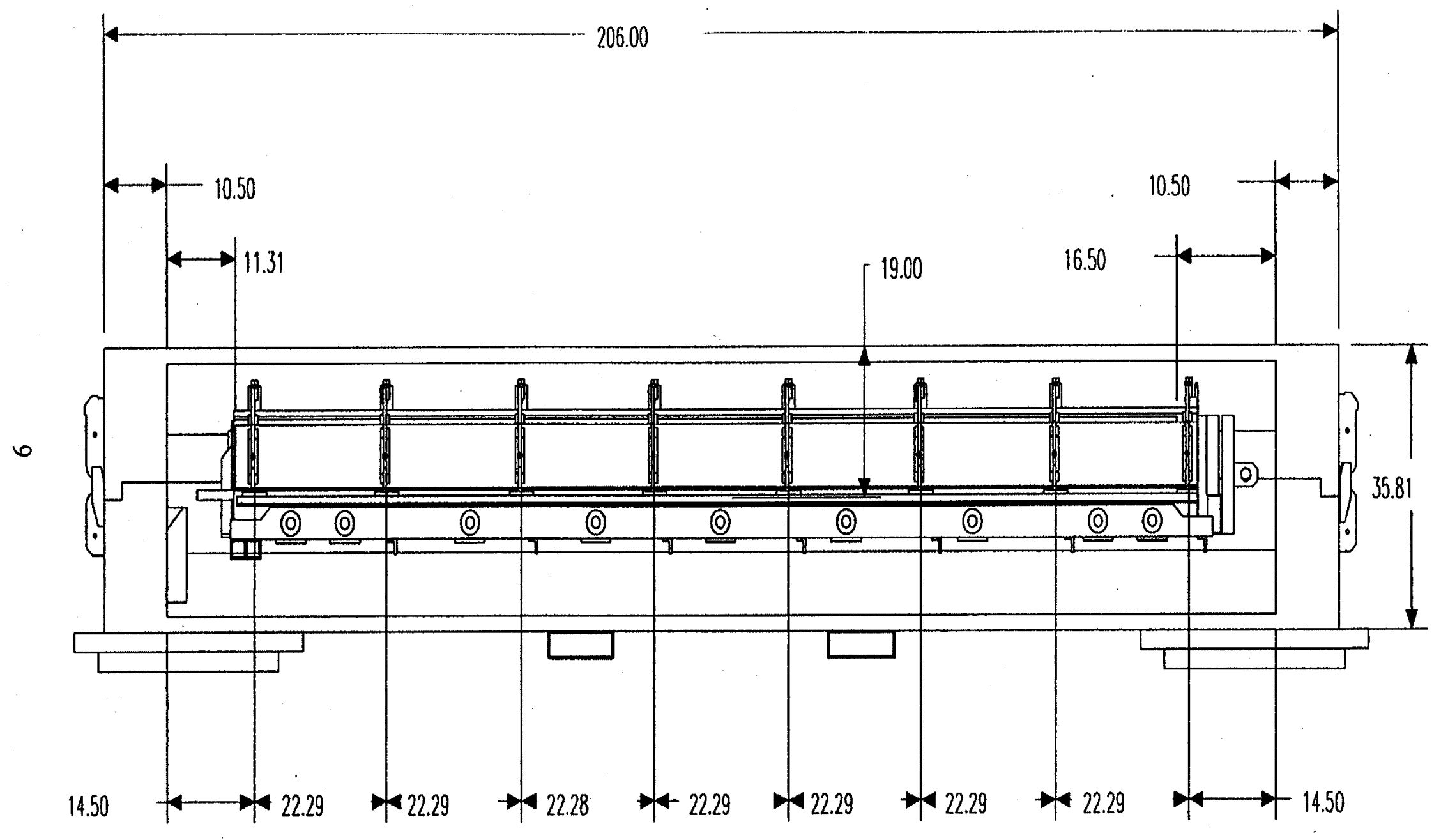

Fig. 2.2. Cutaway side view of MO-1 (all dimensions are in inches). 


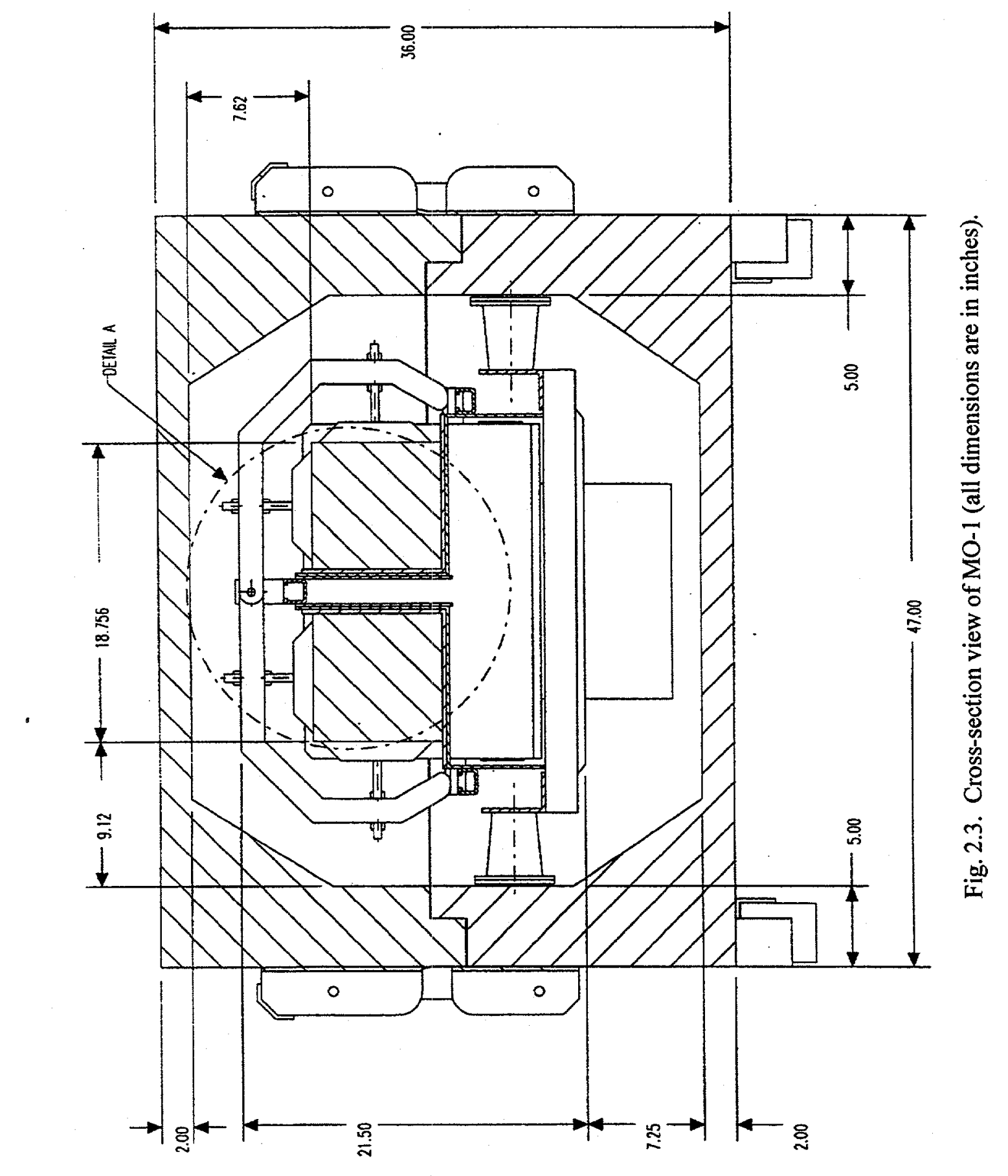




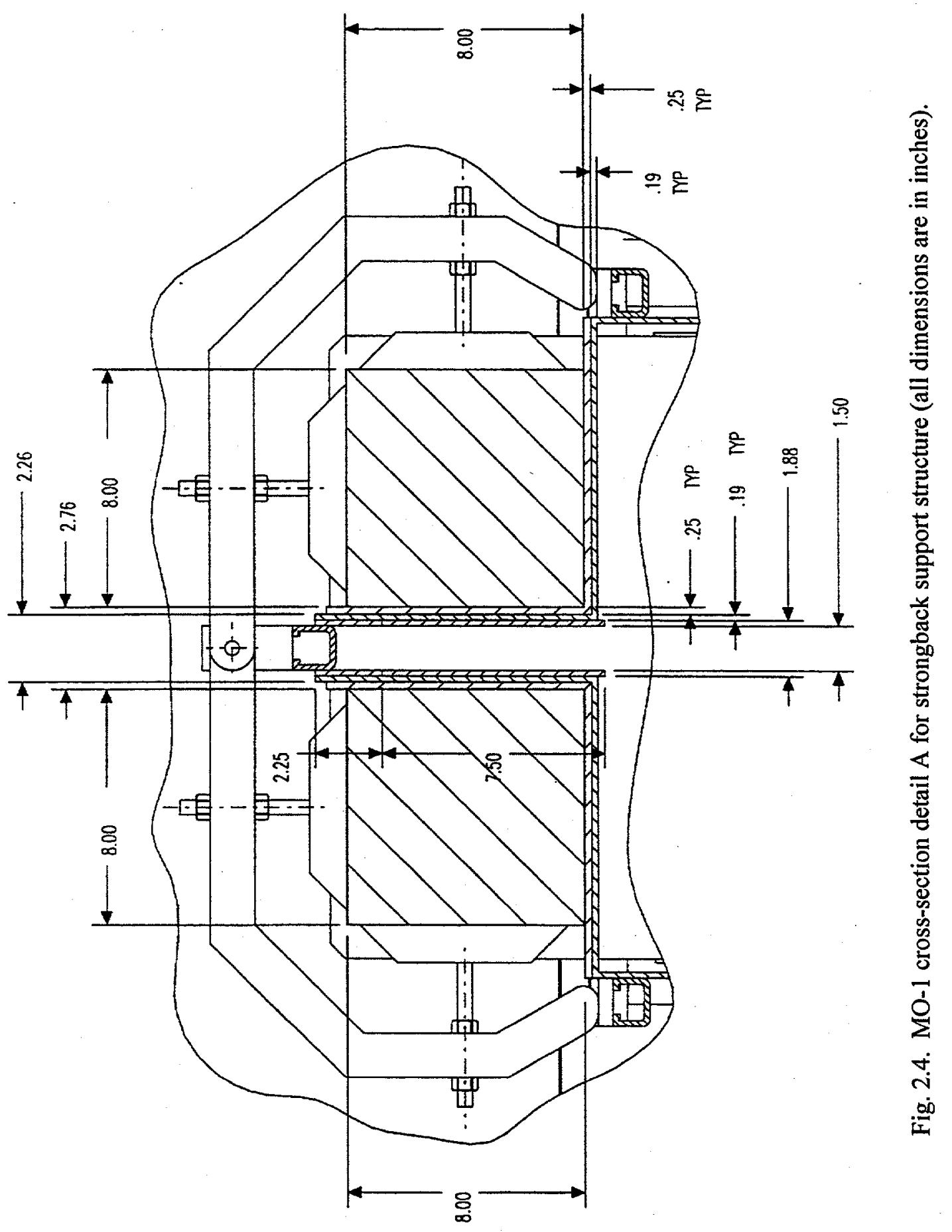




\subsection{TRANSPORT INDEX}

In accordance with $10 \mathrm{CFR} \S 71$, the number of damaged and undamaged packages that are acceptably subcritical in an array configuration is presented in Sects. 6.1 and 6.2 for each MOX loading (i.e., non-weapons-grade and weapons-grade MOX fuel) in the MO-1. Using the array information in Sects. 6.1 and 6.2, the transport index (TI) for criticality control is determined for each MOX loading and is presented in Sect. 6.3. 


\section{CRITICALITY SAFETY ANALYSIS MODELS}

\subsection{GENERAL MODEL}

As noted in Sect. 2.2, the evaluation considers two different fuel assembly configurations. In particular, a $14 \times 14$ assembly with non-weapons-grade MOX fuel and a $17 \times 17$ Westinghouse assembly with WG MOX fuel are considered for shipment in the MO-1 package. In the following sections, model descriptions are presented for the calculational models used in the criticality safety evaluation. If the different MOX configurations require separate geometric model descriptions, a separate geometric model is presented and discussed for each fuel configuration as appropriate. Otherwise, a single geometric model description is applicable for both MOX fuel configurations.

\subsubsection{Dimensions}

A horizontal sketch of the package model is provided in Fig. 3.1 and depicts an internal lengthwise view of the MO-1 package. The cross-sectional view A-A in Fig. 3.1 is presented in Figs. 3.2 and 3.4 for the $14 \times 14$ and $17 \times 17$ assemblies, respectively. In addition, a corresponding detailed view of the fuel package model in Figs. 3.2 and 3.4 is provided in Figs. 3.3 and 3.5, respectively. Each of the figures provides dimensions that are used in the calculational models. The guide tubes in Figs. 3.3 and 3.5 are modeled with the same dimensions as the fuel rods, except that the internal region is void. During flooding conditions, these tubes are filled with water.

\subsubsection{Materials}

As noted in Sect. 3.1.1, the models of the MO-1 package and fuel contents are provided in Figs. 3.1-3.5. Each figure identifies the materials used in the calculation, and Table 3.1 further identifies each material and corresponding density.

Table 3.1 Material specifications for Figs. 3.1-3.5

\begin{tabular}{cccc}
\hline Material No. & Material & $\begin{array}{c}\text { Density } \\
\left(\mathrm{g} / \mathrm{cm}^{3}\right)\end{array}$ & $\begin{array}{c}\text { Density } \\
\left(\mathrm{lb} / \mathrm{in}^{3}\right)\end{array}$ \\
\hline 1 & ${\mathrm{WG} \mathrm{PuO}_{2}-\mathrm{UO}_{2}}^{3}$ & 10.26 & 0.37 \\
& $6 \mathrm{wt} \% \mathrm{PuO}_{2}-\mathrm{UO}_{2}$ & 10.99 & 0.40 \\
& $4.4 \mathrm{wt} \% \mathrm{PuO}_{2}-\mathrm{UO}_{2}$ & 10.98 & 0.40 \\
2 & $3.03 \mathrm{wt} \% \mathrm{PuO}_{2}-\mathrm{UO}_{2}$ & 10.97 & 0.40 \\
3 & Zirc-2 & 6.56 & 0.24 \\
4 & Carbon steel & 7.8212 & 0.283 \\
5 & Polyurethane foam & $8.0 \times 10^{-2}$ & 0.29 \\
\hline
\end{tabular}




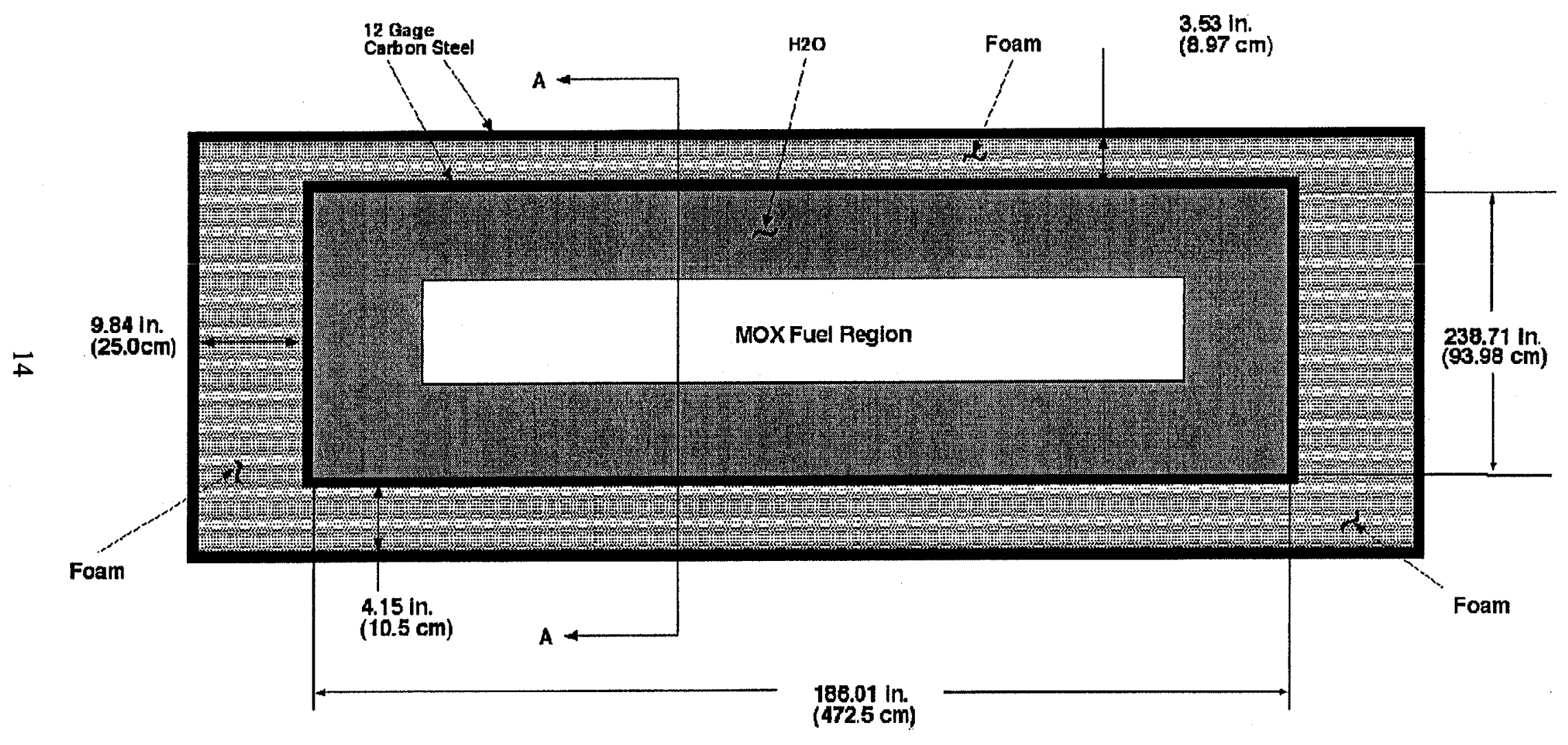

Fig. 3.1. Lengthwise view of MO-1 transportation package model. 


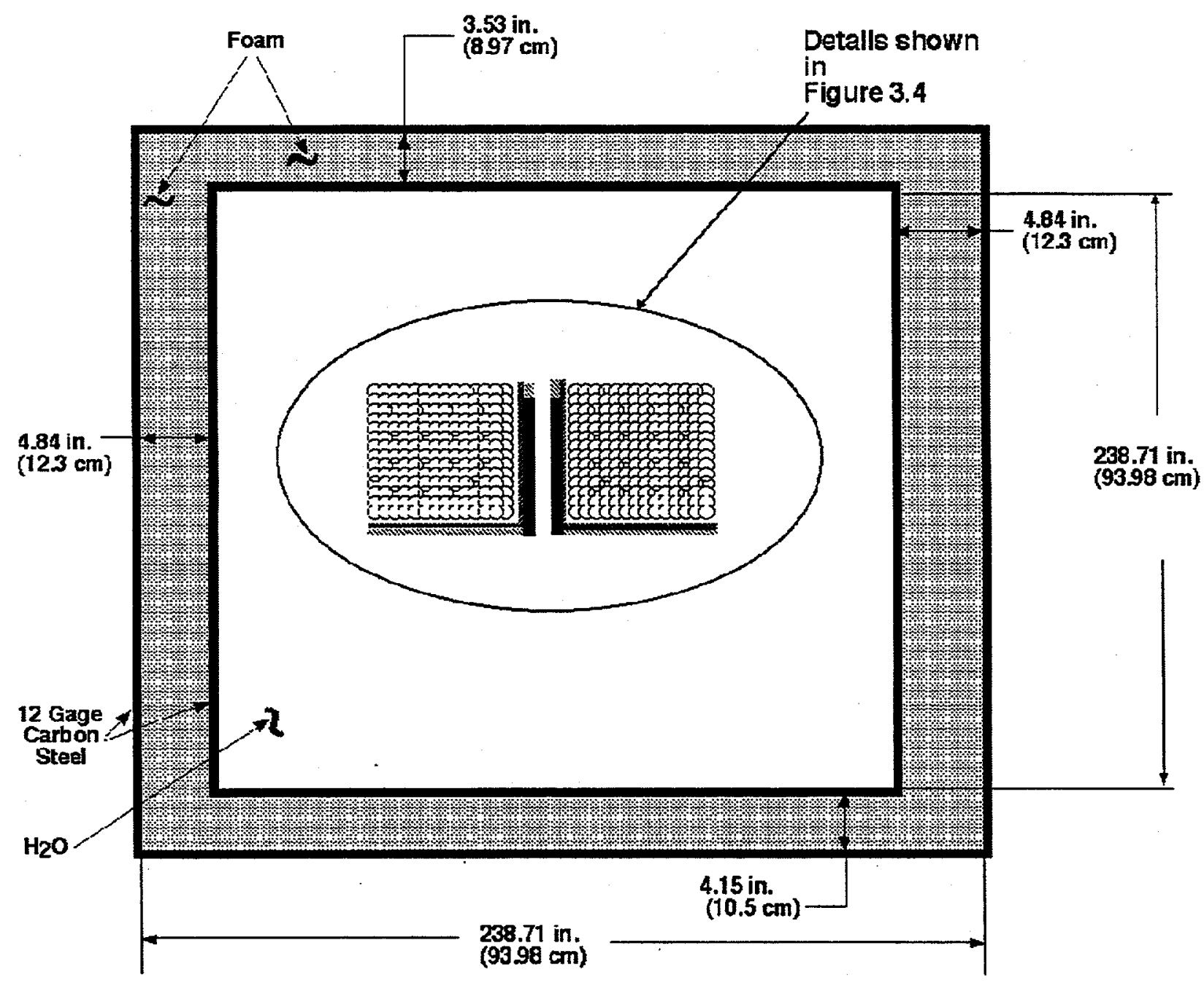

Fig. 3.2. MO-1 cross-section view A-A (see Fig. 3.1) with two $14 \times 14$ non-weapons-grade MOX fuel assemblies. 


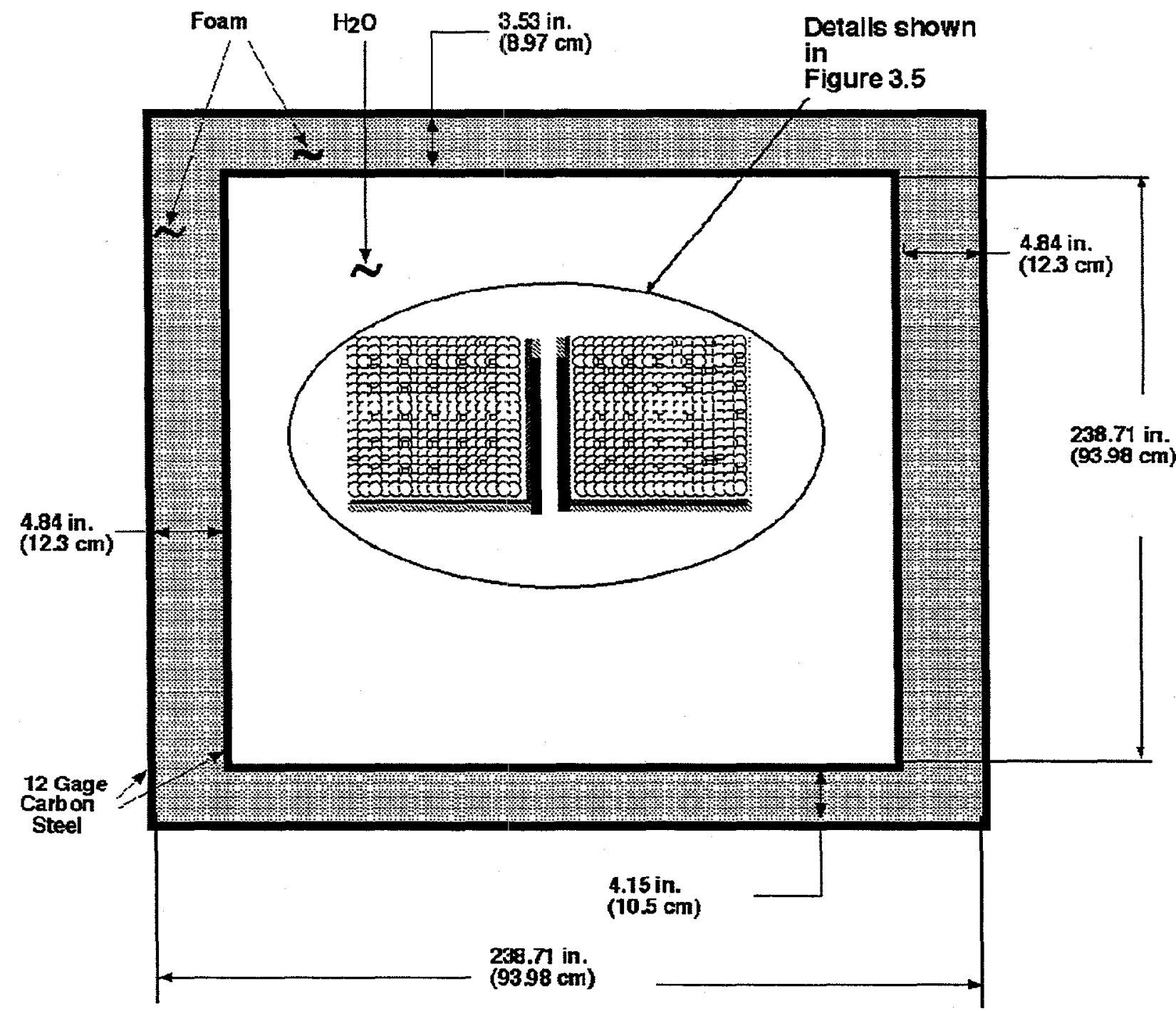

Fig. 3.3. MO-1 cross-section view A-A (see Fig. 3.1) with two weapons-grade MOX fuel assemblies. 


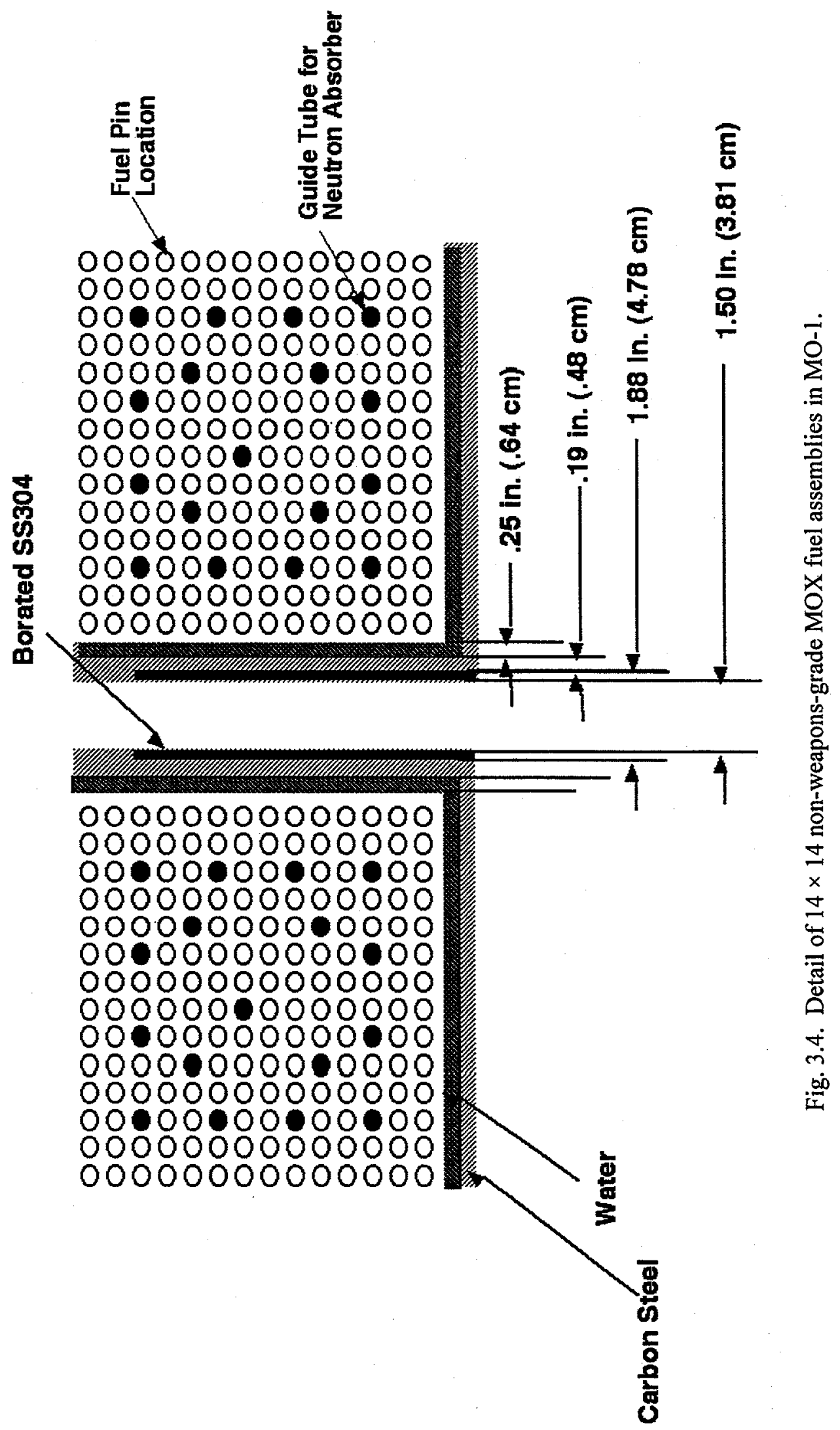




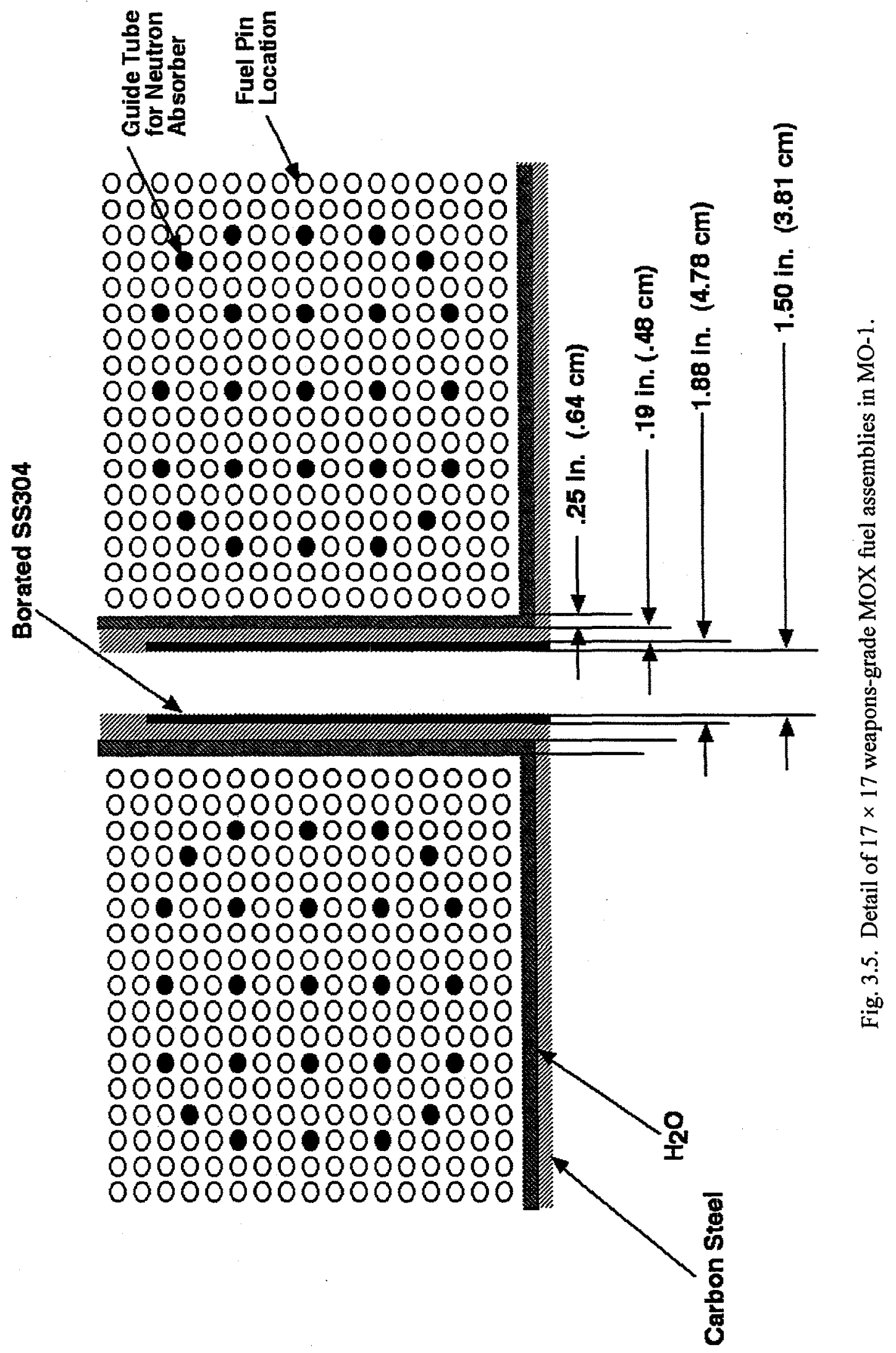




\subsubsection{Models-Actual Package Differences}

The cladding material in the non-weapons-grade and WG MOX assemblies is Zircaloy-4; however, the cladding in the calculational models is Zircaloy-2. The isotopics for Zircaloy-2 and Zircaloy-4 are essentially the same, except Zircaloy- 2 has $0.135 \mathrm{wt} \%$ iron relative to $0.210 \mathrm{wt} \%$ in Zircaloy- 4 . Furthermore, Zircaloy-2 has an additional constituent which is $0.055 \mathrm{wt} \%$ nickel. In terms of reactivity, these isotopic differences are judged to be negligible.

The single-package ( 2 assemblies) calculation model of the package internals differs from the actual package in the treatment of the strongback support structure and shock mount system. In the model, the particle board plates on the strongback support are not modeled. In cases that evaluate internal package flooding, the region occupied by the particle board is modeled as water. In reality, the particle board would become saturated with water during internal flooding conditions. Consequently, substituting water for the particle board is considered to be an insignificant approximation to the actual package support.

With regard to the strongback support frame, the model includes the 0.19-in. $(0.48-\mathrm{cm})$ horizontal carbon-steel plates that are below each assembly. Moreover, the model includes the carbon-steel plates that are located between the assemblies. However, the model does not include the spacer bar between the assemblies, the eight clamping frames or the remaining components of the carbon-steel support frame. In addition, the model does not include the rubber shock mounts which connect the support frame to the internal shell wall. Note that the region directly below the horizontal carbon-steel support plates is void, except for the seven horizontal crossbar members, which are located 6.44 in. $(16.4 \mathrm{~cm})$ below the fuel assemblies. Because of the relatively small volume occupied by these structures, omitting the support frame, clamping frames and shock mounts from the model should have a negligible impact on the system $k$-effective $\left(k_{e f f}\right)$.

As shown in Fig. 2.4, the two neutron-absorber plates are located between the two assemblies. Moreover, each neutron-absorber plate extends slightly below the horizontal carbon-steel support plate and creates a "lip" that extends into the void region below the assemblies. The calculational model neglects the "lip" created by each plate and models the neutron absorber to be flush with the carbon-steel support plates. Omitting the additional borated SS304 reduces the amount of neutron-absorbing material present in the system and is conservative with regard to reactivity (i.e., leads to higher $k_{e f f}$ ).

The cross-sectional view of the entire MO-1 package is provided in Fig. 2.3. As shown in the cross-sectional view, the four corners of the inner shell are angled, as opposed to being square. In the calculational model, the angled corners are neglected, and the internal region is a rectangular cavity. Modeling the internal region as a rectangular cavity is considered to have a negligible impact on system reactivity. In an effort to assess the impact on system multiplication, a model of the MO-1 with a revised internal cavity is presented in Fig. 3.6. As shown in Fig. 3.6, the internal corners are modeled as blocks of polyurethane foam. The model with the revised internal cavity is used in subsequent analyses to assess the omission of the angled corners from the internal region.

\subsection{CONTENTS MODEL}

Because different MOX loadings are considered in the evaluation, a contents model is presented for the WG MOX fuel, as well as the non-weapons-grade MOX fuel assemblies. The contents model of the MO-1, which includes a maximum of two non-weapons-grade MOX fuel assemblies arranged on the strongback, is presented in Figs. 3.2 and 3.4. Similarly, the contents model of the WG MOX fuel in the MO-1 is presented in Figs. 3.3 and 3.4. For the WG MOX case, partial-load configurations are considered in which the fuel package consists of a single assembly on the strongback support frame. This partial-load configuration simply involves the removal of a single assembly from the model. 


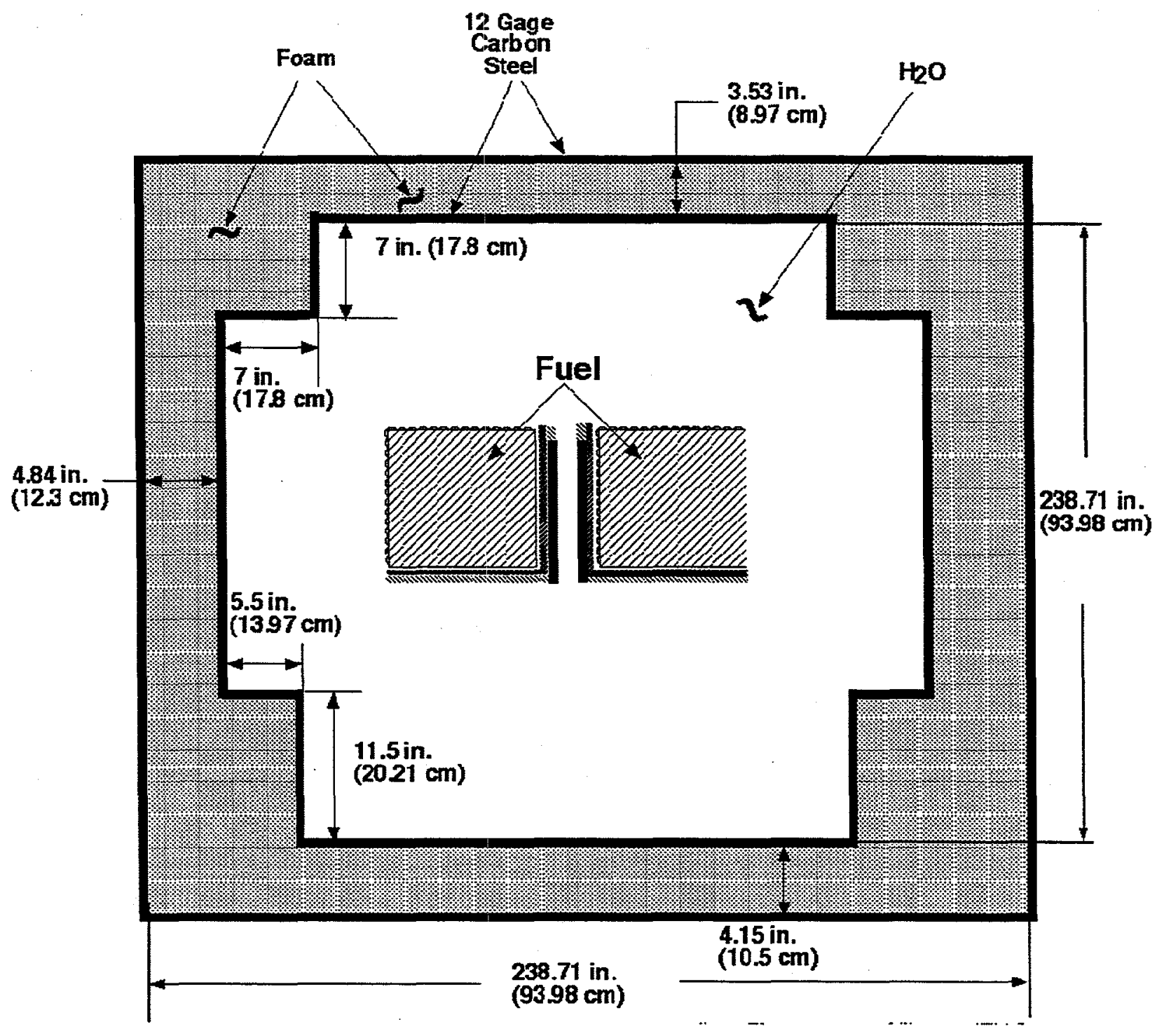

Fig. 3.6. MO-1 package model with revised internal cavity. 
The single-package and package-array evaluations are presented in Sects. 3.3 and 3.4. The single package and array evaluations consider the MOX contents as specified in CoC 9069, Revision 10, as well as the proposed WG MOX contents.

\subsection{SINGLE PACKAGES}

In accordance with $10 \mathrm{CFR} \S 71.55$, a single package must be designed and its contents limited to ensure that the package is subcritical under the most reactive configuration of the material, optimum moderation, and close reflection of the containment system by water on all sides or surrounding materials of the packaging. ${ }^{11}$ For each MOX loading under normal condition's of transport, the most reactive package configuration is determined by evaluating the single package model under partial and full flooding conditions. For comparison, the optimum single-package model is compared with a single-containment (i.e., inner shell and fuel package) model that is reflected by 12 in. $(30 \mathrm{~cm})$ of water. Additional variations in external package reflection conditions are considered. Specifically, the single package is modeled with full-water reflection ( $12 \mathrm{in}$. or $30 \mathrm{~cm}$ ). Furthermore, full-external-package reflection by polyurethane foam and carbon steel is considered in separate single-package models. Based on the thermal evaluation, the maximum temperature the package may experience during normal conditions of transport is $232.0^{\circ} \mathrm{F}$ $(384.3 \mathrm{~K}){ }^{10}$ A separate model is used to evaluate the single package under elevated temperature conditions. Reference 10 presents the assessment for meeting the requirements for normal conditions of transport. Based on the assessment in ref. 10, the undamaged single-package model represents the physical condition of the package under normal conditions of transport.

The assessment of the MO-1 package subjected to hypothetical accident conditions is presented in ref. 10. The MO-1 structural analysis evaluates various impact conditions (i.e., flat side, long edge, corner and short edge). ${ }^{10}$ Due to forces generated by impact and possible payload shift, the impact can lead to various reductions in external wall thickness. The most severe deformation leads to a reduced external wall thickness of $0.028 \mathrm{in} .(0.071 \mathrm{~cm})$. This maximum deformation occurs during a flat-side impact on the bottom or top of the MO-1 package. The $0.028-\mathrm{in} .(0.071-\mathrm{cm})$ reduced wall thickness is localized to positions on the bottom surface where the crossbar members of the support structure impact the inner shell of the MO-1. At other locations the exterior containment thickness is greater than $0.028 \mathrm{in} .(0.071 \mathrm{~cm})$. In order to maximize interaction between packages, the maximum deformation is used for the exterior wall thickness. The deformation of the external shells assumes the insulating foam is lost and the remaining exterior containment consists of a 0.028 -in. $(0.071-\mathrm{cm})$ carbon-steel shell. Note that this assumption is consistent with the original criticality safety analysis. ${ }^{10}$

During impact conditions, the fuel assemblies, including the strongback support frame, could shift within the MO-1. If two assemblies are transported, shifting the assemblies toward the centerline of the package would most likely lead to a loss in spacing between the two assemblies. During fire conditions, the thermal analysis evaluates the MO- 1 package exposed to a source temperature of $1475.0^{\circ} \mathrm{F}(1074.8 \mathrm{~K})$ for $30 \mathrm{~min}$. Based on the thermal analysis, the fire scenario would lead to a temperature gradient throughout the MO-1 package. In particular, the temperatures in the fuel assemblies would range between $260.0^{\circ} \mathrm{F}$ $(399.8 \mathrm{~K})$ and $340.0^{\circ} \mathrm{F}(444.3 \mathrm{~K})$. Moreover, the maximum temperature of the internal cavity during the fire scenario would be $410.0^{\circ} \mathrm{F}(483.15 \mathrm{~K})$. A separate model is used to evaluate the temperature increase during fire conditions.

Although the package is not designed to be pressurized, the assessment in ref. 10 addressess the pressure conditions within the package. The package is equipped with a pressure release valve, which limits the internal pressure to $8.5 \mathrm{psig}$ (23.196 psia) under normal conditions of transport. During fire conditions, a pressure increase could occur; however, the assessment in ref. 10 does not quantify the maximum pressure during accident conditions. 
To meet the requirement of 10 CFR $\S 71.55$ (e), a single-package model is analyzed with optimum internal moderation and full $(12-\mathrm{in}$. or $30-\mathrm{cm})$ water reflection on all sides. Note that varying degrees of internal moderation conditions are considered in the criticality safety evaluation. In an effort to determine the worst-case configuration of a damaged single package, the different accident conditions are evaluated separately to assess the impact on system reactivity. In particular, separate models are used to evaluate the replacement of polyurethane foam with water during ambient temperature conditions ( $293 \mathrm{~K}$ ) as well as fire conditions. Polyurethane foam charring is considered by evaluating varying degrees of water moderation in the foam. In addition, complete removal of the polyurethane foam is considered (i.e., replacement of foam with void in between external and internal steel shells). With regard to impact considerations, the external package wall thickness is reduced to $0.028 \mathrm{in} .(0.071 \mathrm{~cm})$ and the foam is removed from the packaging. To assess impact scenarios, three different models are used to evaluate payload shifting during impact and are presented in Figs. 3.7-3.9. The first configuration is the MO-1 with a reduced carbon steel shell thickness of $0.028 \mathrm{in} .(0.071 \mathrm{~cm})$ and no polyurethane foam insulation as shown in Fig. 3.7. In this damaged configuration, the strongback and fuel assemblies are unshifted in the MO-1. The following models evaluate the single package under impact conditions that lead to a displacement of the entire fuel contents. The shock mount system is designed to absorb the internal forces and permit movement of the support frame during impact conditions. A flat side impact on the bottom surface of the MO-1 would initially lead to an upward movement of the strongback support and fuel assemblies. As the motion of the fuel contents peaks in the upward direction, gravitational forces would pull the strongback and fuel contents toward the bottom of the MO-1 as modeled in Fig. 3.8. The fuel contents would either return to the original location within the MO-1 as the internal forces are absorbed by the shockmount system or come to rest on the innershell wall if the shockmount system fails during impact. A comer or edge impact would allow the fuel contents to shift toward the interior corner, as modeled in Fig. 3.9. The models which are depicted in Figs. 3.7-3.9 are used in Sect. 6 to evaluate upset fuel configurations within the MO-1. For MOX shipments of 2 assemblies, the damaged single-package model also evaluates the loss of spacing between fuel assemblies.

Since water flooding must be considered in the package evaluation, saturation pressures for possible temperature conditions in the MO-1 are provided in Table 3.2. Under normal conditions of transport, the pressure in the MO-1 could reach 23.196 psia before the pressure relief valve is activated. If the pressure exceeds 21.57 psia, full-density-water flooding is possible at $232.0^{\circ} \mathrm{F}\left(384.3^{\circ} \mathrm{K}\right)$. However, the introduction of water into a pressured container from an external source is not considered to be realistic. In an effort to bound the actual configuration, the analysis considers full-density-water flooding under the maximum temperature exposure during normal conditions of transport.

With regard to fire conditions, full-density-water flooding at $483.15 \mathrm{~K}$ would require the internal pressure to exceed 276.5 psia. Since the package seals are only designed to minimize the entrance of external elements such as rain, dust, etc., an internal pressure exceeding 276.5 psia is considered to be unrealistic. The evaluation assumes unrealistic water flooding for the maximum internal temperature conditions during a fire scenario (i.e., $483.15 \mathrm{~K}$ ). By modeling the MO-1 with full-density water, the calculational model is considered to be more reactive than the actual package under fire conditions. 


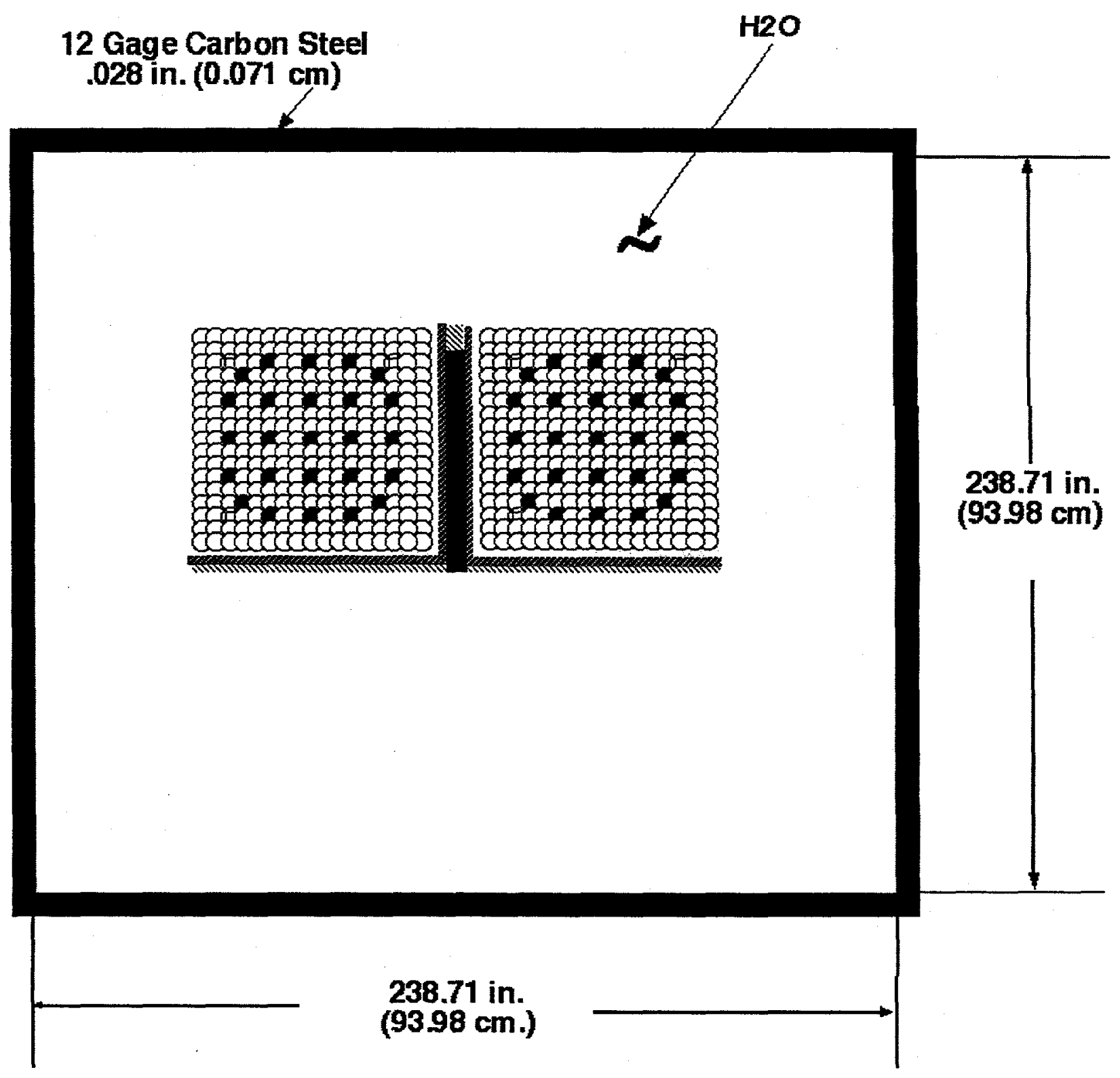

Fig. 3.7. Damaged MO-1 model with fuel positioned in center of package. 


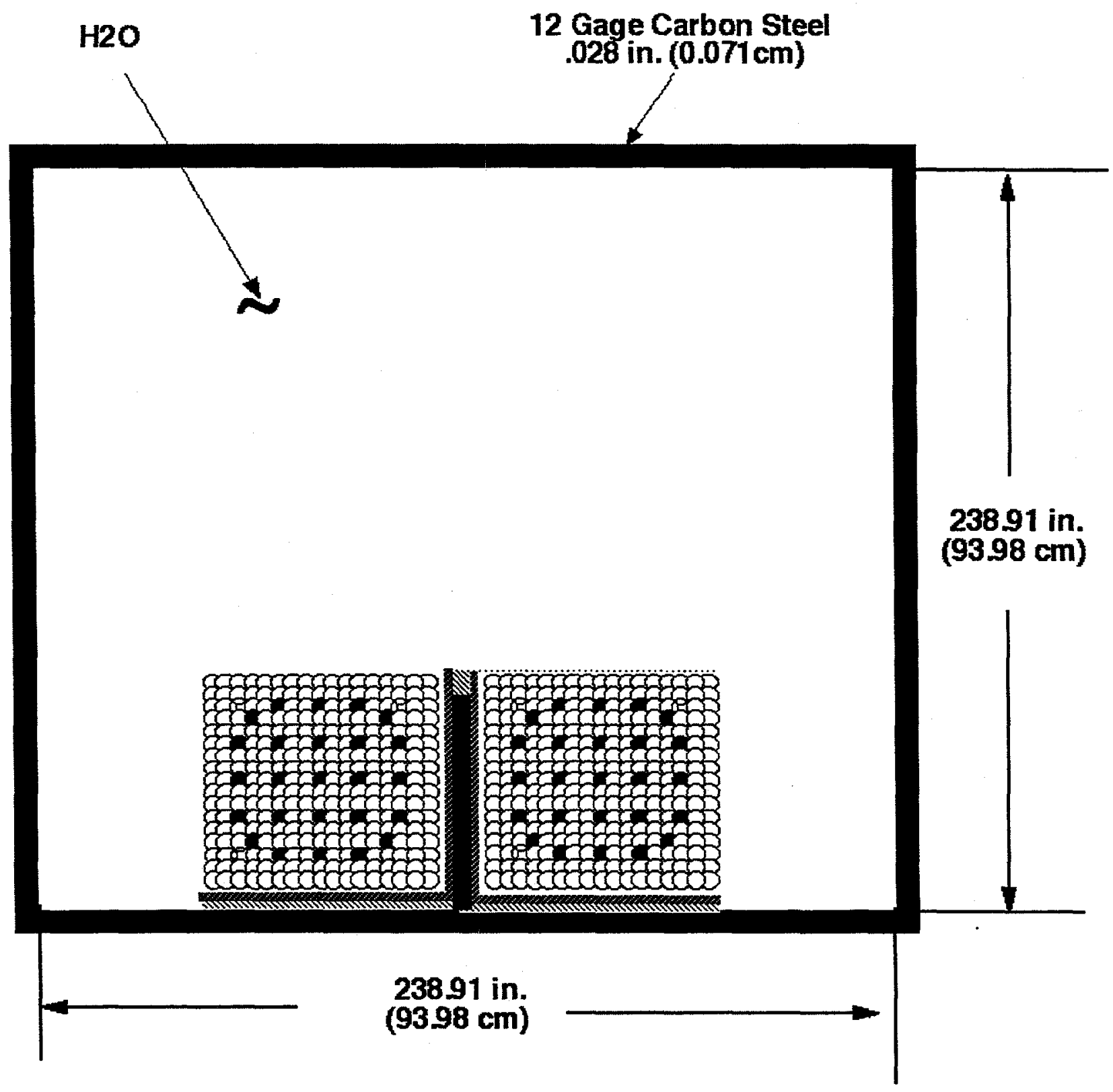

Fig. 3.8. Damaged MO-1 model with fuel positioned at bottom of package. 


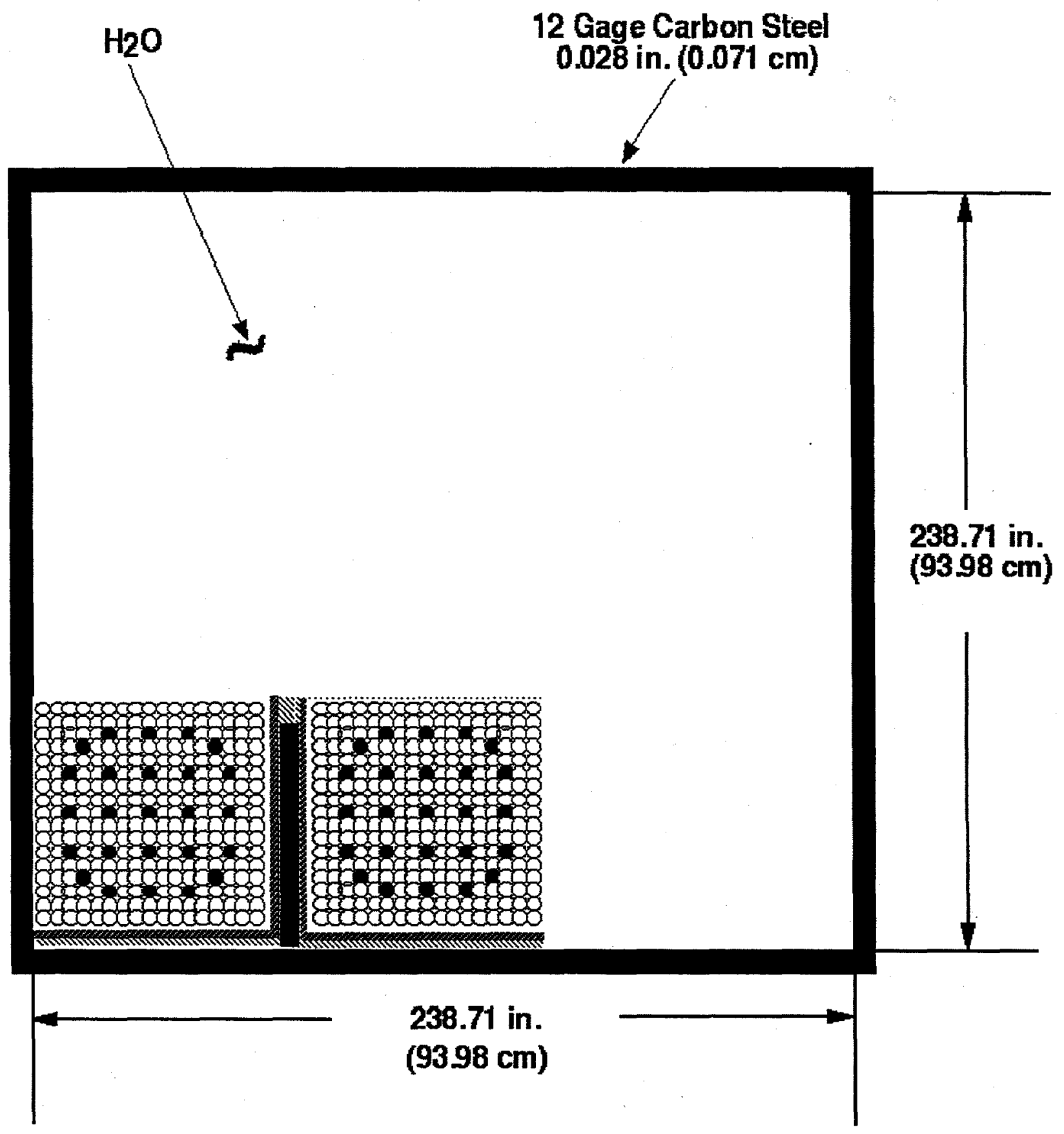

Fig. 3.9. Damaged MO-1 with fuel positioned in interior corner of package. 
Table 3.2. $\mathrm{H}_{2} \mathrm{O}$ saturation pressures for $\mathrm{MO}-1$ temperature conditions

\begin{tabular}{ccc}
\hline $\begin{array}{c}\text { Temperature } \\
\left({ }^{\circ} \mathrm{F}\right)\end{array}$ & $\begin{array}{c}\text { Temperature } \\
(\mathrm{K})\end{array}$ & $\begin{array}{c}\text { Pressure } \\
(\mathrm{psia})\end{array}$ \\
\hline 232.0 & 384.3 & 21.57 \\
260.0 & 399.8 & 35.42 \\
340.0 & 444.3 & 117.93 \\
410.0 & 483.2 & 276.5 \\
\hline
\end{tabular}

\subsection{PACKAGE ARRAYS}

Only two MO-1 transport packages are in existence, and both packages are rectangular in shape. Because of the package size, only one MO-1 package can be transported using a DOE Safe Secure Trailer (SST). However, assembling two transport packages in an array configuration is possible at a reactor or fuel cycle facility (e.g., interim storage of fresh fuel). If two SSTs are used to transport packages simultaneously, a configuration of two packages is also credible. To fulfill the requirements of $10 \mathrm{CFR}$ $\S 71.59$ (ref. 12) and determine a transport index, the MO-1 must be analyzed in array configurations which involve both packages.

Two array model types (i.e., undamaged and damaged packages) are included in the evaluation. The first model type consists of a square-pitched infinite array of undamaged packages consistent with the normal conditions of transport. According to 10 CFR $\S 71.59$, standards for arrays of fissile material packages, undamaged package arrays are evaluated with void between the packages (i.e., no interspersed moderation). However, the single package within the array must be at optimum moderation (i.e., interstitial) conditions unless the analysis demonstrates water inleakage is not credible. The optimum interstitial moderation conditions for a single MO-1 package is not necessarily optimum for an array configuration. To assess the optimum interstitial moderation conditions for an array of undamaged packages, different models are used with varying degrees of interstitial moderation.

In accordance with $10 \mathrm{CFR} \S 71.59$, the damaged MO-1 packages are evaluated with each package subjected to hypothetical accident conditions as specified in 10 CFR $\S 71.73 .^{13}$ The condition of each damaged package in the array is consistent with the damaged single package described in Sect. 3.3. The damaged-package models evaluate optimum interspersed as well as interstitial package moderation conditions. In addition, the finite-array models are fully reflected with $12 \mathrm{in.}(30 \mathrm{~cm})$ of water on all sides. As noted in Sect. 3.3, the strongback and fuel assemblies could move during impact conditions, leading to a shift in fuel contents within the MO-1. Two finite-array models, which optimize interaction between two damaged packages, are presented in Figs. 3.10 and 3.11. In both models, the fuel contents are shifted to neighboring interior corners within each MO-1; however, the entire fuel contents are rotated $90^{\circ}$ in Fig. 3.11. Although the configuration presented in Fig. 3.11 should be more reactive relative to the configuration in Fig. 3.10, both models are presented in an effort to assess the change in reactivity associated with the rotation of the fuel contents during upset conditions. Each MO-1 has a crushed exterior carbon-steel wall $(\Delta t=0.028 \mathrm{in}$. or $0.071 \mathrm{~cm})$ with no polyurethane foam insulation. These configurations are considered to be bounding since the actual wall thickness of each damaged package would probably exceed 0.028 in. $(0.071 \mathrm{~cm})$. Furthermore, there would also be other structural materials (e.g., foam, shock mounts, clamping frames, etc.) present to further separate the fuel contents of both MO-1 packages. Consequently, the models presented in Figs. 3.10 and 3.11 maximize package interaction and reactivity with regard to arrays of damaged packages. 


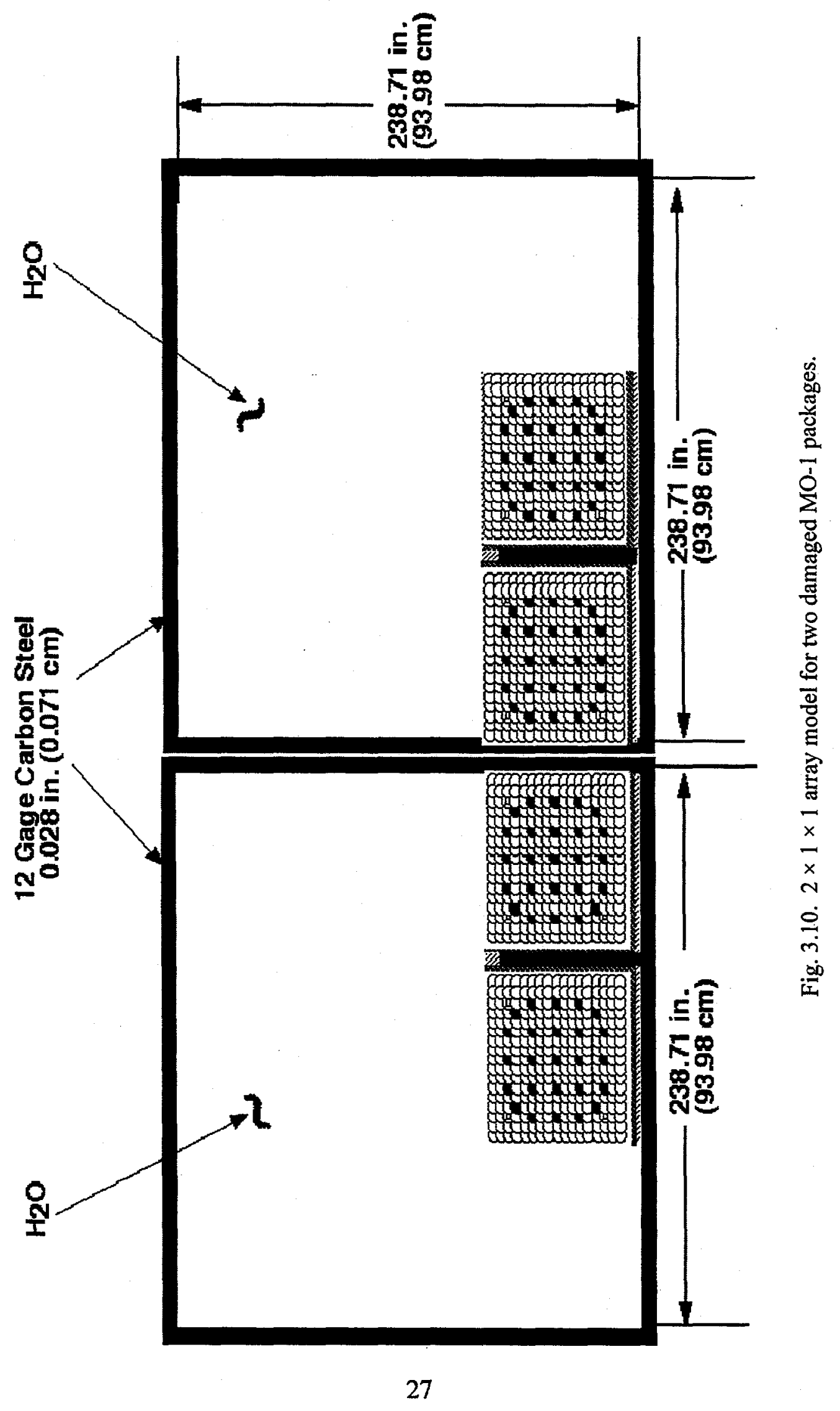




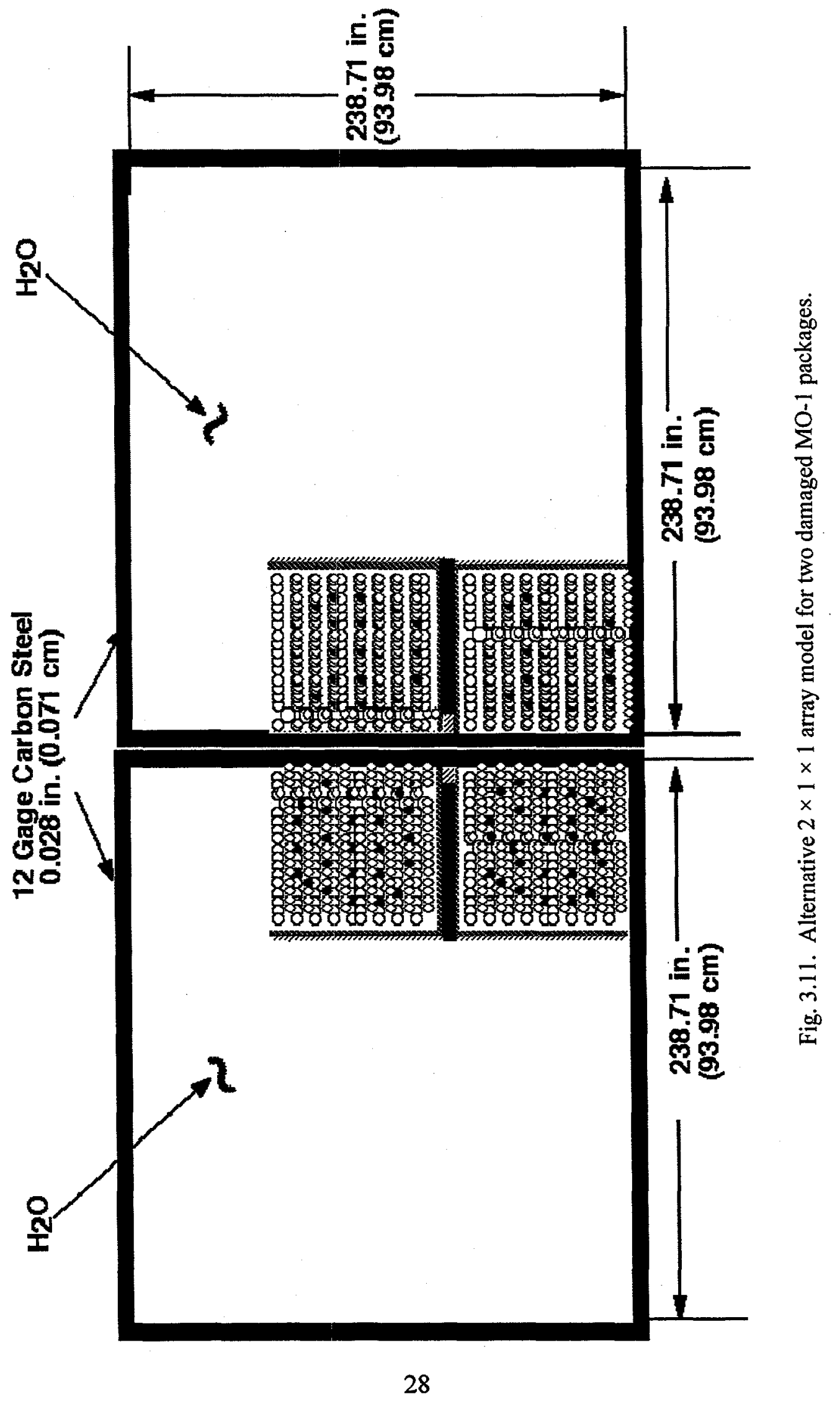




\section{METHOD OF ANALYSIS}

\subsection{OVERVIEW OF CRITICALITY SAFETY EVALUATION}

Prior to evaluating the MO-1, the calculational method used to assess the transportation package must be validated by comparison with appropriate critical experiments. Using the validation information, a calculational upper subcritical limit (USL) is established for subsequent calculations involving the MO-1 transportation package. The objective of the validation process is to provide a basis for the reliability of the calculational method and establish an acceptable margin of subcriticality for the package evaluation. The calculational method validation is presented in Sect. 5 . Once the acceptance criterion is established, the MO-1 transportation package can be evaluated. The objective of the single-package evaluation is to determine the most reactive configuration of the undamaged and damaged single package. Following the evaluation of a single MO-1, the undamaged and damaged transportation packages are evaluated in array configurations. The following outline provides an overview for the criticality safety evaluation of the MO-1 transportation package:

I. Single Package

A. Undamaged Configuration

Develop a worst-case model for the undamaged single-package case under normal conditions by evaluating the package under the following parameters:
a. Internal flooding
b. Temperature variation (i.e., max. normal temperature $=384.3 \mathrm{~K}$ )
c. Full-water reflection (12 in. or $30 \mathrm{~cm}$ )
d. Full reflection by package material (e.g., polyurethane foam, steel)

B. Damaged Configuration

Evaluate the optimum single-package case under different accident scenarios. The following parameters are evaluated in the development of a worst-case model for a damaged single package:
a. Fire conditions
b. Decomposition of polyurethane foam
c. Reduced external wall thickness caused by impact
d. Payload shifting in MO-1
e. Loss of assembly spacing due to impact

II. Array of Packages

\section{A. Undamaged Configuration}

Determine the maximum number of undamaged packages in array. Evaluate the singlepackage model within an array by examining the following parameters: 

a. Internal package moderation
b. Array size
c. Full-water reflection for finite arrays

\section{B. Damaged Configuration}

Determine the maximum number of damaged packages in array. Evaluate the package model within an array by examining the following parameters:
a. Package spacing within array
b. Moderation between packages (interspersed), as well as within each package (interstitial)
c. Fuel configuration that optimizes interaction between packages
d. Array size
e. Full-water reflection for finite arrays

\section{Transport Index (TI)}

Determine the transport index (TI) for the package using the information from the array evaluation in accordance with 10 CFR 71.59:

$$
\begin{aligned}
\mathrm{N}= & \begin{array}{l}
\text { maximum number of packages per shipment for a nonexclusive-use shipment } \\
(5 \leq \mathrm{N} \leq \infty) .
\end{array} \\
2 \mathrm{~N}= & \begin{array}{l}
\text { maximum number of packages per shipment for an exclusive-use shipment } \\
(0.5 \leq \mathrm{N} \leq \infty) .
\end{array} \\
\mathrm{TI}= & 50 \div \mathrm{N} .
\end{aligned}
$$

\subsection{COMPUTER CODE SYSTEM}

All calculations in this evaluation were performed using the Standardized Computer Analysis for Licensing Evaluation (SCALE) code system. Specifically, SCALE version 4.3 (1/06/97 production date) was used with the 238-group ENDF/B-V cross-section library in the in the evaluation. The calculations were performed on CA01, CA02, CA03, CA04 and CA29, IBM RS/6000 workstations in the Computational Physics and Engineering Division at ORNL. The operating system for each workstation is AIX 4.2.

The Criticality Safety Analysis Sequences (CSAS) within the SCALE system provide automated calculational sequences that perform problem-dependent cross-section processing, followed by three-dimensional (3-D) Monte Carlo calculations of the system multiplication factor $\left(k_{e f f}\right){ }^{8}$ In particular, the CSAS25 sequence is used in this evaluation and executes BONAMI, NITAWL-II and KENO V.a. The cross-section processing codes BONAMI and NITAWL-II are discussed further in Sect. 4.3. KENO V.a is a 3-D multigroup Monte Carlo code that calculates the eigenvalue of the Boltzmann transport equation using problem-dependent cross sections and user-specified geometry for the system. Additional quantities calculated by KENO V.a include average neutron lifetime and generation time, energy-dependent leakages, energy- and region-dependent absorptions, fissions, fluxes and fission densities. 


\subsection{CROSS SECTIONS AND CROSS-SECTION PROCESSING}

The SCALE CSAS sequences use the Material Information Processor to calculate material number densities, prepare geometry data for resonance self-shielding and create input files for the cross-section processing codes. BONAMI applies the Bondarenko method of resonance self-shielding in the unresolved resonance range for nuclides that have Bondarenko factors included in the cross-section library. For nuclides that have resonance parameters, the NITAWL-II module performs resonance self-shielding corrections in the resolved resonance range using the Nordheim integral method.

As noted in Sect. 4.2, the 238-group ENDF/B-V library was used in the criticality safety calculations in this evaluation. One important feature related to the 238-group library involves the treatment of resonance data. Initially, the library only included $s$-wave resonance data in the resonance parameters that are passed to NTAWL; however, the library has been extended to include the $p$-wave and $d$-wave resonance data that can be important for undermoderated intermediate-energy problems, such as transportation package evaluations. ${ }^{8}$ In addition, the 238-group library has 148 fast groups and 90 thermal groups below $3 \mathrm{eV}$. The fine-group structure and inclusion of higher-order resonance data make the 238-group ENDF/B-V library suitable for general use in criticality and reactor physics applications.

\subsection{CODE INPUT}

All calculations were started with a flat initial neutron distribution throughout the system in fissile material only. Each case had a minimum of 400 generations with a minimum of 600 neutrons per generation. By skipping the first 20 generations, the total number of histories in a case is at least 228,000 . To simulate an infinite-array model, mirror reflection was applied to the orthogonal boundaries of the single-package model. For models with full-water reflection, the biasing data for water, which is provided with KENO V.a, was used in the external reflector model. Sample CSAS25 input files are provided in Appendix A.

\subsection{CONVERGENCE OF CALCULATIONS}

For the various model configurations, the input geometries were checked by examining the 2-D plots generated by KENO V.a. In addition, the 3-D geometry package KENOVIEW 2.1 (ref. 14) was used to view the KENO V.a models. To evaluate problem convergence, the plots of $k_{\text {eff }}$ by generations run and skipped were examined. No trends have been observed over the last half of total generations in the plots of $k_{e f f}$ by generation run. Likewise, there are no observable trends over the first half of total generations in the plots of $k_{e f f}$ by generation skipped. In addition, the final $k_{e f f}$ edit tables and frequency distribution plots were examined. The frequency distribution plots approximate a normal distribution and are characterized by single peaks and no outlying values of $k_{\text {eff }}$. Based on the frequency distribution data, an adequate sampling of the neutron population has been obtained. 



\section{VALIDATION OF CALCULATIONAL METHOD}

When a calculational method or code is to be used for criticality safety evaluations, the computer code and cross-section library must be validated against applicable experimental data. ${ }^{15}$ The objective of the validation process is to provide a basis for the reliability of the calculational method, which includes the code and cross-section data. Based on the guidance of NUREG/CR-5661, a calculated $k_{\text {eff }}$ plus bias and uncertainties for transportation package analysis should be $\leq 0.95$ (ref. 7).

As noted in Sect. 4.2, all calculations in this evaluation were performed using the CSAS25 sequence of the SCALE 4.3 package on CA01, CA02, CA03, CA04 and CA29 (IBM RS/6000 workstations) in the Computational Physics and Engineering Division at ORNL. A complete validation study has been performed for the FMDP program using the SCALE 4.3 CSAS25 sequence and the 238-group ENDF/B-V cross-section library on the same IBM RS/6000 workstations used in this evaluation. ${ }^{16}$ Moreover, the referenced validation report provides a complete listing and description of the critical experiments used to establish the upper subcritical limit (USL) for the FMDP criticality safety evaluations. Based on the complete documentation of the validation report presented in ref. 16, the validation study will not be reproduced in this document. However, the validation study as it pertains to this evaluation is discussed and documented in accordance with the guidance of NUREG/CR-5661. Note that no additional experiments are added to the general validation study presented in ref. 16, and the validation presented herein is for illustration purposes. An overview of the critical experiments and their relation to the MO-1 study is discussed in Sect. 5.1. A discussion related to establishment of the bias, uncertainties and acceptance criteria is presented in Sect. 5.2. In conjunction with the information presented in Sect. 5.1, a description of the range of applicability for the calculational method is provided in Sect. 5.3.

\subsection{SELECTION OF CRITICAL EXPERIMENTS}

Three principal parameters must be considered in the selection of applicable experiments for transportation package analysis. Specifically, the materials of construction (including fissionable materials), the geometry of construction and the neutron energy spectrum affecting the fissionable material. ${ }^{17}$ The neutron energy spectrum is determined in large part by the fissile material, amount or degree of moderation, package geometry and neutron absorbing materials present in the package.

With regard to experimental needs for the MO-1 evaluation, the critical experiments should include MOX fuel with 3 to $6 \mathrm{wt} \% \mathrm{PuO}_{2}$. Moreover, the Pu fissile fraction should range between 71 and $94 \mathrm{wt} \%$ (i.e., wt $\%{ }^{239} \mathrm{Pu}+\mathrm{wt} \%{ }^{241} \mathrm{Pu}$ ). The fuel should be configured as fuel pins (OD between $0.35 \mathrm{in}$. and 0.43 in. or $0.9 \mathrm{~cm}$ and $1.1 \mathrm{~cm}$ ) arranged on a $14 \times 14$ or $17 \times 17$ square lattice with pitch spacing between 0.39 and $0.79 \mathrm{in}$. ( 1 and $2 \mathrm{~cm}$ ). The experiments should permit the investigation of varying degrees of interstitial hydrogenous moderation. In addition, the critical experiments should include various package reflection conditions involving water and polyurethane foam.

Only a few MOX critical experiments are comprised of weapons-grade Pu. Moreover, a single set of benchmark experiments that exactly replicates the MO- 1 transportation package with the specified fuel contents does not exist. However, the selected experiments in the validation study can be characterized by specific parameters that are directly applicable to the MO-1 transportation package evaluation. The experimental database for the validation effort consists of 102 critical experiments with $\mathrm{Pu}$ as well as $\mathrm{Pu}-\mathrm{U}$ mixtures in various chemical forms. A complete listing and description of each of the experiments is provided in ref. 16. Based on the information in the validation study a complete characterization of the critical experiments with regard to parameters affecting criticality safety is presented in Table 5.1. 
Table 5.1. Characterization variables of selected critical experiments

\begin{tabular}{|c|c|c|}
\hline Parameter & Values & Number of experiments \\
\hline \multirow[t]{6}{*}{ Fissile material } & Pu metal & 1 \\
\hline & $\mathrm{Pu}\left(\mathrm{NO}_{3}\right)_{4}$ solution & 65 \\
\hline & $\mathrm{PuO}_{2}$-polystyrene compacts & 4 \\
\hline & $\begin{array}{c}\mathrm{PuO}_{2}-\mathrm{UO}_{2} \text {-polystyrene } \\
\text { compacts }\end{array}$ & 14 \\
\hline & $\mathrm{Pu}-\mathrm{U}$ nitrate solution & 8 \\
\hline & $\mathrm{PuO}_{2}-\mathrm{UO}_{2}$ (MOX assemblies) & 10 \\
\hline Total & & 102 \\
\hline \multirow[t]{3}{*}{ Moderation } & $\mathrm{H}$ in polystyrene & 18 \\
\hline & $\mathrm{H}_{2} \mathrm{O}$ in solution & 73 \\
\hline & $\mathrm{H}_{2} \mathrm{O}$ interstitial & 10 \\
\hline Total & & 101 \\
\hline \multirow[t]{4}{*}{ Absorber } & Soluble Gd nitrate & 14 \\
\hline & Soluble B (ppm) & 6 \\
\hline & $\mathrm{B}_{4} \mathrm{C}$ in concrete & 7 \\
\hline & Cd-polyethylene & 1 \\
\hline Total & & 28 \\
\hline \multirow[t]{5}{*}{ Geometry } & Sphere & 6 \\
\hline & $\begin{array}{l}\text { Arrays of rectangular } \\
\text { parallelpiped compacts }\end{array}$ & 18 \\
\hline & Cylinder & 63 \\
\hline & Annular & 5 \\
\hline & Square lattice of rods & 10 \\
\hline Total & & 102 \\
\hline \multirow[t]{3}{*}{ External reflection } & Unreflected & 23 \\
\hline & $\mathrm{H}_{2} \mathrm{O}$ & 61 \\
\hline & $\begin{array}{l}\text { Plexiglass }\left(\mathrm{C}_{5} \mathrm{H}_{8} \mathrm{O}_{2}\right) \\
\text { plastic methacrylate }\end{array}$ & 18 \\
\hline Total & & 102 \\
\hline
\end{tabular}


Table 5.1 (continued)

\begin{tabular}{ccc}
\hline Parameter & Values & Number of experiments \\
\hline Structural reflection & SS304 and carbon steel & 8 \\
& SS304L & 46 \\
& SS347 & 5 \\
& Carbon steel & 4 \\
\hline Total & & 63 \\
\hline Cladding & Zirc-2 & 6 \\
& SS316 & 4 \\
\hline Total & & $\mathbf{1 0}$ \\
\hline Other materials & Polyethylene $\left(\mathrm{CH}_{2}\right)$ & 1 \\
& Concrete & 7 \\
\hline Total & & $\mathbf{8}$ \\
\hline
\end{tabular}

Based on the validation report presented in ref. 16 relative to the MO-1 package characteristics, the Pu fissile fraction (wt $\%{ }^{239} \mathrm{Pu}+\mathrm{wt} \%{ }^{241} \mathrm{Pu}$ ) of the critical experiments range between 88 and $98.2 \mathrm{wt} \%$. The Pu fissile fraction of the 10 MOX experiments is $92.2 \mathrm{wt} \%$ (6 exp.) and $88 \mathrm{wt} \%$ (4 exp.). As noted in Sect. 2.1.1, the fissile fractions for the original certified MOX contents are 70.97, 81.18 and $85.607 \mathrm{wt} \%$ for $6.0,4.4$ and $3.03 \mathrm{wt} \% \mathrm{PuO}_{2}$, respectively. Although the fissile fraction range in the critical experiments is higher than the original MOX contents, the ratio of ${ }^{241} \mathrm{Pu}$ to ${ }^{239} \mathrm{Pu}$ in the experimental database is comparable to the MOX contents. Specifically, the ratio of ${ }^{241} \mathrm{Pu}$ to ${ }^{239} \mathrm{Pu}$ is 0.05 and 0.04 for the 3.03 and $4.4 \mathrm{wt} \% \mathrm{PuO}_{2}$ configurations whereas the corresponding ratio for the $6.0 \mathrm{wt} \% \mathrm{PuO}_{2}$ case is 0.23 . Regarding the experimental database, the ${ }^{241} \mathrm{Pu} /{ }^{239} \mathrm{Pu}$ ratios range between 0.003 and 0.26 . In the mixed $\mathrm{Pu}-\mathrm{U}$ criticals, the ${ }^{241} \mathrm{Pu} /{ }^{239} \mathrm{Pu}$ ratio in the $\mathrm{PuO}_{2}-\mathrm{UO}_{2}$-polystyrene experiments is $\sim 0.02$, but the ratio in four of the MOX fuel experiments is 0.03 . The ratio of ${ }^{241} \mathrm{Pu}$ to ${ }^{239} \mathrm{Pu}$ in nine of the critical experiments is 0.26 . With regard to the ratio of ${ }^{240} \mathrm{Pu}$ to ${ }^{239} \mathrm{Pu}$ in Table 2.2, the original certified MOX ratios are $0.17,0.23$ and 0.39 . The ratio of ${ }^{240} \mathrm{Pu}$ to ${ }^{239} \mathrm{Pu}$ in the set of critical experiments ranges between 0.02 to 1.04 , with several experiments in the low ${ }^{240} \mathrm{Pu}{ }^{239} \mathrm{Pu}$ range (e.g., $0.09,0.13,0.16$ ). Based on the $\mathrm{Pu}$ isotopic distribution data, the selected critical experiments have comparable $\mathrm{Pu}$ isotopic distributions with the three original MOX fuel loadings.

From Table 2.4, the ${ }^{241} \mathrm{Pu} /{ }^{239} \mathrm{Pu}$ and ${ }^{240} \mathrm{Pu} /{ }^{239} \mathrm{Pu}$ ratios for the proposed WG MOX are 0.004 and 0.06 , respectively. These low isotopic ratios further illustrate the relatively large amount of ${ }^{239} \mathrm{Pu}$ present in the WG fuel. Note that the ${ }^{241} \mathrm{Pu} /{ }^{239} \mathrm{Pu}$ ratio in six of the MOX fuel pin experiments is 0.004 , which is identical to the proposed WG fuel contents. The ${ }^{240} \mathrm{Pu} /{ }^{239} \mathrm{Pu}$ ratio in these six experiments is 0.08 , which is slightly higher than the WG fuel. As noted above, the ${ }^{241} \mathrm{Pu} /{ }^{239} \mathrm{Pu}$ and ${ }^{240} \mathrm{Pu} /{ }^{239} \mathrm{Pu}$ ratios in the selected validation experiments cover a wide range of values including the $\mathrm{Pu}$ isotopic distributions in the proposed WG MOX fuel. Furthermore, the fissile fraction range in the selected experiments bounds the WG fuel. 
The uranium present in the original MOX fuel is natural (i.e., $0.71 \mathrm{wt} \%{ }^{235} \mathrm{U}$ ), but the WG MOX fuel has depleted uranium (i.e., $0.2 \mathrm{wt} \%{ }^{235} \mathrm{U}$ ). The ${ }^{235} \mathrm{U}$ content in the MOX and mixed $\mathrm{Pu}-\mathrm{U}$ experiments is either 0.2 or $0.71 \mathrm{wt} \%$, except for two mixed Pu-U nitrate experiments with $\sim 2.3 \mathrm{wt} \%{ }^{235} \mathrm{U}$. Since the uranium isotopics in the critical experiments are comparable to the MOX fuel loadings, the selected experiments are applicable for the MO-1 package evaluation.

The experimental database also represents a wide range of hydrogenous moderation. Specifically, the $\mathrm{H}^{239} \mathrm{Pu}$ ratio ranges between 0.0 and 2437 , with a variety of experiments in the low-moderation range (e.g., $\mathrm{H}^{239} \mathrm{Pu}: 0.0,5.86,10.97,11.2,13.2,14.07,14.7,22.67$ and 73.86 ). The range of $\mathrm{H}^{239} \mathrm{Pu}$ ratios with regard to the range of applicability is discussed further in Sect. 5.3. In the criticality safety evaluation, the MO-1 package is evaluated under various moderation conditions. Based on the wide range of moderation ratios, the selected set of critical experiments can be used to investigate the bias associated with various hydrogenous moderation conditions.

The material specifications associated with the MO-1 transportation package are presented in Sect. 2.1. As noted in Sect. 2.2, the MO-1 strongback structure has two borated SS304 plates that serve as neutron absorbers. The natural boron accounts for $1.3 \mathrm{wt} \%$ of the S\$304 which is modeled as $0.975 \mathrm{wt} \%$ of the steel as discussed in Sect. 2.1. Twenty eight of the critical experiments investigate the effects of neutron-absorbing material in $\mathrm{Pu}$ and mixed $\mathrm{Pu}-\mathrm{U}$ systems. Regarding the package characteristics, 13 experiments involve boron as either a soluble neutron absorber or solid insert $\left(\mathrm{B}_{4} \mathrm{C}\right.$ concrete) in mixed $\mathrm{Pu}-\mathrm{U}$ systems. In the experiments involving $\mathrm{B}_{4} \mathrm{C}$ concrete, the boron is natural and accounts for $1.56 \mathrm{wt} \%$ of the concrete. Since there are specific criticals involving natural boron as a solid neutron-absorbing insert, these experiments are suitable for evaluating biases associated with natural boron as a reactivity control in mixed $\mathrm{Pu}-\mathrm{U}$ systems. Polyethylene is specified for use as a possible sheath around the assemblies. Various critical experiments involve polyethylene or materials having C-H molecular bonds (e.g., plastic) as a reflector in the validation study. Although water is not a material of construction in the MO-1 package, water is evaluated as a reflector and moderator in the critical safety evaluation. As noted above, several of the critical experiments investigate the effects of water moderation and reflection in $\mathrm{Pu}$ and mixed $\mathrm{Pu}-\mathrm{U}$ systems. An additional package material reflector is the polyurethane foam which fills the region between the inner- and outer-carbon-steel shells. Although none of the selected critical experiments directly involve polyurethane foam, the foam constituents, which include carbon, hydrogen, nitrogen and oxygen, are accounted for in the selected set of validation experiments. Specifically, 79 of the critical experiments have external material reflectors involving hydrogen and oxygen, as noted in Table 5.1. Moreover, 18 experiments have external material reflectors that involve carbon. Although none of the selected experiments have nitrogen-based reflectors, 73 experiments have nitrogen as a constituent in the fissile system. In addition to polyurethane foam, carbon steel is specified as a material of construction in the MO-1 package (e.g., inner- and outer-shell walls, strongback frame, etc.). Table 5.1 also presents structural information pertaining to the critical experiments in the validation study. Based on the information in Table 5.1, 63 of the critical experiments involve various forms of steel. Relative to the MO-1 package, 12 of the experiments have carbon steel structural material and 54 of the experiments have SS304 structural components. These experiments are suitable for evaluating biases associated with SS304 and carbon steel structures that are similar to the MO-1 package configuration. Based on the characterization information in Table 5.1, the selected critical experiments are applicable for evaluating the biases associated with materials that are specified as components of the MO-1 transportation package.

As discussed in Sect. 2, the transportation package consists of 1 or 2 assemblies with fuel pins arranged in a square-pitch lattice. The pitch dimensions are $0.556 \mathrm{in}$. and $0.496 \mathrm{in} .(1.412 \mathrm{~cm}$ and $1.26 \mathrm{~cm}$, respectively) for the original MOX. and WG MOX fuel assemblies, respectively. Regarding the validation study, the MOX fuel assembly experiments have pitches between $0.375 \mathrm{in}$. and $0.989 \mathrm{in}$. $(0.953 \mathrm{~cm}$ and $2.51 \mathrm{~cm})$. In particular, there are critical MOX fuel experiments with pitch dimensions of 
$0.496 \mathrm{in}$. and $0.602 \mathrm{in.}(1.26 \mathrm{~cm}$ and $1.53 \mathrm{~cm})$ which are comparable to the fuel assembly configuration in the MO-1 transportation package. The single-package analysis also addresses interstitial hydrogenous moderation with full-water reflection. Four of the ten MOX assembly experiments investigate the reactivity of $\mathrm{PuO}_{2}-\mathrm{UO}_{2}$ fuel pins under water moderation and reflector conditions. Because of the configuration of the $10 \mathrm{MOX}$ assembly experiments, these experiments are suitable for investigating biases associated with MOX assemblies under water moderation and reflector conditions.

Regarding array configurations, 14 critical experiments evaluate arrays of $\mathrm{PuO}_{2}-\mathrm{UO}_{2}$-polystyrene units with interstitial hydrogen moderation. In addition, 4 critical experiments evaluate $\mathrm{PuO}_{2}$-polystyrene units with interstitial hydrogen moderation. Although the critical array experiments do not have identical characteristics as the modeled MO-1 transportation package arrays, a variety of experiments were selected to demonstrate the capability of KENO V.a in predicting $k_{e f f}$ for each experiment that has characteristics common to the MO-1 package.

\subsection{ESTABLISHMENT OF BIAS, UNCERTAINTY AND ACCEPTANCE CRITERIA}

Calculational models used to evaluate the 102 critical experiments are discussed in the validation report, along with appropriate descriptions of known experimental uncertainties. ${ }^{16}$ As noted in Sect. 4, the SCALE criticality safety sequence CSAS25 was used with the 238-energy-group ENDF/B-V library to evaluate the benchmark experiments. The calculational results obtained for each experiment are presented in ref. 16.

ANSI/ANS-8.17 provides the guidelines for establishing subcriticality based on a numerical calculation of the multiplication factor $\left(k_{e f f}\right)$ for a fissile system. ${ }^{18}$ The calculated $k_{\text {eff }}$ for a fissile system is considered to be acceptably subcritical provided the calculated $k_{\text {eff }}$ plus $2 \sigma$ is less than a specified upper subcritical limit (USL). The following relationship is used to establish the acceptance criteria for a calculated multiplication factor for a subcritical system, $\mathrm{k}_{\mathrm{s}}$ :

$$
k_{s} \leq k_{c}-\Delta k_{c}-\Delta k_{s}-\Delta k_{m}
$$

where

$$
\begin{aligned}
k_{c}= & \text { mean value of } k_{e f} \text { resulting from the calculation of benchmark critical experiments } \\
& \text { using a specific calculational method and data, } \\
\Delta k_{c}= & \text { uncertainty in the value of } k_{c} \\
\Delta k_{s}= & \text { uncertainty in the calculated value for } k_{s}, \\
\Delta k_{m}= & \text { required administrative margin of subcriticality. }
\end{aligned}
$$

In Monte Carlo analysis, the uncertainty in the value for $k_{s}$ is typically two times the standard deviation $(2 \sigma)$ of the calculated $k_{e f f}$ of the system (i.e., $\Delta k_{s}=2 \sigma$ ). For transportation package applications, the minimum administrative margin of subcriticality is typically $5 \%$ (i.e., $\Delta k_{m}=0.05$ ). The acceptance criteria for a subcritical system can be rewritten in the following form:

$$
k_{s}+2 \sigma \leq k_{c}-\Delta k_{c}-0.05 \text {. }
$$

The bias, $\beta$, in the calculational method is the difference between the mean value of the calculated $k_{\text {eff }}$ for the critical experiments, $k_{c}$, and 1.0 (i.e., $\beta=k_{c}-1$ ). Based on the definition of the calculational bias, the uncertainty in the bias is identical to the uncertainty in $k_{c}$. Thus, $\Delta k_{c}=\Delta \beta$, and the acceptance criteria becomes

$$
k_{s}+2 \sigma \leq 1.00+\beta-\Delta \beta-0.05
$$


A USL is an upper subcritical limit such that there is a specified level of confidence that a calculated $k_{\text {eff }}$ is considered to be subcritical. Using the acceptance criteria for a subcritical system, the USL can be defined as follows:

$$
U S L=0.95+\beta-\Delta \beta .
$$

A fissile system is considered to be acceptably subcritical provided the following condition is met:

$$
k_{e f f}+2 \sigma \leq U S L \text {. }
$$

The calculational bias in the acceptance criteria can be positive if $k_{c}$ is greater than 1 ; however, a positive bias is not used in this evaluation. Therefore, the bias is always $\leq 0.0$. Regarding the uncertainty in the validation, the sources of uncertainty include the calculational method, the experimental data or technique and calculational models, as well as the particular analyst. The sources of uncertainty are cumulatively observed in the variability of the calculated $k_{\text {eff }}$ results obtained for the modeled critical experiments. Furthermore, this variability includes the Monte Carlo standard deviation in each calculated $k_{\text {eff }}$ for the critical experiment, as well as changes in the calculated value due to consideration of the experimental uncertainties. Consequently, the noted uncertainties are included in the bias and uncertainty in the bias. ${ }^{7}$ The remainder of this section is devoted to the calculation of the bias and uncertainty in the bias.

As noted in NUREG/CR-5661, the bias should have no dependence with respect to a characteristic parameter (e.g., hydrogen-to-fissile ratio $(\mathrm{H} / \mathrm{X})$, enrichment, etc.) or be a "smooth, well-behaved function" of a characteristic parameter. ${ }^{7}$ To investigate possible trends between the calculated $k_{\text {eff }}$ values and different characteristic parameters for the set of experiments, a correlation study is presented in ref. 16. The study investigates possible correlations with various parameters including $\mathrm{H} /{ }^{39} \mathrm{Pu}$, experiment reference number, temperature, average energy of fission (AEF) as well as $\mathrm{Ga}, \mathrm{B}, \mathrm{Gd}, \mathrm{Fe}, \mathrm{N}, \mathrm{O}, \mathrm{H},{ }^{239} \mathrm{Pu}$, ${ }^{240} \mathrm{Pu},{ }^{241} \mathrm{Pu},{ }^{242} \mathrm{Pu},{ }^{235} \mathrm{U}$ and ${ }^{238} \mathrm{U}$ atom densities. Both the calculated $\mathrm{k}_{\mathrm{eff}}$ values and independent characteristic variable were tested for normality using the chi-square test available in USLSTATS, a statistical code which calculates upper subcritical limits (USLs). ${ }^{17}$ After establishing normality for the calculated multiplication factor and corresponding independent variable, the Pearson's product moment coefficient or correlation coefficient was determined for the calculated $k_{\text {eff }}$ values as a function of each independent variable using the following relation:

$$
r_{x, y}=\frac{\sum x y-\frac{1}{n} \sum x \sum y}{(n-1) s_{x} s_{y}},
$$

where

$$
\begin{aligned}
& \mathrm{x}=\text { characteristic parameter } \\
& \mathrm{y}=\text { calculated } k_{\text {eff }} \\
& \mathrm{s}_{\mathrm{x}}=\text { sample standard deviation of } \mathrm{x}, \\
& \mathrm{s}_{\mathrm{y}}=\text { sample standard deviation of } \mathrm{y}, \\
& \mathrm{n}=\text { sample population size. }
\end{aligned}
$$

The value of the correlation coefficient can range between -1 and 1 , indicating an inverse or direct correlation, respectively. A correlation coefficient equal to zero indicates no correlation between the calculated $k_{e f f}$ values and the corresponding independent parameter. A correlation coefficient that lies 
between \pm 0.3 (i.e., $|r|<0.3$ ) is judged to be a weak correlation. In addition to the correlation coefficient, the significance level of the correlation can be calculated. A test statistic, $t$, is used to test the null hypothesis that the population correlation equals zero. The value of $t$ for each xy correlation can be calculated using the relation: ${ }^{16}$

$$
t=r_{x, y}(n-2)^{1 / 2}\left(1-r^{2}\right)^{-1 / 2}
$$

The probability or level of significance for accepting the null hypothesis is obtained from a $t$-distribution for the calculated value of $t$. Consequently, the lower the significance level, the higher the degree of confidence that the computed correlation represents a true phenomena. Based on the correlation coefficients between the calculated $k_{e f f}$ values and each characteristic parameter, the parameters that exhibit a statistically significant correlation (i.e., $|\mathrm{r}| \geq 0.3$ ) with $k_{\text {eff }}$ include $\mathrm{H}^{239} \mathrm{Pu}, \mathrm{H}, \mathrm{N}, \mathrm{Gd}, \mathrm{Fe}{ }^{16}$ In addition to the variables analyzed in ref. 16 , a study is presented in this document to investigate possible correlations between the calculated $k_{\text {eff }}$ values and ${ }^{241} \mathrm{Pu} /{ }^{239} \mathrm{Pu}$ as well as ${ }^{240} \mathrm{Pu} /{ }^{239} \mathrm{Pu}$. The results of the correlation study for the set of 102 critical experiments are summarized in Table 5.2.

Table 5.2. Correlation coefficients for characteristic parameters

\begin{tabular}{cccc}
\hline Parameter & $\begin{array}{c}\text { Observations } \\
(\mathrm{n})\end{array}$ & $\begin{array}{c}\text { Correlation coefficient } \\
\left(\mathrm{r}_{\mathrm{xy}}\right)\end{array}$ & Significance \\
\hline $\mathrm{N}$ & 73 & 0.503 & $5.6 \times 10^{-6}$ \\
$\mathrm{Gd}$ & 19 & -0.493 & $3.2 \times 10^{-2}$ \\
$\mathrm{Fe}$ & 22 & -0.404 & $5.6 \times 10^{-2}$ \\
$\mathrm{H}^{239} \mathrm{Pu}$ & 102 & 0.375 & $1.0 \times 10^{-4}$ \\
$\mathrm{H}$ & 102 & 0.373 & $4.8 \times 10^{-4}$ \\
${ }^{241} \mathrm{Pu} /{ }^{239} \mathrm{Pu}$ & 102 & 0.408 & $2.08 \times 10^{-5}$ \\
${ }^{240} \mathrm{Pu} /{ }^{239} \mathrm{Pu}$ & 102 & 0.364 & $1.4 \times 10^{-4}$ \\
\hline
\end{tabular}

The MO-1 package does not use gadolinium (Gd) as a poison, and $\mathrm{Gd}$ is not a suitable parameter for establishing subcritical limits. Furthermore, the significance level for the $\mathrm{Fe}$ atom density parameter is several orders of magnitude greater than the values obtained for $\mathrm{H}^{239} \mathrm{Pu},{ }^{241} \mathrm{Pu}{ }^{239} \mathrm{Pu},{ }^{240} \mathrm{Pu}{ }^{239} \mathrm{Pu}, \mathrm{H}$ and $\mathrm{N}$ atom density. Based on the significance level for $\mathrm{Fe}$, the null hypothesis (i.e., no correlation between $k_{\text {eff }}$ and Fe atom density) cannot be rejected. Therefore, the computed correlation for Fe does not represent a true phenomena. The parameters that are most suitable for further analysis are hydrogen and nitrogen atom density as well as $\mathrm{H}^{239} \mathrm{Pu},{ }^{241} \mathrm{Pu} /{ }^{239} \mathrm{Pu}$ and ${ }^{240} \mathrm{Pu}{ }^{239} \mathrm{Pu}$. Note that the characteristic parameters that involve hydrogen evaluate $k_{e f f}$ as a function of the hydrogen atom density in the moderator, as opposed to reflector materials which may contain hydrogen.

NUREG/CR-5661 discusses two different methods for determining an upper subcritical limit: (1) a confidence band with administrative margin approach, and (2) a single-sided uniform-width closedinterval approach. The latter approach is also referred to as the lower tolerance band (LTB) method because statistical techniques are used to determine a combined lower tolerance band plus subcritical margin. Moreover, the LTB approach yields a statistical estimate of $\Delta k_{m}$, which is generally less than 0.05 . 
In contrast, the confidence band with administrative margin approach allows the analyst to impose a specified administrative margin apriori in the USL calculation. Thus, the USL that is determined by the first method is used in the MO-1 package evaluation. The LTB method is also used to estimate the administrative margin and demonstrate the 0.05 administrative margin is acceptable for the given set of critical experiments.

The validation study which is documented in ref. 16 presents a detailed overview of the USL determination using the confidence band with administrative margin approach and LTB approach. As noted in the validation study, the first method provides the following expression for the USL:

$$
U S L_{1}(x)=1.0-\Delta k_{m}-W+\beta(x) .
$$

$\mathrm{W}$ is the confidence band width for the lower confidence limit. $\mathrm{W}$ is determined statistically based on a specified confidence level $\left(1-\gamma_{1}\right)$ and the calculated $k_{e f f}$ values for the critical experiments. The lower confidence limit, which is $k_{c}(x)-\mathrm{W}$, provides a $\left(1-\gamma_{1}\right)$ confidence that the calculated $k_{e f f}$ values for the critical experiments are above the lower confidence limit. The confidence band is directly proportional to the standard deviation in the data and the specified level of confidence. A higher confidence level or larger standard deviation will lead to a larger value for $\mathrm{W}$. The confidence band accounts for uncertainties in the experiments, the calculational method and data. Furthermore, W provides a statistical estimate for the uncertainty in the bias, $\Delta \beta$. For the USL determination, the confidence level is $95 \%$, and the approach for determining the confidence band is presented in ref. 16 .

The following discussion outlines the approach for calculating an upper subcritical limit. Initially, the independent variable $\mathrm{H}^{239} \mathrm{Pu}$ is used in the following discussion; however, USLs based on the variables that exhibit a statistically significant correlation are also presented in the following discussion.

In order to determine the USL, the following linear regression fit was obtained using USLSTATS for the $k_{\text {eff }}$ values as a function of $\mathrm{x}=\mathrm{H}^{239} \mathrm{Pu}$ :

$$
k_{c}(x)=1.0024+6.6039 \times 10^{-6} x .
$$

The calculational bias is defined as $\beta(x)=k_{c}(x)-1$. Using the definition for $\beta(x)$, the calculation bias is expressed by the relation:

$$
\beta(x)=0.0024+6.6039 \times 10^{-6} x .
$$

Since the expression for the bias is always positive, the bias is set to zero (i.e., $\beta(x)=0$ ), which is consistent with NUREG/CR-5661. Using a $95 \%$ confidence level, the value for $W$ as determined by USLSTATS for the $k_{\text {eff }}$ values as a function of $\mathrm{H}^{239} \mathrm{Pu}$ is 0.0146 . As noted previously, the confidence band is a statistical estimate for the uncertainty in the bias, $\Delta \beta$. Using the linear regression fit, administrative margin, confidence band and calculational bias, the expression for the USL can be expressed as follows:

$$
U S L=0.9354 \text {. }
$$

To evaluate the adequacy of the 0.05 administrative margin, the LTB approach was used to calculate the upper subcritical limit. The USL as defined in the LTB approach is given by the following expression: ${ }^{16}$

$$
U S L_{2}(x)=1.0-\left(C_{\alpha / \rho} * s_{\rho}\right)+\beta(x) .
$$

In the above expression, $s_{p}$ is the pooled variance for the linear fit to the data, $k_{c}(x) . \mathrm{C}_{\alpha / \rho}$ is a statistically determined multiplier which is tabulated in most statistical handbooks for a specified confidence, $\alpha$, and probability, $\rho$. The term $C_{\alpha / p}{ }^{*} s_{\rho}$ provides a lower tolerance band such that there is $\alpha$ confidence that a future calculation of a critical system within the range of applicability will lie above the lower tolerance band with probability, $\rho$. For example, if $\alpha$ is $95 \%$ and $\rho$ is 99.5 , there is a $95 \%$ 
confidence that 995 out of 1000 future calculations of critical systems within the range of applicability will lie above the USL. Also, the converse is true. There is a $95 \%$ confidence that 995 out of 1000 future calculations of subcritical systems within the range of applicability will lie below the USL. The term $\mathrm{C}_{\alpha / \mathrm{p}}{ }^{*} \mathrm{~s}_{\rho}$ can also be used to provide a statistical estimate of the administrative subcritical margin, $\Delta k_{m}$. Moreover, $\Delta k_{m}$ is the difference between $C_{\alpha / p}{ }^{*} s_{\rho}$ and the confidence band, W (i.e., $\Delta \mathrm{k}_{\mathrm{m}}=\mathrm{C}_{\alpha / \mathrm{p}}{ }^{*} \mathrm{~s}_{\rho}-\mathrm{W}$ ).

In addition to calculating a USL using the confidence band with administrative margin approach, USLSTATS also calculates a USL using the LTB method. Based on the $k_{\text {eff }}$ values as a function of $\mathrm{H}^{239} \mathrm{Pu}$ and corresponding linear fit to the data, the pooled standard deviation, $\mathrm{s}_{\rho}$, is $8.0294 \times 10^{-3}$. Using a specified confidence of $95 \%$ and probability of $99.5 \%$, the statistical multiplier, $\mathrm{C}_{\alpha / \mathrm{p}}$, is 3.8669 which is determined by USLSTATS. As a result, the term $\mathrm{C}_{\alpha / \mathrm{p}}{ }^{*} \mathrm{~s}_{\mathrm{\rho}}$ is $3.1049 \times 10^{-2}$. The USL obtained with the LTB approach can be expressed as follows:

$$
U S L_{2}=0.9690 \text {. }
$$

The USL obtained with the LTB method is less conservative relative to the USL obtained with the specified administrative margin. Using the LTB approach, the statistical estimate for $\Delta k_{m}$ is 0.016 , which is much smaller than the imposed 0.05 administrative margin. These results indicate a small uncertainty in the bias over the range of applicability. Furthermore, the 0.05 administrative margin is a conservative margin of subcriticality for $k_{e f f}$ as a function of $\mathrm{H}^{239} \mathrm{Pu}$.

Following the procedure outlined for $\mathrm{H}^{239} \mathrm{Pu}$, USLs were also calculated as a function of ${ }^{241} \mathrm{Pu} /{ }^{239} \mathrm{Pu}$ and ${ }^{240} \mathrm{Pu} /{ }^{239} \mathrm{Pu}$, as well as $\mathrm{H}$ and $\mathrm{N}$ atom density for the complete set of experiments. Based on the test for normality provided by USLSTATS, the calculated $k_{\text {eff }}$ values are normally distributed for each independent variable. A summary of the USL calculations is presented in Table 5.3. For each variable, the USL obtained with the LTB approach is less conservative relative to the USL calculated with the 5\% administrative margin. The calculated eigenvalues as a function of $\mathrm{H}^{239} \mathrm{Pu}$ are presented in Figs. 5.1a and 5.1b. The $k_{\text {eff }}$ values as a function of $\mathrm{H}^{239} \mathrm{Pu}$ are separated into two plots because the wide range of $\mathrm{H}^{239} \mathrm{Pu}$ values obscures the data in the lower moderation range. The calculated eigenvalues as a function of $\mathrm{H}$ and $\mathrm{N}$ atom density are presented in Figs. 5.2 and 5.3, respectively. Due to the wide range of $\mathrm{N}$ atom densities, the calculated eigenvalues as a function of nitrogen atom density are separated into Figs. 5.3a and 5.3b. Moreover, the calculated $k_{\text {eff }}$ values as a function of ${ }^{241} \mathrm{Pu} /{ }^{239} \mathrm{Pu}$ and ${ }^{240} \mathrm{Pu} /{ }^{239} \mathrm{Pu}$ are provided in Figs. 5.4 and 5.5, respectively. Also provided in each figure is a linear regression for $k_{\text {eff }}$ as a function of the independent variable over the range of applicability. In Figs. 5.1-5.5, there appears to be a positive trend in $k_{e f f}$ with the increasing value of each independent variable.

Table 5.3. Summary of USL calculations for 102 critical experiments

\begin{tabular}{ccllc}
\hline Fig. & Variable & \multicolumn{1}{c}{ USL $_{1}(x)$ with $\Delta k_{m}=0.05 ;$} & \multicolumn{1}{c}{ USL $_{2}(x)$} & $\mathrm{C}_{\alpha / p}{ }^{*} s_{\rho}-\mathrm{W}$ \\
\hline 5.1 & $\mathrm{H}^{239} \mathrm{Pu}$ & $0.9354(0 \leq x \leq 2437)$ & $0.9690(0 \leq x \leq 2437)$ & 0.0165 \\
5.2 & $\mathrm{H}$ & $0.9285+0.21975^{*} x(0 \leq x<.033)$ & $0.9627+0.21975(0 \leq x<0.033)$ & 0.0157 \\
& & $0.9358(0.033 \leq x \leq 0.0667)$ & $0.97(0.033 \leq x \leq 0.0667)$ & \\
5.3 & $\mathrm{~N}$ & $0.9359(0.0 \leq x \leq 0.0443)$ & $0.9696(0.0 \leq x \leq 0.0443)$ & 0.0163 \\
5.4 & ${ }^{241} \mathrm{Pu}{ }^{239} \mathrm{Pu}$ & $0.9361(0.0 \leq x \leq 0.26)$ & $0.9711(0.0 \leq x \leq 0.26)$ & 0.015 \\
5.5 & ${ }^{240} \mathrm{Pu}{ }^{239} \mathrm{Pu}$ & $0.9359(0.0178 \leq x \leq 1.0342)$ & $0.9706(0.0178 \leq x \leq 1.0342)$ & 0.0153 \\
\hline
\end{tabular}


N

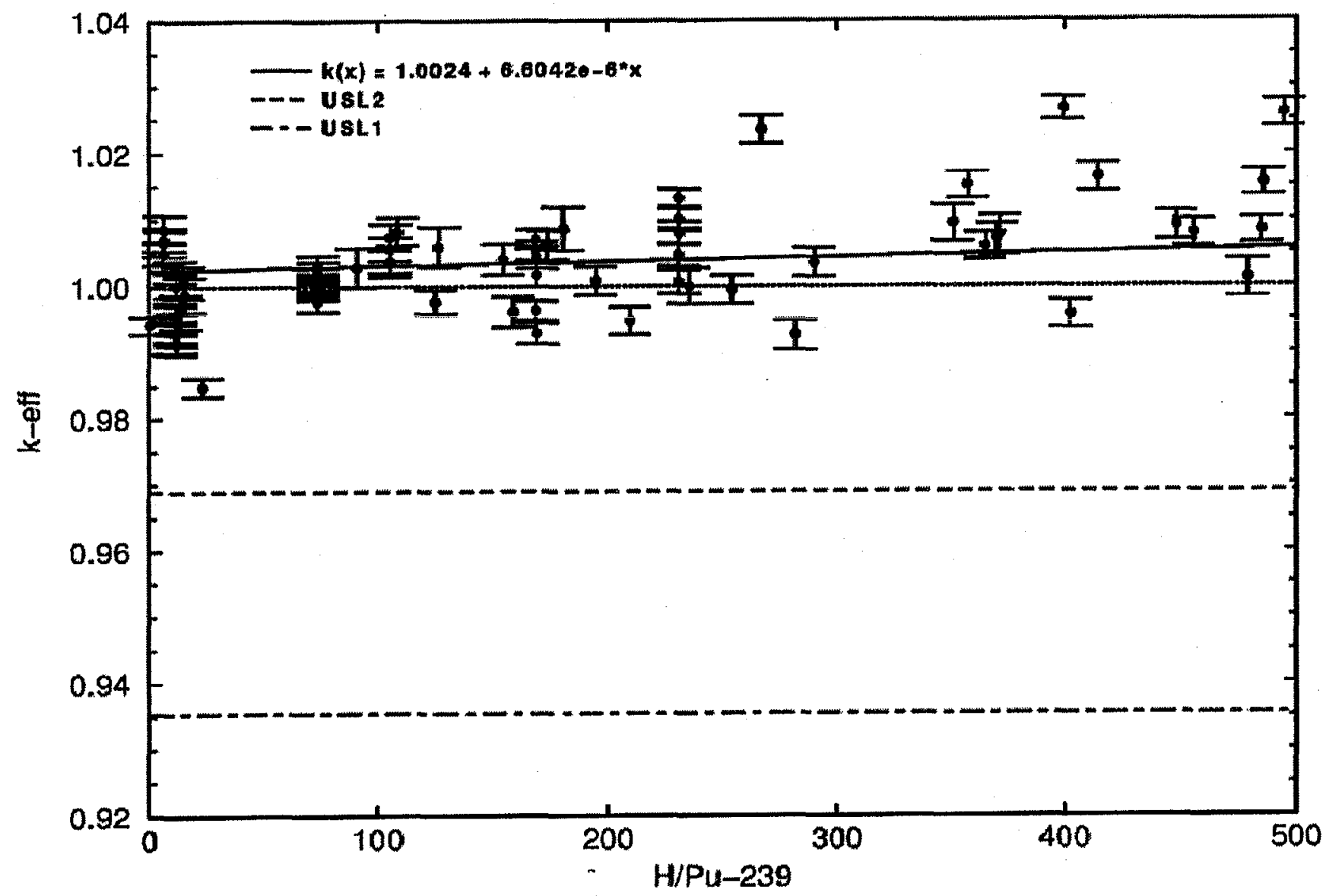

Fig. 5.1a. Calculated USLs as a function of $\mathrm{H}^{239} \mathrm{Pu}$ for 102 critical experiments. 


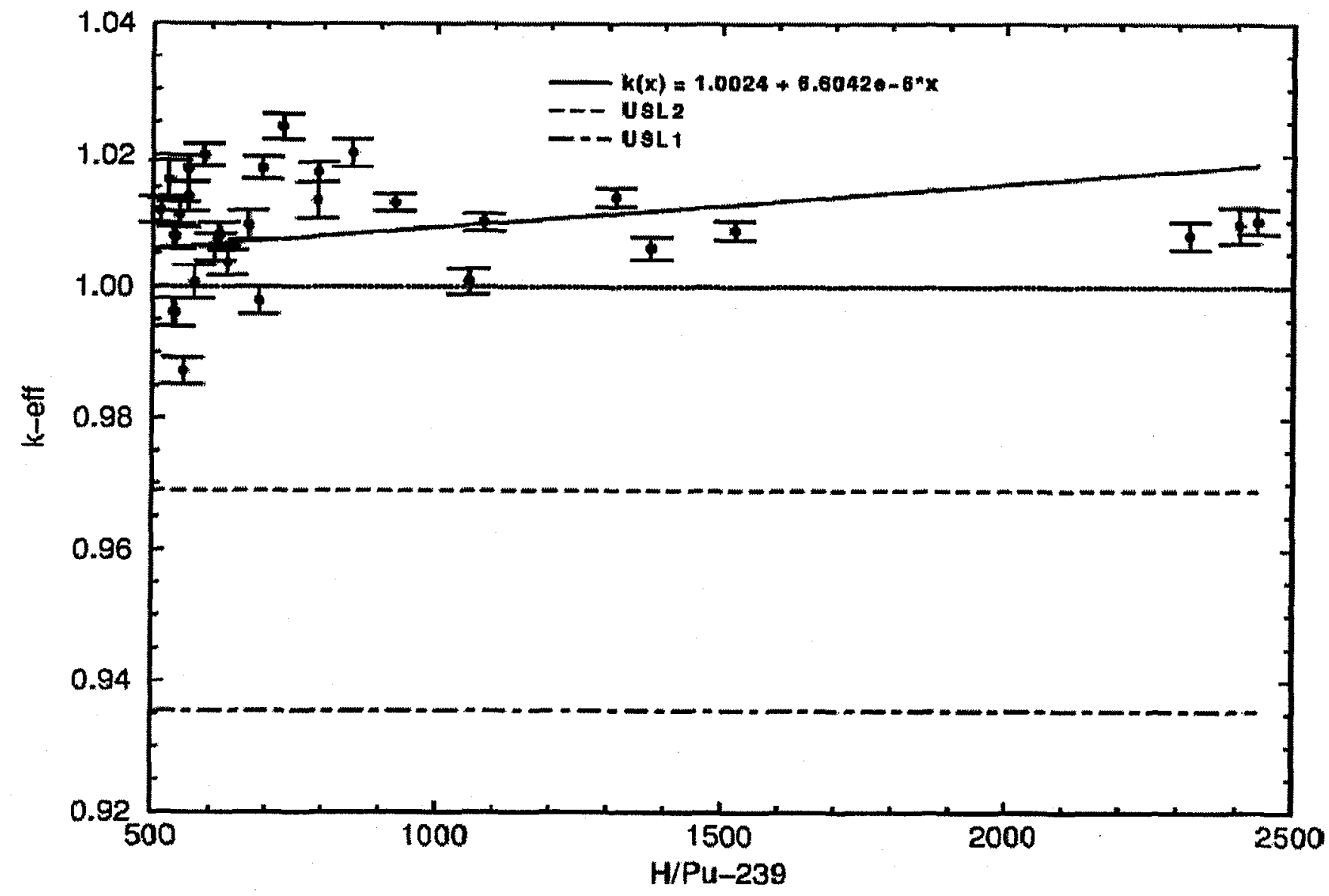

Fig. 5.1b. Calculated USLs as a function of $\mathrm{H}^{239} \mathrm{Pu}$ for 102 critical experiments. 
$\pm$

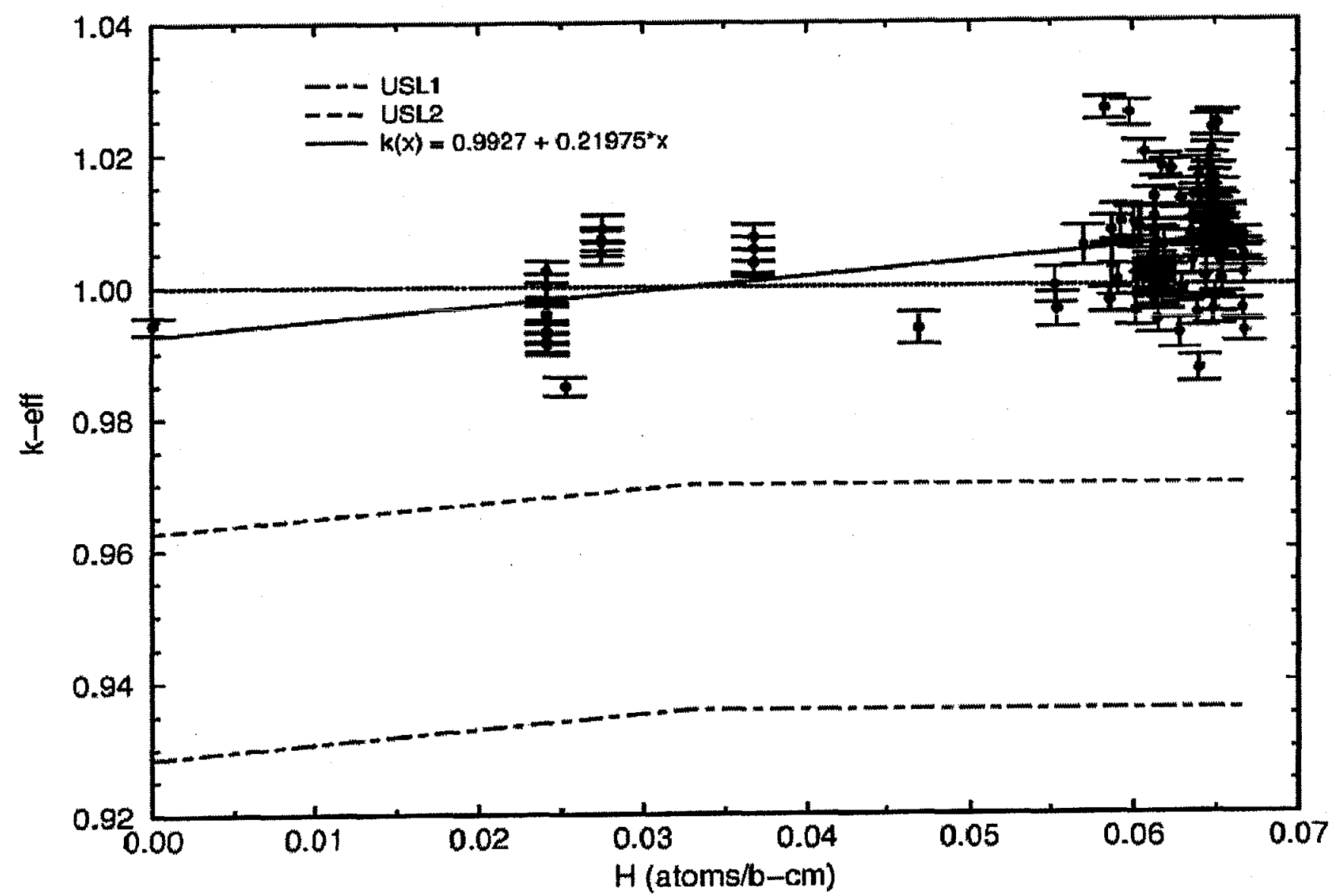

Fig. 5.2. Calculated USLs as a function of $\mathrm{H}$ atom density for 102 critical experiments. 


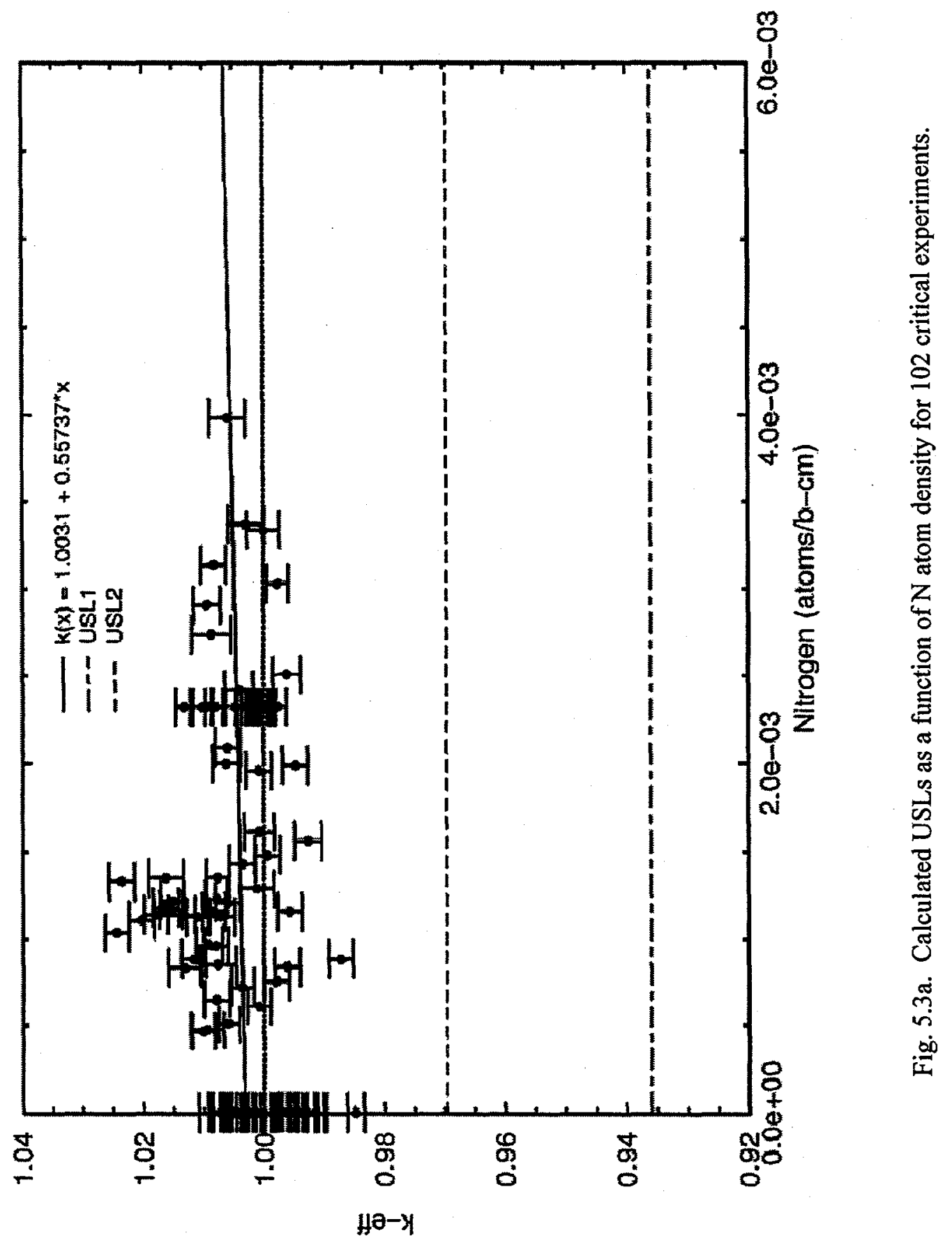




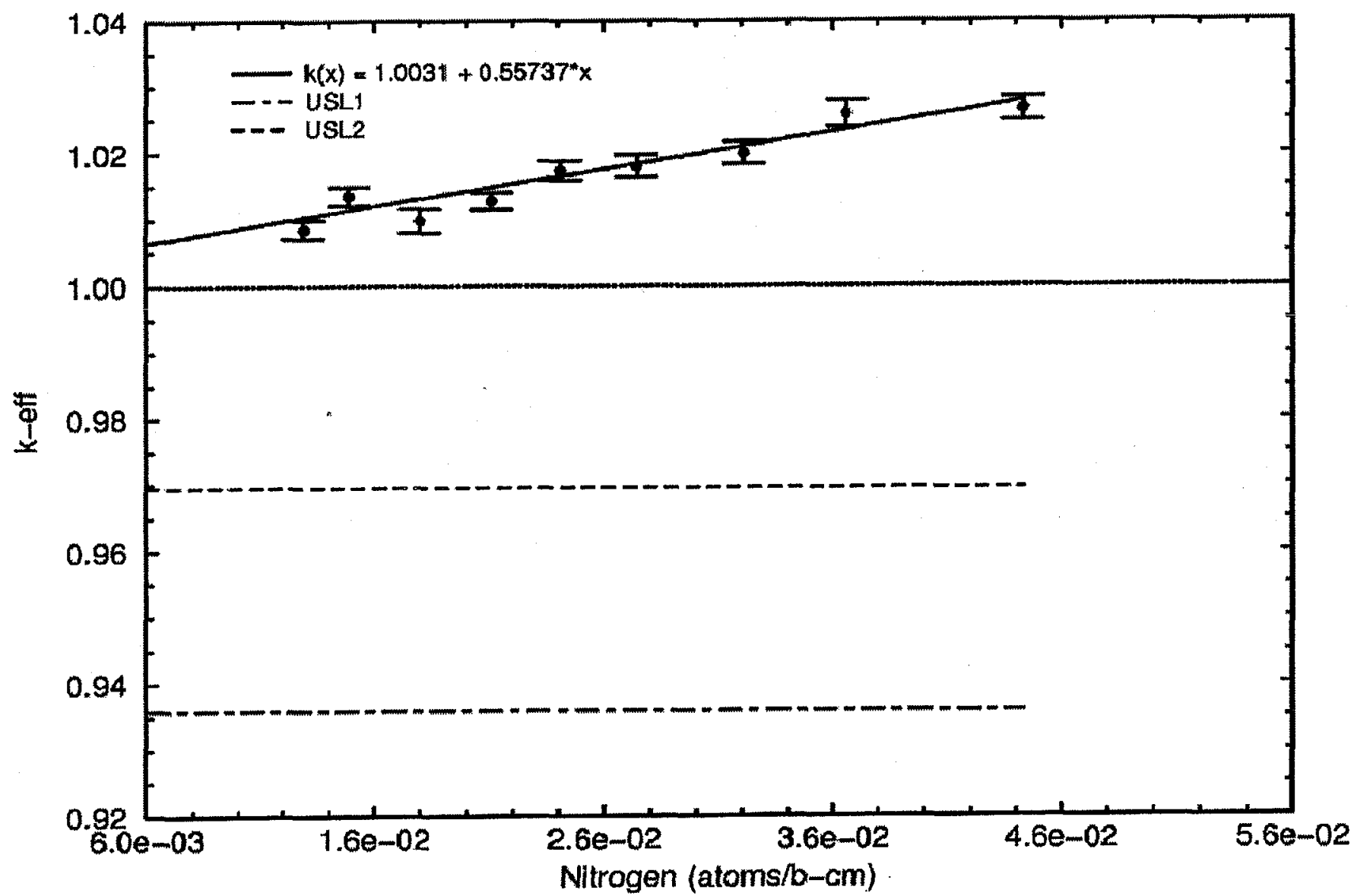

Fig. 5.3b. Calculated USLs as a function of $\mathrm{N}$ atom density for 102 critical experiments. 


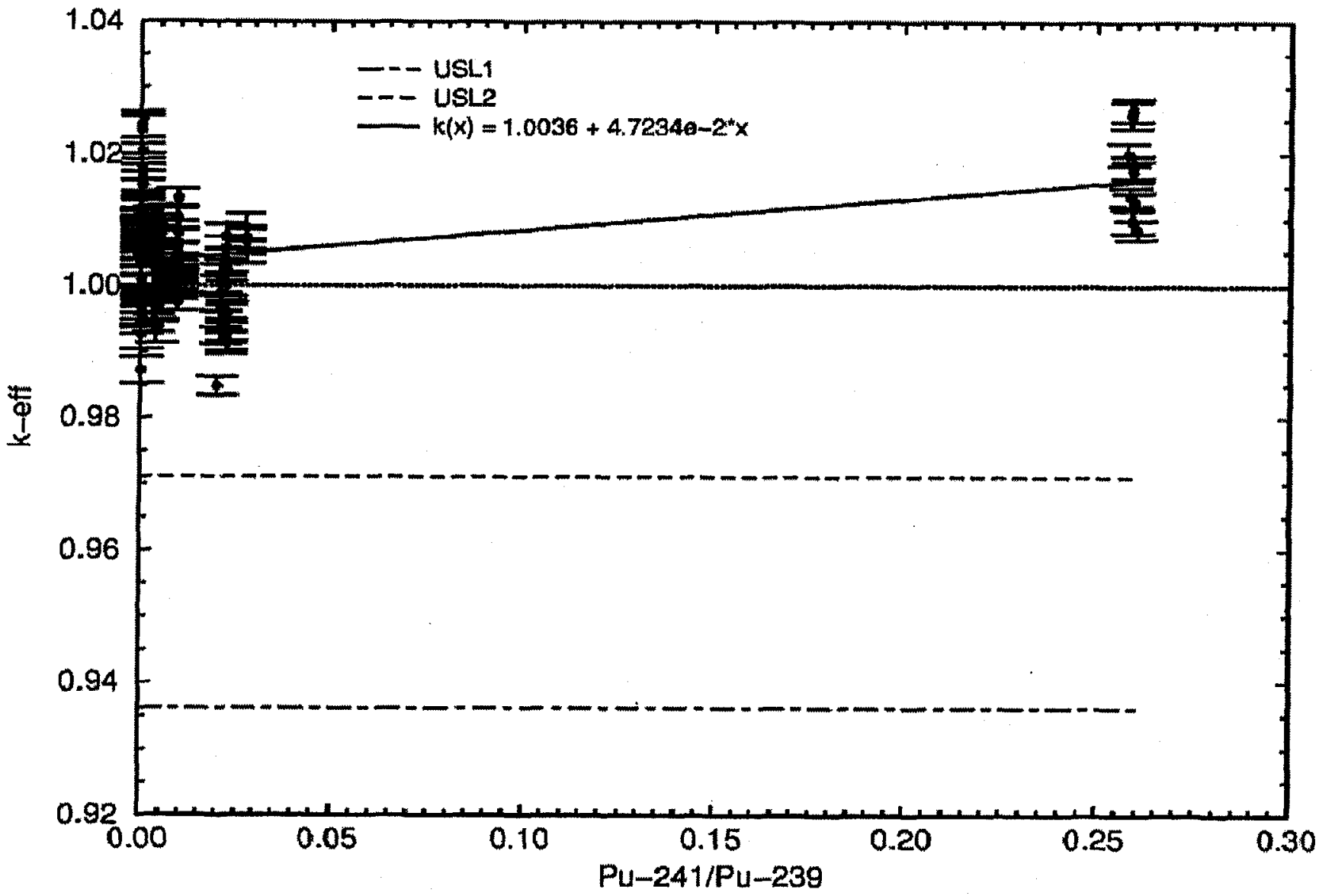

Fig. 5.4. Calculated USLs as a function of ${ }^{241} \mathrm{Pu}{ }^{239} \mathrm{Pu}$ for 102 critical experiments. 


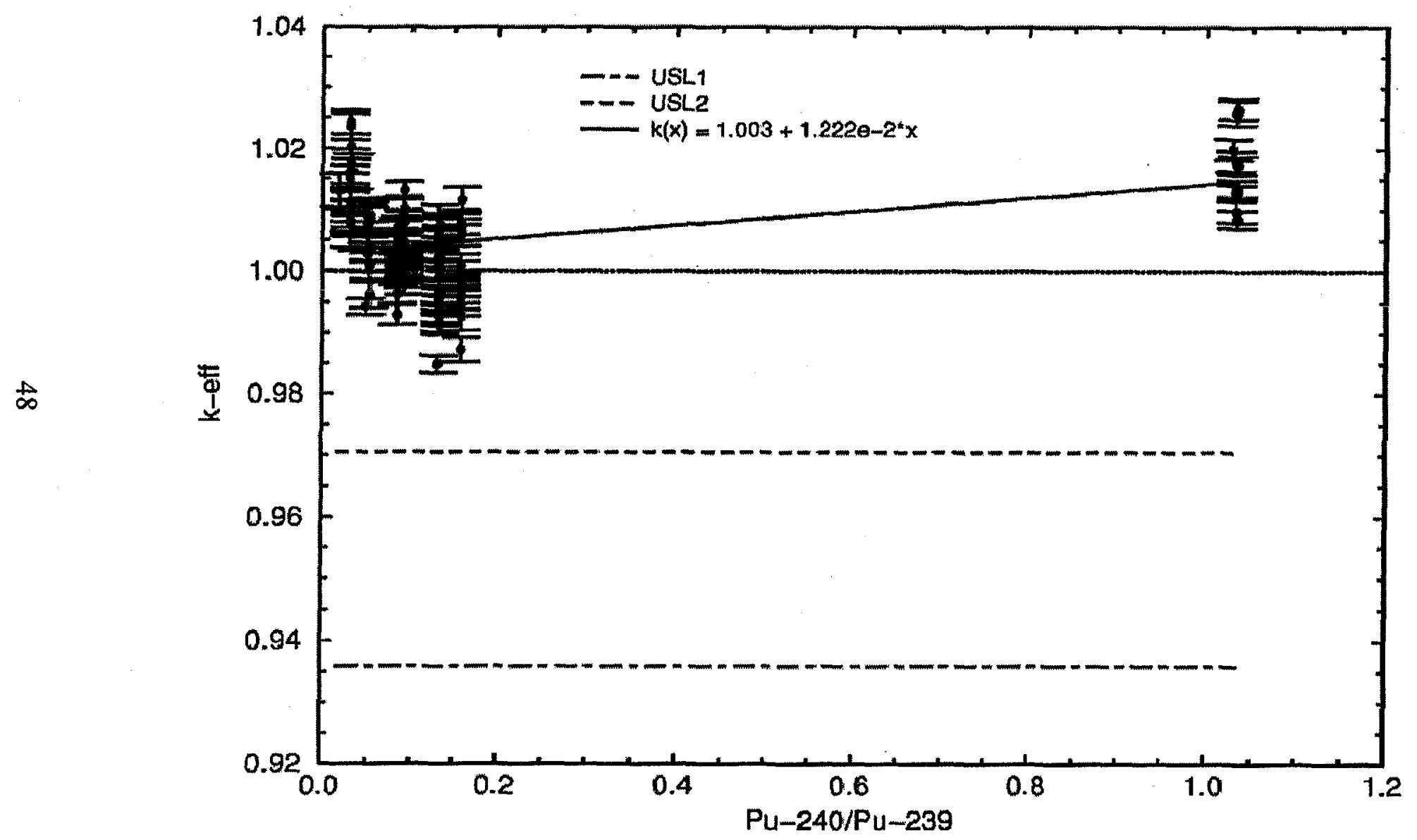

Fig. 5.5. Calculated USLs as a function of ${ }^{240} \mathrm{Pu} /{ }^{239} \mathrm{Pu}$ for 102 critical experiments. 
Although the $k_{\text {eff }}$ values have a stronger correlation with nitrogen atom density, the calculated USLs obtained for $\mathrm{H}$ and $\mathrm{H}^{239} \mathrm{Pu}$ are slightly lower over the range of applicability for each variable. Since the $\mathrm{N}$ atom density variable does not provide sufficient information about the neutron spectrum characteristics of the package or the amount of fissile material in the system, $\mathrm{N}$ atom density is not a suitable choice for the independent variable in the establishment of the USL. With regard to ${ }^{241} \mathrm{Pu} /{ }^{239} \mathrm{Pu}$ and ${ }^{240} \mathrm{Pu} /{ }^{239} \mathrm{Pu}$, the calculated USLs are less conservative relative to the variables involving hydrogen moderation. The calculated USLs for $k_{e f f}$ as a function of $\mathrm{H}^{239} \mathrm{Pu}$ and $\mathrm{H}$ atom density are essentially equivalent except in the low moderation range. In particular, there is a negative bias for $\mathrm{H}$ atom densities below 0.033 , as shown in Fig. 5.2. Over the range 0 to $0.033 \mathrm{H}$ atoms/b-cm, $\mathrm{USL}_{1}(x=\mathrm{H})$ has a minimum value of 0.9285 and has the following functional form:

$$
\operatorname{USL}_{1}(H)=0.9285+0.21975 H \text {. }
$$

Based on the equation for $\mathrm{USL}_{1}$ as a function of $\mathrm{H}$, the USL is greater than 0.9354 (i.e., $\mathrm{USL}_{1}\left(\mathrm{H}^{239} \mathrm{Pu}\right)$ ) for hydrogen atom densities greater than 0.031 atoms $/ \mathrm{b}-\mathrm{cm}$. Conversely, the USL based on $\mathrm{H}$ atom density is more conservative for hydrogen atom density values below 0.031 atoms $/ \mathrm{b}-\mathrm{cm}$. The ${ }^{239} \mathrm{Pu}$ atom densities for the different MOX loadings are provided in Table 5.4 with the $\mathrm{H}^{239} \mathrm{Pu}$ ratios for a hydrogen atom density of 0.031 atoms $/ \mathrm{b}-\mathrm{cm}$. Since water flooding is the primary mechanism of moderation in the MO- 1 analysis, the 0.031 hydrogen atom density can also be expressed in terms of the $\mathrm{H}_{2} \mathrm{O}$ volume fraction. The water volume fraction, which corresponds to a hydrogen atom density of 0.031 atoms $/ \mathrm{b}-\mathrm{cm}$, is computed in Appendix B and is presented in Table 5.4. Based on the data in Table 5.4, the USL of 0.9354 is used for configurations with $\mathrm{H}_{2} \mathrm{O}$ volume fractions that are greater than 0.46 . For $\mathrm{H}_{2} \mathrm{O}$ volume fractions that are less than 0.46 , the USL is 0.9285 .

Before the USL can be implemented in the evaluation, the adequacy of the acceptance criteria should be evaluated further. In particular, the complete set of experiments should be divided into subsets that are directly applicable to the MO-1 transportation package. Each subset can be evaluated to reveal any trends or biases that may be hidden by the complete set of experiments. If any hidden biases or trends are revealed which could lead to a more conservative acceptance criteria, the USL should be lowered to account for the additional negative bias. The remaining discussion in this section is devoted to the analysis of various subsets of the 102 critical experiments.

As noted above, a plot of $\mathrm{USL}_{1}$ and $\mathrm{USL}_{2}$ as a function of $\mathrm{H}^{239} \mathrm{Pu}$ is provided in Fig. 5.1. The range of $\mathrm{H}^{239} \mathrm{Pu}$ for the MO-1 package evaluation, which is discussed in Sect. 5.3, extends between 0.0 and 111. Since the range of $\mathrm{H}^{239} \mathrm{Pu}$ in the experimental database extends from 0.0 to 2437 , the evaluated moderation ratios are within the range of experimental data. However, there are 36 experiments with $\mathrm{H}^{239} \mathrm{Pu}$ ratios below 126.4 in the experimental database. Consequently, there are 66 experiments with ratios beyond the range considered in the MO-1 package evaluation. Due to the large range of moderation ratios in the experimental data, any trends in the low-moderation range could be obscured by experiments with higher $\mathrm{H}^{239} \mathrm{Pu}$ ratios. In an effort to investigate possible trends in the low moderation range, the set of experiments with $\mathrm{H}^{239} \mathrm{Pu}$ ratios below 126.4 are evaluated for possible trends in the data.

A correlation study is presented for the 36 experiments. The calculated correlation coefficient and significance level for $k_{e f f}$ as a function of $\mathrm{H} /{ }^{239} \mathrm{Pu}$ are presented in Table 5.5 with the correlation results obtained for the 102 experiments. The correlation coefficient in both sets of experiments is statistically significant (i.e., $|r| \geq 0.3$ ); however, there appears to be a slightly stronger correlation between system multiplication and moderation ratio for the 36-experiment subset. 
Table 5.4. ${ }^{239} \mathrm{Pu}$ atom densities for different MOX loadings in MO-1

\begin{tabular}{|c|c|c|c|c|}
\hline MOX fuel & $\begin{array}{c}{ }^{239} \mathrm{Pu} \\
\text { (atoms } / \mathrm{b}-\mathrm{cm} \text { ) }\end{array}$ & $\begin{array}{c}\mathrm{H} \\
\text { (atoms/b-cm) }\end{array}$ & $\mathrm{H}^{239} \mathrm{Pu}$ & $\begin{array}{c}\mathrm{H}_{2} \mathrm{O} \text { Volume } \\
\text { fraction }\end{array}$ \\
\hline $6 \mathrm{wt} \% \mathrm{PuO}_{2}$ & $8.42 \times 10^{-4}$ & 0.031 & 36.835 & 0.46 \\
\hline $4.4 \mathrm{wt} \% \mathrm{PuO}_{2}$ & $8.39 \times 10^{-4}$ & 0.031 & 36.958 & 0.46 \\
\hline 3.03 wt $\% \mathrm{PuO}_{2}$ & $6.04 \times 10^{-4}$ & 0.031 & 51.325 & 0.46 \\
\hline WG MOX & $1.16 \times 10^{-3}$ & 0.031 & 26.678 & 0.46 \\
\hline
\end{tabular}

Table 5.5. Correlation results for $k_{e f f}$ as a function of $\mathrm{H}^{239} \mathrm{Pu}$

\begin{tabular}{cccccc}
\hline $\begin{array}{c}\mathrm{H}^{239} \mathrm{Pu} \\
\text { range }\end{array}$ & $\begin{array}{c}\text { No. of } \\
\text { exp. }\end{array}$ & $\mathrm{r}$ & Significance & $\begin{array}{c}\text { Regression equation } \\
k_{c}(x)\end{array}$ & $\beta(x)=k_{c}(x)-1.0$ \\
\hline $0-2437$ & 102 & 0.375 & 0.0001 & $1.0024+6.604 \times 10^{-6 *} \mathrm{H}^{239} \mathrm{Pu}$ & $0.0024+6.604 \times 10^{-6 *} \mathrm{H}{ }^{239} \mathrm{Pu}$ \\
$0-126.4$ & 36 & 0.443 & 0.0068 & $0.9970+5.817 \times 10^{-5 *} \mathrm{H}^{239} \mathrm{Pu}$ & $-0.003+5.817 \times 10^{-5 *} \mathrm{H} /{ }^{339} \mathrm{Pu}$ \\
\hline
\end{tabular}

Following the same procedure for the set of 102 experiments, $\mathrm{USL}_{1}(x)$ and $\mathrm{USL}_{2}(x)$ can be determined for the 36-experiment subset using USLSTATS with the same confidence level and administrative margin. The calculated USLs are presented in Table 5.6 for the set of 36 experiments. Figure 5.6 illustrates the calculated USLs for the 36 experiment subset as a function of $\mathrm{H} /{ }^{239} \mathrm{Pu}$. As shown in Fig. 5.6, there is a positive trend in $k_{\text {eff }}$ with increasing $\mathrm{H}^{239} \mathrm{Pu}$ which is consistent with the results obtained with the larger set of experiments. Based on the regression analysis, the bias as a function of $\mathrm{H}^{239} \mathrm{Pu}$ is negative from 0 to 51.124 which differs from the larger set of 102 experiments. Inspection of the calculated results in Fig. 5.6 reveals that the negative bias in the subset of experiments is attributed to the calculated $k_{\text {eff }}$ values which are below 1.0 for $\mathrm{H}^{239} \mathrm{Pu}<25$. In comparison, there appears to be a larger positive bias in the calculated $k_{\text {eff }}$ values for $200<\mathrm{H} /{ }^{239} \mathrm{Pu}<900$, as shown in Fig. 5.1. As a result, inclusion of the experiments which have $\mathrm{H}^{239} \mathrm{Pu}$ between 200 and 900 creates a positive shift in the functional bias over the entire range of moderation ratios. Consequently, the negative bias which is observed in the 36-experiment subset for $\mathrm{H}^{239} \mathrm{Pu}<25$ is obscured by the experiments with $\mathrm{H}^{239} \mathrm{Pu}>200$. Although there is a negative bias in the low moderation range (i.e., $\mathrm{H}^{239} \mathrm{Pu}<51.124$ ), the calculated USL with administrative margin is less conservative for the 36-experiment subset relative to the overall set of experiments. The difference in $\mathrm{USL}_{1}(x)$ is attributed to the difference in the calculated confidence band width, W, for each set of experiments. Specifically, the calculated confidence band width for the 36-experiment subset is $9.773 \times 10^{-3}$, which is smaller relative to the overall set of experiments (i.e., $\mathrm{W}=1.459 \times 10^{-2}$ ). Consequently, there is less uncertainty in the bias for $\mathrm{H}^{239} \mathrm{Pu} \leq 126.4$. Upon comparing the results in Figs. 5.1 and 5.6, the calculated $k_{\text {eff }}$ values are tightly clustered around $k_{\text {eff }}=1.0$ for the 36-experiment subset relative to the overall set of experiments. Based on the regression analysis for the 36 experiments, the most negative bias in system multiplication is -0.003 (i.e., $\beta(x)=k_{c}(x)-1$ ). Combining the negative bias with $\mathrm{W}=9.773 \times 10^{-3}$ yields a minimum value of 0.9373 for $\mathrm{USL}_{1}(x)$. 
Table 5.6. Calculated USLs for $k_{e f f}$ as a function of $\mathrm{H}^{239} \mathrm{Pu}$

\begin{tabular}{|c|c|c|c|c|}
\hline Fig. & $\begin{array}{l}\text { No. } \\
\text { of } \\
\text { Exp. }\end{array}$ & W & $\begin{array}{c}\mathrm{USL}_{\mathrm{l}}(x) \text { with } \Delta \mathrm{k}_{\mathrm{m}}=0.05 \\
x=\mathrm{H}^{239} \mathrm{Pu}\end{array}$ & $\mathrm{USL}_{2}(x)$ \\
\hline 5.1 & 102 & $1.459 \times 10^{-2}$ & $0.9354(0 \leq x \leq 2437)$ & $0.9690(0 \leq x \leq 2437)$ \\
\hline 5.6 & 36 & $9.773 \times 10^{-3}$ & $\begin{array}{l}0.9373+5.8165 \times 10^{-5 . *} * x(0 \leq x<51.124) \\
0.9402(51.124 \leq x \leq 126.4)\end{array}$ & $\begin{array}{l}0.9747+5.8165 \times 10^{-5 *} * \quad(0 \leq x<51.124) \\
0.9776 \quad(51.124 \leq x \leq 126.4)\end{array}$ \\
\hline
\end{tabular}

With regard to the overall set of experiments, the bias is set to zero over the entire moderation range, and the minimum value for $\mathrm{USL}_{1}(x)$ is 0.9354 (i.e., $\mathrm{USL}_{1}(x)=1.0-0.05-1.459 \times 10^{-2}=0.9354$ ). As a result, the larger bias uncertainty in the set of 102 experiments leads to a slightly lower USL value. Since the overall set of experiments yields a lower USL, the more conservative USL should be used in the calculational analysis.

In Sect. 5.1, the critical experiments used in the validation analysis are correlated with the parameters that characterize the MO-1 package. Based on the complete set of experiments, the most suitable calculational acceptance criteria are a function of hydrogen moderation. Due to the large number of experiments with differing fissile material configurations, the calculational bias and associated uncertainty could be larger for a particular group or subset of experiments relative to the overall set of experiments. Prior to establishing the USL for the MO-1 package evaluation, the overall set of experiments should be divided into subsets that correlate with the characteristics of the MO-1 transportation package. In addition, the calculated $k_{\text {eff }}$ values for the experimental subset should be evaluated as a function of independent variables that are directly applicable to the MO-1 package analysis. Specifically, the biases and associated bias uncertainty should be evaluated for each experimental subset. Analysis of the experimental subsets should reveal any hidden trends or biases that could be obscured by the overall set of experiments. With regard to the MO-1 package analysis, the set of 102 experiments is divided into 11 subsets that correspond to the MO-1 package characteristics outlined in Sect. 5.1. The experimental subsets are presented in Table 5.7 with the corresponding number of experiments for each subset.

Following the same procedure for the set of 102 experiments, a correlation study is presented to assess possible correlations between system multiplication and different independent variables. The set of independent variables, which correspond to the MO-1 package characteristics, include $\mathrm{H}^{239} \mathrm{Pu},{ }^{241} \mathrm{Pu} /{ }^{239} \mathrm{Pu}$, ${ }^{240} \mathrm{Pu} /{ }^{239} \mathrm{Pu}$, AEF and pitch, as well as $\mathrm{H}, \mathrm{O}, \mathrm{N},{ }^{235} \mathrm{U},{ }^{238} \mathrm{U},{ }^{239} \mathrm{Pu},{ }^{240} \mathrm{Pu}$ and ${ }^{241} \mathrm{Pu}$ atom densities. A summary of the correlation study for each experimental subset is presented in Table 5.8. For the experimental subsets in Table 5.8, a USL calculation is presented for each independent variable with a correlation to system multiplication indicated by $|r| \geq 0.3$. Prior to calculating each USL, USLSTATS tests the data for normality by performing a Chi Square Test. The code requires a minium of 25 data points (i.e., calculated $k_{e f f}$ values) to determine normality. In addition, USLSTATS divides the distribution of $k_{e f f}$ values around the mean into five equally probable bins. As a further constraint, the test for normality may not be reliable if there are fewer than five observations in each bin. USLSTATS provides a warning message if the data do not satisfy either constraint. For the eleven experimental subsets presented in Table 5.7, four subsets did not satisfy the equal probable bin criteria in the test for normality. These groups include the mixed $\mathrm{Pu}-\mathrm{U}$ experiments, neutron-absorbing experiments, carbon-reflected experiments and experiments involving array configurations. Consequently, these four subsets are considered to be unreliable for establishing biases apart from the complete set of experiments. 


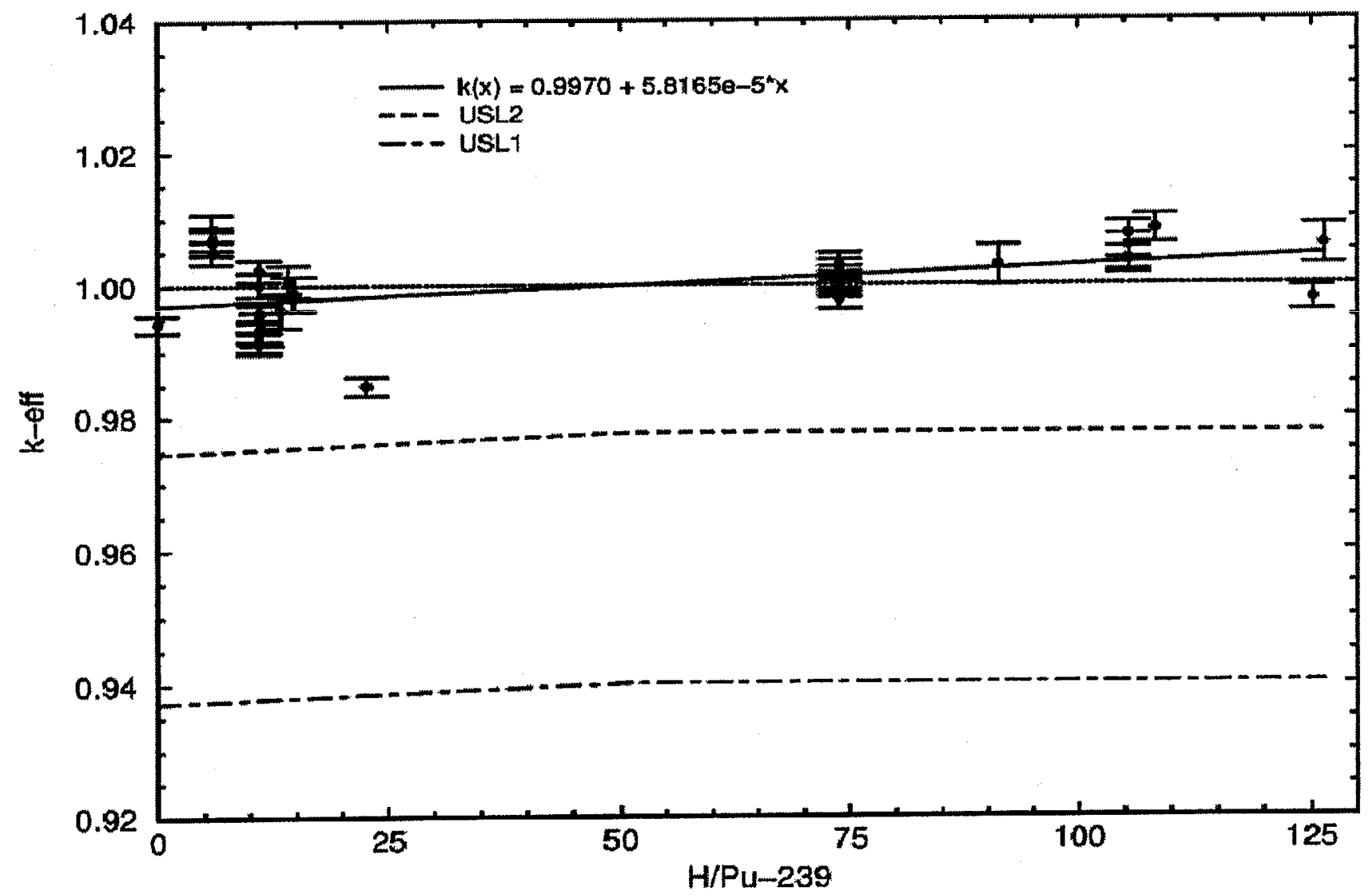

Fig. 5.6. USLs for 36 critical experiments with $\mathrm{H}^{239} \mathrm{Pu} \leq 126.4$. 
Table 5.7. Experimental subsets for validation analysis

\begin{tabular}{lc}
\hline \multicolumn{1}{c}{ Subset } & Number of experiments \\
\hline Mixed $\mathrm{Pu}-\mathrm{U}$ experiments & 32 \\
Pu experiments & 70 \\
$\mathrm{H}_{2} \mathrm{O}$-moderated experiments & 83 \\
$\mathrm{H}$-moderated experiments & 101 \\
Experiments involving neutron-absorbing material & 28 \\
$\mathrm{H}_{2} \mathrm{O}$-reflected experiments & 61 \\
Experiments involving carbon & 30 \\
Experiments involving nitrogen & 73 \\
Experiments involving structural steel & 63 \\
Experiments involving cylindrical or annular geometry & 68 \\
Array experiments & 28 \\
\hline
\end{tabular}

The remaining seven experimental subsets are evaluated for biases and trends in the bias. USLs based on the confidence band with administrative margin approach and the LTB method (i.e., $\mathrm{USL}_{1}(x)$ and $\mathrm{USL}_{2}(x)$, respectively) are presented in Table 5.9 for each statistically significant correlation. For each USL calculation, the range of applicability is also presented in Table 5.9 with the statistical estimate of the administrative margin of subcriticality (i.e., $\Delta k_{m}=\mathrm{C}_{\alpha / \rho}{ }^{*} \mathrm{~s}_{\rho}-\mathrm{W}$ ), the correlation coefficient and linear regression for $k_{e f f}$ as a function of the corresponding independent variable. In an effort to assess each USL calculation, the minimum value of $\mathrm{USL}_{1}(x)$ is also provided in Table 5.9 for each independent variable. Inspection of the results in Table 5.9 reveals that the largest estimate of the administrative margin of subcriticality, $\Delta k_{m}$, is $\mathbf{0 . 0 2 1 5}$, which is less than the imposed 0.05 administrative margin. Therefore, a USL based on the confidence band with administrative margin approach is an adequate margin of subcriticality within the range of applicability. 
Table 5.8. Summary of correlation study for 102 critical experiments

\begin{tabular}{|c|c|c|c|}
\hline Variable & $\mathbf{r}$ & $\mathbf{t}$ & Significance level \\
\hline \multicolumn{4}{|c|}{ Mixed $\mathrm{Pu}-\mathrm{U}$ experiments } \\
\hline H/Pu-239 & 0.5259 & 3.3863 & $1.99 \times 10^{-3}$ \\
\hline Pu-241/Pu-239 & -0.4837 & 3.0267 & $5.04 \times 10^{-3}$ \\
\hline $\mathbf{P u - 2 4 0 / P u - 2 3 9}$ & -0.4754 & 2.9594 & $5.97 \times 10^{-3}$ \\
\hline AEF & -0.4899 & 2.6357 & $1.51 \times 10^{-2}$ \\
\hline $\mathbf{H}$ & 0.5382 & 3.4977 & $1.49 \times 10^{-3}$ \\
\hline Pu-239 & -0.5289 & 3.4135 & $1.86 \times 10^{-3}$ \\
\hline Pu-240 & -0.5264 & 3.3913 & $1.97 \times 10^{-3}$ \\
\hline Pu-241 & -0.5352 & 3.4706 & $1.60 \times 10^{-3}$ \\
\hline U-235 & 0.0187 & 0.1026 & $9.19 \times 10^{-1}$ \\
\hline U-238 & -0.0601 & 0.3299 & $7.44 \times 10^{-1}$ \\
\hline $\mathbf{O}$ & 0.2758 & 1.5714 & $1.27 \times 10^{-1}$ \\
\hline $\mathbf{N}$ & 0.3056 & 1.7577 & $8.90 \times 10^{-2}$ \\
\hline \multicolumn{4}{|c|}{ Pu experiments } \\
\hline H/Pu-239 & 0.3399 & 2.9805 & $3.99 \times 10^{-3}$ \\
\hline $\mathbf{P u}-241 / \mathbf{P u}-239$ & 0.4526 & 4.1852 & $8.37 \times 10^{-5}$ \\
\hline $\mathrm{Pu}-240 / \mathrm{Pu}-239$ & 0.3856 & 3.4463 & $9.79 \times 10^{-4}$ \\
\hline AEF & -0.1906 & 1.5286 & $1.31 \times 10^{-1}$ \\
\hline $\mathbf{H}$ & 0.1543 & 1.2878 & $2.02 \times 10^{-1}$ \\
\hline Pu-239 & -0.2110 & 1.7798 & $7.96 \times 10^{-2}$ \\
\hline Pu-240 & -0.1568 & 1.3093 & $1.95 \times 10^{-1}$ \\
\hline $\mathbf{0}$ & 0.1581 & 1.3204 & $1.91 \times 10^{-1}$ \\
\hline Pu-241 & 0.0127 & 0.1050 & $9.17 \times 10^{-1}$ \\
\hline $\mathbf{N}$ & 0.5090 & 4.8768 & $6.80 \times 10^{-6}$ \\
\hline \multicolumn{4}{|c|}{$\mathrm{H}_{2} \mathrm{O}$-moderated experiments } \\
\hline H/Pu-239 & 0.3058 & 2.8909 & $4.93 \times 10^{-3}$ \\
\hline $\mathbf{P u}-241 / \mathbf{P u}-239$ & 0.4437 & 4.4554 & $2.66 \times 10^{-5}$ \\
\hline Pu-240/Pu-239 & 0.3830 & 3.7313 & $3.52 \times 10^{-4}$ \\
\hline AEF & -0.3257 & 2.8411 & $5.93 \times 10^{-3}$ \\
\hline $\mathbf{H}$ & 0.1783 & 1.6306 & $1.07 \times 10^{-1}$ \\
\hline Pu-239 & -0.3485 & 3.3457 & $1.25 \times 10^{-3}$ \\
\hline Pu-240 & -0.2279 & 2.1062 & $3.83 \times 10^{-2}$ \\
\hline $\mathbf{O}$ & 0.2496 & 2.3200 & $2.29 \times 10^{-2}$ \\
\hline Pu-241 & -0.0810 & 0.7312 & $4.67 \times 10^{-1}$ \\
\hline $\mathbf{N}$ & 0.5161 & 5.4225 & $5.93 \times 10^{-7}$ \\
\hline U-235 & -0.2514 & 2.3377 & $2.19 \times 10^{-2}$ \\
\hline U-238 & -0.2515 & 2.3387 & $2.18 \times 10^{-2}$ \\
\hline
\end{tabular}


Table 5.8 (continued)

\begin{tabular}{|c|c|c|c|}
\hline Variable & $r$ & $\mathbf{t}$ & Significance level \\
\hline \multicolumn{4}{|c|}{ H-moderated experiments } \\
\hline H/Pu-239 & 0.3689 & 3.9494 & $1.47 \times 10^{-4}$ \\
\hline Pu-241/Pu-239 & 0.4068 & 4.4313 & $2.42 \times 10^{-5}$ \\
\hline Pu-240/Pu-239 & 0.3610 & 3.8511 & $2.09 \times 10^{-4}$ \\
\hline AEF & -0.2204 & 2.0952 & $3.91 \times 10^{-2}$ \\
\hline $\mathbf{H}$ & 0.3732 & 4.0022 & $1.21 \times 10^{-4}$ \\
\hline Pu-239 & -0.3319 & 3.5002 & $6.99 \times 10^{-4}$ \\
\hline $\mathrm{Pu}-240$ & -0.2650 & 2.7348 & $7.40 \times 10^{-3}$ \\
\hline $\mathbf{0}$ & 0.2910 & 3.0269 & $3.15 \times 10^{-3}$ \\
\hline Pu-241 & -0.1585 & 1.5975 & $1.13 \times 10^{-1}$ \\
\hline $\mathbf{N}$ & 0.5099 & 5.8970 & $5.16 \times 10^{-8}$ \\
\hline U-235 & -0.1917 & 1.9435 & $5.48 \times 10^{-2}$ \\
\hline $\mathbf{U}-238$ & -0.2571 & 2.6465 & $9.46 \times 10^{-3}$ \\
\hline \multicolumn{4}{|c|}{ Experiments involving neutron-absorbing materials } \\
\hline H/Pu-239 & 0.4152 & 2.3270 & $2.80 \times 10^{-2}$ \\
\hline $\mathrm{Pu}-241 / \mathrm{Pu}-239$ & 0.0527 & 0.2692 & $7.90 \times 10^{-1}$ \\
\hline Pu-240/Pu-239 & 0.2402 & 1.2616 & $2.18 \times 10^{-1}$ \\
\hline AEF & -0.4867 & 2.3635 & $2.96 \times 10^{-2}$ \\
\hline $\mathbf{H}$ & -0.0535 & 0.2731 & $7.87 \times 10^{-1}$ \\
\hline Pu-239 & -0.5166 & 3.0768 & $4.88 \times 10^{-3}$ \\
\hline Pu-240 & -0.5011 & 2.9528 & $6.60 \times 10^{-3}$ \\
\hline Pu-241 & -0.3956 & 2.1966 & $3.72 \times 10^{-2}$ \\
\hline $\mathbf{0}$ & 0.0592 & 0.3025 & $7.65 \times 10^{-1}$ \\
\hline $\mathbf{N}$ & 0.0658 & 0.3363 & $7.39 \times 10^{-1}$ \\
\hline U-235 & -0.2676 & 1.4162 & $1.69 \times 10^{-1}$ \\
\hline $\mathrm{U}-238$ & -0.2676 & 1.4159 & $1.69 \times 10^{-1}$ \\
\hline \multicolumn{4}{|c|}{$\mathrm{H}_{2} \mathrm{O}$-reflected experiments } \\
\hline H/Pu-239 & 0.3454 & 2.8270 & $6.41 \times 10^{-3}$ \\
\hline $\mathrm{Pu}-241 / \mathrm{Pu}-239$ & 0.4338 & 3.6983 & $4.78 \times 10^{-4}$ \\
\hline $\mathrm{Pu}-240 / \mathrm{Pu}-239$ & 0.4104 & 3.4569 & $1.02 \times 10^{-3}$ \\
\hline AEF & -0.3857 & 2.8354 & $6.78 \times 10^{-3}$ \\
\hline $\mathbf{H}$ & 0.2555 & 2.0300 & $4.69 \times 10^{-2}$ \\
\hline Pu-239 & -0.4901 & 4.3189 & $6.09 \times 10^{-5}$ \\
\hline$P u-240$ & -0.3372 & 2.7515 & $7.87 \times 10^{-3}$ \\
\hline $\mathbf{0}$ & 0.2538 & 2.0157 & $4.84 \times 10^{-2}$ \\
\hline$P u-241$ & -0.2059 & 1.6163 & $1.11 \times 10^{-1}$ \\
\hline $\mathbf{N}$ & 0.5386 & 4.9103 & $7.54 \times 10^{-6}$ \\
\hline U-235 & -0.3946 & 3.2987 & $1.65 \times 10^{-3}$ \\
\hline U-238 & -0.3948 & 3.3002 & $1.64 \times 10^{-3}$ \\
\hline
\end{tabular}


Table 5.8 (continued)

\begin{tabular}{|c|c|c|c|}
\hline Variable & $r$ & $\mathrm{t}$ & Significance level \\
\hline \multicolumn{4}{|c|}{ Experiments with carbon } \\
\hline H/Pu-239 & 0.4646 & 2.7763 & $9.69 \times 10^{-3}$ \\
\hline Pu-241/Pu-239 & -0.2965 & 1.6430 & $1.12 \times 10^{-1}$ \\
\hline $\mathrm{Pu}-240 / \mathrm{Pu}-239$ & -0.4286 & 2.5102 & $1.81 \times 10^{-2}$ \\
\hline AEF & 0.1813 & 0.8246 & $4.19 \times 10^{-1}$ \\
\hline $\mathbf{H}$ & 0.4300 & 2.5200 & $1.77 \times 10^{-2}$ \\
\hline Pu-239 & -0.1800 & 0.9684 & $3.41 \times 10^{-1}$ \\
\hline Pu-240 & -0.1836 & 0.9883 & $3.31 \times 10^{-1}$ \\
\hline Pu-241 & -0.0798 & 0.4236 & $6.75 \times 10^{-1}$ \\
\hline $\mathbf{0}$ & 0.0532 & 0.2818 & $7.80 \times 10^{-1}$ \\
\hline $\mathbf{N}$ & 0.2586 & 1.4164 & $1.68 \times 10^{-1}$ \\
\hline U-235 & -0.2778 & 1.5299 & $1.37 \times 10^{-1}$ \\
\hline $\mathrm{U}-238$ & -0.5479 & 3.4660 & $1.72 \times 10^{-3}$ \\
\hline \multicolumn{4}{|c|}{ Experiments with nitrogen } \\
\hline H/Pu-239 & 0.2438 & 2.1187 & $3.76 \times 10^{-2}$ \\
\hline $\mathbf{P u}-241 / \mathbf{P u}-239$ & 0.4506 & 4.2536 & $6.31 \times 10^{-5}$ \\
\hline$P u-240 / P u-239$ & 0.3819 & 3.4816 & $8.57 \times 10^{-4}$ \\
\hline AEF & -0.1067 & 0.8176 & $4.17 \times 10^{-1}$ \\
\hline $\mathbf{H}$ & 0.1416 & 1.2049 & $2.32 \times 10^{-1}$ \\
\hline Pu-239 & -0.4025 & 3.7051 & $4.15 \times 10^{-4}$ \\
\hline Pu-240 & 0.0597 & 0.5043 & $6.16 \times 10^{-1}$ \\
\hline $\mathbf{O}$ & 0.1596 & 1.3622 & $1.77 \times 10^{-1}$ \\
\hline$P u-241$ & 0.4205 & 3.9050 & $2.12 \times 10^{-4}$ \\
\hline $\mathbf{N}$ & 0.5030 & 4.9039 & $5.75 \times 10^{-6}$ \\
\hline $\mathbf{U}-235$ & -0.1001 & 0.8475 & $4.00 \times 10^{-1}$ \\
\hline U-238 & -0.0979 & 0.8286 & $4.10 \times 10^{-1}$ \\
\hline \multicolumn{4}{|c|}{ Experiments with structural steel } \\
\hline H/Pu-239 & 0.3169 & 2.6095 & $1.14 \times 10^{-2}$ \\
\hline $\mathrm{Pu}-241 / \mathrm{Pu}-239$ & 0.6285 & 6.3114 & $3.48 \times 10^{-8}$ \\
\hline Pu-240/Pu-239 & 0.5941 & 5.7690 & $2.85 \times 10^{-7}$ \\
\hline AEF & -0.2191 & 1.5556 & $1.26 \times 10^{-1}$ \\
\hline $\mathbf{H}$ & 0.1433 & 1.1309 & $2.63 \times 10^{-1}$ \\
\hline Pu-239 & -0.3459 & 2.8796 & $5.49 \times 10^{-3}$ \\
\hline $\mathrm{Pu}-240$ & -0.1843 & 1.4641 & $1.48 \times 10^{-1}$ \\
\hline $\mathbf{0}$ & 0.3581 & 2.9954 & $3.96 \times 10^{-3}$ \\
\hline Pu-241 & -0.0199 & 0.1554 & $8.77 \times 10^{-1}$ \\
\hline $\mathbf{N}$ & 0.7010 & 7.6766 & $1.59 \times 10^{-10}$ \\
\hline U-235 & -0.2671 & 2.1645 & $3.43 \times 10^{-2}$ \\
\hline $\mathrm{U}-238$ & -0.2670 & 2.1816 & $3.29 \times 10^{-2}$ \\
\hline
\end{tabular}


Table 5.8 (continued)

\begin{tabular}{|c|c|c|c|}
\hline Variable & $\mathbf{r}$ & $\mathrm{t}$ & Significance level \\
\hline \multicolumn{4}{|c|}{ Experiments with cylindrical or annular geometry } \\
\hline H/Pu-239 & 0.2400 & 2.0083 & $4.87 \times 10^{-2}$ \\
\hline $\mathrm{Pu}-241 / \mathrm{Pu}-239$ & 0.4697 & 4.3221 & $5.33 \times 10^{-5}$ \\
\hline $\mathrm{Pu}-240 / \mathrm{Pu}-239$ & 0.4046 & 3.5943 & $6.21 \times 10^{-4}$ \\
\hline AEF & -0.1067 & 0.8176 & $4.17 \times 10^{-1}$ \\
\hline $\mathbf{H}$ & 0.1170 & 0.9571 & $3.42 \times 10^{-1}$ \\
\hline Pu-239 & -0.3903 & 3.4443 & $1.00 \times 10^{-3}$ \\
\hline Pu-240 & 0.0877 & 0.7155 & $4.77 \times 10^{-1}$ \\
\hline $\mathbf{0}$ & 0.2054 & 1.7052 & $9.29 \times 10^{-2}$ \\
\hline Pu-241 & 0.4432 & 4.0171 & $1.53 \times 10^{-4}$ \\
\hline $\mathbf{N}$ & 0.5238 & 4.9959 & $4.56 \times 10^{-6}$ \\
\hline U-235 & -0.0968 & 0.7903 & $4.32 \times 10^{-1}$ \\
\hline U-238 & -0.0946 & 0.7720 & $4.43 \times 10^{-1}$ \\
\hline \multicolumn{4}{|c|}{ Array experiments } \\
\hline H/Pu-239 & 0.3000 & 1.6035 & $1.21 \times 10^{-1}$ \\
\hline $\mathbf{P u}-241 / \mathbf{P u}-239$ & 0.0032 & 0.0161 & $9.87 \times 10^{-1}$ \\
\hline Pu-240/Pu-239 & -0.1434 & 0.7387 & $4.67 \times 10^{-1}$ \\
\hline AEF & 0.0773 & 0.3955 & $6.96 \times 10^{-1}$ \\
\hline $\mathbf{H}$ & 0.1962 & 1.0200 & $3.17 \times 10^{-1}$ \\
\hline pitch & 0.0537 & 0.2740 & $7.86 \times 10^{-1}$ \\
\hline Pu-239 & 0.0411 & 0.2099 & $8.35 \times 10^{-1}$ \\
\hline $\mathbf{P u}-240$ & 0.0342 & 0.1744 & $8.63 \times 10^{-1}$ \\
\hline $\mathbf{P u}-241$ & 0.1338 & 0.6882 & $4.97 \times 10^{-1}$ \\
\hline $\mathbf{0}$ & -0.2289 & 1.1989 & $2.41 \times 10^{-1}$ \\
\hline $\mathbf{N}$ & 0.0000 & 0.0000 & 0.00 \\
\hline U-235 & 0.0870 & 0.4454 & $6.60 \times 10^{-1}$ \\
\hline $\mathrm{U}-238$ & 0.0180 & 0.0916 & $9.28 \times 10^{-1}$ \\
\hline \multicolumn{4}{|c|}{ 36-Experiment subset $(0.0 \leq \mathrm{H} / \mathrm{Pu}-239 \leq 126.42)$} \\
\hline H/Pu-239 & 0.4426 & 2.8781 & $6.87 \times 10^{-3}$ \\
\hline $\mathrm{Pu}-241 / \mathrm{Pu}-239$ & -0.0642 & 0.3752 & $7.10 \times 10^{-1}$ \\
\hline Pu-240/Pu-239 & -0.2021 & 1.2030 & $2.37 \times 10^{-1}$ \\
\hline AEF & -0.1643 & 0.9422 & $3.53 \times 10^{-1}$ \\
\hline $\mathbf{H}$ & 0.2946 & 1.7976 & $8.11 \times 10^{-2}$ \\
\hline Pu-239 & -0.1691 & 1.0006 & $3.24 \times 10^{-1}$ \\
\hline Pu-240 & -0.1576 & 0.9308 & $3.59 \times 10^{-1}$ \\
\hline $\mathbf{0}$ & 0.0134 & 0.0780 & $9.38 \times 10^{-1}$ \\
\hline Pu-241 & -0.0014 & 0.0082 & $9.94 \times 10^{-1}$ \\
\hline $\mathbf{N}$ & 0.2792 & 1.6955 & $9.91 \times 10^{-2}$ \\
\hline U-235 & -0.2193 & 1.3103 & $1.99 \times 10^{-1}$ \\
\hline U-238 & -0.4223 & 2.7162 & $1.03 \times 10^{-2}$ \\
\hline
\end{tabular}


Based on the results in Table 5.9, the strongest correlation for system multiplication is observed for the steel reflected experiments. Specifically, the correlation coefficient for $k_{\text {eff }}$ as a function of nitrogen atom density is $\mathbf{0 . 7 0 1 0}$. Plots of the calculated $k_{e f f}$ values as a function of nitrogen atom density for the steelreflected experiments are provided in Figs. 5.7a and 5.7b. The calculated results in Figs. 5.7a and 5.7b are consistent with the results that are presented in Fig. 5.3 for the complete set of experiments. As shown in Figs. 5.3 and 5.7, there is a positive trend in system multiplication with increasing nitrogen atom density. The trend appears to be attributed to nine experiments with $\mathrm{N}$ atom densities from $1.29 \times 10^{-2}$ to $4.43 \times 10^{-2}$ atoms $/ \mathrm{b}-\mathrm{cm}$. These nine experiments involve $\mathrm{Pu}$ nitrate solution in a cylindrical steel (304-L) vessel completely reflected with water. To assess the impact of these experiments, the correlation coefficient is presented without the nine $\mathrm{Pu}$ nitrate experiments. The resulting correlation coefficient is 0.067 , which indicates no correlation with nitrogen atom density. Therefore, the positive trend in $k_{\text {eff }}$ with increasing nitrogen atom density is attributed to the nine Pu nitrate experiments. Note that the calculated USL $\mathrm{US}_{1}$ as a function of nitrogen atom density is $\mathbf{0 . 9 3 8 7}$, which is less conservative relative to the $\mathrm{USL}_{1}$ as a function of $\mathrm{H} /{ }^{23} \mathrm{Pu}$ or $\mathrm{H}$ atom density for the complete set of experiments. These results indicate that the independent variable with the strongest correlation to $k_{\text {eff }}$ may not be the most suitable choice for establishing the acceptance criteria.

In Table 5.9, the calculated USLs that yield a more conservative acceptance criteria (i.e., relative to $\mathrm{USL}_{1}$ for $\mathrm{H}^{239} \mathrm{Pu}$ or $\mathrm{H}$ atom density for the complete set of experiments) are evaluated further in an effort to identify hidden biases or trends in the data. The variables from Table 5.9 which have a minimum $\mathrm{USL}_{1}$ value below 0.9354 are presented in Table 5.10 for each experiment subset. The calculated $k_{e f f}$ values as a function of $\mathrm{H}^{239} \mathrm{Pu}$ for the $\mathrm{H}_{2} \mathrm{O}$-moderated experiments are presented in Fig. 5.8. As shown in Fig. 5.8 and Table 5.10, the calculated $\mathrm{USL}_{1}$ as a function of $\mathrm{H}^{239} \mathrm{Pu}$ for the $\mathrm{H}_{2} \mathrm{O}$-moderated experiments is equivalent to the corresponding $\mathrm{USL}_{1}$ obtained for the complete set of experiments. Consequently, there are no hidden biases for system multiplication as a function of $\mathrm{H}^{239} \mathrm{Pu}$. With regard to hydrogen atom density, the $\mathrm{USL}_{1}$ as a function of $\mathrm{H}$ for the hydrogen-moderated experiments is presented in Fig. 5.9. As observed for the complete set of experiments, the calculated $\mathrm{USL}_{1}$ as a function of $\mathrm{H}$ atom density is more conservative in the low moderation range relative to $\mathrm{H}^{239} \mathrm{Pu}$. In addition, there are no hidden trends or biases in calculated system multiplication as a function of $\mathrm{H}$ atom density for the hydrogen-moderated experiments.

In addition to $\mathrm{H}^{239} \mathrm{Pu}$ and $\mathrm{H}$ atom density, there are five additional variables in Table 5.10 which must be evaluated further. In particular, the minimum values for $\mathrm{USL}_{1}(x)$ as a function of $\mathrm{AEF}$, as well as ${ }^{239} \mathrm{Pu},{ }^{240} \mathrm{Pu},{ }^{235} \mathrm{U}$ and ${ }^{238} \mathrm{U}$ atom densities, are less than 0.9354 . When these five variables are considered with the complete set of experiments, the variables do not have a statistically significant correlation with system multiplication. Although the correlations in Table 5.10 are statistically significant, the strongest correlation occurs for water-reflected experinents involving ${ }^{239} \mathrm{Pu}$ (i.e., $\mathrm{r}=-0.4901$ ). For the subsets listed in Table $5.10,{ }^{239} \mathrm{Pu}$ has a statistically significant correlation with $k_{\text {eff }}$ for each subset except for the 36-experiment subset with $\mathrm{H}^{239} \mathrm{Pu}$ ratios between 0.0 and 126.42 . Likewise, ${ }^{240} \mathrm{Pu}$ has a statistically significant correlation for the experiments involving water reflection. Moreover, ${ }^{235} \mathrm{U}$ and ${ }^{238} \mathrm{U}$ are also correlated with system multiplication for the water-reflected experiments. For the 36-experiment subset with $\mathrm{H}^{239} \mathrm{Pu}$ ratios between 0.0 and 126.42 , the corresponding calculated $k_{\text {eff }}$ values are also correlated with ${ }^{238} \mathrm{U}$ atom density. With regard to the water-moderated and water-reflected experiments, there is a statistically significant correlation between system multiplication and AEF. 
Table 5.9. Summary of USL calculations for experiment subsets

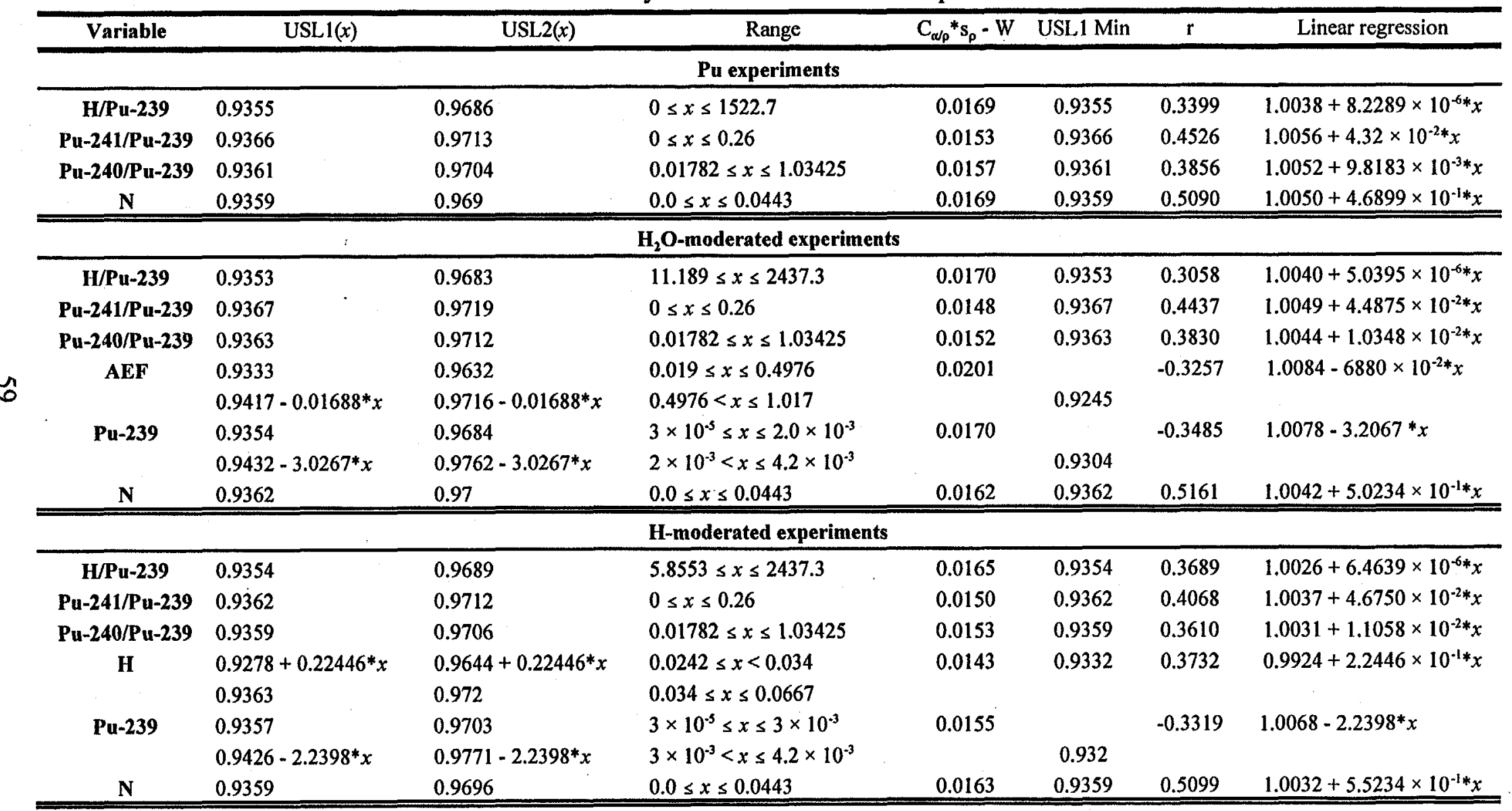


Table 5.9 (continued)

\begin{tabular}{|c|c|c|c|c|c|c|c|}
\hline Variable & $\operatorname{USL1}(x)$ & USL2(x) & Range & $\mathrm{C}_{\alpha / \rho}{ }^{*} \mathrm{~s}_{p}-\mathrm{W}$ & USL1 Min & $\mathrm{r}$ & Linear regression \\
\hline \multicolumn{8}{|c|}{$\mathrm{H}_{2} \mathrm{O}$-reflected experiments } \\
\hline H/Pu-239 & 0.9354 & 0.9678 & $11.189 \leq x \leq 2437.3$ & 0.0176 & 0.9354 & 0.3454 & $1.0056+5.0954 \times 10^{-6 *} x$ \\
\hline Pu-241/Pu-239 & 0.9367 & 0.9713 & $0 \leq x \leq 0.26$ & 0.0154 & 0.9367 & 0.4338 & $1.0064+3.8270 \times 10^{-2 *} x$ \\
\hline Pu-240/Pu-239 & 0.9365 & 0.971 & $0.01782 \leq x \leq 1.03425$ & 0.0156 & 0.9365 & 0.4104 & $1.0060+9.5238 \times 10^{-3 *} x$ \\
\hline \multirow[t]{2}{*}{ AEF } & 0.9329 & 0.9614 & $0.019 \leq x \leq 0.594$ & 0.0215 & & -0.3857 & $1.0106-1.7800 \times 10^{-2 k} x$ \\
\hline & $0.9435-0.0178^{*} x$ & $0.9720-0.0178^{*} x$ & $0.594<x \leq 1.017$ & & 0.9254 & & \\
\hline \multirow{2}{*}{ Pu-239 } & 0.9364 & 0.9699 & $3.0 \times 10^{-5} \leq x \leq 3.0 \times 10^{-3}$ & 0.0165 & & -0.4901 & $1.0102-3.8839^{*} x$ \\
\hline & $0.9466-3.8839^{*} x$ & $0.9801-3.8839^{*} x$ & $3.0 \times 10^{-3}<x \leq 4.2 \times 10^{-3}$ & & 0.9302 & & \\
\hline \multirow[t]{2}{*}{ Pu-240 } & 0.9354 & 0.9677 & $1.5 \times 10^{-6} \leq x \leq 4.776 \times 10^{-4}$ & 0.0177 & & -0.3372 & $1.0095-1.9891^{*} x$ \\
\hline & $0.9448-19.891^{*} x$ & $0.9771-19.891^{*} x$ & $4.776 \times 10^{-4}<x \leq 5.6 \times 10^{-4}$ & & 0.9336 & & \\
\hline $\mathbf{N}$ & 0.9365 & 0.9699 & $0.0 \leq x \leq 0.0443$ & 0.0165 & 0.9365 & 0.5386 & $1.0058+4.5297 \times 10^{-1 *} x$ \\
\hline \multirow[t]{2}{*}{ U-235 } & 0.9362 & 0.9699 & $0.0 \leq x \leq 2.735 \times 10^{-4}$ & 0.0163 & & -0.3946 & $1.0094-3.4364^{*} x$ \\
\hline & $0.9456-34.364^{*} x$ & $0.9793-34.364^{*} x$ & $2.735 \times 10^{-4}<x \leq 3 \times 10^{-4}$ & & 0.9352 & & \\
\hline \multirow[t]{2}{*}{ U-238 } & 0.9362 & 0.9699 & $0.0 \leq x \leq 0.038$ & 0.0163 & & -0.3948 & $1.0094-2.4861 \times 10^{-1 *} x$ \\
\hline & $0.9456-0.24861 * x$ & $0.9793-0.24861^{*} x$ & $0.038<x \leq 0.0412$ & & 0.9353 & & \\
\hline \multicolumn{8}{|c|}{ Experiments with nitrogen } \\
\hline Pu-241/Pu-239 & 0.9368 & 0.9719 & $0.0 \leq x \leq 0.26$ & 0.0149 & 0.9368 & 0.4506 & $1.0057+4.2646 \times 10^{-2 k} x$ \\
\hline Pu-240/Pu-239 & 0.9364 & 0.971 & $0.01782 \leq x \leq 1.03425$ & 0.0154 & 0.9364 & 0.3819 & $1.0053+9.6599 \times 10^{-3 *} x$ \\
\hline \multirow[t]{2}{*}{ Pu-239 } & 0.9366 & 0.9718 & $3 \times 10^{-5} \leq x \leq 8.06 \times 10^{-4}$ & 0.0148 & & -0.4025 & $1.0106-1.3145 \times 10^{*} x$ \\
\hline & $0.9473-13.145^{*} x$ & $0.9824-13.145^{*} x$ & $8.06 \times 10^{-4}<x \leq 8.29 \times 10^{-4}$ & & 0.9364 & & \\
\hline Pu-241 & 0.9356 & 0.9685 & $0.0 \leq x \leq 4 \times 10^{-5}$ & 0.0171 & 0.9356 & 0.4205 & $1.0055+4.3475 \times 10^{2 *} x$ \\
\hline $\mathbf{N}$ & 0.9361 & 0.9696 & $4.7 \times 10^{-3} \leq x \leq 0.0443$ & 0.0165 & 0.9361 & 0.5030 & $1.0050+4.6354 \times 10^{-1 *} x$ \\
\hline \multicolumn{8}{|c|}{ Experiments with structural steel } \\
\hline H/Pu-239 & 0.9359 & 0.969 & $11.189 \leq x \leq 2437.3$ & 0.0169 & 0.9359 & 0.3169 & $1.0030+4.4156 \times 10^{-6 *} x$ \\
\hline Pu-241/Pu-239 & 0.9388 & 0.9758 & $0.0 \leq x \leq 0.26$ & 0.0130 & 0.9388 & 0.6285 & $1.0029+5.3759 \times 10^{-2 *} x$ \\
\hline Pu-240/Pu-239 & 0.9384 & 0.9751 & $0.01782 \leq x \leq 1.03425$ & 0.0133 & 0.9384 & 0.5941 & $1.0018+1.3782 \times 10^{-2 *} x$ \\
\hline \multirow[t]{2}{*}{ Pu-239 } & 0.936 & 0.9691 & $3 \times 10^{-5} \leq x \leq 2.43 \times 10^{-3}$ & 0.0169 & & -0.3459 & $1.0065-2.6712 * x$ \\
\hline & $0.9425-2.6712^{*} x$ & $0.9756-2.6712^{*} x$ & $2.43 \times 10^{-3}<x \leq 4.2 \times 10^{-3}$ & & 0.9312 & & \\
\hline $\mathbf{o}$ & 0.9365 & 0.9706 & $0.03410 \leq x \leq 0.0409$ & 0.0159 & 0.9365 & 0.3581 & $0.9396+1.7975^{*} x$ \\
\hline
\end{tabular}


Table 5.9 (continued)

\begin{tabular}{|c|c|c|c|c|c|c|c|}
\hline Variable & USLI $(\mathrm{X})$ & USL2(X) & Range & $C_{\alpha / \rho}^{*} s_{\rho}-W$ & USL1 Min & $\mathrm{r}$ & Linear regression \\
\hline \multicolumn{8}{|c|}{ Experiments with cylindrical or annular geometry } \\
\hline Pu-241/Pu-239 & 0.9367 & 0.9715 & $0.0 \leq x \leq 0.26$ & 0.0152 & 0.9367 & 0.4697 & $1.0054+4.4018 \times 10^{-2 *} x$ \\
\hline Pu-240/Pu-239 & 0.9363 & 0.9706 & $0.01782 \leq x \leq 1.03425$ & 0.0156 & 0.9363 & 0.4046 & $1.0049+1.0179 \times 10^{-2 *} x$ \\
\hline \multirow[t]{2}{*}{ Pu-239 } & 0.9363 & 0.9709 & $3 \times 10^{-5} \leq x \leq 8.08 \times 10^{-4}$ & 0.0154 & & -0.3903 & $1.0104-1.2869^{*} x$ \\
\hline & $0.9467-12.869^{*} x$ & $0.9812-12.869^{*} x$ & $8.08 \times 10^{-4}<x \leq 8.3 \times 10^{-4}$ & & 0.936 & & \\
\hline Pu-241 & 0.9355 & 0.9681 & $0.0 \leq x \leq 4 \times 10^{-5}$ & 0.0174 & 0.9355 & 0.4432 & $1.0051+4.5444 \times 10^{2 *} x$ \\
\hline \multirow[t]{2}{*}{$\mathbf{N}$} & 0.9361 & 0.9693 & $4.7 \times 10^{-3} \leq x \leq 0.0443$ & 0.0168 & 0.9361 & 0.5238 & $1.0047+4.7757 \times 10^{-1 *} x$ \\
\hline & 0.9383 & 0.9723 & $75.9 \leq x \leq 169.05$ & & & & \\
\hline \multicolumn{8}{|c|}{ 36-Experiment subset $(0.0<=\mathrm{H} / \mathrm{Pu}-239<=126.42)$} \\
\hline \multirow[t]{2}{*}{ H/Pu-239 } & $0.9373+5.8165 \times 10^{-5 *} x$ & $0.9747+5.8165 \times 10^{-5 *} x$ & $0 \leq x<51.124$ & 0.0126 & 0.9373 & 0.4426 & $0.9970+5.8165 \times 10^{-5 *} x$ \\
\hline & 0.9402 & 0.9776 & $51.124 \leq x \leq 126.42$ & & & & \\
\hline \multirow[t]{2}{*}{ U-238 } & 0.9398 & 0.9766 & $0.0 \leq x \leq 4 \times 10^{-3}$ & 0.0133 & & -0.4223 & $1.0017-4.4203 \times 10^{-1 *} x$ \\
\hline & $0.9415-0.44203 * x$ & $0.9782-0.44203^{*} x$ & $4 \times 10^{-3}<x \leq 0.01690$ & & 0.934 & & \\
\hline
\end{tabular}




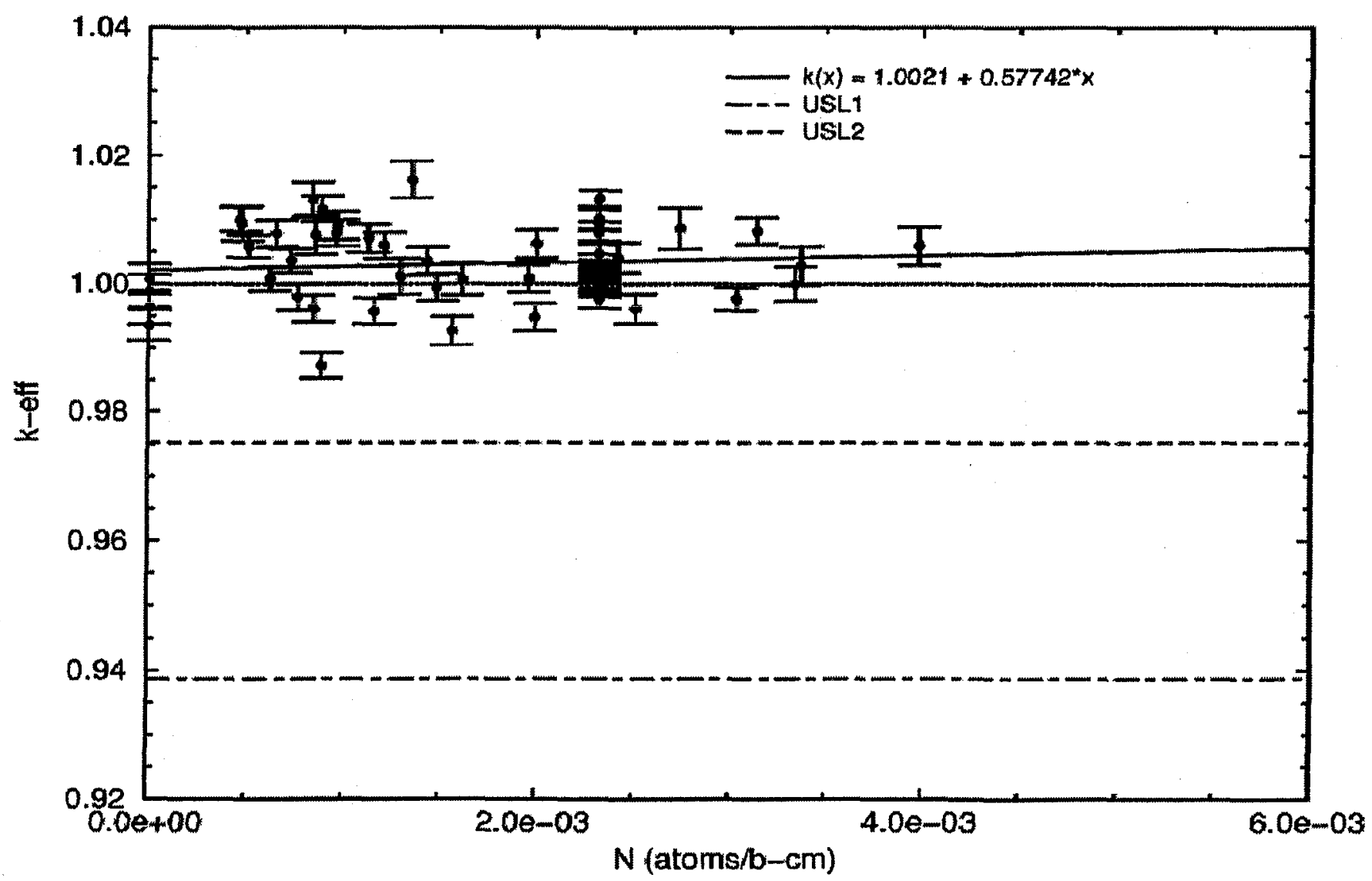

Fig. 5.7a. Calculated USLs as a function of nitrogen atom density for 63 experiments involving structural steel. 


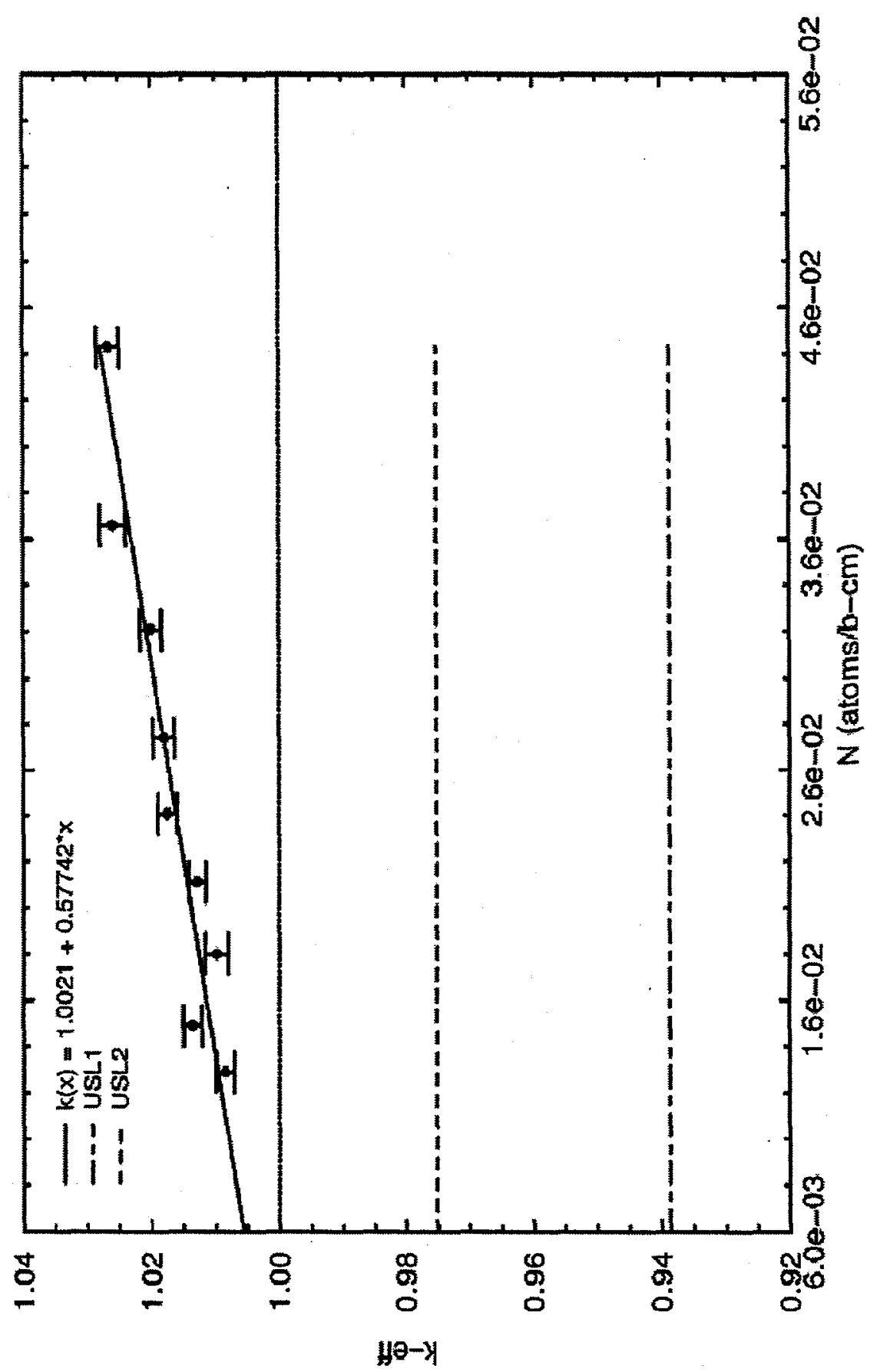

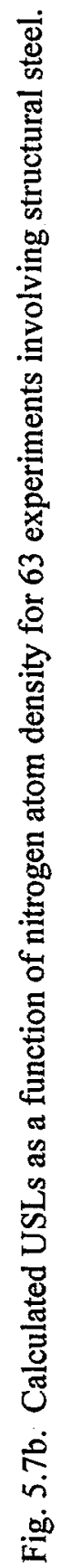


Table 5.10. USL calculations for selected experiment subsets

\begin{tabular}{|c|c|c|c|c|c|c|c|}
\hline Variable & USL1 $(x)$ & USL2 $2(x)$ & Range & $C_{\alpha p_{p}}{ }^{*} s_{p}-W$ & USL1 Min & $r$ & Linear regression \\
\hline \multicolumn{8}{|c|}{$\mathrm{H}_{2} \mathrm{O}$-moderated experiments } \\
\hline H/Pu-239 & 0.9353 & 0.9683 & $11.189 \leq x \leq 2437.3$ & 0.0170 & 0.9353 & 0.3058 & $1.0040+5.0395 \times 10^{-6 *} x$ \\
\hline \multirow[t]{2}{*}{ AEF } & 0.9333 & 0.9632 & $0.019 \leq x \leq 0.4976$ & 0.0201 & & -0.3257 & $1.0084-6880 \times 10^{-2 *} x$ \\
\hline & $0.9417-0.01688^{*} x$ & $0.9716-0.01688^{*} x$ & $0.4976<x \leq 1.017$ & & 0.9245 & & \\
\hline \multirow[t]{2}{*}{ Pu-239 } & 0.9354 & 0.9684 & $3 \times 10^{-5} \leq x \leq 2.0 \times 10^{-3}$ & 0.0170 & & -0.3485 & $1.0078-3.2067^{*} x$ \\
\hline & $0.9432-3.0267^{*} x$ & $0.9762-3.0267^{*} x$ & $2 \times 10^{-3}<x \leq 4.2 \times 10^{-3}$ & & 0.9304 & & \\
\hline \multicolumn{8}{|c|}{ H-moderated experiments } \\
\hline \multirow[t]{2}{*}{$\mathbf{H}$} & $0.9278+0.22446^{*} x$ & $0.9644+0.22446^{*} x$ & $0.0242 \leq x<0.034$ & 0.0143 & 0.9332 & 0.3732 & $0.9924+2.2446 \times 10^{-1 *} x$ \\
\hline & 0.9363 & 0.972 & $0.034 \leq x \leq 0.0667$ & & & & \\
\hline \multirow{2}{*}{ Pu-239 } & 0.9357 & 0.9703 & $3 \times 10^{-5} \leq x \leq 3 \times 10^{-3}$ & 0.0155 & & -0.3319 & $1.0068-2.2398 * x$ \\
\hline & $0.9426-2.2398^{*} x$ & $0.9771-2.2398 * x$ & $3 \times 10^{-3}<x \leq 4.2 \times 10^{-3}$ & & 0.932 & & \\
\hline \multicolumn{8}{|c|}{$\mathrm{H}_{2} \mathrm{O}$-reflected experiments } \\
\hline \multirow[t]{2}{*}{ AEF } & 0.9329 & 0.9614 & $0.019 \leq x \leq 0.594$ & 0.0215 & & -0.3857 & $1.0106-1.7800 \times 10^{-2 *} x$ \\
\hline & $0.9435-0.0178^{*} x$ & $0.9720-0.0178^{*} x$ & $0.594<x \leq 1.017$ & & 0.9254 & & \\
\hline \multirow[t]{2}{*}{ Pu-239 } & 0.9364 & 0.9699 & $3.0 \times 10^{-5} \leq x \leq 3.0 \times 10^{-3}$ & 0.0165 & & -0.4901 & $1.0102-3.8839^{*} x$ \\
\hline & $0.9466-3.8839^{*} x$ & $0.9801-3.8839^{*} x$ & $3.0 \times 10^{-3}<x \leq 4.2 \times 10^{-3}$ & & 0.9302 & & \\
\hline \multirow[t]{2}{*}{ Pu-240 } & 0.9354 & 0.9677 & $1.5 \times 10^{-6} \leq x \leq 4.776 \times 10^{-4}$ & 0.0177 & & -0.3372 & $1.0095-1.9891^{*} x$ \\
\hline & $0.9448-19.891^{*} x$ & $0.9771-19.891^{*} x$ & $4.776 \times 10^{-4}<x \leq 5.6 \times 10^{-4}$ & & 0.9336 & & \\
\hline \multirow[t]{2}{*}{ U-235 } & 0.9362 & 0.9699 & $0.0 \leq x \leq 2.735 \times 10^{-4}$ & 0.0163 & & -0.3946 & $1.0094-3.4364^{*} x$ \\
\hline & $0.9456-34.364^{*} x$ & $0.9793-34.364^{*} x$ & $2.735 \times 10^{-4}<x \leq 3 \times 10^{-4}$ & & 0.9352 & & \\
\hline \multirow[t]{2}{*}{ U-238 } & 0.9362 & 0.9699 & $0.0 \leq x \leq 0.038$ & 0.0163 & & -0.3948 & $1.0094-2.4861 \times 10^{-1 *} x$ \\
\hline & $0.9456-0.24861^{*} x$ & $0.9793-0.24861^{*} x$ & $0.038<x \leq 0.0412$ & & 0.9353 & & \\
\hline \multicolumn{8}{|c|}{ Experiments with structural steel } \\
\hline \multirow[t]{2}{*}{ Pu-239 } & 0.936 & 0.9691 & $3 \times 10^{-5} \leq x \leq 2.43 \times 10^{-3}$ & 0.0169 & & -0.3459 & $1.0065-2.6712^{*} x$ \\
\hline & $0.9425-2.6712^{*} x$ & $0.9756-2.6712^{*} x$ & $2.43 \times 10^{-3}<x \leq 4.2 \times 10^{-3}$ & & 0.9312 & & \\
\hline \multicolumn{8}{|c|}{ 36-Experiment subset $(0.0<=\mathrm{H} / \mathrm{Pu}-239<=126.42)$} \\
\hline \multirow[t]{2}{*}{ U-238 } & 0.9398 & 0.9766 & $0.0 \leq x \leq 4.0 \times 10^{-3}$ & 0.0133 & & -0.4223 & $1.0017-4.4203 \times 10^{-1 *} x$ \\
\hline & $0.9415-0.44203^{*} x$ & $0.9782-0.44203^{*} x$ & $4.0 \times 10^{-3}<x \leq 0.01690$ & & 0.934 & & \\
\hline
\end{tabular}




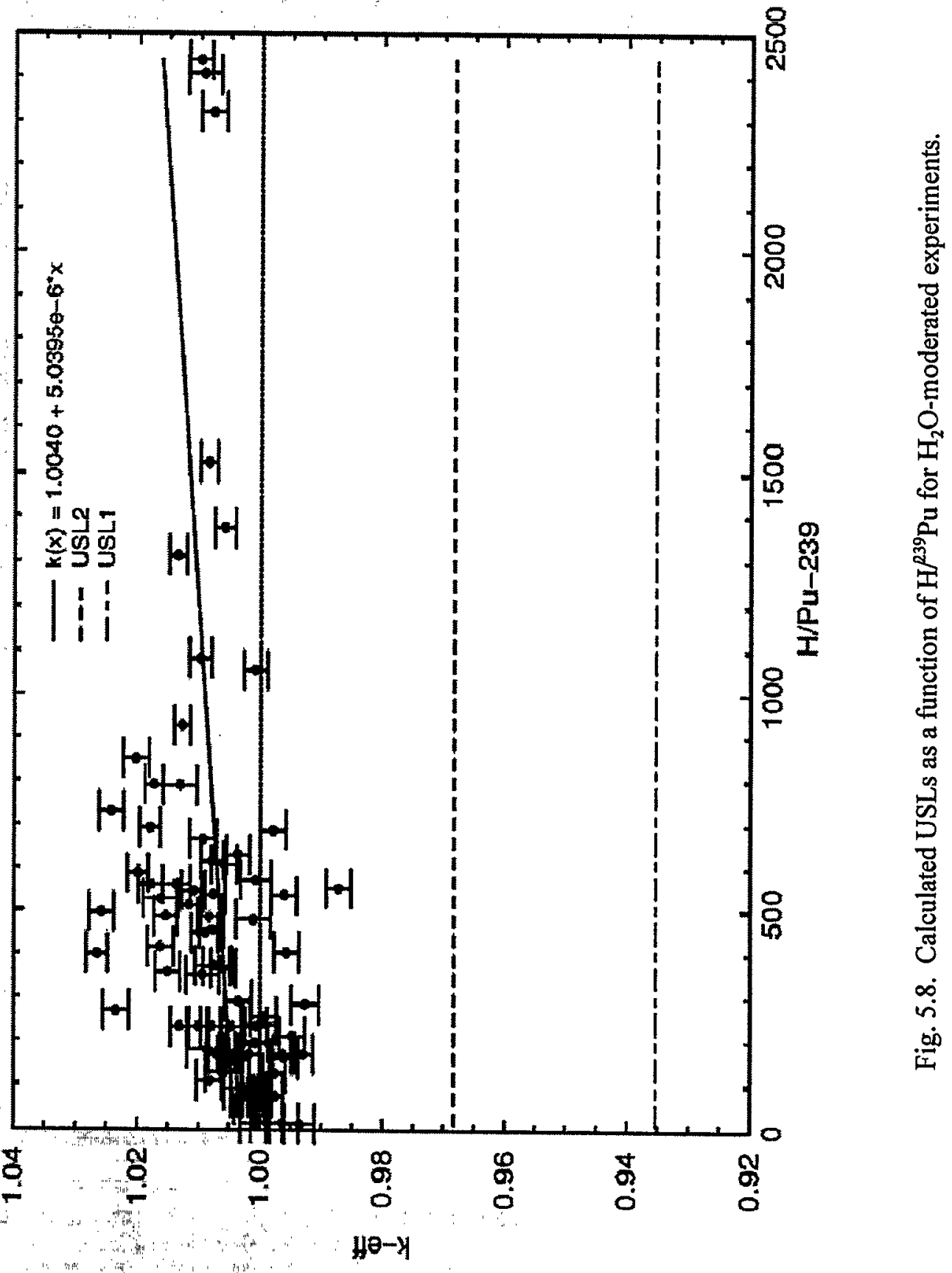




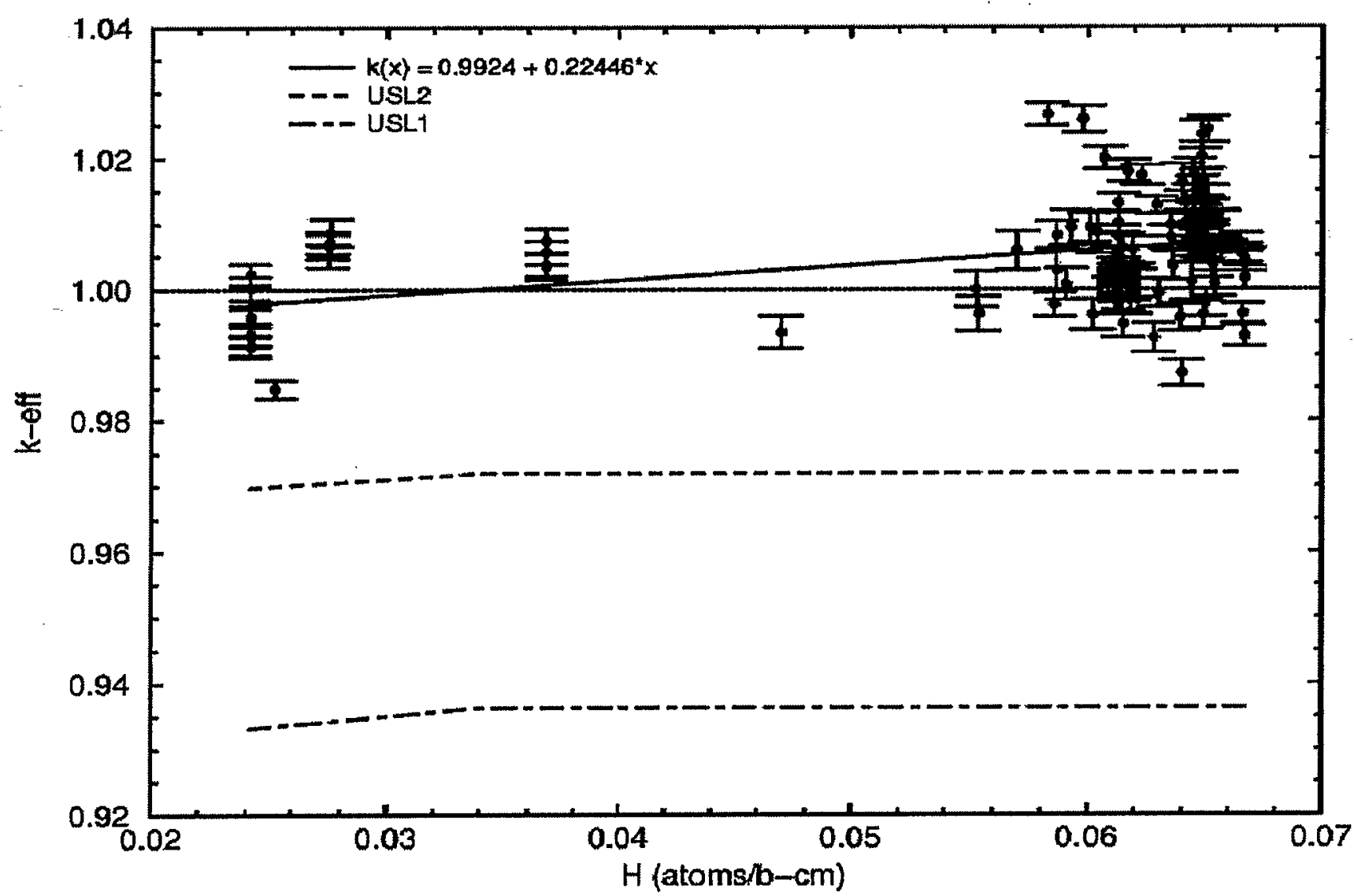

Fig. 5.9. Calculated USLs as a function of $\mathrm{H}$ atom density for $\mathrm{H}$-moderated experiments. 
For the ${ }^{239} \mathrm{Pu}$ atom density variable in Table 5.10, the lowest value for $\mathrm{USL}_{1}(x)$ is observed for the subset of water-reflected experiments. The calculated $k_{\text {eff }}$ values as a function of ${ }^{239} \mathrm{Pu}$ are presented in Fig. 5.10 for the water-reflected experiments. As shown in Fig. 5.10, the experiments as a function of ${ }^{239} \mathrm{Pu}$ atom density are concentrated below $1.0 \times 10^{-3}$ atoms/b-cm. The ${ }^{239} \mathrm{Pu},{ }^{240} \mathrm{Pu},{ }^{235} \mathrm{U}$ and ${ }^{238} \mathrm{U}$ atom densities for the different MOX loadings considered in this evaluation are presented in Table 5.11. Based on the data in Table 5.11 and the USLs presented in Table 5.10, the minimum USL for the proposed ${ }^{239} \mathrm{Pu}$ fuel loadings is 0.9354 . Consequently, no additional margin of subcriticality is required for the acceptance criteria based on ${ }^{239} \mathrm{Pu}$ atom density. The calculated $k_{e f f}$ values as a function of ${ }^{240} \mathrm{Pu}$ atom density are presented in Fig. 5.11 for the water-reflected experiments. For water-reflected experiments in Fig. 5.11, there is a paucity of data for ${ }^{240} \mathrm{Pu}$ atom densities between $1.5 \times 10^{-4}$ and $5.6 \times 10^{-4}$ atoms $/ \mathrm{b}-\mathrm{cm}$. Based on the results in Fig. $5.11,{ }^{240} \mathrm{Pu}$ atom density is not suitable for establishing acceptance criteria from $1.5 \times 10^{-4}$ to $5.6 \times 10^{-4}$ atoms $/ \mathrm{b}-\mathrm{cm}$.

Based on the results for the water-reflected experiments, the calculated $k_{\text {eff }}$ values as a function of ${ }^{235} \mathrm{U}$ atom density are provided in Fig. 5.12. Likewise, the calculated $k_{\text {eff }}$ values as a function of ${ }^{238} \mathrm{U}$ atom density for the water reflected experiments and the 36 -experiment subset with $\mathrm{H}^{239} \mathrm{Pu}$ ratios between 0.0 and 126.42 are provided in Figs. 5.13 and 5.14, respectively. There are a limited number of experimental values for ${ }^{235} \mathrm{U}$ and ${ }^{238} \mathrm{U}$ atom densities in Figures 5.12-5.14. As a result, ${ }^{235} \mathrm{U}$ and ${ }^{238} \mathrm{U}$ are not suitable independent variables for establishing trends or biases in the data.

As noted in Table 5.10, there is a statistically significant correlation between $k_{e f f}$ and AEF for the water-moderated and water-reflected experiments. Plots of the calculated $k_{\text {eff }}$ values as a function of AEF are provided in Figs. 5.15 and 5.16 for the set of water-moderated experiments and the set of waterreflected experiments, respectively. The majority of experiments have AEF values below $0.3 \mathrm{eV}$, which indicates that the systems are well moderated. For the water-moderated and water-reflected sets of experiments, the minimum value of the USL(AEF) is lower relative to the USL as a function of hydrogen moderation. Specifically, the minimum value of $\mathrm{USL}_{1}$ as a function of AEF is 0.9245 for the watermoderated experiments. The USL based on hydrogen moderation is used for the criticality safety evaluation; however, the USL should be lowered to 0.9245 to account for negative biases as a function of AEF for the water-moderated and water-reflected experiments. In the following sections, a calculated $k_{\text {eff }}+2 \sigma$ for fissile system is considered acceptably subcritical. The range of applicability for the USL is defined in Sect. 5.3.

Table 5.11. Selected atom densities for different MOX loadings in MO-1

\begin{tabular}{|c|c|c|c|c|}
\hline \multirow[b]{2}{*}{ MOX fuel } & \multicolumn{4}{|c|}{ Atom density (atoms/b-cm) } \\
\hline & ${ }^{239} \mathrm{Pu}$ & ${ }^{240} \mathrm{Pu}$ & ${ }^{235} \mathrm{U}$ & ${ }^{238} \mathrm{U}$ \\
\hline $6 \mathrm{wt} \% \mathrm{PuO}_{2}$ & $8.42 \times 10^{-4}$ & $3.28 \times 10^{-4}$ & $1.64 \times 10^{-4}$ & $2.25 \times 10^{-5}$ \\
\hline $4.4 \mathrm{wt} \% \mathrm{PuO}_{2}$ & $8.39 \times 10^{-4}$ & $1.95 \times 10^{-4}$ & $1.66 \times 10^{-4}$ & $9.65 \times 10^{-7}$ \\
\hline $3.03 \mathrm{wt} \% \mathrm{PuO}_{2}$ & $6.04 \times 10^{-4}$ & $9.98 \times 10^{-5}$ & $1.69 \times 10^{-4}$ & $1.69 \times 10^{-6}$ \\
\hline WG MOX & $1.16 \times 10^{-3}$ & $7.30 \times 10^{-5}$ & $4.39 \times 10^{-5}$ & $2.16 \times 10^{-2}$ \\
\hline
\end{tabular}




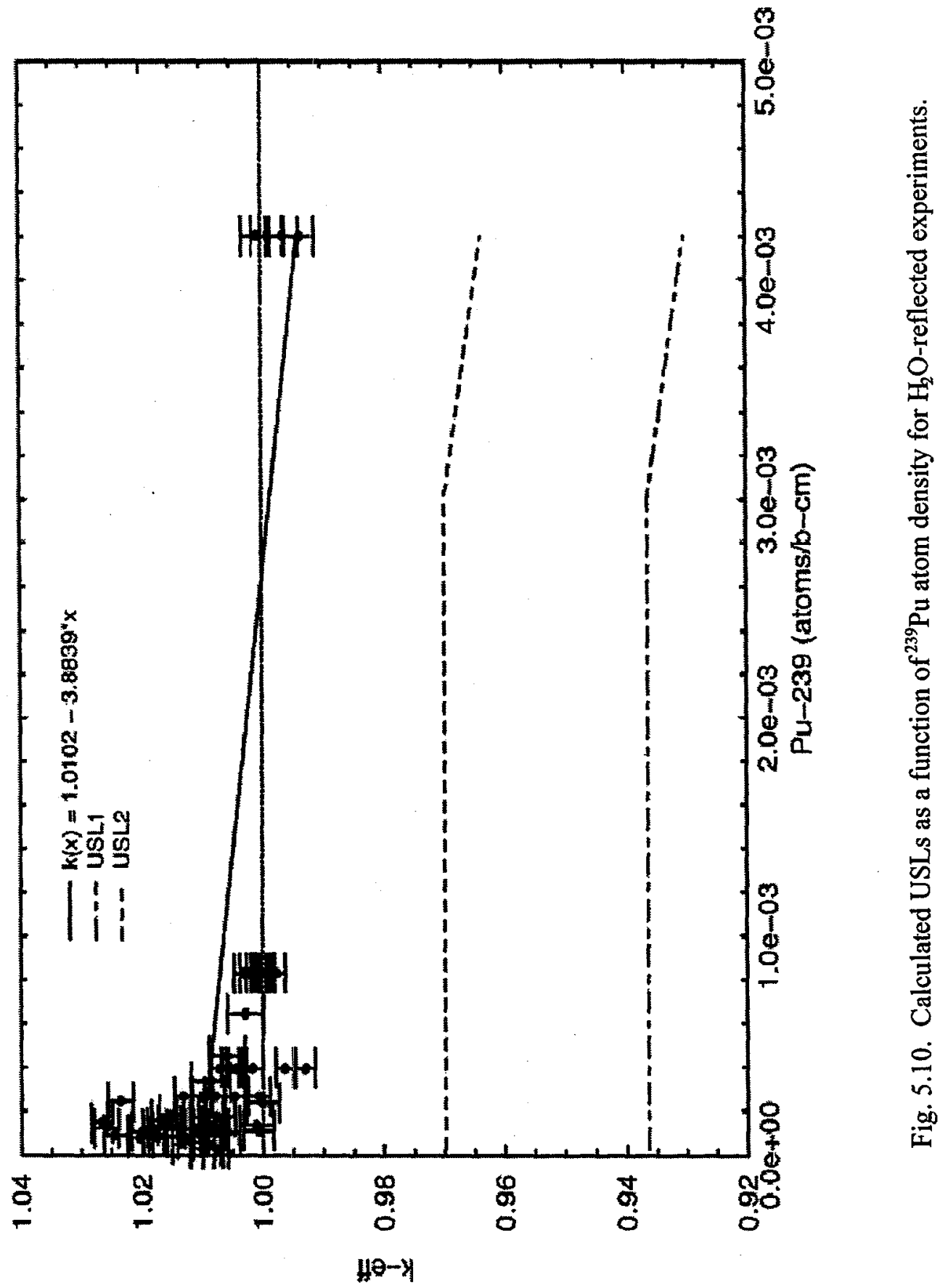




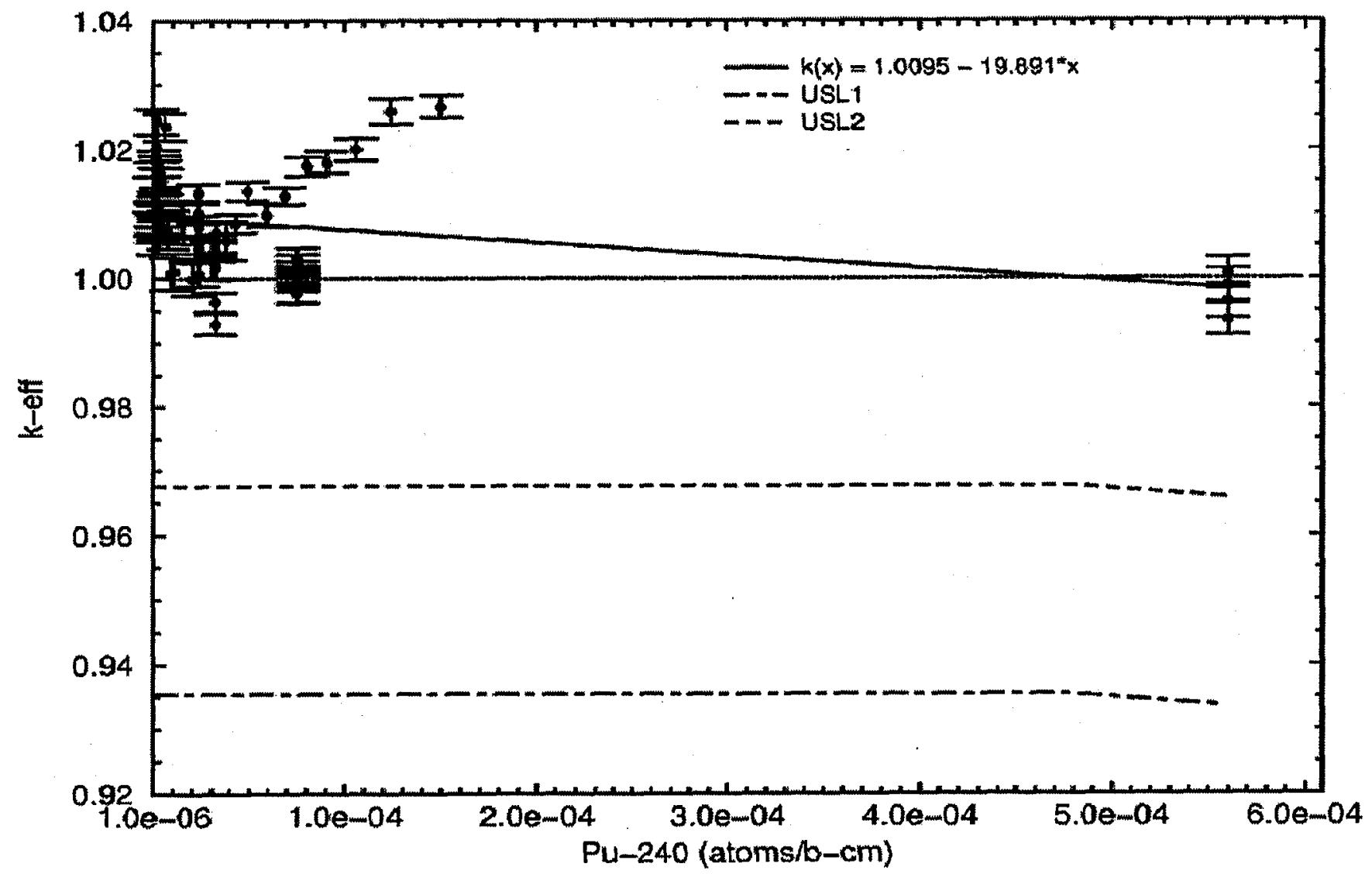

Fig. 5.11. Calculated USLs as a function of ${ }^{240} \mathrm{Pu}$ atom density for $\mathrm{H}_{2} \mathrm{O}$-reflected experiments. 


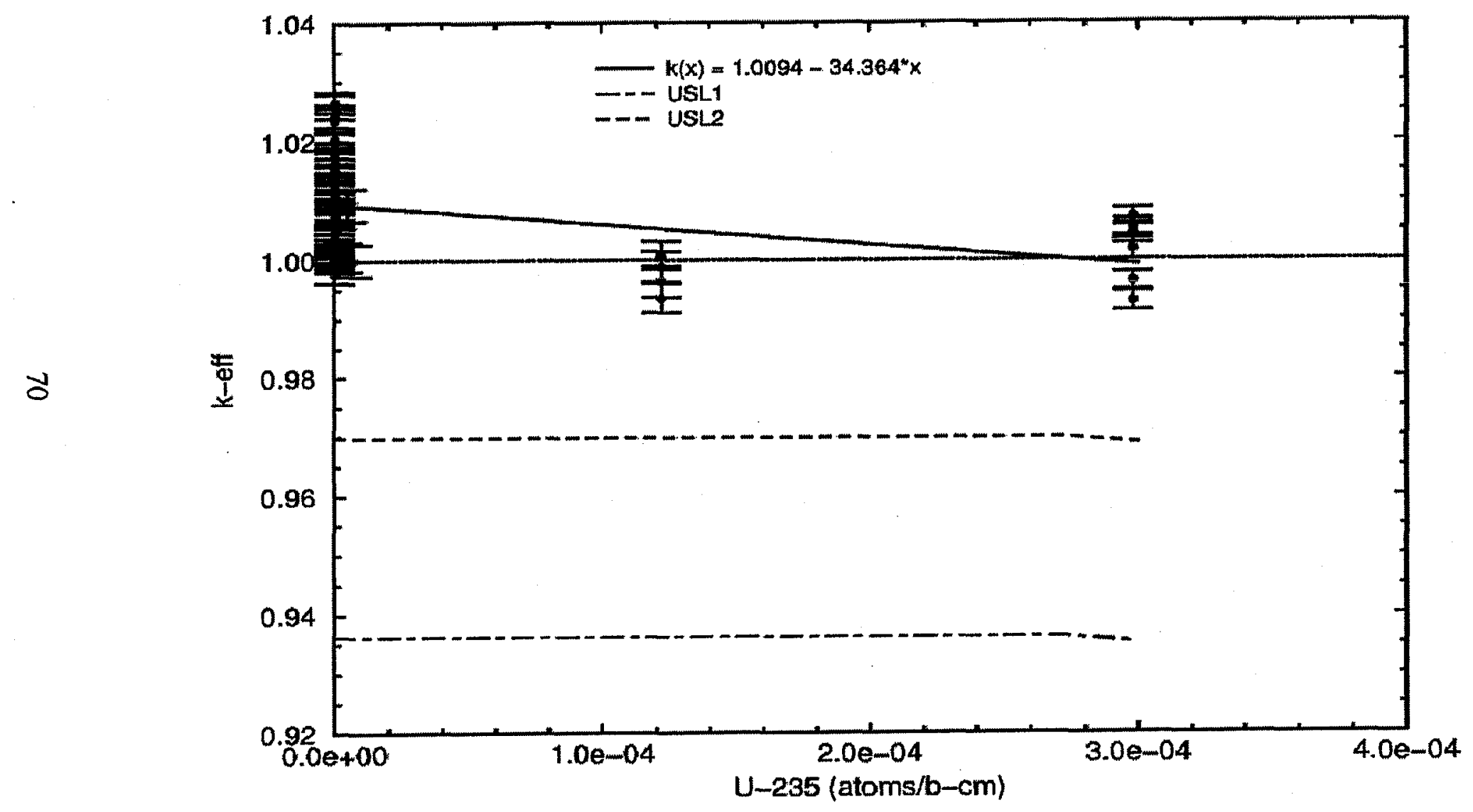

Fig. 5.12. Calculated USLs as a function of ${ }^{235} \mathrm{U}$ atom density for $\mathrm{H}_{2} \mathrm{O}$-reflected experiments. 


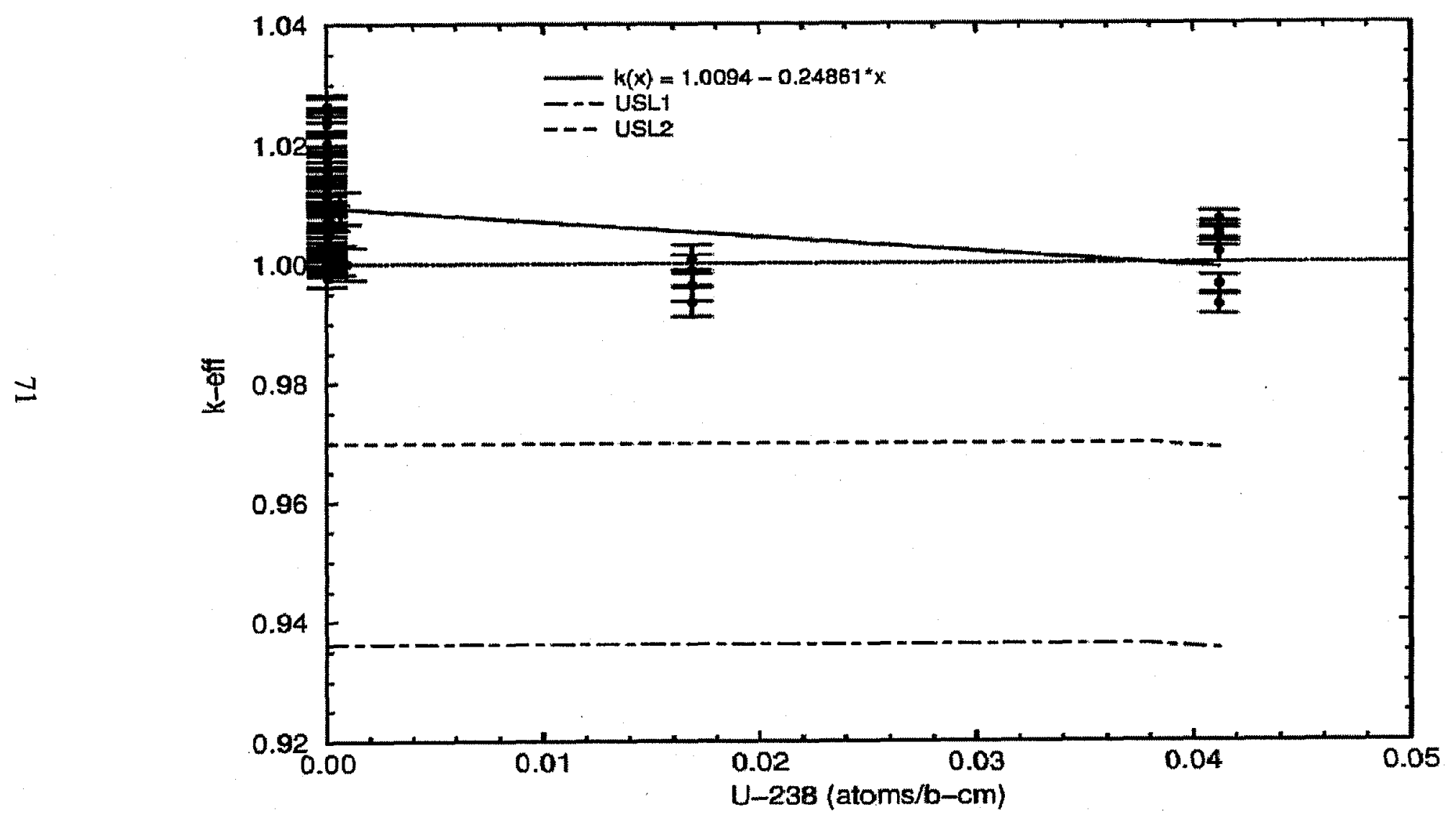

Fig. 5.13. Calculated USLs as a function of ${ }^{238} \mathrm{U}$ atom density for $\mathrm{H}_{2} \mathrm{O}$-reflected experiments. 


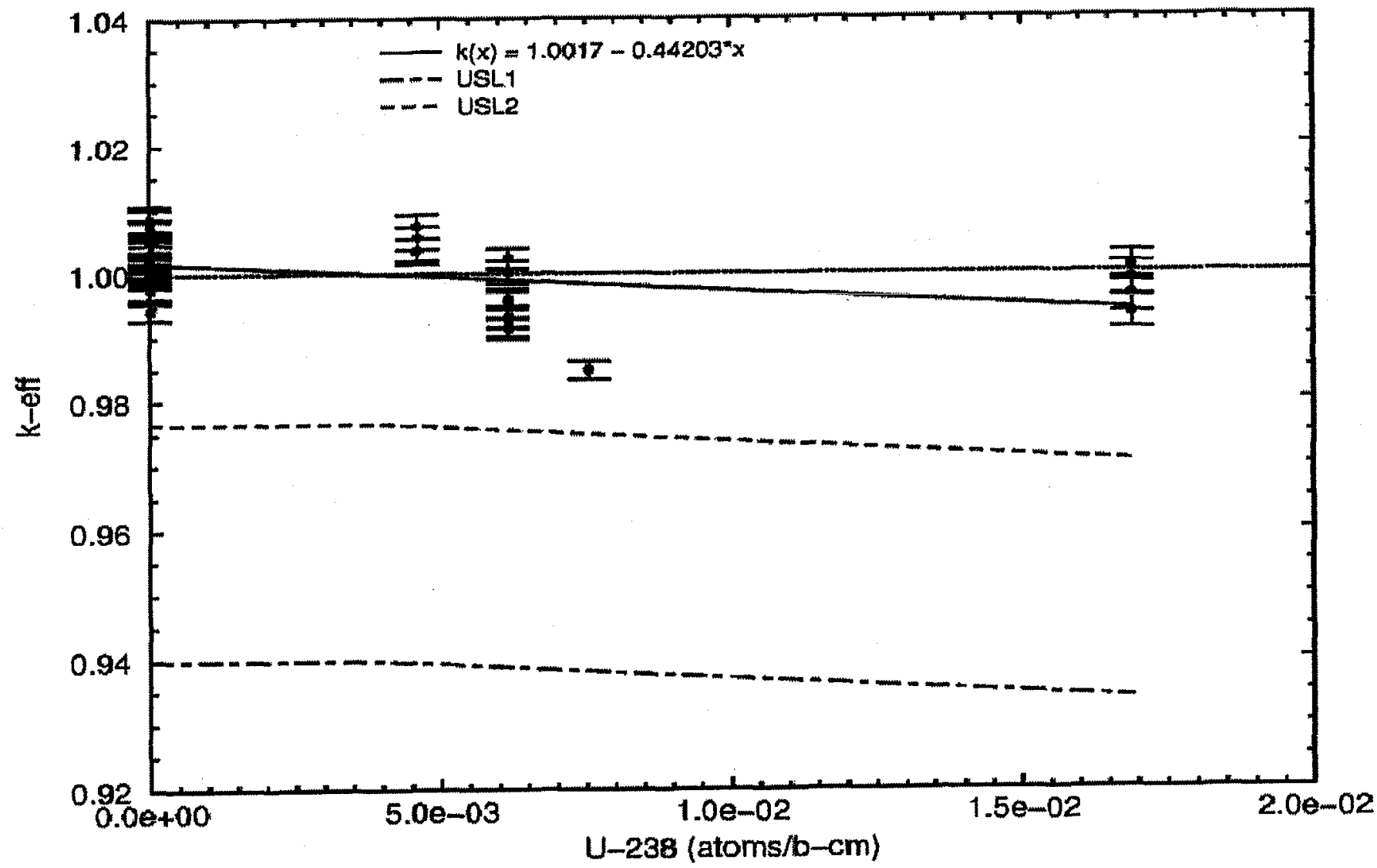

Fig. 5.14. Calculated USLs as a function of ${ }^{238} \mathrm{U}$ for 36 experiments with $\mathrm{H}^{239} \mathrm{Pu}$ ratios between 0.0 and 126.42 . 


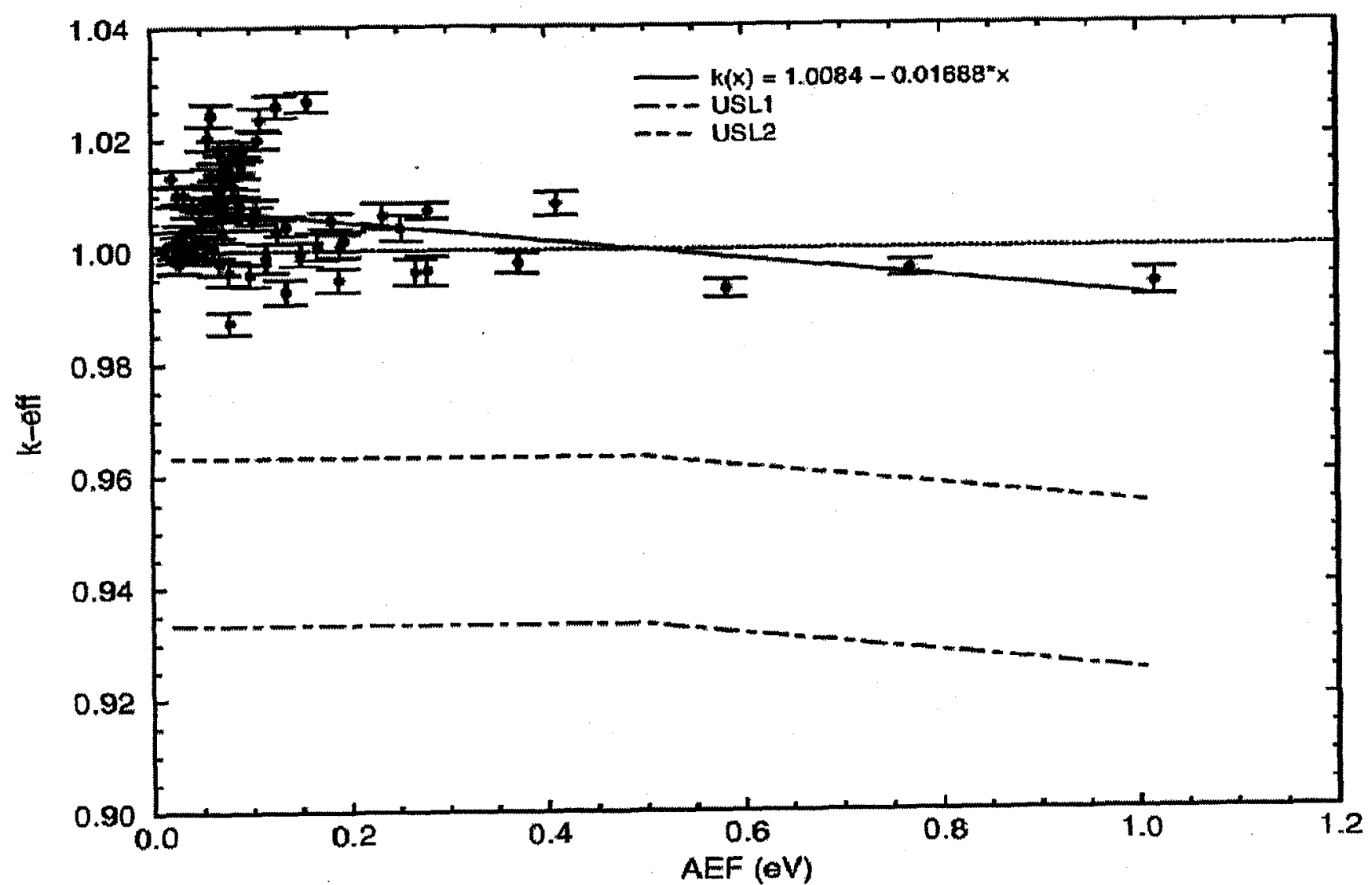

Fig. 5.15. Calculated USLs as a function of $\mathrm{AEF}$ for $\mathrm{H}_{2} \mathrm{O}$-moderated experiments. 


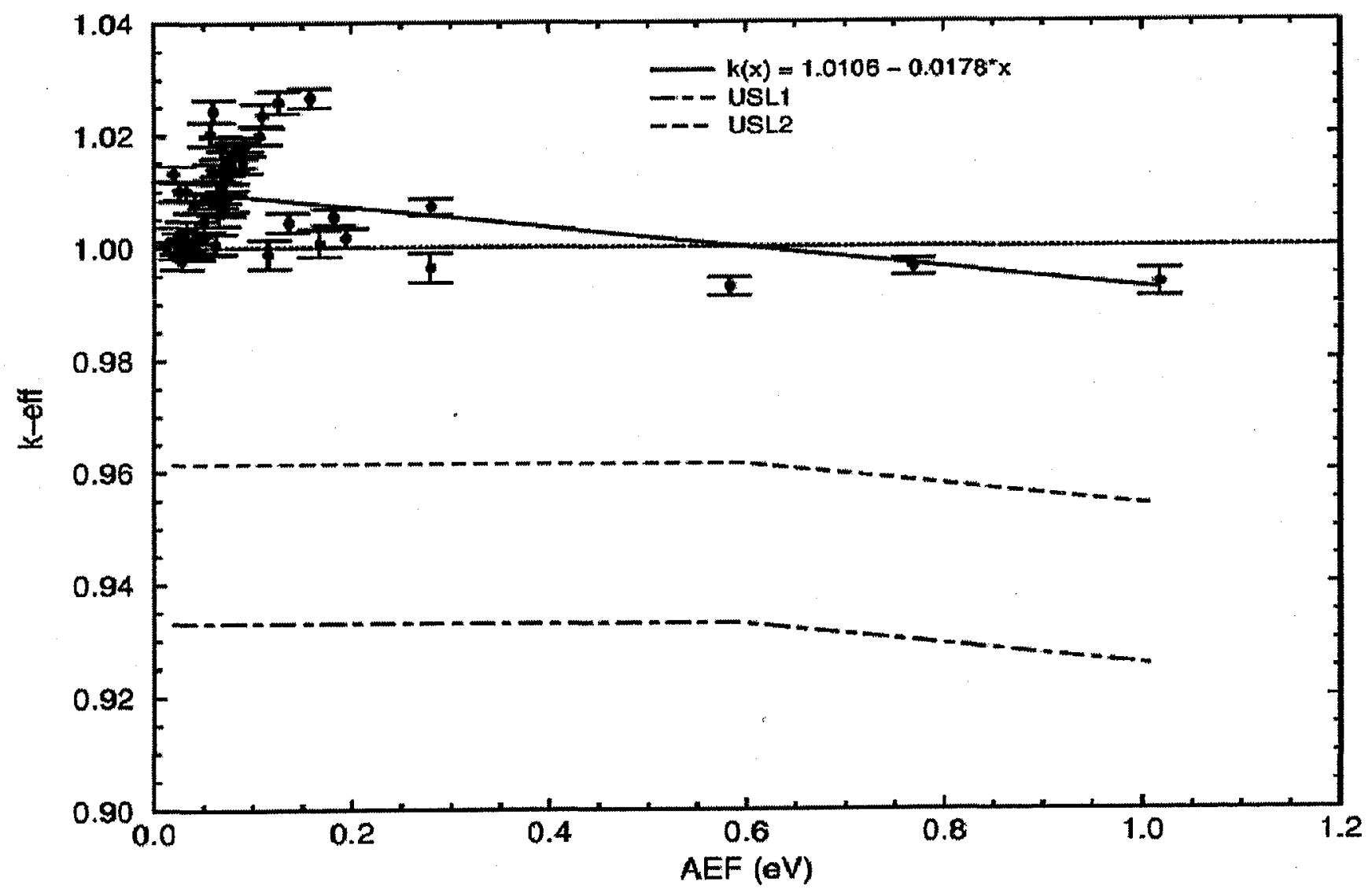

Fig. 5.16. Calculated USLs as a function of AEF for $\mathrm{H}_{2} \mathrm{O}$-reflected experiments. 


\subsection{ESTABLISHMENT OF RANGE OF APPLICABILITY}

Sect. 5.1 provides an overview of the selected experiments for the validation study and correlates the MO-1 package characteristics with the validated experimental parameters. In particular, Sect. 5.1 establishes the correlation between the experiments and the MO-1 package with regard to the materials and geometry of construction, as well as the neutron energy spectrum, which is defined in large part by the fissile material, degree of moderation, package geometry, reflector conditions and absorber material. Using the selected experimental database, a correlation study is presented in Sect. 5.2 and is used to determine the most suitable parameter for establishing the calculational acceptance criteria. As noted in Sect. 5.2, the acceptance criteria are established based on the degree of hydrogen moderation. However, an additional margin of subcriticality is also included in the acceptance criteria to account for negative biases associated with the water-reflected and water-moderated experimental subsets. The resulting USL is 0.9245 . A calculated $k_{\text {eff }}$ plus $2 \sigma$, which is less than the USL (i.e., $k_{\text {eff }}+2 \sigma<0.9245$ ), is considered acceptably subcritical.

Prior to using the acceptance criteria, the area or range of applicability for the acceptance criteria must be defined. For this evaluation, the range of applicability for applying the USL is largely defined by the degree of hydrogen moderation (i.e., $\mathrm{H}^{239} \mathrm{Pu}$ and $\mathrm{H}$ atom density) for the modeled critical experiments. The hydrogen-moderation parameters considered in this evaluation are presented in Table 5.12 for each of the different fuel loading configurations.

As noted in Sect. 5.1, the range of $\mathrm{H}^{239} \mathrm{Pu}$ ratios extends between 0.0 and 2437. Although the experimental range of moderation ratios brackets the range considered in the evaluation, the endpoints of the experimental range alone cannot demonstrate direct applicability to the transportation package evaluation without further discussion. The moderation ratios presented in Table 5.12 are concentrated below 130. In comparison with the selected experimental database, there are 36 experiments with $\mathrm{H}^{239} \mathrm{Pu}$ ratios between 0.0 and 126.42. The experimental $\mathrm{H}^{239} \mathrm{Pu}$ ratios include $0.0,5.86,10.97,11.2,13.2,14.07,14.7,22.67$, $73.86,91.25,105.44,108.32,125.15$ and 126.42. Based on the concentrated range of moderation ratios in the low-moderation range, the selected set of critical experiments corresponds to the range of $\mathrm{H}^{239} \mathrm{Pu}$ ratios considered in the MO-1 evaluation. In addition, the range of hydrogen atom densities in the experiments extends between 0.0 and 0.067 atoms/b-cm and is presented graphically in Figs. 5.2 and 5.9 of Sect. 5.2. As with the moderation ratios, the range of hydrogen atom densities in the complete set of experiments corresponds to the flooding scenarios of the MO-1 evaluation. Therefore, the selected set of critical experiments can be used to establish the range of applicability for the calculational acceptance criteria for subcritical systems. As noted in Sect. 5.2, the range of $\mathrm{H}^{239} \mathrm{Pu}$ values for the set of 102 experiments extends between 0.0 and 2437. Based on the values presented in Table 5.12, the range of $\mathrm{H}^{239} \mathrm{Pu}$ values for the MO-1 evaluation are concentrated over a small portion of the entire set of 102 criticals. However, the evaluation in Sect. 5.2 demonstrates that the more consetvative USL is obtained by considering the entire set of experiments as opposed to the 36-experiment subset with $\mathrm{H}^{239} \mathrm{Pu}$ values between 0.0 and 126.42 . The range of applicability for the USL includes the hydrogen-moderation parameters that are presented in Table 5.12. 
Table 5.12. Hydrogen moderation parameters for different MOX loadings in MO-1

\begin{tabular}{lccccc}
\hline \multirow{2}{*}{$\begin{array}{c}\mathrm{H}_{2} \mathrm{O} \\
\text { volume } \\
\text { fraction }\end{array}$} & $\begin{array}{c}\mathrm{H} \\
\text { (atoms/b-cm) }\end{array}$ & $6 \mathrm{wt} \% \mathrm{PuO}_{2}$ & $4.4 \mathrm{wt} \% \mathrm{PuO}_{2}$ & $3.303 \mathrm{wt} \% \mathrm{PuO}_{2}$ & $\mathrm{WG} \mathrm{MOX}^{2}$ \\
\cline { 3 - 6 } 0.0 & 0.0 & 0.0 & 0.0 & 0.0 & 0.0 \\
0.001 & $6.68 \times 10^{-5}$ & $7.93 \times 10^{-2}$ & $7.96 \times 10^{-2}$ & 0.111 & $5.75 \times 10^{-2}$ \\
0.003 & $2.00 \times 10^{-4}$ & 0.238 & 0.239 & 0.332 & 0.172 \\
0.01 & $6.68 \times 10^{-4}$ & 0.793 & 0.796 & 1.106 & 0.575 \\
0.05 & $3.34 \times 10^{-3}$ & 3.966 & 3.98 & 5.527 & 2.873 \\
0.1 & $6.68 \times 10^{-3}$ & 7.934 & 7.960 & 11.06 & 5.75 \\
0.4 & $2.67 \times 10^{-2}$ & 31.73 & 31.84 & 44.22 & 22.98 \\
0.6 & $4.01 \times 10^{-2}$ & 47.60 & 47.76 & 66.33 & 34.48 \\
0.8 & $5.34 \times 10^{-2}$ & 63.47 & 63.68 & 88.44 & 45.97 \\
0.9 & $6.01 \times 10^{-2}$ & 71.40 & 71.64 & 99.49 & 51.72 \\
0.95 & $6.34 \times 10^{-2}$ & 75.37 & 75.62 & 105.02 & 54.59 \\
1.0 & $6.68 \times 10^{-2}$ & 79.34 & 79.60 & 110.55 & 57.46 \\
\hline
\end{tabular}




\section{CRITICALITY CALCULATIONS AND RESULTS FOR SHIPMENT OF ASSEMBLIES}

This evaluation assesses the reactivity of a single package (Sect. 3.3) and an array of packages (Sect. 3.4) during normal conditions of transport and hypothetical accident conditions. Due to the different MOX fuel loadings, a separate discussion of the single package and array of packages evaluation is provided for the previously approved MOX fuel and proposed WG MOX fuel. The transport index for criticality control of a damaged and undamaged shipment is provided in Sect. 6.3.

\subsection{SINGLE PACKAGE}

To meet the requirements of $10 \mathrm{CFR} \S 71.55$, the evaluation must demonstrate that the single package remains subcritical under normal conditions of transport as well as hypothetical accident conditions. Regarding normal conditions of transport, the single package must be evaluated under the most reactive configuration of the material, optimum moderation and full reflection $(12 \mathrm{in}$. or $30 \mathrm{~cm})$ of the containment system by water or packaging materials on all sides. Several calculations are presented to assess the most reactive single-package configuration during normal conditions of transport. In particular, the evaluation considers internal package flooding, variations in external package reflection as well as temperature variations. Using the most reactive normal single-package configuration, the single package is evaluated under hypothetical accident conditions. The accident conditions include the loss of polyurethane foam, replacement of foam with water, fire conditions, impact induced external wall reduction, payload shift and loss of assembly spacing.

\subsubsection{Previously Certified MOX Fuel}

\subsubsection{Undamaged Package Configurations}

The original certified MOX contents include three possible fuel loadings (i.e., 6, 4.4 and $3.03 \mathrm{wt} \%$ $\mathrm{PuO}_{2}$ ). The package contents in the subsequent calculations include two fuel assemblies positioned on the strongback support structure. The MO-1 is not an air- or water-tight package. Consequently, the inleakage of water is not an incredible scenario during normal conditions of transport. Figure 6.1 presents the infinite multiplication factor as a function of pitch for each MOX loading. Based on the results in Fig. 6.1, full-density water is optimum for each loading because the fuel is undermoderated at a pitch of 0.556 in. $(1.412 \mathrm{~cm}$ ). To further assess internal moderation conditions, results for the single-package model (see Figs. 3.2 and 3.4) with $6 \mathrm{wt} \% \mathrm{PuO}_{2}$ are presented in Table 6.1 for progressive states of water flooding. The results in Table 6.1 also consider the effects of full-water-reflection conditions. As shown in Table 6.1, the expected optimum moderation for the package does occur at full-water density, and the corresponding calculated $k_{e f f}$ is $0.8261 \pm 0.0016$, which is less than the USL (i.e., $k_{e f f}+2 \sigma=0.8293<0.9245$ ). 


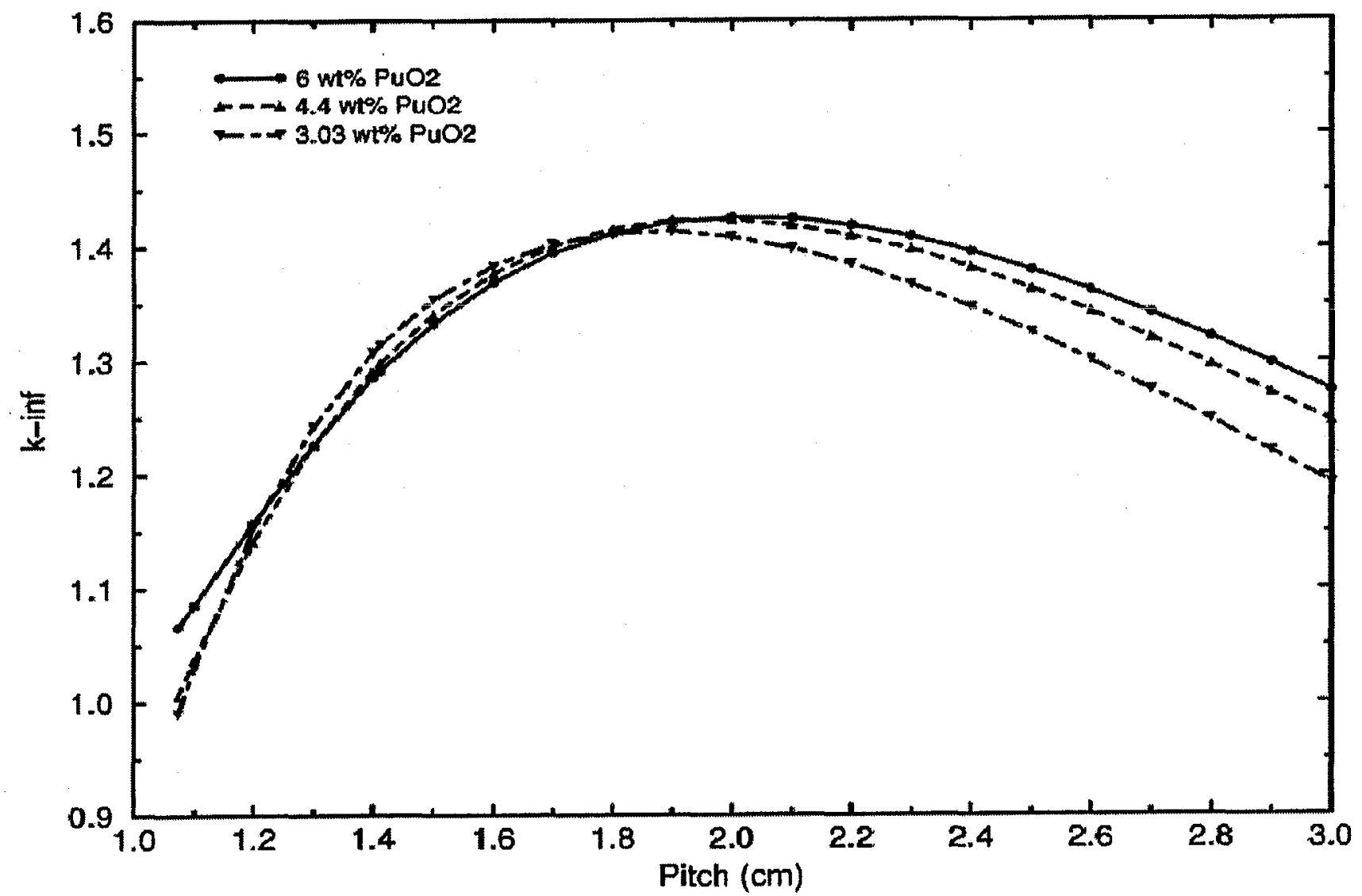

Fig. 6.1. $k_{\infty}$ as a function of pitch for previously certified MOX fuel. 
Table 6.1. Calculated $k_{\text {eff }}$ values for the $\mathrm{MO}-1$ with $6 \mathrm{wt} \% \mathrm{PuO}_{2}$ under different moderation conditions

\begin{tabular}{ccccc}
\hline Case & $\mathrm{H}_{2} \mathrm{O}$ reflection & $\mathrm{H}_{2} \mathrm{O}$ volume fraction & $k_{\text {eff }} \pm \sigma$ & $k_{\text {eff }}+2 \sigma$ \\
\hline $6 \mathrm{~m}-1$ & No & 0.0 & $0.1333 \pm 0.0004$ & 0.1341 \\
$6 \mathrm{~m}-2$ & Yes & 0.0 & $0.2558 \pm 0.0009$ & 0.2576 \\
$6 \mathrm{~m}-3$ & Yes & 0.001 & $0.2556 \pm 0.0010$ & 0.2576 \\
$6 \mathrm{~m}-4$ & Yes & 0.003 & $0.2545 \pm 0.0009$ & 0.2563 \\
$6 \mathrm{~m}-5$ & Yes & 0.05 & $0.2729 \pm 0.0009$ & 0.2747 \\
$6 \mathrm{~m}-6$ & Yes & 0.1 & $0.3326 \pm 0.0011$ & 0.3348 \\
$6 \mathrm{~m}-7$ & Yes & 0.4 & $0.5715 \pm 0.0014$ & 0.5743 \\
$6 \mathrm{~m}-8$ & Yes & 0.6 & $0.6696 \pm 0.0016$ & 0.6728 \\
$6 \mathrm{~m}-9$ & Yes & 0.8 & $0.7528 \pm 0.0017$ & 0.7562 \\
$6 \mathrm{~m}-10$ & Yes & 1.0 & $0.8261 \pm 0.0016$ & 0.8293 \\
$6 \mathrm{~m}-11$ & No & 1.0 & $0.8286 \pm 0.0015$ & 0.8316 \\
\hline
\end{tabular}

As noted in Sect. 3.1.3, the MO-1 calculational model neglects the angled corners of the internal cavity, and the internal region is modeled as a rectangular cavity. To assess the impact of neglecting the angled corners, Case $6 \mathrm{~m}-10$ was recalculated with blocks of polyurethane foam present in the corners of the internal cavity (see Fig. 3.6). The calculated $k_{\text {eff }}$ for the MO-1 with the revised internal cavity is denoted as Case $6 \mathrm{mpf}-10$ and is presented in Table 6.2. Based on the results in Table 6.2, the system multiplication for Case $6 \mathrm{mpf}-10$ is statistically the same as Case $6 \mathrm{~m}-10$. Consequently, omitting the angled corners of the internal cavity has a negligible impact on system reactivity.

In accordance with NUREG/CR-5661, ${ }^{7}$ a model of the single containment (i.e., inner shell and fuel package), which is completely flooded and fully reflected with water, is presented in Table 6.2. The waterreflected single-containment model is within $2 \sigma$ of the optimally moderated and fully reflected MO-1 package with polyurethane foam. Results are also presented in Table 6.2 which evaluate the MO-1 package with reflection by 12 in. $(30 \mathrm{~cm})$ of carbon steel (Case $6 \mathrm{r}-1)$ and 12 in. $(30 \mathrm{~cm})$ polyurethane foam (Case 6r-2). Using the optimum moderation case from Table 6.1 (Case $6 \mathrm{~m}-10$ ), the calculated $k_{e f f}$ values for the single package under different reflection conditions are presented in Table 6.2. Based on the results in Table 6.2, the calculated $k_{\text {eff }}$ values obtained with carbon steel and polyurethane foam reflection are statistically the same as the full-water-reflection case. Consequently, full-water reflection is used in the subsequent single-package analyses.

In accordance with the thermal analysis presented in ref. 10, the maximum temperature exposure for the MO-1 package during normal conditions of transport is $232.0^{\circ} \mathrm{F}(384.3 \mathrm{~K})$. As noted in Sect. 3.3, the maximum internal pressure within the package during normal conditions of transport is $23.196 \mathrm{psia}$. In the event the pressure exceeds 21.57 psia (i.e., saturation pressure corresponding to $384.3 \mathrm{~K}$ ), full-density-water flooding is possible at $232.0^{\circ} \mathrm{F}(384.3 \mathrm{~K})$. In an effort to assess the temperature increase in terms of reactivity, the calculated $k_{\text {eff }}$ for the optimally moderated single-package case at $384.26 \mathrm{~K}$ is presented in 
Table 6.2. Calculated results for single package under normal conditions with 6 wt $\% \mathrm{PuO}_{2} \mathrm{MOX}$

\begin{tabular}{|c|c|c|c|}
\hline Case & Description & $k_{e f f} \pm \sigma$ & $k_{e f f}+2 \sigma$ \\
\hline $6 \mathrm{~m}-10$ & $\begin{array}{l}\text { Optimally moderated undamaged package with } \\
\text { 12-in. }(30-\mathrm{cm}) \mathrm{H}_{2} \mathrm{O} \text { reflection }\end{array}$ & $0.8261 \pm 0.0016$ & 0.8293 \\
\hline $6 \mathrm{mpf}-10$ & $\begin{array}{l}\text { Case } 6 \mathrm{~m}-10 \text { with revised internal region which } \\
\text { accounts for angled walls of internal cavity, } \\
\text { as shown in Fig. } 3.6\end{array}$ & $0.8253 \pm 0.0016$ & 0.8285 \\
\hline sc- 6 & $\begin{array}{l}\text { Optimally moderated single containment with } \\
12 \text {-in. }(30-\mathrm{cm}) \mathrm{H}_{2} \mathrm{O} \text { reflection }\end{array}$ & $0.8263 \pm 0.0016$ & 0.8295 \\
\hline $6 r-1$ & $\begin{array}{l}\text { Optimally moderated undamaged package with } \\
12-\mathrm{in} .(30-\mathrm{cm}) \text { carbon steel reflection }\end{array}$ & $0.8231 \pm 0.0017$ & 0.8265 \\
\hline $6 r-2$ & $\begin{array}{l}\text { Optimally moderated undamaged package with } \\
12-\text { in. }(30-\mathrm{cm}) \text { polyurethane foam reflection }\end{array}$ & $0.8235 \pm 0.0016$ & 0.8267 \\
\hline $6 \mathrm{t}-1$ & $\begin{array}{l}\text { Optimally moderated undamaged package at } \\
384.3 \mathrm{~K} \text { with } 12 \text {-in. }(30-\mathrm{cm}) \mathrm{H}_{2} \mathrm{O} \text { reflection }\end{array}$ & $0.8346 \pm 0.0019$ & 0.8384 \\
\hline
\end{tabular}

Table 6.2 and is $\sim 1 \%$ higher relative to the optimally moderated single package at room temperature. The increase in reactivity associated with the increased temperature is evaluated further in the following accident scenarios. Although the higher temperature leads to an increase in reactivity, the package is considered to be acceptably subcritical relative to the USL. These results demonstrate that the single MO-1 package with two $6 \mathrm{wt} \% \mathrm{PuO}_{2}$ assemblies is subcritical under normal conditions of transport.

Based on the results in Fig. 6.1, the $4.4 \mathrm{wt} \%$ and $3.03 \mathrm{wt} \% \mathrm{PuO}_{2} \mathrm{MOX}$ fuel are also undermoderated at a pitch of $0.556 \mathrm{in} .(1.412 \mathrm{~cm})$. Consequently, full-density-water moderation is optimum for these loadings. The optimum single-package cases $6 \mathrm{~m}-10,6 \mathrm{mpf}-10, \mathrm{sc}-6$ and $6 \mathrm{t}-1$ are evaluated with the $4.4 \mathrm{wt} \%$ and $3.03 \mathrm{wt} \% \mathrm{PuO}_{2} \mathrm{MOX}$ fuel, and the results are presented in Table 6.3. The calculated $k_{\text {eff }}$ values for each fuel loading are within $2 \sigma$ of the respective $6 \mathrm{wt} \% \mathrm{PuO}_{2} \mathrm{MOX}$ fuel case in Table 6.2. As a result, the reactivity difference for the different MOX loadings in the undamaged single package is statistically insignificant. As observed for the $6 \mathrm{wt} \% \mathrm{PuO}_{2}$ case, each water-reflected, single-containment model for the 4.4 and $3.03 \mathrm{wt} \% \mathrm{PuO}_{2}$ is statistically the same relative to the respective fully reflected MO-1 package with polyurethane foam. Therefore, the package materials do not provide better reflection than water. Following the same procedure used for the $6 \mathrm{wt} \% \mathrm{PuO}_{2} \mathrm{MOX}$ study, Cases $4 \mathrm{mpf}-10$ and $3 \mathrm{mpf}-10$ include polyurethane blocks in the corners of the internal cavity as shown in Fig. 3.6. Based on the calculated $\mathrm{k}_{\mathrm{eff}}$ values for Cases $4 \mathrm{mpf}-10$ and $3 \mathrm{mpf}-10$, omitting the angled corners of the internal MO-1 cavity has a negligible impact on system multiplication. Regarding temperature effects under normal conditions, the increase in temperature leads to $\sim 1 \%$ increase in reactivity for either MOX loading. The increase in reactivity associated with an increase in temperature is evaluated in more detail in the following accident scenario discussion. Note that the calculated results presented in Table 6.3 are less than the USL acceptance criteria for each case. Based on the results presented in Table 6.3, a single MO-1 package with two $4.4 \mathrm{wt} \% \mathrm{PuO}_{2}$ or two $3.03 \mathrm{wt} \% \mathrm{PuO}_{2} \mathrm{MOX}$ assemblies is subcritical under normal conditions of transport. 
Table 6.3. Calculated $k_{\text {eff }}$ values for the MO-1 under normal conditions with 4.4 wt $\%$ and 3.03 wt $\% \mathrm{PuO}_{2} \mathrm{MOX}$

\begin{tabular}{|c|c|c|c|}
\hline Case & Description & $k_{e f f} \pm \sigma$ & $k_{e f f}+2 \sigma$ \\
\hline $4 m-10$ & $\begin{array}{l}\text { Optimally moderated undamaged package with } \\
4.4 \mathrm{wt} \% \mathrm{PuO}_{2} \mathrm{MOX} \text { fuel and } 12-\mathrm{in} .(30-\mathrm{cm}) \mathrm{H}_{2} \mathrm{O} \\
\text { reflection }\end{array}$ & $0.8263 \pm 0.0018$ & 0.8299 \\
\hline $4 m p f-10$ & $\begin{array}{l}\text { Case } 4 \mathrm{~m}-10 \text { with revised internal region, which } \\
\text { accounts for angled walls of internal cavity, as shown } \\
\text { in Fig. } 3.6\end{array}$ & $0.8287 \pm 0.0017$ & 0.8321 \\
\hline$s c-4$ & $\begin{array}{l}\text { Optimally moderated single containment with } 4.4 \mathrm{wt} \% \\
\mathrm{PuO}_{2} \mathrm{MOX} \text { fuel and } 12-\mathrm{in} .(30-\mathrm{cm}) \mathrm{H}_{2} \mathrm{O} \text { reflection }\end{array}$ & $0.8317 \pm 0.0017$ & 0.8351 \\
\hline $3 m-10$ & $\begin{array}{l}\text { Optimally moderated undamaged package with } \\
3.03 \text { wt } \% \mathrm{PuO}_{2} \mathrm{MOX} \text { fuel and } 12 \text {-in. }(30-\mathrm{cm}) \mathrm{H}_{2} \mathrm{O} \\
\text { reflection }\end{array}$ & $0.8235 \pm 0.0017$ & 0.8269 \\
\hline $3 \mathrm{mpf}-10$ & $\begin{array}{l}\text { Case } 3 \mathrm{~m}-10 \text { with revised internal region which accounts } \\
\text { for angled walls of internal cavity, as shown in } \\
\text { Fig. } 3.6\end{array}$ & $0.8267 \pm 0.0015$ & 0.8297 \\
\hline sc-3 & $\begin{array}{l}\text { Optimally moderated single containment with } \\
3.03 \text { wt } \% \mathrm{PuO}_{2} \mathrm{MOX} \text { fuel and } 12 \text {-in. (30-cm) } \mathrm{H}_{2} \mathrm{O} \\
\text { reflection }\end{array}$ & $0.8247 \pm 0.0015$ & 0.8277 \\
\hline $4 t-1$ & $\begin{array}{l}\text { Optimally moderated undamaged package with } \\
4.4 \mathrm{wt} \% \mathrm{PuO}_{2} \mathrm{MOX} \text { fuel and } 12-\mathrm{in} .(30-\mathrm{cm}) \mathrm{H}_{2} \mathrm{O} \\
\text { reflection }(\text { Temperature }=384.3 \mathrm{~K})\end{array}$ & $0.8375 \pm 0.0016$ & 0.8407 \\
\hline $3 t-1$ & $\begin{array}{l}\text { Optimally moderated undamaged package with } \\
3.03 \text { wt } \% \mathrm{PuO}_{2} \mathrm{MOX} \text { fuel and } 12-\text { in. }(30-\mathrm{cm}) \mathrm{H}_{2} \mathrm{O} \\
\text { reflection (Temperature }=384.3 \mathrm{~K})\end{array}$ & $0.8328 \pm 0.0017$ & 0.8362 \\
\hline
\end{tabular}

\subsubsection{Damaged Package Configurations}

Additional calculations are presented which evaluate the single package under hypothetical accident conditions. As noted in Sect. 3.3, the MO-1 is designed to limit the internal pressure to 23.196 psia during normal conditions of transport; however, the assessment in ref. 10 does not quantify the maximum pressure during accident conditions. During a fire scenario, the maximum temperature within the MO- 1 could reach $483.15 \mathrm{~K}$. The saturation pressure corresponding to $483.15 \mathrm{~K}$ is 276.5 psia. As the polyurethane foam decomposes during a fire, the resulting gases could lead to a pressure buildup within in the MO-1. However, the pressure must exceed 276.5 psia before full-density-water flooding is possible at $483.15 \mathrm{~K}$. The introduction of water from an external source into a pressurized container is considered to be unlikely. The accident evaluation assumes. full-density-water flooding. By using full-density-water flooding for the package, the calculational model during a fire scenario is considered to be more reactive than the actual package under fire conditions. 
The calculated results for the single package with two $6 \mathrm{wt} \% \mathrm{PuO}_{2} \mathrm{MOX}$ assemblies under fire conditions are presented in Table 6.4. Case $6 \mathrm{f}-1$ evaluates the single package with a maximum internal temperature of $483.15 \mathrm{~K}$, and cases $6 \mathrm{f} .1 \mathrm{a}-6 \mathrm{f} .1 \mathrm{e}$ evaluate varying degrees of polyurethane foam charring during a fire scenario. For example, in Case $6 \mathrm{f} .1 \mathrm{a}$ the foam is considered to be $10 \mathrm{wt} \% \mathrm{H}_{2} \mathrm{O}$. For Cases 6f.1a through $6 \mathrm{f} .1 \mathrm{e}$, the water added to the foam mixture is assumed to be at full density. The remaining models, Cases $6 \mathrm{f}-2$ and $6 \mathrm{f}-3$, consider the single package under fire conditions with the polyurethane foam replaced by water and void, respectively.

Based on the results in Table 6.4, the elevated package temperature during a fire (Case $6 \mathrm{f}-1$ ) leads to a $1.8 \%$ increase in reactivity relative to the package at room temperature. In an effort to assess the reactivity increase associated with the increase in temperature, the calculated neutron flux as a function of energy for the $6 \mathrm{wt} \% \mathrm{PuO}_{2} \mathrm{MOX}$ fuel is presented in Fig. 6.2 for temperatures of $293 \mathrm{~K}$ and $483.15 \mathrm{~K}$. As shown in Fig. 6.2, the neutron flux for energy groups between 205 and 220 is higher for the package at $483.15 \mathrm{~K}$ relative to the fuel at room temperature. In addition to the neutron flux, the macroscopic total and fission cross sections of the MOX fuel are presented in Fig. 6.3 and 6.4 as a function of energy, respectively. ${ }^{240} \mathrm{Pu}$ has a large capture resonance at $1.058 \mathrm{eV}$, which is depicted at energy group 184 in Fig. 6.3. Based on the results in Fig. 6.3, the increase in temperature leads to a $10.3 \%$ decrease in the resonance peak at group 184; however, the overall width of the resonance does not increase significantly. Consequently, the decreased resonance peak at the higher temperature allows more neutrons to escape the ${ }^{240} \mathrm{Pu}$ capture resonance during the slowing down process. Thus, the higher neutron flux at thermal energies is directly attributed to the decrease in the ${ }^{240} \mathrm{Pu}$ resonance as temperature increases. Based on the results in Fig. 6.4, the fission cross section for the MOX fuel at both temperatures is relatively large in the thermal energy range. Since more neutrons are available for fission at thermal energies, the reactivity increase associated with the higher fuel temperature is attributed to the increased neutron flux above energy group 210. The remaining accident configurations consider the package at $483.15 \mathrm{~K}$.

With regard to foam charring, the calculated $k_{e f f}$ values presented for the varying degrees of charring are statistically the same as the package with foam material. Moreover, replacing the foam with void and water does not lead to statistically higher system multiplication. Consequently, the remaining models consider the package with complete foam material.

As noted in Sect. 3.3, the fuel payload could shift during impact. Three different shifted fuel configurations are presented in Figs. 3.7-3.9 and are considered in this section. A brief description of each configuration model and corresponding calculated $k_{e f f}$ is provided in Table 6.4. Cases $6 \mathrm{c}-1$ and $6 \mathrm{c}-2$ consider an external impact on the MO-1, resulting in the loss of the polyurethane foam and a reduced exterior carbon steel shell thickness of $0.028 \mathrm{in} .(0.071 \mathrm{~cm}$.). In both cases, the location of the strongback and fuel assemblies within the MO-1 is not altered (Fig. 3.7). The fuel assemblies in Case 6c-1 remain unshifted during impact (i.e., fuel separation maintained during impact). In Case $6 c-2$, the model is the same as Case 6c-1, except the spacing between the two fuel assemblies is removed. As long as the assembly spacing is maintained (Case $6 \mathrm{c}-1$ ), crushing the exterior walls and removing the polyurethane foam does not significantly increase the reactivity relative to the uncrushed package exposed to fire temperatures (i.e., Case $6 \mathrm{f}-1$ ). However, the loss of assembly spacing during a fire leads to a $\sim 5.7 \%$ increase in reactivity relative to the package with spaced assemblies in Case $6 \mathrm{c}-1$. Despite the increase in reactivity, the calculated $k_{e f f}+2 \sigma$ is 0.8945 , which is less than the calculational USL

The following cases evaluate the single package under impact conditions that result in movement of the entire fuel package within the MO-1. As noted in Sect. 3.3, the shockmount system is designed to absorb the internal forces generated during impact conditions and provide flexibility for the supporting frame. Consequently, the entire fuel package could move during impact conditions. Cases 6a-1 and 6a-2 evaluate the vertical displacement of the fuel package to the bottom of the MO-1, as shown in Fig. 3.8. 
Table 6.4. Calculated results for the damaged single package $6 \mathrm{wt} \% \mathrm{PuO}_{2} \mathrm{MOX}$

\begin{tabular}{|c|c|c|c|}
\hline Case & Description & $k_{e f f} \pm \sigma$ & $k_{e f f}+2 \sigma$ \\
\hline $6 f-1$ & $\begin{array}{l}\text { Optimally moderated package with } 12-\text { in. }(30-\mathrm{cm}) \\
\mathrm{H}_{2} \mathrm{O} \text { reflection during fire conditions. Temp }= \\
483.15 \mathrm{~K}\end{array}$ & $0.8425 \pm 0.0016$ & 0.8457 \\
\hline $6 f-1 a$ & Case $6 \mathrm{f}-1$ with foam content $10 \% \mathrm{H}_{2} \mathrm{O}$ & $0.8437 \pm 0.0015$ & 0.8467 \\
\hline $6 f-1 b$ & Case $6 \mathrm{f}-1$ with foam content $30 \% \mathrm{H}_{2} \mathrm{O}$ & $0.8428 \pm 0.0016$ & 0.8460 \\
\hline $6 \mathrm{f}-1 \mathrm{c}$ & Case $6 \mathrm{f}-1$ with foam content $50 \% \mathrm{H}_{2} \mathrm{O}$ & $0.8425 \pm 0.0016$ & 0.8457 \\
\hline $6 f-1 d$ & Case $6 \mathrm{f}-1$ with foam content $70 \% \mathrm{H}_{2} \mathrm{O}$ & $0.8405 \pm 0.0016$ & 0.8437 \\
\hline $6 \mathrm{f}-1 \mathrm{e}$ & Case $6 \mathrm{f}-1$ with foam content $90 \% \mathrm{H}_{2} \mathrm{O}$ & $0.8445 \pm 0.0015$ & 0.8475 \\
\hline $6 f-2$ & Case $6 \mathrm{f}-1$ with foam content $100 \% \mathrm{H}_{2} \mathrm{O}$ & $0.8375 \pm 0.0017$ & 0.8409 \\
\hline $6 f-3$ & Case $6 \mathrm{f}-1$ with foam replaced by void & $0.8424 \pm 0.0015$ & 0.8454 \\
\hline $6 c-1$ & $\begin{array}{l}\text { Optimally moderated package with } 12-\mathrm{in} .(30-\mathrm{cm}) \\
\mathrm{H}_{2} \mathrm{O} \text { reflection. Fuel positioned in } \mathrm{MO}-1 \text {, as shown } \\
\text { in Fig. } 3.7 . \text { Package has carbon steel wall thickness } \\
=0.028 \text { in. }(0.071 \mathrm{~cm}) \text { with no polyurethane foam. } \\
\text { Spacing between fuel assemblies is maintained. } \\
\text { Temp }=483.15 \mathrm{~K}\end{array}$ & $0.8438 \pm 0.0016$ & 0.8470 \\
\hline $6 c-2$ & $\begin{array}{l}\text { Optimally moderated package with } 12-\text { in. }(30-\mathrm{cm}) \\
\mathrm{H}_{2} \mathrm{O} \text { reflection. Fuel positioned in } \mathrm{MO}-1 \text {, as shown } \\
\text { in Fig. } 3.7 . \text { Package has carbon steel wall thickness } \\
=0.028 \text { in. }(0.071 \mathrm{~cm}) \text { with no polyurethane foam. } \\
\text { Spacing between fuel assemblies is removed. Temp } \\
=483.15 \mathrm{~K}\end{array}$ & $0.8915 \pm 0.0015$ & 0.8945 \\
\hline $6 a-1$ & $\begin{array}{l}\text { Optimally moderated package with } 12-\text { in. }(30-\mathrm{cm}) \\
\mathrm{H}_{2} \mathrm{O} \text { reflection. Fuel positioned in } \mathrm{MO}-1 \text {, as shown } \\
\text { in Fig. 3.8. Spacing between fuel assemblies is } \\
\text { maintained. Temp }=483.15 \mathrm{~K}\end{array}$ & $0.8235 \pm 0.0019$ & 0.8273 \\
\hline $6 a-2$ & $\begin{array}{l}\text { Optimally moderated package with } 12 \text {-in. }(30-\mathrm{cm}) \\
\mathrm{H}_{2} \mathrm{O} \text { reflection. Fuel positioned in } \mathrm{MO}-1 \text {, as shown } \\
\text { in Fig. 3.8. Spacing between fuel assemblies is } \\
\text { removed. Temp }=483.15 \mathrm{~K}\end{array}$ & $0.8775 \pm 0.0018$ & 0.8811 \\
\hline $6 b-1$ & $\begin{array}{l}\text { Optimally moderated package with } 12-\mathrm{in} .(30-\mathrm{cm}) \\
\mathrm{H}_{2} \mathrm{O} \text { reflection. Fuel positioned in } \mathrm{MO}-1 \text {, as shown } \\
\text { in Fig. 3.9. Spacing between fuel assemblies is } \\
\text { maintained. Temp }=483.15 \mathrm{~K}\end{array}$ & $0.8149 \pm 0.0018$ & 0.8185 \\
\hline
\end{tabular}


Table 6.4 (continued)

\begin{tabular}{|c|c|c|c|}
\hline Case & Description & $k_{e f f} \pm \sigma$ & $k_{e f f}+2 \sigma$ \\
\hline $6 \mathrm{~b}-2$ & $\begin{array}{l}\text { Optimally moderated package with } 12 \text {-in. }(30-\mathrm{cm}) \\
\mathrm{H}_{2} \mathrm{O} \text { reflection. Fuel positioned in } \mathrm{MO}-1 \text {, as shown } \\
\text { in Fig. 3.9. Spacing between fuel assemblies is } \\
\text { removed. Temp }=483.15 \mathrm{~K}\end{array}$ & $0.8618 \pm 0.0017$ & 0.8652 \\
\hline $6 a-3$ & $\begin{array}{l}\text { Case } 6 \mathrm{a}-2 \text { with carbon steel wall thickness }= \\
0.028 \mathrm{in} .(0.071 \mathrm{~cm}) \text { and no polyurethane foam. } \\
\text { Spacing between fuel assemblies is removed. } \\
\text { Temp }=483.15 \mathrm{~K}\end{array}$ & $0.8903 \pm 0.0015$ & 0.8933 \\
\hline
\end{tabular}




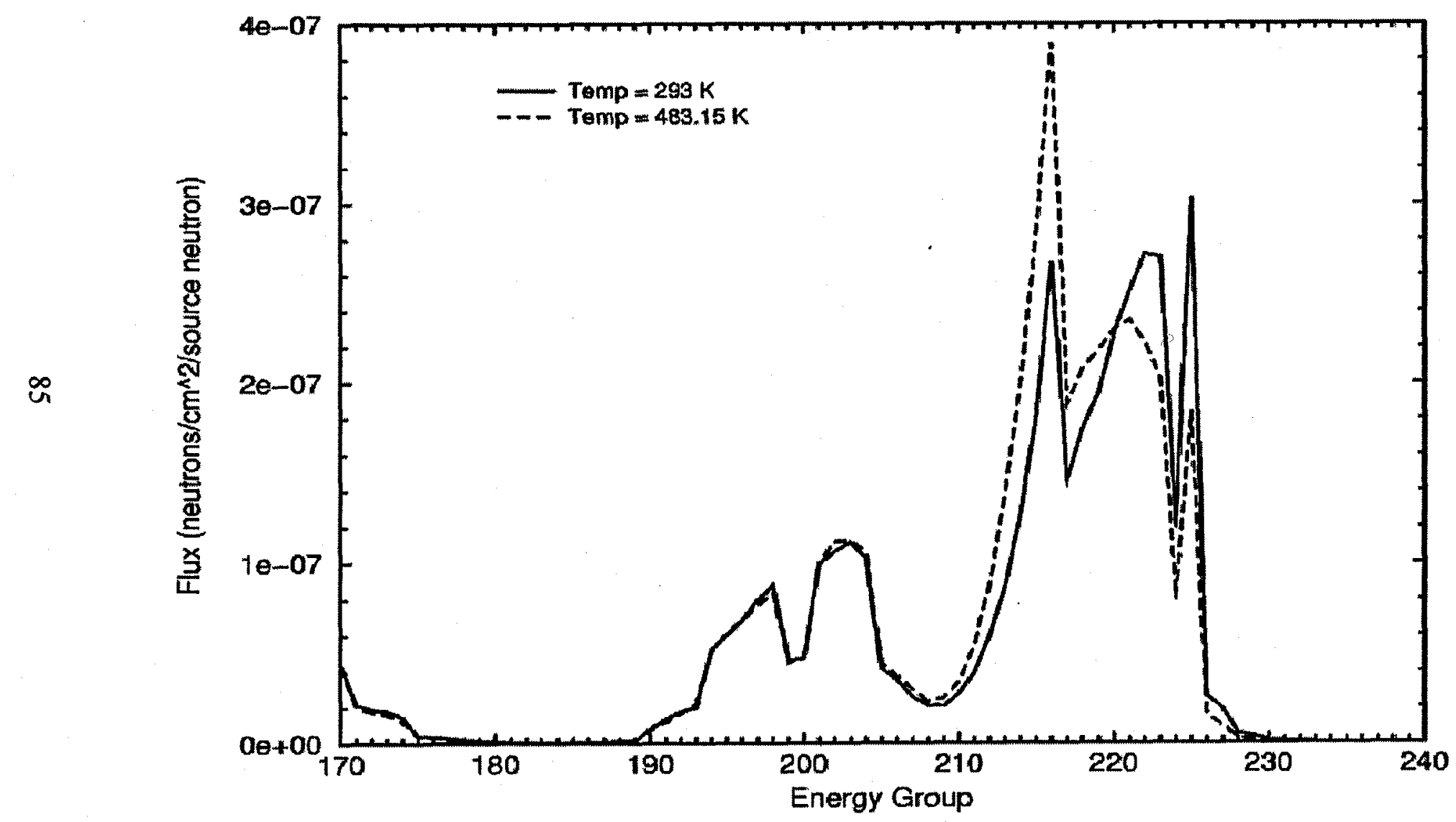

Fig. 6.2. Calculated neutron flux in $6 \mathrm{wt} \% \mathrm{PuO}_{2} \mathrm{MOX}$ fuel at $293 \mathrm{~K}$ and $483.15 \mathrm{~K}$. 


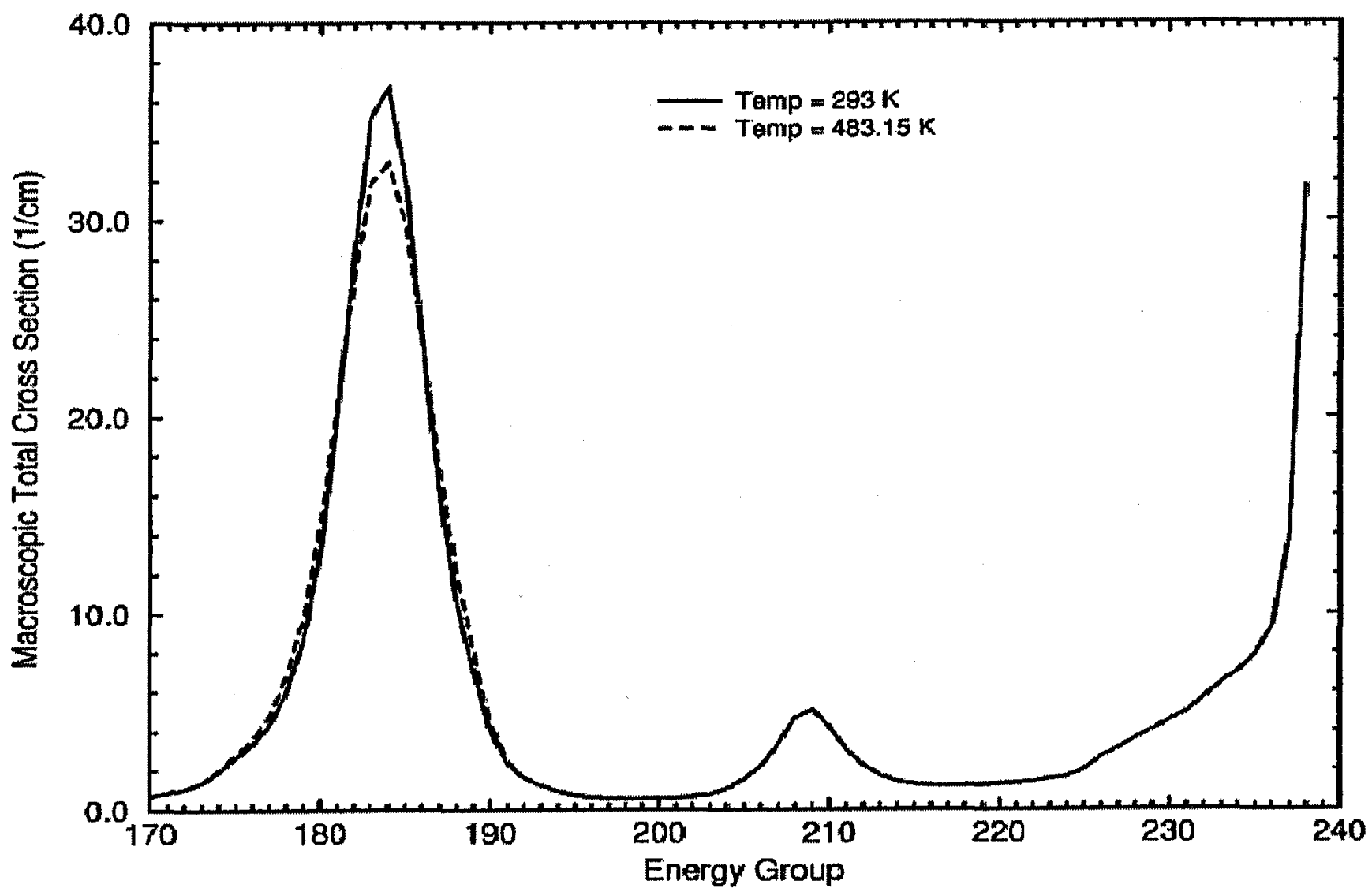

Fig. 6.3. Macroscopic total cross section of $6 \mathrm{wt} \% \mathrm{PuO}_{2} \mathrm{MOX}$ fuel at $293 \mathrm{~K}$ and $483.15 \mathrm{~K}$. 


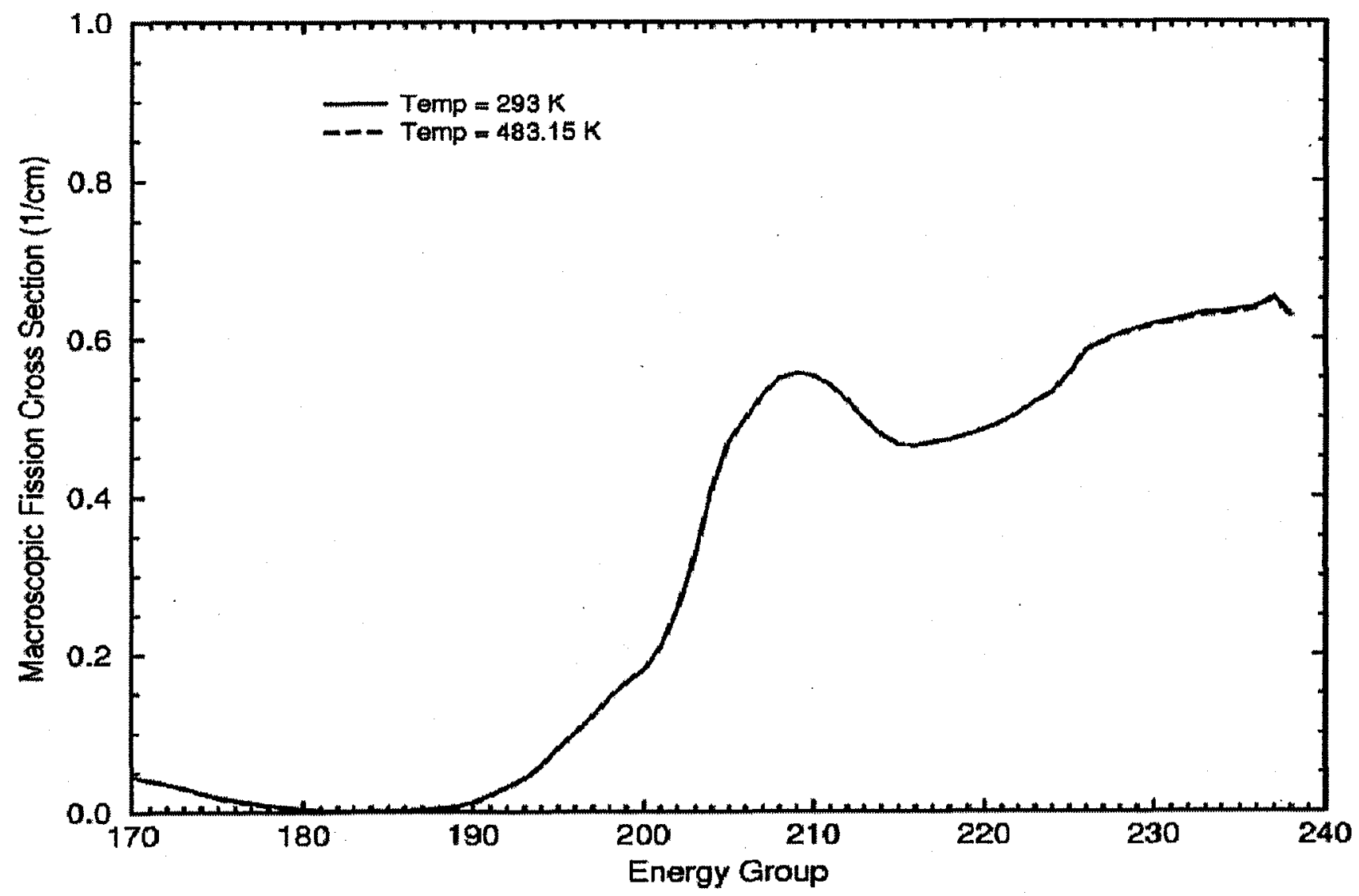

Fig. 6.4. Macroscopic fission cross section for $6 \mathrm{wt} \% \mathrm{PuO}_{2} \mathrm{MOX}$ fuel at $293 \mathrm{~K}$ and $483.15 \mathrm{~K}$. 
During a flat-side impact on the bottom surface of the MO-1, the internal forces within the package would initially lead to an upward movement of the strongback support and fuel assemblies. As the motion of the fuel package peaks in the upward direction, gravitational forces would pull the strongback and fuel package toward the bottom of the MO-1, as depicted in Fig. 3.8. The fuel package would either return to the original location within the MO-1 as the internal forces are absorbed by the shockmount system or come to rest on the inner-shell wall if the shockmount system fails during impact. With the fuel package positioned on the bottom inner shell of the MO-1, the fuel assembly separation is maintained in Case 6a-1 while the assemblies are pushed together in Case 6a-2. During a corner- or edge-impact condition, the fuel package could shift toward the corner of the MO-1, as shown in Fig. 3.9. Cases $6 \mathrm{~b}-1$ and $6 \mathrm{~b}-2$ evaluate the repositioning of the fuel package to the interior corner of the MO-1. Although the fuel positioning is the same in both cases, the difference between the two models is the fuel assembly spacing. In particular, the separation between the two assemblies is maintained in Case $6 \mathrm{~b}-1$, and the assemblies are pushed together in $6 \mathrm{~b}-2$. Based on the results in Table 6.4, movement of the fuel package toward the bottom internal shell results in a slightly more reactive configuration relative to repositioning the package in the interior corner of the MO-1. Note that the exterior containment is present in Cases $6 \mathrm{a}-1,6 \mathrm{a}-2,6 \mathrm{~b}-1$ and $6 \mathrm{~b}-2$. To assess the deformation of the exterior containment, Case $6 \mathrm{a}-2$, which is the most reactive of the four cases, is modeled in Case 6a-3 with a crushed exterior containment having a carbon steel wall thickness of 0.028 in. $(0.071$ $\mathrm{cm}$.). As in the previous cases, the single package is fully reflected with water. Based on the calculated multiplication factors in Table 6.4, the single package with $6 \mathrm{wt} \% \mathrm{PuO}_{2} \mathrm{MOX}$ fuel under impact conditions is acceptably subcritical. The calculated results presented in Table 6.5 are provided for a damaged MO- 1 with different MOX fuel loadings. In particular, the most reactive single-package accident case, Case $6 \mathrm{c}-2$, is presented in Table 6.4 with $4.4 \mathrm{wt} \%$ and $3.03 \mathrm{wt} \% \mathrm{PuO}_{2} \mathrm{MOX}$ fuel assemblies (i.e., Cases $4 \mathrm{c}-2$ and $3 \mathrm{c}-2$, respectively). The calculated multiplication factor for the damaged configurations in Table 6.4 are also acceptably subcritical relative to the calculational acceptance criteria.

Table 6.5. Calculated $k_{e f f}$ values for a damaged MO-1 with $4.4 \mathrm{wt} \%$ and $3.03 \mathrm{wt} \% \mathrm{PuO}_{2} \mathrm{MOX}$

\begin{tabular}{|c|c|c|c|}
\hline Case & Description & $k_{e f f} \pm \sigma$ & $k_{e f f}+2 \sigma$ \\
\hline $4 c-2$ & $\begin{array}{l}\text { Optimally moderated package with } 12 \text {-in. }(30-\mathrm{cm}) \\
\mathrm{H}_{2} \mathrm{O} \text { reflection. } 4.4 \mathrm{wt} \% \mathrm{PuO}_{2} \mathrm{MOX} \text { fuel } \\
\text { positioned in MO- } 1 \text {, as shown in Fig. } 3.7 . \text { Package } \\
\text { has carbon steel wall thickness }=0.028 \mathrm{in} \text {. } \\
(0.071 \mathrm{~cm}) \text { with no polyurethane foam. Spacing } \\
\text { between fuel assemblies is removed. Temp }= \\
483.15 \mathrm{~K}\end{array}$ & $0.8899 \pm 0.0016$ & 0.8931 \\
\hline $3 c-2$ & $\begin{array}{l}\text { Optimally moderated package with } 12 \text {-in. }(30-\mathrm{cm}) \\
\mathrm{H}_{2} \mathrm{O} \text { reflection. } 3.03 \mathrm{wt} \% \mathrm{PuO}_{2} \mathrm{MOX} \text { fuel } \\
\text { positioned in } \mathrm{MO}-1 \text {, as shown in Fig. } 3.7 . \text { Package } \\
\text { has carbon steel wall thickness }=0.028 \mathrm{in} \text {. } \\
(0.071 \mathrm{~cm}) \text { with no polyurethane foam. Spacing } \\
\text { between fuel assemblies is removed. Temp }= \\
483.15 \mathrm{~K}\end{array}$ & $0.8866 \pm 0.0017$ & 0.8900 \\
\hline
\end{tabular}




\subsubsection{Weapons-Grade MOX Fuel}

\subsubsection{Undamaged Package Configurations}

The models and evaluation approach for the MO-1 single package analysis with WG MOX fuel are essentially the same as the evaluation presented in Sect. 6.1.1. The difference between the analyses resides in the fuel package contents. The WG MOX fuel is $4.803 \mathrm{wt} \% \mathrm{Pu}$ with a Pu fissile fraction of $94 \mathrm{wt} \%$, as discussed in Sect. 2.1.2. In addition, the WG MOX fuel is configured as a $17 \times 17$ assembly of fuel pins with a pitch of 0.496 in. $(1.26 \mathrm{~cm})$, as discussed in Sect. 2.1.2.

In an effort to evaluate the WG MOX fuel, calculated results are presented in Table 6.6 for a single water flooded $17 \times 17$ WG assembly reflected on all sides with $12 \mathrm{in.}(30 \mathrm{~cm})$ of water. For comparison, the calculated multiplication factors for a flooded and fully reflected $14 \times 14$ assembly with $6 \mathrm{wt} \%$, $4.4 \mathrm{wt} \%$ and $3.03 \mathrm{wt} \% \mathrm{PuO}_{2} \mathrm{MOX}$ fuel are also presented in Table 6.6. Based on the single-assembly results, the calculated $k_{\text {eff }}$ for the WG MOX assembly is $\sim 12$ to $13 \%$ higher than an assembly with the previously certified MOX fuel pins. Because of the large difference in reactivity, the single-package case is initially evaluated with one WG assembly positioned on the strongback. The evaluation also considers two assemblies in the MO-1, and these results are presented following the single-assembly discussion.

Table 6.6. Comparison of reactivity between WG MOX assembly and non-weapons-grade MOX assemblies

\begin{tabular}{ccc}
\hline Case & \multicolumn{1}{c}{ Description } & $k_{\text {eff }} \pm \sigma$ \\
\hline wasm-1 & $\begin{array}{c}17 \times 17 \text { WG MOX assembly, completely flooded and } \\
\text { reflected with } 12 \text { in. }(30 \mathrm{~cm}) \mathrm{H}_{2} \mathrm{O}\end{array}$ & $0.9333 \pm 0.0019$ \\
643 asm-1 & $\begin{array}{l}14 \times 14 \mathrm{MOX}\left(6 \mathrm{wt} \% \mathrm{PuO}_{2}\right) \text { assembly, completely flooded, } \\
\text { reflected with } 12 \mathrm{in.}(30 \mathrm{~cm}) \mathrm{H}_{2} \mathrm{O}\end{array}$ & $0.8249 \pm 0.0017$ \\
643 asm-2 & $\begin{array}{l}14 \times 14 \mathrm{MOX}\left(4.4 \mathrm{wt} \% \mathrm{PuO}_{2}\right) \text { assembly, completely } \\
\text { flooded, reflected with } 12 \mathrm{in} .(30 \mathrm{~cm}) \mathrm{H}_{2} \mathrm{O}\end{array}$ & $0.8317 \pm 0.0019$ \\
643 asm-3 & $\begin{array}{l}14 \times 14 \mathrm{MOX}\left(3.03 \mathrm{wt} \% \mathrm{PuO}_{2}\right) \text { assembly, completely } \\
\text { flooded, reflected with } 12 \mathrm{in} .(30 \mathrm{~cm}) \mathrm{H}_{2} \mathrm{O}\end{array}$ & $0.8267 \pm 0.0017$ \\
\hline
\end{tabular}

With regard to the single-package evaluation, Fig. 6.5 presents the infinite multiplication factor as a function of pitch for the WG MOX fuel. Based on the results in Fig. 6.5, full-water density is optimum for the WG loading because the fuel is undermoderated at a pitch of $0.496 \mathrm{in} .(1.26 \mathrm{~cm})$. To further address internal moderation, the results presented in Table 6.7 provide calculated $k_{\text {eff }}$ values for progressive states of water flooding in the MO-1 with one WG MOX assembly. Based on the results in Table 6.7, optimum moderation for the package occurs at full-water density. Cases wm-10 and wm-11 evaluate the effectiveness of full-water reflection for a completely flooded package. The calculated multiplication factors for both cases are statistically the same, indicating the reflector return is statistically insignificant. Nonetheless, the calculated multiplication factors for Cases wm-10 and wm-11 are less than the acceptance criteria (i.e., $k_{\text {eff }}+2 \sigma<0.9245$ ). The results in Table 6.7 indicate the single package is less reactive at lower $\mathrm{H}_{2} \mathrm{O}$ densities, as observed for the MO- 1 with the originally certified MOX fuel. 


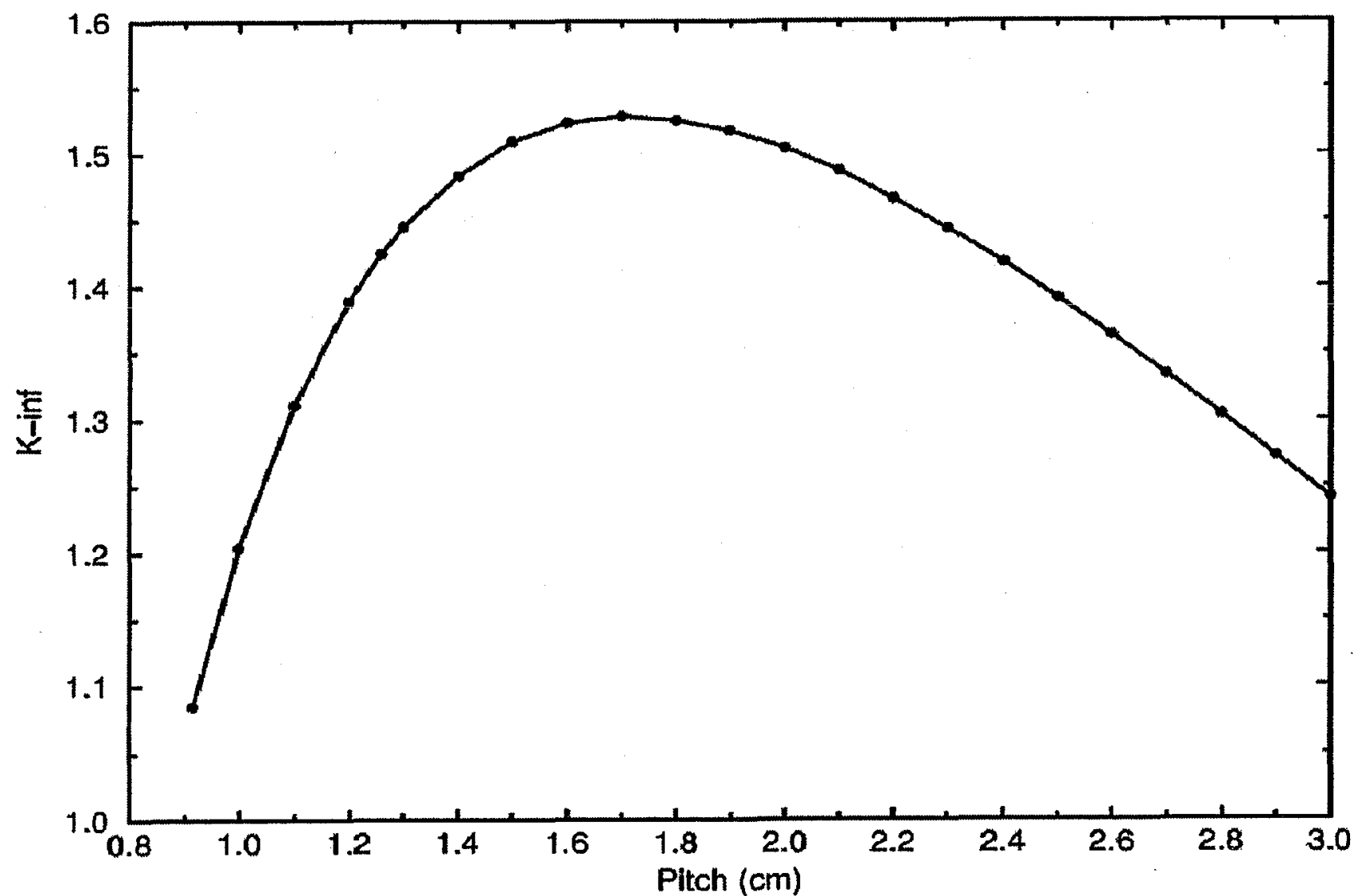

Fig. 6.5. $k_{\infty}$ as a function of pitch for weapons-grade MOX fuel. 
Table 6.7. Calculated $k_{e f f}$ values for the MO-1 with WG MOX fuel under different moderation conditions

\begin{tabular}{ccccc}
\hline Case & $\mathrm{H}_{2} \mathrm{O}$ Reflection & $\mathrm{H}_{2} \mathrm{O}$ Volume fraction & $k_{e f f} \pm \sigma$ & $k_{\text {eff }}+2 \sigma$ \\
\hline wm-1 & No & 0.0 & $0.1079 \pm 0.0003$ & 0.1085 \\
wm-2 & Yes & 0.0 & $0.1838 \pm 0.0009$ & 0.1856 \\
wm-3 & Yes & 0.001 & $0.1842 \pm 0.0007$ & 0.1856 \\
wm-4 & Yes & 0.003 & $0.1830 \pm 0.0008$ & 0.1846 \\
wm-5 & Yes & 0.05 & $0.1999 \pm 0.0008$ & 0.2015 \\
wm-6 & Yes & 0.1 & $0.2482 \pm 0.0010$ & 0.2502 \\
wm-7 & Yes & 0.4 & $0.5433 \pm 0.0014$ & 0.5461 \\
wm-8 & Yes & 0.6 & $0.6856 \pm 0.0017$ & 0.6890 \\
wm-9 & Yes & 0.8 & $0.7990 \pm 0.0017$ & 0.8024 \\
wm-10 & Yes & 1.0 & $0.8969 \pm 0.0018$ & 0.9005 \\
wm-11 & No & 1.0 & $0.8985 \pm 0.0019$ & 0.9023 \\
\hline
\end{tabular}

As noted in Sect. 3.1.3, the MO-1 calculational model neglects the angled corners of the internal cavity, and the internal region is modeled as a rectangular cavity. To assess the impact of neglecting the angled corners, Case wm-10 is presented with blocks of polyurethane foam in the corners of the internal cavity, as shown in Fig. 3.6. The calculated $k_{e f f}$ for the MO-1 with the revised internal cavity is denoted as Case wmpf-10 and is presented in Table 6.8. Based on the results in Table 6.8, the system multiplication for Case wmpf-10 is statistically the same as Case wm-10. Consequently, omitting the angled corners of the internal cavity has a negligible impact on system reactivity.

To assess reflection by package materials, calculations are presented in Table 6.8 for the optimally moderated inner containment (i.e., inner shell and fuel package) reflected on all sides by $12 \mathrm{in}$. (30 cm) of water (Case sc-wg). In comparison with the optimally moderated and fully reflected MO-1, Case sc-wg is statistically the same as the package with polyurethane foam. Both cases yield a calculated $k_{e f f}+2 \sigma$, which is below the USL. Additional calculations are provided in Table 6.8 for the optimum single package $($ Case $\mathrm{wm}-10)$ reflected by $12 \mathrm{in} .(30 \mathrm{~cm})$ of carbon steel and $12 \mathrm{in} .(30 \mathrm{~cm})$ of polyurethane foam. The calculated $k_{\text {eff }}$ values obtained with the carbon steel and polyurethane foam reflection are statistically the same as the full-water-reflection case. As a result, full-water reflection is considered to be optimum. As noted in Sect. 6.1.1, the maximum temperature exposure for the MO-1 during normal conditions of transport is $232^{\circ} \mathrm{F}(384.3 \mathrm{~K})$. The calculated multiplication factor for the optimum single-package model (Case wm-10) at $384.3 \mathrm{~K}$ is also provided in Table 6.8. Based on the single-package evaluation, a single MO-1 with one WG MOX assembly is subcritical under normal conditions of transport. 
Table 6.8. Calculated results for the MO-1 under normal conditions with a single WG MOX assembly

\begin{tabular}{cccc}
\hline Case & \multicolumn{1}{c}{ Description } & $k_{\text {eff }} \pm \sigma$ & $k_{\text {eff }}+2 \sigma$ \\
\hline wm-10 & $\begin{array}{c}\text { Optimally moderated undamaged package with } \\
\text { 12-in. (30-cm) } \mathrm{H}_{2} \mathrm{O} \text { reflection }\end{array}$ & $0.8969 \pm 0.0018$ & 0.9005 \\
wmpf-10 & $\begin{array}{c}\text { Case wm-10 with revised internal region which } \\
\text { accounts for angled walls of internal cavity, } \\
\text { as shown in Fig. 3.6 }\end{array}$ & $0.8978 \pm 0.0020$ & 0.9018 \\
sc-wg & $\begin{array}{l}\text { Optimally moderated inner containment } \\
\text { package with 12-in. (30-cm) } \mathrm{H}_{2} \mathrm{O} \text { reflection }\end{array}$ & $0.8946 \pm 0.0019$ & 0.8984 \\
wr-1 & $\begin{array}{l}\text { Optimally moderated undamaged package with } \\
\text { 12-in. (30-cm) carbon steel reflection }\end{array}$ & $0.8960 \pm 0.0019$ & 0.8998 \\
wr-2 & $\begin{array}{l}\text { Optimally moderated undamaged package with } \\
\text { 12-in. (30-cm) polyurethane foam reflection }\end{array}$ & $0.8974 \pm 0.0016$ & 0.9006 \\
wt-1 & $\begin{array}{l}\text { Optimally moderated undamaged package at } \\
\text { 384.3 K with 12-in. (30-cm) } \mathrm{H}_{2} \mathrm{O} \text { reflection }\end{array}$ & $0.9018 \pm 0.0019$ & 0.9056 \\
\hline
\end{tabular}

The previous calculations consider one WG MOX assembly in the single package. The following cases are presented to address the shipment of two WG lead test assemblies in the MO-1. As noted above, the single package is undermoderated with one assembly, and optimum moderation conditions occur with full-density water. Consequently, the MO-1 is also undermoderated if an additional fuel assembly is added to the package. Therefore, full-density water provides optimum moderation conditions for the MO-1 with two WG MOX fuel assemblies. The calculated $k_{e f f}$ for a fully $\mathrm{H}_{2} \mathrm{O}$ reflected and moderated single package with two fuel assemblies is presented as Case wm2-10 in Table 6.9. In addition, the cases that evaluate carbon steel and polyurethane foam as reflectors are also presented in Table 6.9 along with the optimum single-package model at $384.3 \mathrm{~K}$ (Case wt2-10). Based on the calculated results for two assemblies, the fully flooded and $\mathrm{H}_{2} \mathrm{O}$-reflected package is above the acceptable upper-subcritical limit. Moreover, the calculated $k_{e f f}+2 \sigma$ for the single package with full polyurethane foam or carbon steel reflection is also greater than the USL. Consequently, the single MO-1 package with two WG MOX assemblies is not subcritical during normal conditions of transport. Based on these results, the subsequent calculations only consider one WG MOX assembly for shipment in the MO-1. 
Table 6.9. Calculated results for the MO-1 under normal conditions with two WG MOX assemblies

\begin{tabular}{cccc}
\hline Case & \multicolumn{1}{c}{ Description } & $k_{\text {eff }} \pm \sigma$ & $k_{\text {eff }}+2 \sigma$ \\
\hline wm2-10 & $\begin{array}{c}\text { Optimally moderated undamaged package with } \\
\text { 12-in. (30-cm) } \mathrm{H}_{2} \mathrm{O} \text { reflection }\end{array}$ & $0.9282 \pm 0.0019$ & 0.9320 \\
wr2-1 & $\begin{array}{c}\text { Optimally moderated undamaged package with } \\
\text { 12-in. (30-cm) carbon steel reflection }\end{array}$ & $0.9325 \pm 0.0018$ & 0.9361 \\
wr2-2 & $\begin{array}{c}\text { Optimally moderated undamaged package with } \\
\text { 12-in. (30-cm) polyurethane foam reflection }\end{array}$ & $0.9355 \pm 0.0023$ & 0.9401 \\
wt2-1 & $\begin{array}{l}\text { Optimally moderated undamaged package at } \\
\text { 384.3 K with 12-in. (30-cm) } \mathrm{H}_{2} \mathrm{O} \text { reflection }\end{array}$ & $0.9330 \pm 0.0017$ & 0.9364 \\
\hline
\end{tabular}

\subsubsection{Damaged Package Configurations}

The calculated results for the single package under hypothetical accident conditions with one WG MOX assembly are provided in Table 6.10. As with the previously certified MOX fuel, the single package is evaluated under fire conditions. The calculated results for the single package with one WG MOX assembly under fire conditions are presented in Table 6.10. Case wf-1 evaluates the single package with a maximum internal temperature of $483.15 \mathrm{~K}$, and cases wf.1a through wf.le evaluate varying degrees of polyurethane foam charring during a fire scenario. Cases wf- 2 and wf- 3 evaluate the single package under fire conditions, with the polyurethane foam replaced by water and void, respectively.

Increasing the internal temperature to $483.15 \mathrm{~K}$ leads to an $\sim 1.2 \%$ increase in the calculated $k_{\text {eff }}$ for the package relative to $293 \mathrm{~K}$ (i.e., Case wm-10). The reactivity increase with temperature is consistent with the results obtained with the previously certified MOX fuel. Following the same procedure as presented for the $6 \mathrm{wt} \% \mathrm{PuO}_{2} \mathrm{MOX}$ fuel study, the calculated neutron flux as a function of energy for the WG MOX fuel is presented in Fig. 6.6 at $293 \mathrm{~K}$ and $483.15 \mathrm{~K}$. Based on the calculated flux above energy group 200,4.1\% more neutrons reach thermal energies above group 210 at $483.15 \mathrm{~K}$ relative to the fuel at room temperature. The macroscopic total and fission cross sections are presented in Figs. 6.7 and 6.8, respectively. As observed for the $6 \mathrm{wt} \% \mathrm{PuO}_{2} \mathrm{MOX}$ fuel, there is an $\sim 10 \%$ decrease in the ${ }^{240} \mathrm{Pu}$ resonance peak at energy group 184 in Fig. 6.7. The decrease in the resonance at energy group 184 leads to a higher number of neutrons available for fission at energy groups above 200. Although the reactivity increases for the fire scenarios, the calculated $k_{\text {eff }}$ values for these fire scenarios are less than the USL.

As discussed in Sects. 3.3 and 6.1.1, the fuel payload could shift during impact, and the shifted fuel configurations presented in Sect. 6.1.1 for the original certified MOX fuel are also considered for the shipment of WG MOX fuel. Case wc-1 addresses an external impact on the MO-1, resulting in the loss of the polyurethane foam and a reduced exterior carbon steel thickness of $0.028 \mathrm{in} .(0.071 \mathrm{~cm})$. The location of the fuel package is the same as the undamaged package (i.e., fuel is not shifted). The calculated $k_{\text {eff }}+2 \sigma$ for Case wc-1 is 0.9104 , which is less than the USL. Cases wa-1 and wb-1 evaluate repositioning the fuel package within the MO-1. Specifically, Case wa-1 considers the vertical displacement of the fuel to the bottom inner shell of the MO-1, as depicted in Fig. 3.8; Case wb-1 evaluates the fuel positioned in the interior corner of the MO-1, as shown in Fig. 3.9. Unlike the original certified MOX fuel, the WG 
Table 6.10. Calculated results for the damaged MO-1 with one WG MOX assembly

\begin{tabular}{|c|c|c|c|}
\hline Case & Description & $k_{e f f} \pm \sigma$ & $k_{\text {eff }}+2 \sigma$ \\
\hline wf-1 & $\begin{array}{l}\text { Optimally moderated package with } 12-\mathrm{in} .(30-\mathrm{cm}) \mathrm{H}_{2} \mathrm{O} \\
\text { reflection during fire conditions. Temp }=483.15 \mathrm{~K}\end{array}$ & $0.9079 \pm 0.0018$ & 0.9115 \\
\hline wf-la & Case $6 \mathrm{f}-1$ with foam content $10 \% \mathrm{H}_{2} \mathrm{O}$ & $0.9028 \pm 0.0017$ & 0.9062 \\
\hline wf-1b & Case $6 \mathrm{f}-1$ with foam content $30 \% \mathrm{H}_{2} \mathrm{O}$ & $0.9067 \pm 0.0015$ & 0.9097 \\
\hline$w f-1 c$ & Case $6 \mathrm{f}-1$ with foam content $50 \% \mathrm{H}_{2} \mathrm{O}$ & $0.9084 \pm 0.0017$ & 0.9118 \\
\hline wf-1d & Case $6 \mathrm{f}-1$ with foam content $70 \% \mathrm{H}_{2} \mathrm{O}$ & $0.9090 \pm 0.0017$ & 0.9124 \\
\hline wf-le & Case 6f-1 with foam content $90 \% \mathrm{H}_{2} \mathrm{O}$ & $0.9083 \pm 0.0017$ & 0.9117 \\
\hline wf-2 & Case $6 \mathrm{f}-1$ with foam content $100 \% \mathrm{H}_{2} \mathrm{O}$ & $0.9080 \pm 0.0020$ & 0.9120 \\
\hline$w f-3$ & Case $6 \mathrm{f}-1$ with foam replaced by void & $0.9079 \pm 0.0018$ & 0.9115 \\
\hline wc-1 & $\begin{array}{l}\text { Optimally moderated package with } 12-\text { in. }(30-\mathrm{cm}) \mathrm{H}_{2} \mathrm{O} \\
\text { reflection. Fuel positioned in MO- } 1 \text { as shown in Fig. } 3.7 \text {. } \\
\text { Package has carbon steel wall thickness }=0.028 \text { in. } \\
(0.071 \mathrm{~cm}) \text { with no polyurethane foam. Temp }= \\
483.15 \mathrm{~K}\end{array}$ & $0.9066 \pm 0.0019$ & 0.9104 \\
\hline wa-1 & $\begin{array}{l}\text { Optimally moderated package with } 12 \text {-in. }(30-\mathrm{cm}) \mathrm{H}_{2} \mathrm{O} \\
\text { reflection. Fuel positioned in } \mathrm{MO}-1 \text { as shown in Fig. } 3.8 \text {. } \\
\text { Temp }=483.15 \mathrm{~K}\end{array}$ & $0.9037 \pm 0.0021$ & 0.9079 \\
\hline wb-1 & $\begin{array}{l}\text { Optimally moderated package with } 12 \text {-in. }(30-\mathrm{cm}) \mathrm{H}_{2} \mathrm{O} \\
\text { reflection. Fuel positioned in MO- } 1 \text { as shown in Fig. } 3.9 \text {. } \\
\text { Temp }=483.15 \mathrm{~K}\end{array}$ & $0.8886 \pm 0.0016$ & 0.8918 \\
\hline wa-2 & $\begin{array}{l}\text { Case wa- } 1 \text { with crushed carbon steel walls: thickness }= \\
0.028 \text { in. }(0.071 \mathrm{~cm}) . \text { Reflected with } 12 \text { in. }(30 \mathrm{~cm}) \mathrm{H}_{2} \mathrm{O} \text {. } \\
\text { Temp }=483.15 \mathrm{~K}\end{array}$ & $0.9054 \pm 0.0018$ & 0.9090 \\
\hline wb-2 & $\begin{array}{l}\text { Case wb- } 1 \text { with crushed carbon steel walls: thickness }= \\
0.028 \text { in. }(0.071 \mathrm{~cm}) . \text { Reflected with } 12 \text { in. }(30 \mathrm{~cm}) \mathrm{H}_{2} \mathrm{O} \text {. } \\
\text { Temp }=483.15 \mathrm{~K}\end{array}$ & $0.9062 \pm 0.0018$ & 0.9098 \\
\hline
\end{tabular}




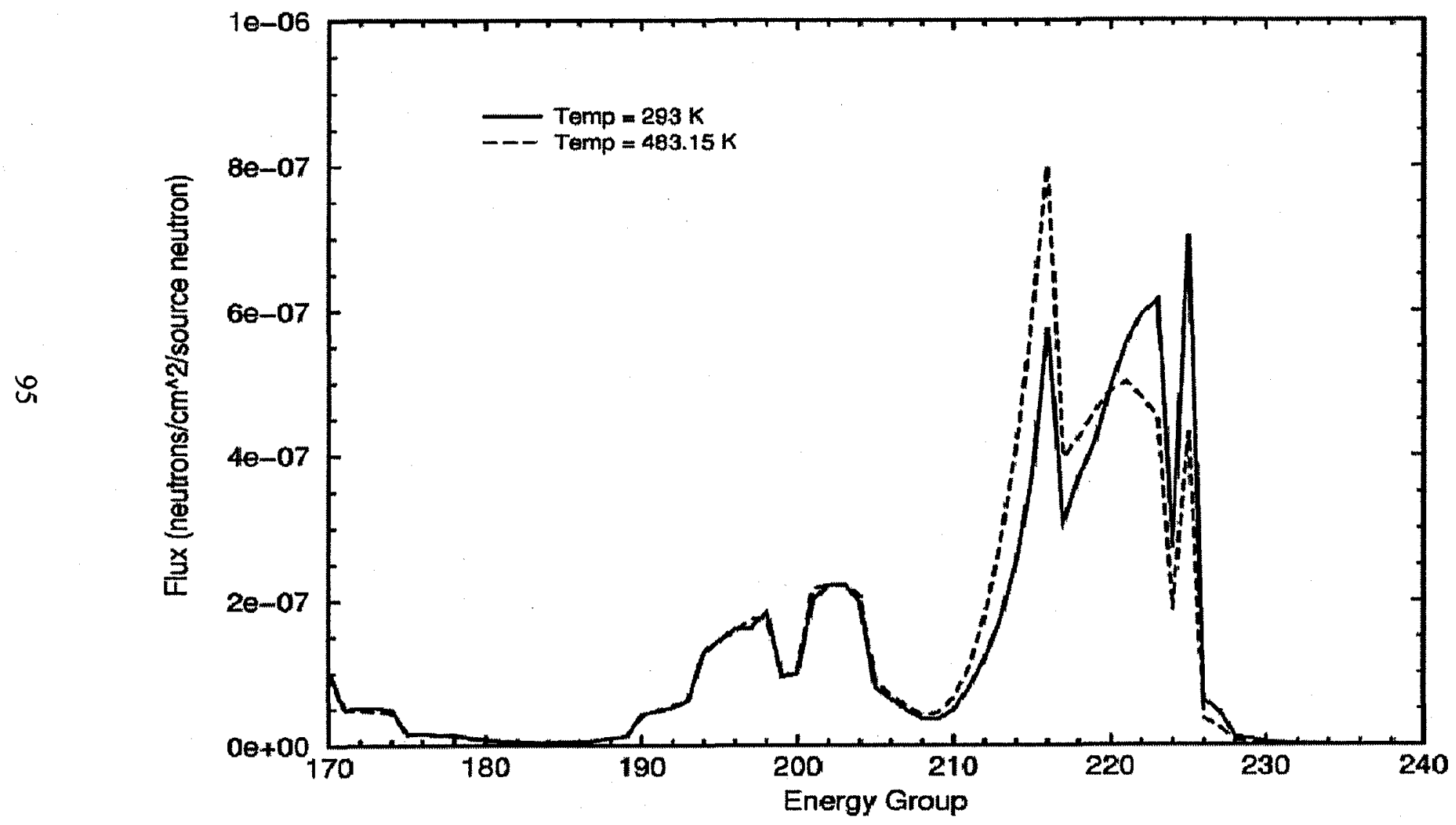

Fig. 6.6. Calculated neutron flux in WG MOX fuel at $293 \mathrm{~K}$ and $483.15 \mathrm{~K}$. 


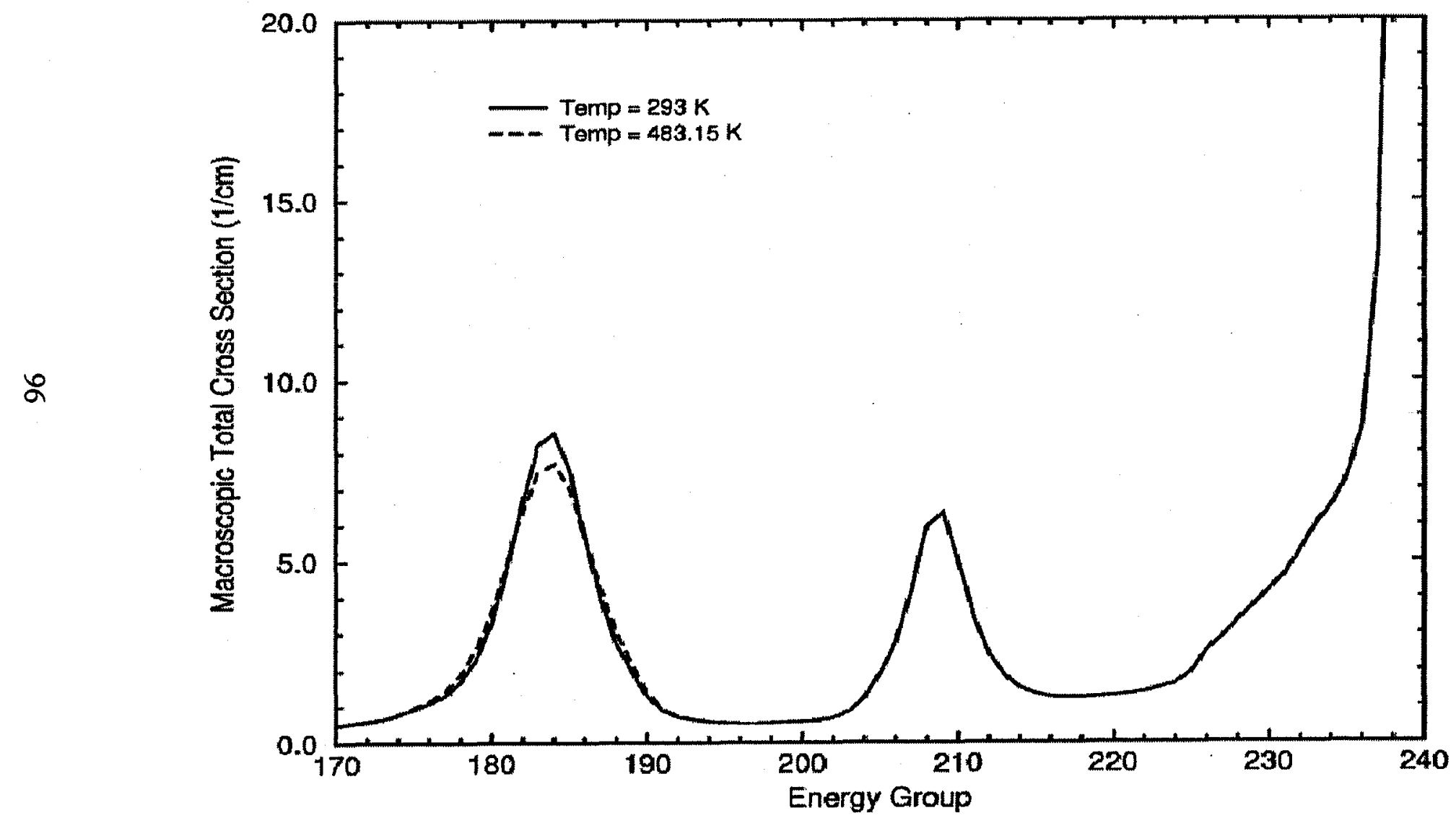

Fig. 6.7. Macroscopic total cross section for WG MOX fuel at $293 \mathrm{~K}$ and $483.15 \mathrm{~K}$. 


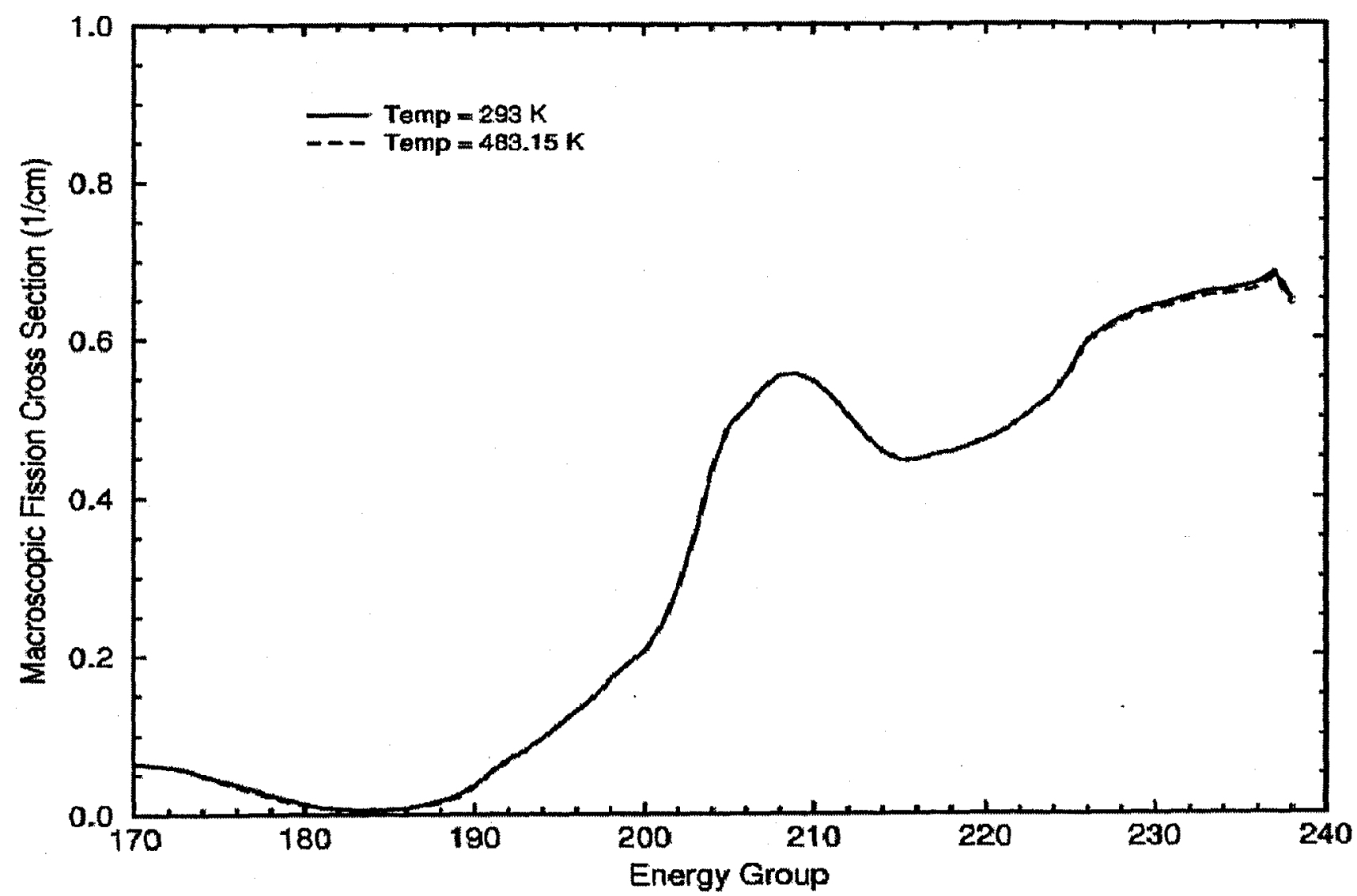

Fig. 6.8. Macroscopic fission cross section for WG MOX fuel at $293 \mathrm{~K}$ and $483.15 \mathrm{~K}$. 
package is comprised of one assembly. Based on the results presented in Table 6.10 , the calculated results for Cases wa- 1 and wb-1 are statistically the same and subcritical relative to the acceptance criteria. The previous two models did not consider the deformation of the exterior containment. In reality, an impact that causes the fuel package to shift would most likely result in damage to the outer and inner shells of the MO-1. To assess the deformation of the MO-1 exterior containment, Cases wa- 1 and wb- 1 are re-evaluated in Cases wa-2 and wb-2 with a crushed exterior containment having a carbon steel wall thickness of $0.028 \mathrm{in} .(0.071 \mathrm{~cm})$. With damaged exterior containment, the calculated $k_{\text {eff }}$ values for both wa- 2 and wb-2 are acceptably subcritical.

\subsection{PACKAGE ARRAYS}

Based on the guidance of NUREG/CR-5661 (ref. 7) for satisfying the statutory requirements of 10 CFR $\S 71.59$, the transport index (TI) must be determined based on the evaluation of package arrays under normal and accident conditions. As in the single-package study, the array of packages evaluation is provided separately for the previously approved MOX fuel and proposed WG MOX fuel.

\subsubsection{Previously Certified MOX Fuel}

\subsubsection{Undamaged Package Configurations}

Based on the calculational results presented for the single package under normal conditions, the optimum model is completely flooded and fully reflected with water. The fuel package contents in the optimum case includes two fuel assemblies positioned on the strongback support structure, as shown in Figs. 3.2 and 3.4. As discussed in Sect. 6.1.1, the completely flooded and fully reflected single package $k_{\text {eff }}$ is statistically the same as a completely flooded and unreflected single package. As a result, the fuel assemblies are neutronically isolated from the exterior boundary of the MO-1. Although the optimum single package is completely flooded with water, an array of undamaged MO-1 packages may not be optimum at full internal flooding. In particular, a fully flooded MO-1 in an array configuration may be neutronically isolated from another fully flooded package. Therefore, the internal package moderation for the undamaged package in an array configuration must be reevaluated. To assess internal package moderation conditions, the results for an infinite array of undamaged MO-1s with $6 \mathrm{wt} \% \mathrm{PuO}_{2} \mathrm{MOX}$ fuel are presented in Table 6.11 for progressive states of water flooding. Note that there is no spacing between the packages within the infinite array. As shown in Table 6.11, the optimum internal moderation in the array configuration occurs at full-water density. These results illustrate the neutronic isolation between the undamaged packages in an array configuration. Based on the results in Table 6.11 , an infinite number of undamaged $\mathrm{MO}-1 \mathrm{~s}$ with two MOX fuel assemblies $\left(6 \mathrm{wt} \% \mathrm{PuO}_{2}\right)$ is acceptably subcritical during normal conditions of transport. Regarding the $4.4 \mathrm{wt} \%$ and $3.03 \mathrm{wt} \% \mathrm{PuO}_{2} \mathrm{MOX}$ loadings, the calculated $k_{\infty}$ for an infinite array of fully flooded undamaged packages is provided in Table 6.12 for each fuel loading. As observed for the $6 \mathrm{wt} \% \mathrm{PuO}_{2} \mathrm{MOX}$ loading, the infinite array of undamaged packages with $4.4 \mathrm{wt} \%$ and $3.03 \mathrm{wt} \% \mathrm{PuO}_{2} \mathrm{MOX}$ fuel is subcritical during normal conditions of transport. 
Table 6.11. Calculated system multiplication for an infinite array of undamaged MO-1s with $6 \mathrm{wt} \% \mathrm{PuO}_{2}$

\begin{tabular}{cccc}
\hline Case & $\mathrm{H}_{2} \mathrm{O}$ volume fraction & $k_{\infty} \pm \sigma$ & $k_{\infty}+2 \sigma$ \\
\hline $6 \mathrm{i}-1$ & 0.0 & $0.7165 \pm 0.0011$ & 0.7187 \\
$6 \mathrm{i}-2$ & 0.001 & $0.7131 \pm 0.0011$ & 0.7153 \\
$6 \mathrm{i}-3$ & 0.003 & $0.7054 \pm 0.0012$ & 0.7078 \\
$6 \mathrm{i}-4$ & 0.05 & $0.6095 \pm 0.0013$ & 0.6121 \\
$6 \mathrm{i}-5$ & 0.1 & $0.5480 \pm 0.0013$ & 0.5506 \\
$6 \mathrm{i}-6$ & 0.4 & $0.5915 \pm 0.0014$ & 0.5943 \\
$6 \mathrm{i}-7$ & 0.6 & $0.6846 \pm 0.0016$ & 0.6878 \\
$6 \mathrm{i}-8$ & 0.8 & $0.7608 \pm 0.0015$ & 0.7638 \\
$6 \mathrm{i}-9$ & 0.9 & $0.8018 \pm 0.0016$ & 0.8050 \\
$6 \mathrm{i}-10$ & 0.95 & $0.8155 \pm 0.0016$ & 0.8187 \\
$6 \mathrm{i}-11$ & 1.0 & $0.8357 \pm 0.0018$ & 0.8393 \\
\hline
\end{tabular}

Table 6.12. Calculated system multiplication for an infinite array of undamaged MO-1s with 4.4 and 3.03 wt $\% \mathrm{PuO}_{2}$ MOX fuel

\begin{tabular}{cccc}
\hline Case & $\mathrm{H}_{2} \mathrm{O}$ volume fraction & $k_{\infty} \pm \sigma$ & $k_{\infty}+2 \sigma$ \\
\hline $4 \mathrm{i}-11$ & 1.0 & $0.8375 \pm 0.0016$ & 0.8407 \\
$3 \mathrm{i}-11$ & 1.0 & $0.8328 \pm 0.0017$ & 0.8362 \\
\hline
\end{tabular}

\subsubsection{Damaged Package Configurations}

Based on the single-package study, the most reactive damaged single package has the fuel package positioned in the MO-1, as shown in Fig. 3.7, and is designated Case 6c-2 in Sect. 6.1.1. The crushed exterior containment has 0.028 -in. $(0.071-\mathrm{cm})$-thick walls (no polyurethane foam insulation), and the damaged package is completely flooded with full-density water. In the array evaluation, this damaged package was modeled in an infinite array with no spacing between packages. The internal water density was varied to assess the reactivity as a function of water density. The calculated results for the infinite array of damaged packages are provided in Table 6.13. For the infinite array, the optimum internal moderation conditions occur with a water volume fraction of 0.003 . The reduction in exterior wall thickness and loss of polyurethane foam increases the neutron interaction between units. Under optimum internal moderation conditions, an infinite array of damaged packages is not acceptably subcritical; therefore, a finite array analysis must be used to determine the number of damaged subcritical packages. 
Table 6.13. Calculated system multiplication for an infinite array of damaged MO-1s with $6 \mathrm{wt} \% \mathrm{PuO}_{2} \mathrm{MOX}$

\begin{tabular}{cccc}
\hline Case & $\mathrm{H}_{2} \mathrm{O}$ volume fraction & $k_{\infty} \pm \sigma$ & $k_{\infty}+2 \sigma$ \\
\hline 6ai-1 & 0.0 & $0.8593 \pm 0.0007$ & 0.8607 \\
6ai-2 & 0.001 & $0.9102 \pm 0.0008$ & 0.9118 \\
6ai-3 & 0.003 & $0.9742 \pm 0.0009$ & 0.9760 \\
6ai-4 & 0.05 & $0.9639 \pm 0.0016$ & 0.9671 \\
6ai-5 & 0.1 & $0.7700 \pm 0.0014$ & 0.7728 \\
6ai-6 & 0.4 & $0.6396 \pm 0.0015$ & 0.6426 \\
6ai-7 & 0.6 & $0.7351 \pm 0.0017$ & 0.7358 \\
6ai-8 & 0.8 & $0.8216 \pm 0.0017$ & 0.8250 \\
6ai-9 & 0.9 & $0.8551 \pm 0.0018$ & 0.8587 \\
6ai-10 & 0.95 & $0.8756 \pm 0.0015$ & 0.8786 \\
6ai-11 & 1.0 & $0.8937 \pm 0.0015$ & 0.8967 \\
\hline
\end{tabular}

In an array evaluation, the most reactive single-package case may not lead to the most reactive array configuration. With regard to the MO-1, the most reactive damaged single package has the fuel assemblies positioned in the center of the package, as shown in Fig. 3.7; however, this configuration may not optimize the interaction between packages. In an array analysis, the configuration that optimizes unit interaction (e.g., changes in fuel configurations) must be considered. As noted in Sect. 3.3, the fuel package may shift in the MO- 1 during impact conditions. Cases $6 \mathrm{~b}-1$ and -2 evaluate a corner or edge impact which shifts the fuel package to a corner of the internal MO-1 cavity, as shown in Fig. 3.9. This shifted configuration places the fuel assemblies closer to a possible neighboring MO-1 package and could potentially increase package interaction. In order to determine the TI for criticality control, an array of the postulated damaged packages must be evaluated. In accordance with 10 CFR $\S 71.59$ and the guidance of NUREG/CR-5661 (ref. 7), a $2 \times 1 \times 1$ array of damaged packages with shifted fuel contents was modeled. In one damaged package, the fuel contents are shifted to the lower left corner of the internal MO-1 cavity, as shown in Fig. 3.9. The array model considers the second damaged MO-1 package to be placed next to the first MO-1, as indicated in Fig. 3.10. The fuel contents of the second MO-1 is shifted to the lower right corner of the internal cavity, as shown in Fig. 3.10. In both packages, the crushed exterior containment is 0.028 -in. $(0.071-\mathrm{cm})$-thick carbon steel with no polyurethane foam insulation. Both MO-1s are completely flooded, and the array of packages is fully reflected with $12 \mathrm{in}$. $(30 \mathrm{~cm})$ of water. The calculated $k_{e f f}$ of the $2 \times 1 \times 1$ array of damaged packages is provided in Table 6.14. For comparison purposes, the single package case $(1 \times 1 \times 1)$ with shifted fuel contents is also provided in Table 6.14. The calculated $k_{\text {eff }}+2 \sigma$ for the $2 \times 1 \times 1$ array of damaged packages is 0.9509 , which is greater than the USL and is not considered to be acceptably subcritical. Note that Case 6 ar -0 may not be the most reactive configuration 
Table 6.14. Calculated $k_{\text {eff }}$ values for finite array of damaged MO-ls with $6 \mathrm{wt} \% \mathrm{PuO}_{2} \mathrm{MOX}$

\begin{tabular}{|c|c|c|c|c|}
\hline Case & $\begin{array}{l}\text { Internal } \mathrm{H}_{2} \mathrm{O} \\
\text { volume fraction }\end{array}$ & Description & $k_{e f f} \pm \sigma$ & $k_{e f f}+2 \sigma$ \\
\hline $6 b-2$ & 1.0 & $\begin{array}{l}1 \times 1 \times 1 \text { array, damaged package with } \\
\text { shifted fuel contents (Fig. 3.9) }\end{array}$ & $0.8618 \pm 0.0017$ & 0.8652 \\
\hline $6 a r-0$ & 1.0 & $\begin{array}{l}2 \times 1 \times 1 \text { array, damaged packages with } \\
\text { shifted fuel contents (Fig. } 3.10) \\
\text { Crushed wall thickness }=0.028 \mathrm{in} . \\
(0.071 \mathrm{~cm}) . \text { Temp }=483.15 \mathrm{~K}\end{array}$ & $0.9475 \pm 0.0017$ & 0.9509 \\
\hline $6 a r-1$ & 1.0 & $\begin{array}{l}2 \times 1 \times 1 \text { array, damaged packages with } \\
\text { shifted fuel contents (Fig. } 3.10 \text { ). } \\
\text { Undamaged containment with foam } \\
\text { replaced by } \mathrm{H}_{2} \mathrm{O} \text {. Temp }=483.15 \mathrm{~K}\end{array}$ & $0.8879 \pm 0.0017$ & 0.8913 \\
\hline $6 \operatorname{ar}-2$ & 1.0 & $\begin{array}{l}2 \times 1 \times 1 \text { array, damaged packages with } \\
\text { shifted fuel contents (Fig. } 3.10) \text {. } \\
\text { Crushed wall thickness }=0.239 \text { in. } \\
(0.607 \mathrm{~cm}) . \text { Foam replaced by } \mathrm{H}_{2} \mathrm{O} \text {. } \\
\text { Temp }=483.15 \mathrm{~K}\end{array}$ & $0.9462 \pm 0.0019$ & 0.9500 \\
\hline $6 \operatorname{ar}-3$ & 1.0 & $\begin{array}{l}2 \times 1 \times 1 \text { array, damaged packages with } \\
\text { shifted fuel contents (Fig. } 3.10 \text { ). } \\
\text { Crushed wall thickness }=1.836 \text { in. } \\
\left(4.663 \mathrm{~cm} \text { ). Foam replaced by } \mathrm{H}_{2} \mathrm{O} \text {. }\right. \\
\text { Temp }=483.15 \mathrm{~K}\end{array}$ & $0.9032 \pm 0.0016$ & 0.9064 \\
\hline
\end{tabular}

${ }^{\sigma}$ Volume fraction applies to void locations which are within the first containment boundary (i.e., inner containment shell). For cases with the foam replaced by water, the $\mathrm{H}_{2} \mathrm{O}$ is at full density.

of damaged packages. For example, the assemblies in each package of Fig. 3.10 could be rotated $90^{\circ}$, thereby forming a "square" configuration of assemblies, as shown in Fig. 3.11. Since the calculated $k_{e f f}+2 \sigma$ for Case 6 ar- 0 is greater than the calculational USL, only one damaged MO-1 package is acceptably subcritical.

As noted in Sect. 3.3, the maximum deformation during a flat-side impact is used for all exterior wall thicknesses in the calculational model. This maximum deformation is created when the strongback crossbar members impact the inner shell during a flat side impact. Moreover, this maximum deformation is localized to the positions where each crossbar member strikes the inner shell. Using this maximum deformation for all damaged shell thicknesses does optimize package interaction but is very conservative. In the $2 \times 1 \times 1$ array of damaged packages, the side wall thickness of the MO- 1 will be greater than $0.028 \mathrm{in} .(0.071 \mathrm{~cm})$. Based on the impact analysis presented in ref. 10 , shifting the fuel package to the interior corner of the MO- 1 would be induced by a long-edge or short-edge impact. Following a long-edge impact, the minimum crushed side wall thickness would be 1.836 in. $(4.663 \mathrm{~cm}$.). After a short-edge impact, the minimum crushed wall thickness would be $0.239 \mathrm{in} .\left(0.607 \mathrm{~cm}\right.$.). ${ }^{10}$ To assess the conservatism 
in the $2 \times 1 \times 1$ model, additional results are also provided in Table 6.14 for the $2 \times 1 \times 1$ array of damaged packages with different wall thicknesses. Specifically, Case 6ar-1 considers the walls between the neighboring MO-1s to be undamaged; however, the polyurethane foam is replaced by water. In Case 6ar-2, the neighboring walls between the two packages are crushed to $0.239 \mathrm{in} .(0.607 \mathrm{~cm})$. The carbon-steel thickness for the inner and outer shell is $0.081 \mathrm{in} .(0.205 \mathrm{~cm})$, and the foam is also replaced by water. In Case 6ar-3, the crushed side wall thickness for each MO-1 is 1.836 in. $(4.663 \mathrm{~cm})$ with an inner and outer carbon-steel thickness of 0.082 in. $(0.205 \mathrm{~cm})$. For the undamaged wall configuration, the calculated $k_{\text {eff }}+$ $2 \sigma$ is 0.8913 , which is acceptably subcritical relative to the USL. Since the package would sustain damage to the exterior containment during an impact, the undamaged wall configuration is not applicable for the impact analysis. The calculated $k_{\text {eff }}$ values $+2 \sigma$ for Cases $6 a r-2$ and $6 a r-3$ are 0.9492 and 0.9064 , respectively. Based on these results, the array of 2 damaged $\mathrm{MO}-1 \mathrm{~s}$ is not subcritical with a crushed wall thickness of $0.239 \mathrm{in}$. $(0.607 \mathrm{~cm})$; however, two packages are subcritical if the crushed wall thickness is at least $1.836 \mathrm{in} .(4.663 \mathrm{~cm})$. Since a short-edge impact could lead to a wall thickness of $0.239 \mathrm{in} .(0.607 \mathrm{~cm})$, only one damaged package is considered to be acceptably subcritical with two $6 \mathrm{wt} \% \mathrm{PuO}_{2} \mathrm{MOX}$ assemblies.

Using the calculational models developed for the $6 \mathrm{wt} \% \mathrm{PuO}_{2}$ cases, the calculated $k_{\text {eff }}$ for an array of two damaged MO-1s with a crushed exterior wall thickness of $0.028 \mathrm{in} .(0.071 \mathrm{~cm})$ is presented. in Table 6.15 for $4.4 \mathrm{wt} \%$ and $3.03 \mathrm{wt} \% \mathrm{PuO}_{2} \mathrm{MOX}$ fuel (i.e., Cases $4 \mathrm{ar}-0$ and 3ar-0, respectively). Cases 4ar-3 and 3ar-3 assess the $2 \times 1 \times 1$ array of damaged packages with a crushed exterior wall thickness of $1.836 \mathrm{in}$. $(4.663 \mathrm{~cm})$ for $4.4 \mathrm{wt} \%$ and $3.03 \mathrm{wt} \% \mathrm{PuO}_{2} \mathrm{MOX}$ loadings, respectively. The calculated results presented in Table 6.15 are consistent with the results obtained for the $6 \mathrm{wt} \% \mathrm{PuO}_{2}$ case. Consequently, a $2 \times 1 \times 1$ array of damaged MO- 1 s with either $4.4 \mathrm{wt} \%$ or $3.03 \mathrm{wt} \% \mathrm{PuO}_{2} \mathrm{MOX}$ fuel assemblies is not subcritical. Based on the evaluation presented in Sect. 6.1.1, only one damaged MO-1 is acceptably subcritical.

\subsubsection{Weapons-Grade MOX Fuel}

\subsubsection{Undamaged Package Configurations}

In the MO-1 analysis, the most reactive single-package configuration under normal conditions is complete water flooding with full-water reflection on all sides. The results presented in Sect. 6.1.2 indicate the return from the external water reflector is statistically insignificant. In an array configuration, the undamaged single packages may be neutronically isolated with full internal-water flooding. To evaluate the internal package moderation conditions, the results for an infinite array of undamaged MO-1s with WG MOX fuel are presented in Table 6.16 for progressive states of water flooding. In the infinite array, the spacing between the undamaged packages is zero. The calculated $k_{\infty}$ for the infinite array increases as the internal-water density increases to full density, as shown in Table 6.16. Furthermore, optimum internal moderation in the array configuration occurs at full-water density. Comparison of the fully reflected and moderated single-package case to the infinite-array configuration reveals the calculated $k$ 's are statistically the same within $2 \sigma$. Therefore, the packages are neutronically isolated at full-density-water moderation with no spacing between the packages. As a result, the calculated $k_{\infty}$ for the infinite array of completely flooded MO-1s, with no spacing between packages, is the maximum eigenvalue for the array of undamaged packages. Based on the results, the calculated $k_{\infty}+2 \sigma$ for the infinite array is 0.8991 , which is less than the USL. 
Table 6.15. Calculated $k_{e f f}$ values for finite array of damaged MO-1s with $4.4 \mathrm{wt} \%$ and $3.03 \mathrm{wt} \% \mathrm{PuO}_{2} \mathrm{MOX}$ fuel

\begin{tabular}{|c|c|c|c|c|}
\hline Case & $\begin{array}{l}\text { Internal } \\
\mathrm{H}_{2} \mathrm{O} \text { volume } \\
\text { fraction }^{a}\end{array}$ & Description & $k_{e f f} \pm \sigma$ & $k_{e f f}+2 \sigma$ \\
\hline $4 \mathrm{ar}-0$ & 1.0 & $\begin{array}{l}2 \times 1 \times 1 \text { array, damaged packages with } \\
\text { shifted fuel contents (Fig. } 3.10) . \text { Crushed } \\
\text { wall thickness }=0.028 \text { in. }(0.071 \mathrm{~cm}) . \text { Temp } \\
=483.15 \mathrm{~K} . \text { Fuel is } 4.4 \mathrm{wt} \% \mathrm{PuO}_{2} \mathrm{MOX}\end{array}$ & $0.9477 \pm 0.0016$ & 0.9509 \\
\hline $4 a r-3$ & 1.0 & $\begin{array}{l}2 \times 1 \times 1 \text { array, damaged packages with } \\
\text { shifted fuel contents (Fig. } 3.10) . \text { Crushed } \\
\text { wall thickness }=1.836 \text { in. }(4.663 \mathrm{~cm} \text { ). Foam } \\
\text { replaced by } \mathrm{H}_{2} \mathrm{O} . \mathrm{Temp}^{2} 483.15 \mathrm{~K} \text {. } \\
\text { Fuel is } 4.4 \mathrm{wt} \% \mathrm{PuO}_{2} \mathrm{MOX}\end{array}$ & $0.9002 \pm 0.0019$ & 0.9040 \\
\hline $3 \mathrm{ar}-0$ & 1.0 & $\begin{array}{l}2 \times 1 \times 1 \text { array, damaged packages with } \\
\text { shifted fuel contents (Fig. } 3.10) . \text { Crushed } \\
\text { wall thickness }=0.028 \text { in. }(0.071 \mathrm{~cm}) . \text { Temp } \\
=483.15 \mathrm{~K} . \text { Fuel is } 3.03 \mathrm{wt} \% \mathrm{PuO}_{2} \mathrm{MOX}\end{array}$ & $0.9467 \pm 0.0016$ & 0.9499 \\
\hline $3 \mathrm{ar}-3$ & 1.0 & $\begin{array}{l}2 \times 1 \times 1 \text { array, damaged packages with } \\
\text { shifted fuel contents (Fig. } 3.10) . \text { Crushed } \\
\text { wall thickness }=1.836 \text { in. }(4.663 \mathrm{~cm} \text { ). Foam } \\
\text { replaced by } \mathrm{H}_{2} \mathrm{O} . \mathrm{Temp}=483.15 \mathrm{~K} . \\
\text { Fuel is } 3.03 \mathrm{wt} \% \mathrm{PuO}_{2} \mathrm{MOX}\end{array}$ & $0.8975 \pm 0.0016$ & 0.9007 \\
\hline
\end{tabular}

${ }^{a}$ Volume fraction applies to void locations that are within the first containment boundary (i.e., innercontainment shell). For cases with the foam replaced by water, the $\mathrm{H}_{2} \mathrm{O}$ is at full density.

In the above infinite-array model, each MO-1 has one WG MOX fuel assembly positioned on the strongback support frame. To model the infinite array, a single undamaged MO-1 was modeled with mirror reflection on all faces, thereby replicating the single unit an infinite number of times. If one assembly is shipped within the MO-1, there are two possible locations on the strongback support for securing the fuel assembly. The infinite-array model generated with mirror reflection considers the position of the fuel assembly within each MO-1 to be the same throughout the infinite array. To complete the array analysis, an additional model must be considered. In particular, a neighboring MO-1 may have the single fuel assembly located in the position closest to the other MO-1, as shown in Fig. 6.9. In this configuration, the neighboring fuel assemblies are located as close as possible under normal conditions of transport. The calculated $k_{\infty}$ for an infinite array of the configuration, presented in Fig. 6.9, is also provided in Table 6.17. Based on the calculated results, the most reactive configuration occurs when the packages are completely flooded. The calculated $k_{\infty}$ for the loading configuration in Fig. 6.9 is $\sim 1 \%$ higher than a fully reflected single MO-1 (i.e., Case wm-10). As a result, the altered loading configuration slightly increases the system multiplication relative to the single-unit case; however, the system multiplication for the infinite array with this altered fuel configuration is acceptably subcritical (i.e., $k_{\infty}+2 \sigma<$ USL). 
Table 6.16. Calculated system multiplication for an infinite array of undamaged MO-1s with one WG MOX assembly

\begin{tabular}{cccc}
\hline Case & Internal $\mathrm{H}_{2} \mathrm{O}$ volume fraction & $k_{\infty} \pm \sigma$ & $k_{\infty}+2 \sigma$ \\
\hline wi-1 & 0.0 & $0.4967 \pm 0.0012$ & 0.4991 \\
wi-2 & 0.001 & $0.4927 \pm 0.0012$ & 0.4951 \\
wi-3 & 0.003 & $0.4833 \pm 0.0012$ & 0.4857 \\
wi-4 & 0.05 & $0.4093 \pm 0.0012$ & 0.4117 \\
wi-5 & 0.1 & $0.3946 \pm 0.0013$ & 0.3972 \\
wi-6 & 0.4 & $0.5611 \pm 0.0017$ & 0.5645 \\
wi-7 & 0.6 & $0.6955 \pm 0.0015$ & 0.6985 \\
wi-8 & 0.8 & $0.8086 \pm 0.0017$ & 0.8120 \\
wi-9 & 0.9 & $0.8597 \pm 0.0018$ & 0.8633 \\
wi-10 & 0.95 & $0.8823 \pm 0.0018$ & 0.8859 \\
wi-11 & 1.0 & $0.9054 \pm 0.0018$ & 0.9090 \\
\hline
\end{tabular}

Table 6.17. Calculated system multiplication for an infinite array of undamaged MO-1s with altered assembly loading configuration

\begin{tabular}{cccc}
\hline Case & Internal $\mathrm{H}_{2} \mathrm{O}$ volume fraction & $k_{\infty} \pm \sigma$ & $k_{\infty}+2 \sigma$ \\
\hline wi2-1 & 0.0 & $0.5124 \pm 0.0011$ & 0.5146 \\
wi2-2 & 0.001 & $0.5109 \pm 0.0012$ & 0.5133 \\
wi2-3 & 0.003 & $0.5036 \pm 0.0012$ & 0.5060 \\
wi2-4 & 0.05 & $0.4265 \pm 0.0012$ & 0.4289 \\
wi2-5 & 0.1 & $0.4001 \pm 0.0014$ & 0.4029 \\
wi2-6 & 0.4 & $0.5688 \pm 0.0016$ & 0.5720 \\
wi2-7 & 0.6 & $0.7096 \pm 0.0016$ & 0.7128 \\
wi2-8 & 0.8 & $0.8201 \pm 0.0016$ & 0.8233 \\
wi2-9 & 0.9 & $0.8698 \pm 0.0017$ & 0.8732 \\
wi2-10 & 0.95 & $0.8916 \pm 0.0017$ & 0.8950 \\
wi2-11 & 1.0 & $0.9139 \pm 0.0018$ & 0.9175 \\
\hline
\end{tabular}




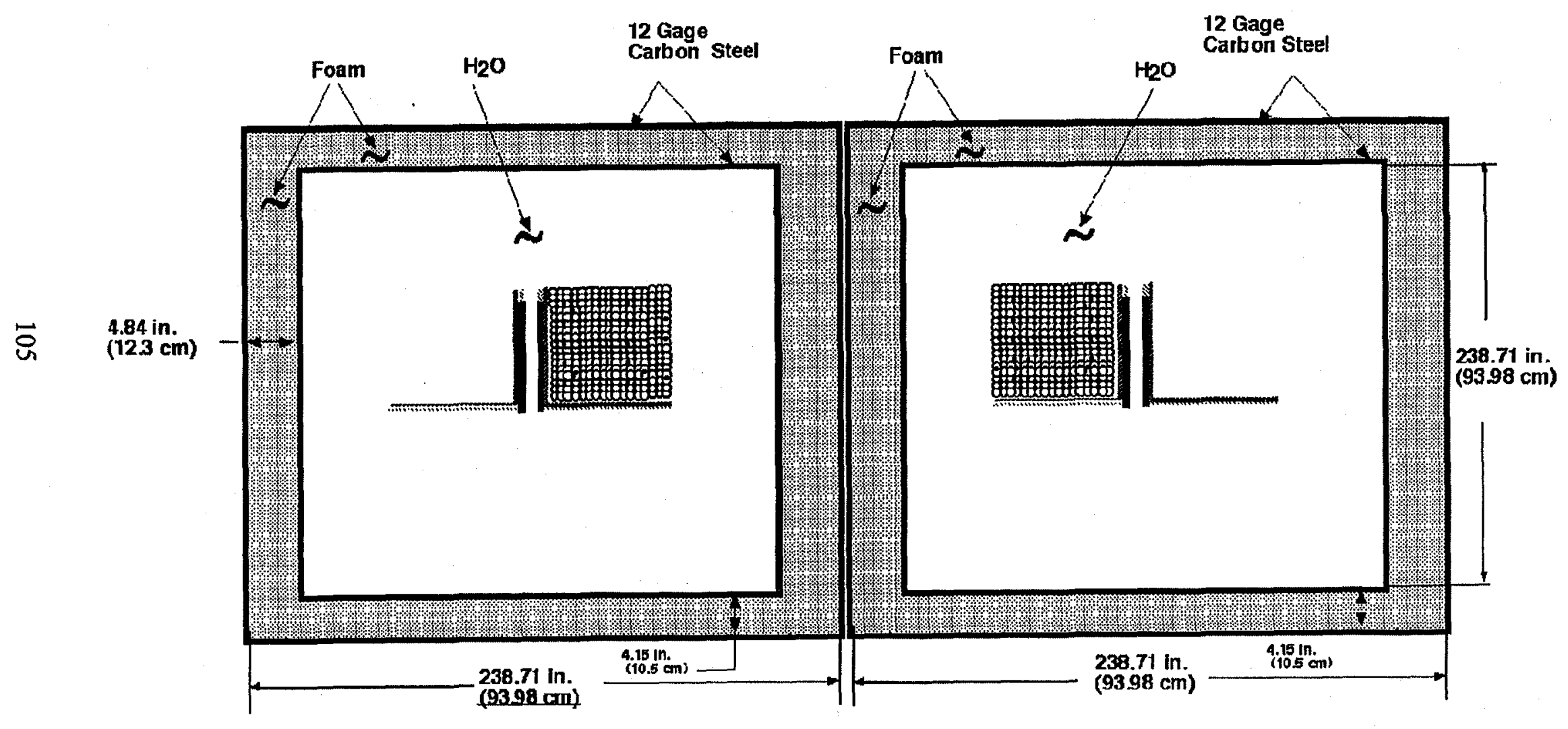

Fig. 6.9. Possible loading configuration for one WG assembly in two undamaged MO-1 packages. 


\subsubsection{Damaged Package Configurations}

As noted in Sect. 6.2.1, the limiting configuration for damaged packages with non-weapons-grade MOX fuel is a $1 \times 1 \times 1$ array. In this limiting case, each MO- 1 has a shifted fuel configuration that optimizes interaction between the two packages. Specifically, the fuel contents of one package are shifted to the lower left corner of the internal MO-1 cavity, as shown in Fig. 3.9. The contents of the second damaged MO-1 is shifted to the lower-right corner of the internal cavity as shown in Fig. 3.10. In both packages, the crushed exterior containment is $0.028 \mathrm{in} .(0.071 \mathrm{~cm})$ thick carbon steel with no polyurethane foam insulation. This configuration is reevaluated with a single WG MOX fuel assembly in each MO-1. As in the previous calculation, both MO-1s are completely flooded and the array of packages is fully reflected with $12 \mathrm{in.}(30 \mathrm{~cm})$ of water. The calculated $k_{e f f}$ of the $2 \times 1 \times 1$ array is provided in Table 6.18 with the calculated result for the damaged single package case with shifted fuel contents. The calculated $k_{\text {eff }}+2 \sigma$ for the two damaged packages is greater than the USL and is not subcritical. Based on the discussion presented in Sect. 6.2.1, the 0.028-in. $(0.071-\mathrm{cm})$ crushed wall thickness increases package interaction but may be overly conservative. Additional calculated results are also presented in Table 6.18 to assess the conservatism in the damaged package model. In Case war-1, the fuel contents are shifted, as shown in Fig. 3.10; however, the walls are undamaged in each MO-1, and the polyurethane foam is replaced by water. Per the discussion in Sect. 6.2.1, two additional crushed wall thicknesses are considered in Cases war- 2 and war-3. Specifically, the crushed wall thickness is 0.239 in. $(0.607 \mathrm{~cm})$ in Case war- 2 and 1.836 in. $(4.663 \mathrm{~cm})$ in Case war-3. The polyurethane foam is replaced by water in each model. If the walls separating the two packages are not crushed, the calculated $k_{e f f}+2 \sigma$ is 0.9019 , which is less than the USL. Since a damaged exterior containment is a credible scenario, the damaged package evaluation must consider containment deformation. The calculated $k_{e f f}$ values $+2 \sigma$ for Cases war- 2 and war- 3 are 1.0135 and 0.9581 , respectively. With the revised crushed wall thicknesses, the package interaction decreases; however, the array of two damaged packages with WG MOX fuel is not subcritical relative to the calculational USL. Therefore, only one damaged MO-1 package is acceptably subcritical with one WG MOX fuel assembly.

\subsection{TRANSPORT INDEX}

In the following sections, the limiting case for the TI determination is the $1 \times 1 \times 1$ array of damaged packages presented in Sects. 6.2.1 and 6.2.2 for the WG and non-weapons-grade MOX fuel loading, respectively. As noted in Sect. 3.4, the array model for the two damaged packages is conservative. Note that the actual wall thickness of each damaged package would most likely exceed $0.028 \mathrm{in} .(0.071 \mathrm{~cm})$, and there would also be other structural materials (e.g., foam, shock mounts, clamping frames, etc.) present to further separate the fuel contents of both MO-1 packages. Consequently, the finite-array model maximizes package interaction and reactivity with regard to the damaged packages. Further refinement of the impact and structural analysis could lead to a refined criticality safety model of the two damaged packages and subsequent reduction in the TI for criticality control. The calculated TI presented in the following sections is considered to be conservative with regard to shipment of WG and non-weapons-grade MOX fuel in the MO-1. 
Table 6.18. Calculated $k_{e f f}$ values for finite array of damaged MO-1s with WG MOX

\begin{tabular}{|c|c|c|c|c|}
\hline Case & $\begin{array}{l}\text { Internal } \\
\mathrm{H}_{2} \mathrm{O} \\
\text { volume } \\
\text { fraction }^{a}\end{array}$ & Description & $k_{e f f} \pm \sigma$ & $k_{e f f}+2 \sigma$ \\
\hline wb-1 & 1.0 & $\begin{array}{l}1 \times 1 \times 1 \text { array, damaged package with shifted } \\
\text { fuel contents (Fig. 3.9). Temp }=483.15 \mathrm{~K}\end{array}$ & $0.8886 \pm 0.0016$ & 0.8918 \\
\hline war-0 & 1.0 & $\begin{array}{l}2 \times 1 \times 1 \text { array, damaged packages with shifted } \\
\text { fuel contents (Fig. } 3.10) . \text { Crushed wall } \\
\text { thickness }=0.028 \text { in. }(0.071 \mathrm{~cm}) . \text { Temp }= \\
483.15 \mathrm{~K}\end{array}$ & $1.0224 \pm 0.0017$ & 1.0258 \\
\hline war-1 & 1.0 & $\begin{array}{l}2 \times 1 \times 1 \text { array, damaged packages with shifted } \\
\text { fuel contents }(\text { Fig. } 3.10 \text { ). Undamaged } \\
\text { containment with foam replaced by } \mathrm{H}_{2} \mathrm{O} \text {. } \\
\text { Temp }=483.15 \mathrm{~K}\end{array}$ & $0.8985 \pm 0.0017$ & 0.9019 \\
\hline war-2 & 1.0 & $\begin{array}{l}2 \times 1 \times 1 \text { array, damaged packages with shifted } \\
\text { fuel contents (Fig. } 3.10) . \text { Crushed wall } \\
\text { thickness }=0.239 \text { in. }(0.607 \mathrm{~cm}) . \text { Foam } \\
\text { replaced by } \mathrm{H}_{2} \mathrm{O} . \text { Temp }=483.15 \mathrm{~K}\end{array}$ & $1.0095 \pm 0.0017$ & 1.0129 \\
\hline war-3 & 1.0 & $\begin{array}{l}2 \times 1 \times 1 \text { array, damaged packages with shifted } \\
\text { fuel contents (Fig. } 3.10 \text { ). Crushed wall } \\
\text { thickness }=1.836 \text { in. }(4.663 \mathrm{~cm} \text { ). Foam } \\
\text { replaced by } \mathrm{H}_{2} \mathrm{O} . \text { Temp }=483.15 \mathrm{~K}\end{array}$ & $0.9403 \pm 0.0017$ & 0.9437 \\
\hline
\end{tabular}

${ }^{a}$ Volume fraction applies to void locations that are within the first containment boundary (i.e., innercontainment shell). For cases with the foam replaced by water, the $\mathrm{H}_{2} \mathrm{O}$ is at full density. 


\subsubsection{Previously Certified MOX Fuel}

The TI for criticality control is determined by the number of packages that are subcritical. Table 6.19 summarizes the results for the number of packages that are subcritical under normal and hypothetical accident conditions. For normal conditions of transport, an infinite array of packages is subcritical. As discussed in Sect. 6.2.1, only one damaged package with two assemblies would remain subcritical. In accordance with $10 \mathrm{CFR} \S 71.59$, the maximum number of packages for an exclusive-use shipment is $1(\mathrm{~N}=0.5)$, and the corresponding $\mathrm{TI}$ is 100 .

Table 6.19. Previously certified MOX fuel parameters used for TI determination

\begin{tabular}{cc}
\hline Case & Number of subcritical packages \\
\hline Undamaged & $\infty$ \\
Damaged & 1 \\
\hline
\end{tabular}

\subsubsection{Weapons-Grade MOX Fuel}

Table 6.20 summarizes the results for the number of packages that are subcritical under normal and hypothetical accident conditions. For normal conditions of transport, an infinite array of packages is subcritical. As discussed in Sect. 6.2.2, only one damaged package with one weapons-grade MOX assembly would remain subcritical. In accordance with 10 CFR $\$ 71.59$, the maximum number of packages for an exclusive use shipment is $1(\mathrm{~N}=0.5)$, and the corresponding $T I$ is 100 .

Table 6.20. Weapons-grade MOX fuel parameters used for TI determination

\begin{tabular}{cc}
\hline Case & Number of subcritical packages \\
\hline Undamaged & $\infty$ \\
Damaged & 1 \\
\hline
\end{tabular}




\section{CRITICALITY CALCULATIONS AND RESULTS FOR SHIPMENT OF FUEL PINS}

This section provides a criticality safety assessment for the shipment of individual MOX fuel pins using the MO-1 shipping package. The design specifications for the previously approved MOX fuel pins and proposed WG MOX fuel pins are presented in Sect. 2.1. Based on the information provided in ref. 10, the fuel pins are shipped in a box with maximum internal dimensions of $8.260 \mathrm{in} . \times 8.260 \mathrm{in} .(20.98 \mathrm{~cm} \times$ $20.98 \mathrm{~cm}$ ). The internal dimensions include the maximum mechanical tolerance. The material specifications and internal length of the rod box are not specified in ref. 10. Consequently, the rod box is not explicitly modeled in the evaluation. However, the specified maximum internal dimensions are used to determine the number of pins that could fit in the fuel rod box.

Following the evaluation process of Sect. 6 , a criticality safety assessment is provided for the shipment of MOX fuel pins in the MO-1. Because this evaluation considers different fuel loadings, a separate discussion is provided for the previously approved MOX fuel and proposed WG MOX fuel.

\subsection{Evaluation Constraints}

Since the only design constraint is the rod box cross-sectional area, the evaluation initially considers the shipment of pins arranged in a triangular-pitch configuration within the box. As noted in Sect. 2.1, the original certified MOX contents include three possible fuel loadings (i.e., 6, 4.4 and $3.03 \mathrm{wt} \% \mathrm{PuO}_{2}$ ). Figure 7.1 presents the infinite multiplication factor as a function of triangular pitch for each MOX loading. Based on the results in Fig. 7.1 for each fuel loading, full-density-water moderation is optimum for a pitch below $2.0 \mathrm{~cm}(5.08 \mathrm{in}$.) in an infinite array. With regard to the WG MOX fuel, the fuel isotopics are also presented in Sect. 2.1. Figure 7.2 presents the infinite multiplication factor as a function of triangular pitch for the WG MOX fuel. The results in Fig. 7.2 also demonstrate that full-density-water moderation is optimum for a pitch which is less than $2.0 \mathrm{~cm}$ (5.08 in.).

Using the specified box dimensions, Table 7.1 provides the maximum number of pins that can fit in the box as a function of triangular pitch for the $6 \mathrm{wt} \% \mathrm{PuO}_{2} \mathrm{MOX}$ fuel. In addition, Table 7.1 also provides the calculated $k_{e f f}$ for a single box containing the specified number pins. For each case, the box is completely flooded and reflected on all sides with $12 \mathrm{in}$. $(30 \mathrm{~cm})$ of water. Since the fuel pin outer radius is $0.211 \mathrm{in}$. $(0.536 \mathrm{~cm})$, the minimum pitch for an array of fuel pins is $0.422 \mathrm{in} .(1.072 \mathrm{~cm})$. Similar results are also provided in Tables 7.2 and 7.3 for the 4.4 and $3.03 \mathrm{wt} \% \mathrm{PuO}_{2}$ MOX Fuel, respectively. Based on the results in Tables 7.1-7.3, the maximum $k_{\text {eff }}$ for each MOX loading occurs at a pitch of 0.75 in. $(1.90 \mathrm{~cm})$. With regard to the WG MOX, Table 7.4 provides the maximum number of pins that can fit in the box as a function of triangular pitch. As with the previously certified MOX fuel, Table 7.4 also provides the calculated $k_{\text {eff }}$ for a single box containing the specified number of pins. Based on the results in Table 7.4, the maximum $k_{\text {eff }}$ occurs at a triangular pitch of $0.75 \mathrm{in} .(1.90 \mathrm{~cm})$. Note that the calculations presented in Tables 7.1-7.4 assume all pins within the box are the same (i.e., no guide tubes or instrumentation tubes are present). 


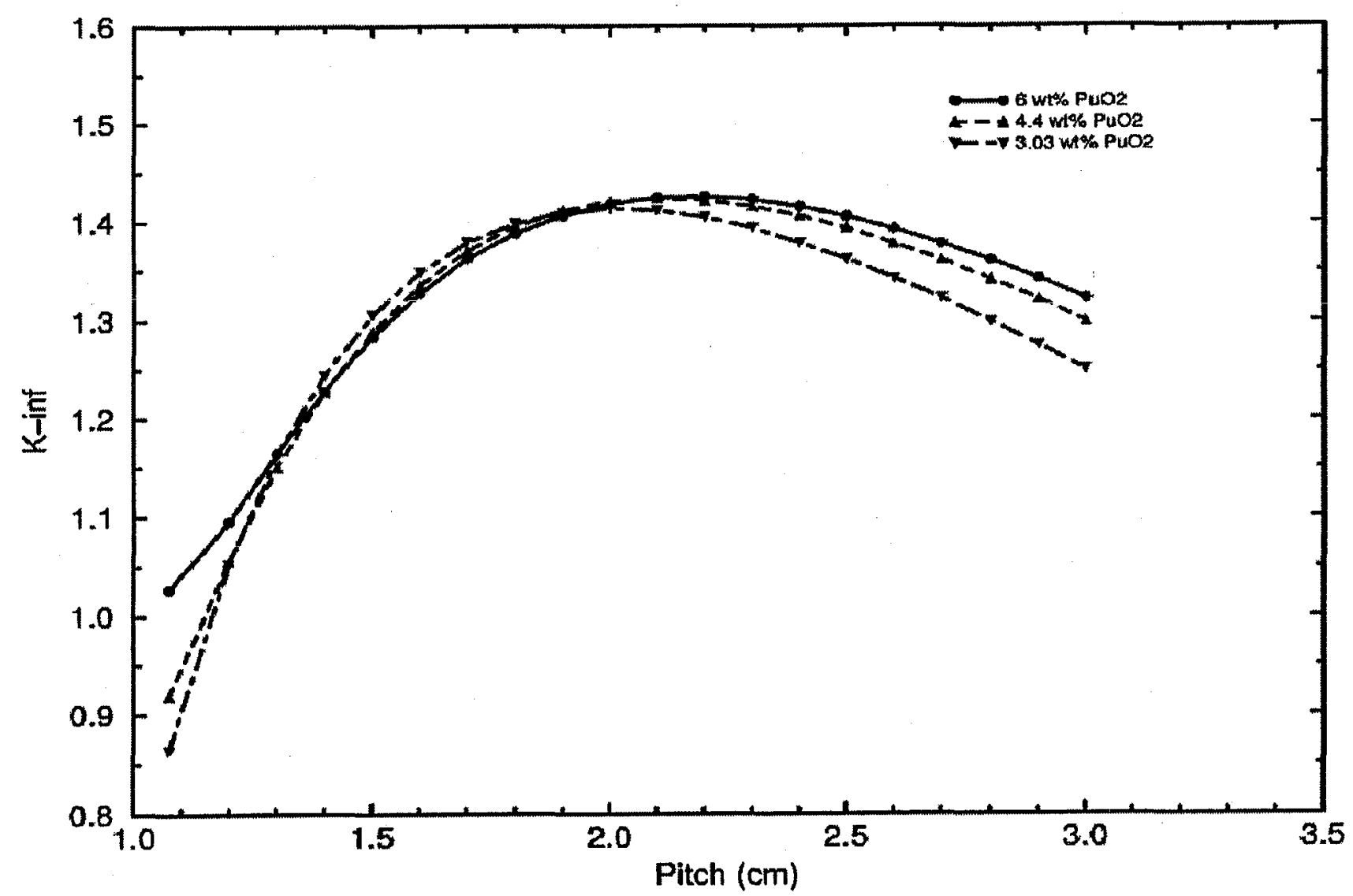

Fig. 7.1. $k_{\infty}$ as a function of triangular pitch for previously certified MOX fuel. 


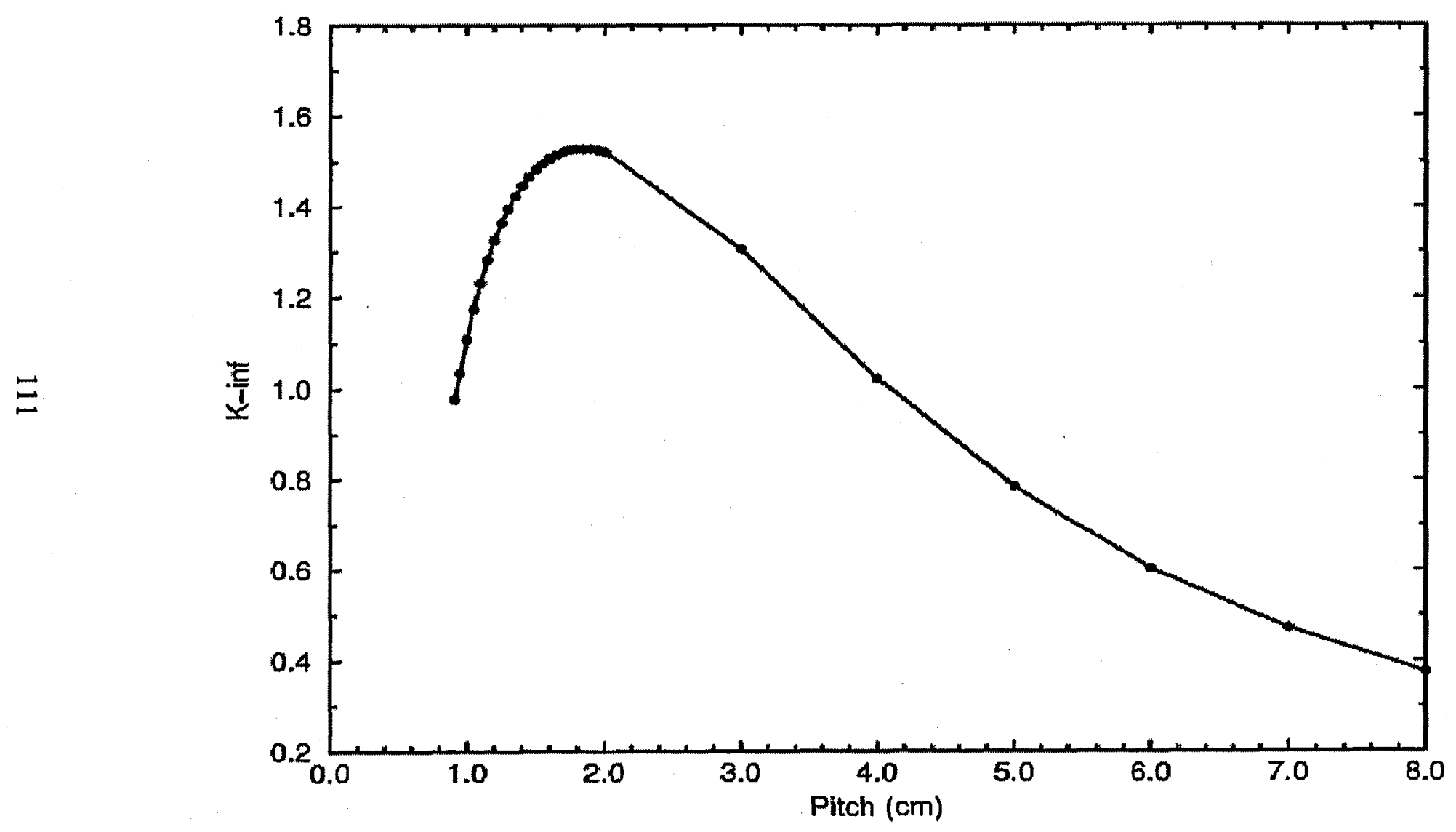

Fig. 7.2. $k_{\infty}$ as a function of triangular pitch for WG MOX fuel. 
Table 7.1. Calculated $k_{e f f}$ values for $6 \mathrm{wt} \% \mathrm{PuO}_{2} \mathrm{MOX}$ fuel in rod box fully moderated and reflected with $\mathrm{H}_{2} \mathrm{O}$

\begin{tabular}{cccccc}
\hline & \multicolumn{2}{c}{ Fuel pitch } & & & \\
\cline { 2 - 3 } Case & $\mathrm{cm}$ & in. & Number of pins & $k_{\text {eff }} \pm \sigma$ & $k_{\text {eff }}+2 \sigma$ \\
\hline $6-1$ & 1.072 & 0.422 & 418 & $0.6427 \pm 0.0013$ & 0.6453 \\
$6-2$ & 1.20 & 0.47 & 340 & $0.6989 \pm 0.0013$ & 0.7015 \\
$6-3$ & 1.40 & 0.55 & 247 & $0.7823 \pm 0.0015$ & 0.7853 \\
$6-4$ & 1.60 & 0.63 & 188 & $0.8418 \pm 0.0018$ & 0.8454 \\
$6-5$ & 1.80 & 0.71 & 150 & $0.8789 \pm 0.0018$ & 0.8825 \\
$6-6$ & 1.90 & 0.75 & 137 & $0.8955 \pm 0.0017$ & 0.8989 \\
$6-7$ & 2.00 & 0.79 & 120 & $0.8914 \pm 0.0018$ & 0.8950 \\
$6-8$ & 2.10 & 0.83 & 105 & $0.8847 \pm 0.0016$ & 0.8879 \\
\hline
\end{tabular}

Table 7.2. Calculated $k_{\text {eff }}$ values for $4.4 \mathrm{wt} \% \mathrm{PuO}_{2}$ MOX fuel in rod box fully moderated and reflected with $\mathrm{H}_{2} \mathrm{O}$

\begin{tabular}{cccccc}
\hline & \multicolumn{2}{c}{ Fuel pitch } & & & \\
\cline { 2 - 3 } Case & $\mathrm{cm}$ & in. & Number of pins & $k_{\text {eff }} \pm \sigma$ & $k_{\text {eff }}+2 \sigma$ \\
\hline $4-1$ & 1.072 & 0.422 & 418 & $0.6195 \pm 0.0014$ & 0.6223 \\
$4-2$ & 1.20 & 0.47 & 340 & $0.6935 \pm 0.0016$ & 0.6967 \\
$4-3$ & 1.40 & 0.55 & 247 & $0.7865 \pm 0.0015$ & 0.7895 \\
$4-4$ & 1.60 & 0.63 & 188 & $0.8495 \pm 0.0020$ & 0.8535 \\
$4-5$ & 1.80 & 0.71 & 150 & $0.8820 \pm 0.0017$ & 0.8854 \\
$4-6$ & 1.90 & 0.75 & 137 & $0.8949 \pm 0.0018$ & 0.8985 \\
$4-7$ & 2.00 & 0.79 & 120 & $0.8909 \pm 0.0019$ & 0.8947 \\
$4-8$ & 2.10 & 0.83 & 105 & $0.8847 \pm 0.0016$ & 0.8879 \\
\hline
\end{tabular}


Table 7.3. Calculated $k_{\text {eff }}$ values for $3.03 \mathrm{wt} \% \mathrm{PuO}_{2} \mathrm{MOX}$ fuel in rod box fully moderated and reflected with $\mathrm{H}_{2} \mathrm{O}$

\begin{tabular}{cccccc}
\hline & \multicolumn{2}{c}{ Fuel pitch } & & & \\
\cline { 2 - 3 } Case & cm & in. & Number of pins & $k_{\text {eff }} \pm \sigma$ & $k_{\text {eff }}+2 \sigma$ \\
\hline $3-1$ & 1.072 & 0.422 & 418 & $0.6024 \pm 0.0014$ & 0.6052 \\
$3-2$ & 1.20 & 0.47 & 340 & $0.6855 \pm 0.0015$ & 0.6885 \\
$3-3$ & 1.40 & 0.55 & 247 & $0.7870 \pm 0.0016$ & 0.7902 \\
$3-4$ & 1.60 & 0.63 & 188 & $0.8432 \pm 0.0018$ & 0.8468 \\
$3-5$ & 1.80 & 0.71 & 150 & $0.8749 \pm 0.0017$ & 0.8783 \\
$3-6$ & 1.90 & 0.75 & 137 & $0.8821 \pm 0.0016$ & 0.8853 \\
$3-7$ & 2.00 & 0.79 & 120 & $0.8746 \pm 0.0016$ & 0.8778 \\
$3-8$ & 2.10 & 0.83 & 105 & $0.8637 \pm 0.0018$ & 0.8673 \\
\hline
\end{tabular}

Table 7.4. Calculated $k_{\text {eff }}$ values for WG MOX fuel in rod box fully moderated and reflected with $\mathrm{H}_{2} \mathrm{O}$

\begin{tabular}{cccccc}
\hline & \multicolumn{2}{c}{ Fuel pitch } & & & \\
\cline { 2 - 3 } Case & cm & in. & Number of pins & $k_{\text {eff }} \pm$ & $k_{\text {eff }}+2 \sigma$ \\
\hline w-1 & 0.9144 & 0.360 & 572 & $0.6352 \pm 0.0013$ & 0.6378 \\
w-2 & 1.00 & 0.39 & 492 & $0.7028 \pm 0.0014$ & 0.7056 \\
w-3 & 1.10 & 0.43 & 407 & $0.7766 \pm 0.0015$ & 0.7796 \\
w-4 & 1.20 & 0.47 & 340 & $0.8346 \pm 0.0018$ & 0.8382 \\
w-5 & 1.30 & 0.51 & 279 & $0.8678 \pm 0.0017$ & 0.8712 \\
w-6 & 1.40 & 0.55 & 247 & $0.9066 \pm 0.0017$ & 0.9100 \\
w-7 & 1.50 & 0.59 & 216 & $0.9290 \pm 0.0020$ & 0.9330 \\
w-8 & 1.60 & 0.63 & 195 & $0.9520 \pm 0.0019$ & 0.9558 \\
w-9 & 1.70 & 0.67 & 168 & $0.9547 \pm 0.0016$ & 0.9579 \\
w-10 & 1.80 & 0.71 & 150 & $0.9559 \pm 0.0018$ & 0.9595 \\
w-11 & 1.85 & 0.73 & 143 & $0.9584 \pm 0.0018$ & 0.9620 \\
w-12 & 1.90 & 0.75 & 143 & $0.9717 \pm 0.0020$ & 0.9757 \\
w-13 & 1.95 & 0.77 & 126 & $0.9480 \pm 0.0016$ & 0.9512 \\
\hline
\end{tabular}


The difficult task involved in the evaluation of a "loose" pin configuration is determining the most reactive fuel configuration within the rod box. If an arbitrary number of pins is placed in the box without controlling the pitch (i.e., nonuniform pitch), a myriad of possible fuel pin configurations can exist within the rod box. A variation of the configurations presented in Tables 7.1-7.4 could yield a more reactive configuration. The following example re-evaluates the minimum-pitch case in Table 7.1 (i.e., Case 6-1) with a slight variation. In particular, 25 pins are arbitrarily removed from the box, as shown in Fig. 7.3. If there is no physical control on pitch, the configuration presented in Figure 7.3 could represent a possible arrangement of "loose" pins if the box is not completely filled. In other words, Figure 7.3 might represent a pin configuration with void pockets in a partially loaded box. Using the $6 \mathrm{wt} \% \mathrm{PuO}_{2} \mathrm{MOX}$ fuel loading, the calculated $k_{e f f}$ for the configuration presented in Fig. 7.3 is $0.6688 \pm 0.0014$, which is $4 \%$ greater than Case 6-1. A similar type variation for the minimum-pitch case in Table 7.4 (i.e., Case w-1) is shown in Fig. 7.4. In the WG MOX case, 40 pins are arbitrarily removed from the box, and the calculated $k_{e f f}$ for the configuration presented in Fig. 7.4 is $0.6761 \pm 0.0015$, which is $\sim 6 \%$ higher than Case $w-1$. Since the configurations in Figs. 7.3 and 7.4 are arbitrary, another configuration may exist which is more reactive. If there is no physical control on pitch, there are an infinite number of configurations which could exist within the fuel rod box. Because of the many possible configurations, a countless number of calculations would be required to determine the most reactive configuration. Consequently, providing approval for the shipment of an arbitrary number of pins arranged in an arbitrary configuration within a rod box is not practical from a criticality safety standpoint. Additional constraints must be defined to facilitate a proper evaluation.

As noted previously, this evaluation is a scoping study intended to illustrate the requisite criticality safety information for a safety analysis report. In order to complete the "loose" pin evaluation, additional design constraints must be defined to reduce the degrees of freedom in the criticalty safety evaluation. The following constraints or assumptions are used in the subsequent calculations:

1. The fuel package (i.e., at most two boxes) within the MO-1 consists of the same type of fuel pins.

2. No guide tubes or instrumentation tubes are loaded in a rod box.

3. The fuel pins within each rod box are arranged on a specified triangular pitch, which is determined in the subsequent calculations for the different fissile loadings.

4. The fuel-pin pitch is maintained using noncombustable materials that do not provide better (i.e., more reactive) interstitial moderation than water.

5. The structural integrity of the materials used to control the pitch is maintained during impact conditions.

6. There are no vacant rod positions within the fuel pin array in the rod box. If a box is partially loaded, the box is filled from the bottom, leaving no vacant pin locations in the array.

In the following discussion, the term "loose" fuel pins refers to an individual pin configuration that conforms to the above constraints. 


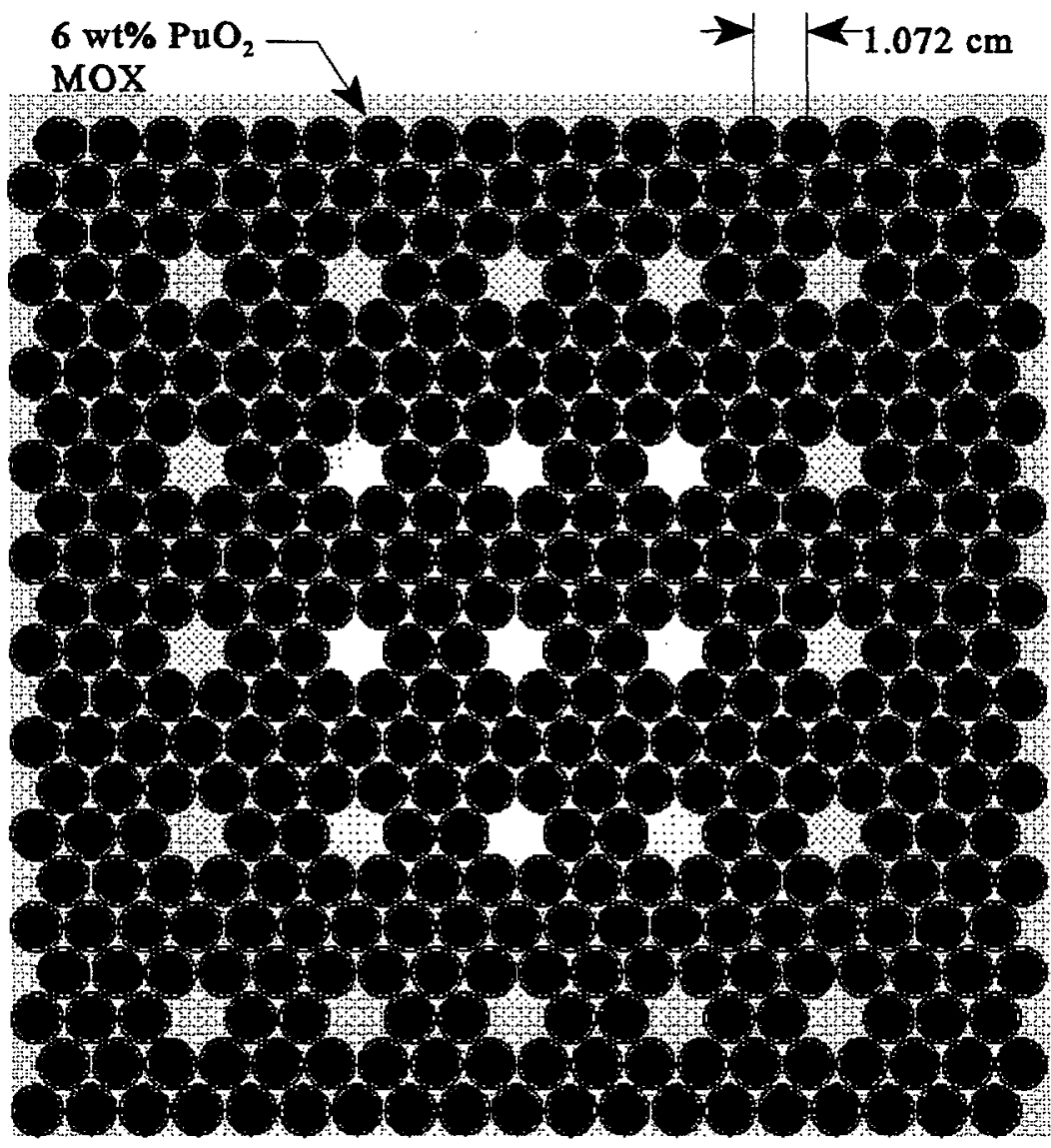

Fig. 7.3. Arbitrary configuration of $6 \mathrm{wt} \% \mathrm{PuO}_{2} \mathrm{MOX}$ fuel pins. 


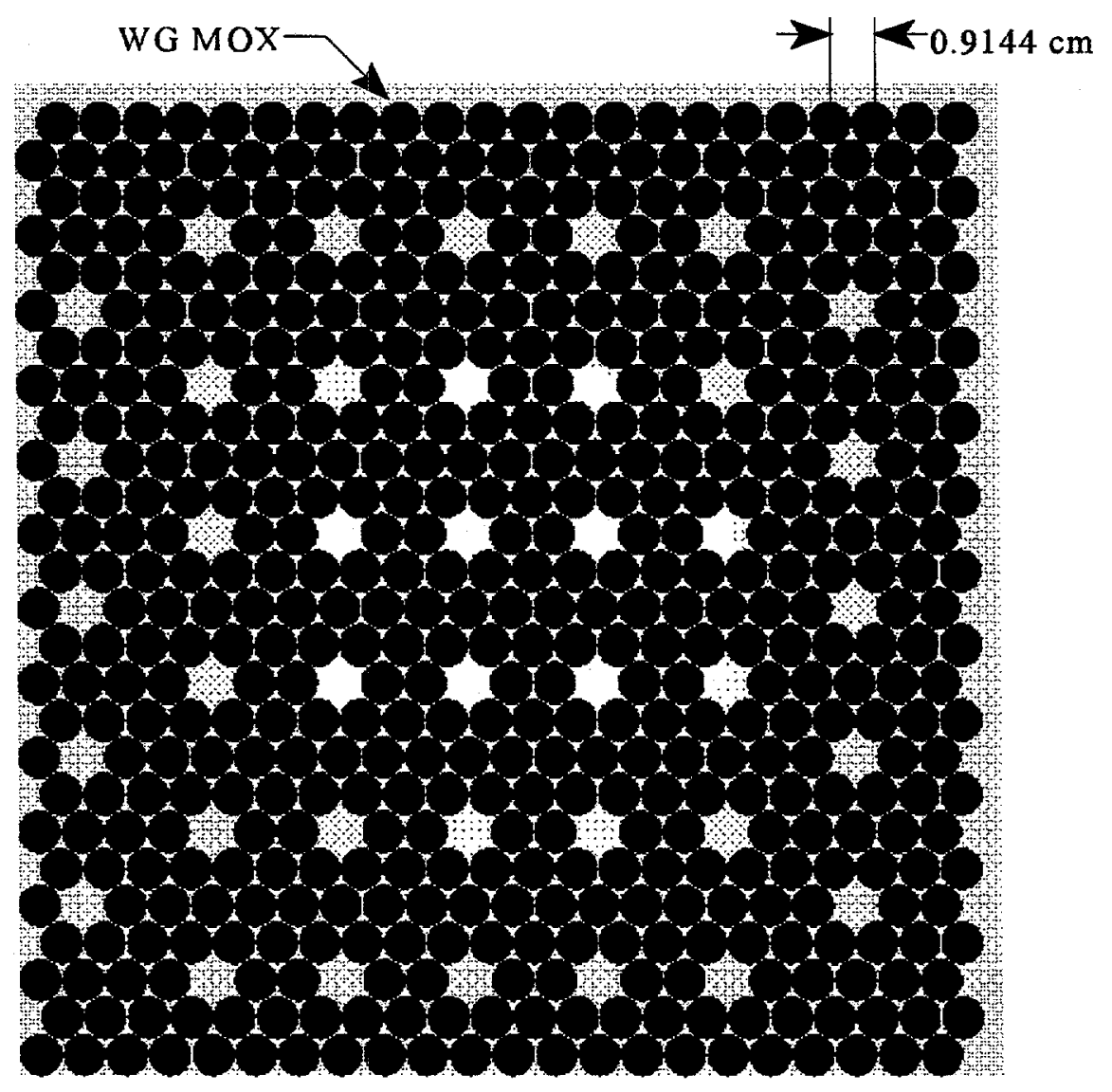

Fig. 7.4. Arbitrary configuration of WG MOX fuel pins. 


\subsection{Single Package}

As noted in Sect. 6.1, the evaluation must demonstrate that the single package remains subcritical under normal conditions of transport as well as hypothetical accident conditions. In an effort to meet this objective, the evaluation considers internal package flooding, variations in external package reflection, as well as temperature variations in the MO-1. Regarding accident conditions, the evaluation considers the loss of polyurethane foam, replacement of foam with water, fire conditions, package wall thickness reduction, payload shift and loss of rod box spacing on strongback support.

\subsubsection{Previously Certified MOX Fuel}

\subsubsection{Undamaged Package Configurations}

Based on the constraints specified in Sect. 7.1 and the results presented in Tables 7.1-7.3, the maximum pitch considered for shipment of the previously certified MOX fuel is $0.47 \mathrm{in} .(1.20 \mathrm{~cm})$. In Sect. 6, the MO-1 is loaded with at most two fuel assemblies which consist of the previously certified MOX fuel. In the following single-package analysis, the single-package models, which are presented in Sect. 6.1.1, are used to reevaluate an MO-1 package loaded with two boxes of fuel pins.

Since the inleakage of water is not an incredible scenario, water flooding of the package must be considered during normal conditions of transport. As noted in Sect. 7.1, the fuel is undermoderated for a pitch less than $0.75 \mathrm{in} .(1.90 \mathrm{~cm})$, and full-density-water flooding is optimum for a $0.47-\mathrm{in} .(1.20-\mathrm{cm})$ pitch. The single-package cases are presented in Table 7.5 for the 6 wt $\% \mathrm{PuO}_{2} \mathrm{MOX}$ fuel pins. The calculated $k_{\text {eff }}$ for the water-flooded and water-reflected MO-1 loaded with 2 boxes of fuel pins (i.e., Case $16 \mathrm{~m}-10$ ) is $0.6919 \pm 0.0016$. In accordance with NUREG/CR-5661 (ref. 7), the single-containment model is presented in Table 7.5 as Case lsc-6. The water-reflected, single-containment model is statistically the same as the optimally moderated and fully reflected MO-1 package with polyurethane foam. Results are also presented in Table 7.5 which evaluate the MO-1 with 12-in. $(30-\mathrm{cm})$ carbon-steel reflection (Case 16r-1) and 12-in. $(30-\mathrm{cm})$ polyurethane foam reflection (Case 16r-2). The calculated $k_{\text {eff }}$ for the carbon steel and polyurethanefoam-reflected cases are statistically the same as the water-reflected, single-package case. Consequently, full-water reflection is used in the subsequent single-package cases.

Regarding temperature variations within the package, the maximum internal temperature for the MO-1 package during normal conditions of transport is $232.0^{\circ} \mathrm{F}(384.3 \mathrm{~K})$. Since the maximum internal pressure within the package during normal conditions of transport is $23.196 \mathrm{psia}$, full-density-water flooding is possible at $384.3 \mathrm{~K}$ if the pressure exceeds $21.57 \mathrm{psia}$ (i.e., saturation pressure corresponding to $384.3 \mathrm{~K}$ ). As noted in Sect. 3.3, the introduction of water into a pressurized container from an external source is not considered to be realistic. In an effort to bound the actual configuration, the analysis assumes full-density-water flooding under the maximum temperature exposure during normal conditions of transport. The calculated single package multiplication factor for the water reflected and flooded MO-1 at $384.3 \mathrm{~K}$ is denoted as Case $16 \mathrm{t}-1$ in Table 7.5 . The increase in package temperature leads to a $\sim 1.4 \%$ increase in system reactivity. The increase in reactivity with temperature is consistent with the results presented in Sect. 6.1.1. Moreover, the reactivity increase is attributed to a reduction in the ${ }^{240} \mathrm{Pu}$ capture resonance at $1.085 \mathrm{eV}$ without a significant increase in resonance width (refer to discussion in Sect. 6.1.1). Although the higher temperature leads to an increase in reactivity, the package is acceptably subcritical relative to the calculation USL. Furthermore, the single MO-1 package with two boxes of $6 \mathrm{wt} \% \mathrm{PuO}_{2} \mathrm{MOX}$ fuel pins is acceptably subcritical under normal conditions of transport. 
Table 7.5. Calculated results for single package under normal conditions with $6 \mathrm{wt} \%, 4.4 \mathrm{wt} \%$ and $3.03 \mathrm{wt} \% \mathrm{PuO}_{2} \mathrm{MOX}$ fuel pins

\begin{tabular}{|c|c|c|c|}
\hline Case & Description & $k_{e f f} \pm \sigma$ & $k_{e f f}+2 \sigma$ \\
\hline $16 m-10$ & $\begin{array}{l}\text { Optimally moderated undamaged package with } 12 \text {-in. } \\
(30-\mathrm{cm}) \mathrm{H}_{2} \mathrm{O} \text { reflection. } 6 \text { wt } \% \mathrm{PuO}_{2} \mathrm{MOX}\end{array}$ & $0.6919 \pm 0.0016$ & 0.6951 \\
\hline lsc-6 & $\begin{array}{l}\text { Optimally moderated single containment with } 12 \text {-in. } \\
(30-\mathrm{cm}) \mathrm{H}_{2} \mathrm{O} \text { reflection. } 6 \mathrm{wt} \% \mathrm{PuO}_{2} \mathrm{MOX}\end{array}$ & $0.6877 \pm 0.0014$ & 0.6905 \\
\hline $16 r-1$ & $\begin{array}{l}\text { Optimally moderated undamaged package with } 12 \text {-in. } \\
(30-\mathrm{cm}) \text { carbon steel reflection. } 6 \mathrm{wt} \% \mathrm{PuO}_{2} \mathrm{MOX}\end{array}$ & $0.6893 \pm 0.0014$ & 0.6921 \\
\hline $16 r-2$ & $\begin{array}{l}\text { Optimally moderated undamaged package with } 12 \text {-in. } \\
(30-\mathrm{cm}) \text { polyurethane foam reflection. } 6 \mathrm{wt} \% \mathrm{PuO}_{2} \\
\text { MOX }\end{array}$ & $0.6882 \pm 0.0013$ & 0.6908 \\
\hline $16 t-1$ & $\begin{array}{l}\text { Optimally moderated undamaged package at } 384.3 \mathrm{~K} \text { with } \\
12 \text {-in. }(30-\mathrm{cm}) \mathrm{H}_{2} \mathrm{O} \text { reflection. } 6 \mathrm{wt} \% \mathrm{PuO}_{2} \mathrm{MOX}\end{array}$ & $0.7020 \pm 0.0017$ & 0.7054 \\
\hline $14 m-10$ & $\begin{array}{l}\text { Optimally moderated undamaged package with } 12 \text {-in. } \\
(30-\mathrm{cm}) \mathrm{H}_{2} \mathrm{O} \text { reflection. } 4.4 \mathrm{wt} \% \mathrm{PuO}_{2} \mathrm{MOX}\end{array}$ & $0.6756 \pm 0.0014$ & 0.6784 \\
\hline Isc-4 & $\begin{array}{l}\text { Optimally moderated single containment with } 12 \text {-in. } \\
(30-\mathrm{cm}) \mathrm{H}_{2} \mathrm{O} \text { reflection. } 4.4 \text { wt } \% \mathrm{PuO}_{2} \text { MOX }\end{array}$ & $0.6783 \pm 0.0013$ & 0.6809 \\
\hline $14 \mathrm{t}-1$ & $\begin{array}{l}\text { Optimally moderated undamaged package at } 384.3 \mathrm{~K} \text { with } \\
\text { 12-in. }(30-\mathrm{cm}) \mathrm{H}_{2} \mathrm{O} \text { reflection. } 4.4 \mathrm{wt} \% \mathrm{PuO}_{2} \mathrm{MOX}\end{array}$ & $0.6867 \pm 0.0014$ & 0.6895 \\
\hline $13 m-10$ & $\begin{array}{l}\text { Optimally moderated undamaged package with } 12 \text {-in. } \\
(30-\mathrm{cm}) \mathrm{H}_{2} \mathrm{O} \text { reflection. } 3.03 \mathrm{wt} \% \mathrm{PuO}_{2} \mathrm{MOX}\end{array}$ & $0.6667 \pm 0.0014$ & 0.6695 \\
\hline lsc-3 & $\begin{array}{l}\text { Optimally moderated single containment with } 12 \text {-in. } \\
\text { (30-cm) } \mathrm{H}_{2} \mathrm{O} \text { reflection. } 3.03 \mathrm{wt} \% \mathrm{PuO}_{2} \mathrm{MOX}\end{array}$ & $0.6694 \pm 0.0015$ & 0.6724 \\
\hline $13 t-1$ & $\begin{array}{l}\text { Optimally moderated undamaged package at } 384.3 \mathrm{~K} \text { with } \\
12 \text {-in. }(30-\mathrm{cm}) \mathrm{H}_{2} \mathrm{O} \text { reflection. } 3.03 \mathrm{wt} \% \mathrm{PuO}_{2} \mathrm{MOX}\end{array}$ & $0.6801 \pm 0.0015$ & 0.6831 \\
\hline
\end{tabular}

The $4.4 \mathrm{wt} \%$ and $3.03 \mathrm{wt} \% \mathrm{PuO}_{2} \mathrm{MOX}$ fuel pins are also undermoderated at a triangular pitch of $0.47 \mathrm{in} .(1.20 \mathrm{~cm})$, and full-water-density moderation is optimum for these fuel loadings. Using the calculational models presented for the $6 \mathrm{wt} \% \mathrm{PuO}_{2} \mathrm{MOX}$ pins, the single-package cases $16 \mathrm{~m}-10$, 1sc- 6 and $16 \mathrm{t}-1$ are evaluated with the $4.4 \mathrm{wt} \%$ and $3.03 \mathrm{wt} \% \mathrm{PuO}_{2} \mathrm{MOX}$ pins; the results are presented in Table 7.5 for each fuel loading. As observed for the $6 \mathrm{wt} \% \mathrm{PuO}_{2} \mathrm{MOX}$ fuel, the temperature increase under normal conditions of transport leads to a 1 to $2 \%$ increase in reactivity. Despite the increase in system multiplication, the single MO- 1 package loaded with $3.03 \mathrm{wt} \%$ or $4.4 \mathrm{wt} \% \mathrm{PuO}_{2} \mathrm{MOX}$ fuel pins is acceptably subcritical under normal conditions of transport. 


\subsubsection{Damaged Package Configurations}

As referenced within NUREG/CR-5661 (ref. 7), the criticality safety evaluation must demonstrate subcriticality for the single package under hypothetical accident conditions. Section 3.3 presents the upset conditions and calculational models for the damaged single-package evaluation. Moreover, the damaged single-package evaluation is presented in Sect. 6.1.1.2 for the shipment of 6, 4.4 and 3.03 wt \% $\mathrm{PuO}_{2} \mathrm{MOX}$ fuel assemblies. The upset cases that are presented for the shipment of MOX assemblies are reevaluated for the shipment of MOX fuel pins. Table 7.6 presents the damaged single-package results for the shipment of $6 \mathrm{wt} \% \mathrm{PuO}_{2} \mathrm{MOX}$ fuel pins in the MO-1. Case $16 \mathrm{f}-1$ evaluates the single package under fire temperature conditions with full-density polyurethane foam present between the inner- and outer-steel shells. Moreover, Cases $16 \mathrm{f}-1$ a through $16 \mathrm{f}-3$ evaluate polyurethane foam decomposition during fire conditions. Specifically, the water content of the foam is increased until the foam is completely replaced with water in Case $16 \mathrm{f}-2$. In Case 16f-3, the foam region is modeled as void to simulate the complete loss of material. As observed for the MOX assembly analysis, the increase in package temperature under fire conditions leads to an $\sim 2.7 \%$ increase in reactivity relative to the package at $293 \mathrm{~K}$ (Case $16 \mathrm{~m}-10$ ). The results presented in Table 7.6 for the various states of foam decomposition are statisically the same as the damaged package with full-density polyurethane foam. Consequently, the foam decomposition does not lead to a statistically significant increase in reactivity. Based on the results for the package exposed to fire conditions, the damaged package is acceptably subcritical relative to the calculation USL.

The remaining cases consider the package exposed to impact conditions. Each damaged package case considers the maximum internal package temperature to be $483.15 \mathrm{~K}$. Cases $16 \mathrm{c}-1$ and $16 \mathrm{c}-2$ consider the damaged MO-1 with a reduced exterior carbon steel shell thickness of $0.028 \mathrm{in} .(0.071 \mathrm{~cm})$, as shown in Fig. 3.7. In Case 16c-1, the spacing between the two boxes of pins is maintained on the strongback support frame; however, Case 16c-2 considers the loss of spacing in the single package. Although both cases are acceptably subcritical, the loss of spacing between the boxes of pins leads to an $-6.4 \%$ increase in reactivity. The remaining cases evaluate the movement of the entire fuel package within the $\mathrm{MO}-1$ under impact conditions. Cases 16a-1 through 16a-3 consider the vertical displacement of the fuel package to the bottom of the MO-1 as shown in Fig. 3.8. In Cases 16a-1 and 16a-2 the wall thickness is not crushed, and polyurethane foam is present between the inner- and outer-steel shells. Although the exterior wall thickness is not reduced, the spacing between the boxes of pins is removed in Case 16a-2. An impact condition that leads to the displacement of the entire fuel package and loss of spacing between the boxes would most likely damage the exterior containment. Therefore, the exterior carbon-steel-shell thickness is reduced to 0.028 in. $(0.071 \mathrm{~cm})$ in Case 16a-3. Based on the results in Table 7.6, a vertical displacement of the fuel package in the MO-1 does not lead to a critical configuration relative to the calculational USL. A comer or edge impact.condition could shift the fuel contents to the interior corner of the MO-1, as shown in Fig. 3.9. Cases $16 \mathrm{~b}-1$ through $16 \mathrm{~b}-3$ are similar to Cases $16 \mathrm{a}-1$ through $16 \mathrm{a}-3$, except the fuel package is positioned in the interior comer of the MO-1, as shown in Fig. 3.10. When the fuel is shifted to the interior corner of the MO-1, the maximum calculated $k_{\text {eff }}$ is $0.7582 \pm 0.0015$, which is less than the calculational USL.

The impact conditions for the $6 \mathrm{wt} \% \mathrm{PuO}_{2}$ MOX fuel package lead to the most reactive configurations based on the damaged package results presented in Table 7.6. To assess the damaged single package with the other possible fuel loadings, calculated results are provided in Table 7.7 for Cases $16 \mathrm{c}-2$, $16 \mathrm{a}-3$ and $16 \mathrm{~b}-3$ for the $4.4 \mathrm{wt} \% \mathrm{PuO}_{2} \mathrm{MOX}$ fuel pins (i.e., $14 \mathrm{c}-2,14 \mathrm{a}-3$ and $14 \mathrm{~b}-3$, respectively). In addition, similar results are also provided for the 3.03 wt \% MOX fuel pins in Cases 13c-2, 13a-3 and 13b-3. The calculated results for the damaged configurations in Table 7.7 are acceptably below the calculational acceptance criteria. 
Table 7.6. Calculated results for the damaged single package with $6 \mathrm{wt} \% \mathrm{PuO}_{2} \mathrm{MOX}$ fuel pins

\begin{tabular}{|c|c|c|c|}
\hline Case & Description & $k_{e f f} \pm \sigma$ & $k_{e f f}+2 \sigma$ \\
\hline $16 f-1$ & $\begin{array}{l}\text { Optimally moderated package with } 12-\mathrm{in} .(30-\mathrm{cm}) \mathrm{H}_{2} \mathrm{O} \\
\text { reflection during fire conditions. Temp }=483.15 \mathrm{~K}\end{array}$ & $0.7109 \pm 0.0015$ & 0.7139 \\
\hline $16 f-1 a$ & Case $16 \mathrm{f}-1$ with foam content $10 \% \mathrm{H}_{2} \mathrm{O}$ & $0.7105 \pm 0.0013$ & 0.7131 \\
\hline $16 f-1 b$ & Case $16 \mathrm{f}-1$ with foam content $30 \% \mathrm{H}_{2} \mathrm{O}$ & $0.7141 \pm 0.0013$ & 0.7167 \\
\hline $16 \mathrm{f}-\mathrm{lc}$ & Case $16 \mathrm{f}-1$ with foam content $50 \% \mathrm{H}_{2} \mathrm{O}$ & $0.7133 \pm 0.0014$ & 0.7161 \\
\hline $16 f-1 d$ & Case $16 \mathrm{f}-1$ with foam content $70 \% \mathrm{H}_{2} \mathrm{O}$ & $0.7142 \pm 0.0013$ & 0.7168 \\
\hline $16 f-1 e$ & Case $16 \mathrm{f}-1$ with foam content $90 \% \mathrm{H}_{2} \mathrm{O}$ & $0.7124 \pm 0.0014$ & 0.7152 \\
\hline $16 f-2$ & Case $16 \mathrm{f}-1$ with foam content $100 \% \mathrm{H}_{2} \mathrm{O}$ & $0.7121 \pm 0.0014$ & 0.7149 \\
\hline $16 f-3$ & Case $16 f-1$ with foam replaced by void & $0.7135 \pm 0.0014$ & 0.7163 \\
\hline $16 c-1$ & $\begin{array}{l}\text { Optimally moderated package with } 12 \text {-in. }(30-\mathrm{cm}) \mathrm{H}_{2} \mathrm{O} \\
\text { reflection. Fuel positioned in MO-1, as shown in } \\
\text { Fig. } 3.7 . \text { Package has carbon steel wall thickness }= \\
0.028 \text { in. }(0.071 \mathrm{~cm}) \text { with no polyurethane foam. } \\
\text { Spacing between fuel assemblies is maintained. Temp = } \\
483.15 \mathrm{~K}\end{array}$ & $0.7146 \pm 0.0014$ & 0.7174 \\
\hline $16 c-2$ & $\begin{array}{l}\text { Optimally moderated package with } 12 \text {-in. }(30-\mathrm{cm}) \mathrm{H}_{2} \mathrm{O} \\
\text { reflection. Fuel positioned in } \mathrm{MO}-1 \text {, as shown in } \\
\text { Fig. } 3.7 . \text { Package has carbon steel wall thickness }= \\
0.028 \text { in. }(0.071 \mathrm{~cm}) \text { with no polyurethane foam. } \\
\text { Spacing between fuel assemblies is removed. Temp = } \\
483.15 \mathrm{~K}\end{array}$ & $0.7602 \pm 0.0014$ & 0.7630 \\
\hline $16 a-1$ & $\begin{array}{l}\text { Optimally moderated package with } 12-\text { in. }(30-\mathrm{cm}) \mathrm{H}_{2} \mathrm{O} \\
\text { reflection. Fuel positioned in } \mathrm{MO}-1 \text {, as shown in } \\
\text { Fig. } 3.8 \text {. Spacing between fuel assemblies is } \\
\text { maintained. Temp }=483.15 \mathrm{~K}\end{array}$ & $0.7083 \pm 0.0015$ & 0.7113 \\
\hline $16 a-2$ & $\begin{array}{l}\text { Optimally moderated package with } 12-\mathrm{in} .(30-\mathrm{cm}) \mathrm{H}_{2} \mathrm{O} \\
\text { reflection. Fuel positioned in } \mathrm{MO}-1 \text {, as shown in } \\
\text { Fig. 3.8. Spacing between fuel assemblies is } \\
\text { removed. Temp }=483.15 \mathrm{~K}\end{array}$ & $0.7566 \pm 0.0015$ & 0.7596 \\
\hline $16 a-3$ & $\begin{array}{l}\text { Case } 16 \mathrm{a}-2 \text { with carbon steel wall thickness }=0.028 \text { in. } \\
(0.071 \mathrm{~cm}) \text { and no polyurethane foam. Spacing between } \\
\text { fuel assemblies is removed. Temp }=483.15 \mathrm{~K}\end{array}$ & $0.7618 \pm 0.0016$ & 0.7650 \\
\hline
\end{tabular}


Table 7.6 (continued)

\begin{tabular}{|c|c|c|c|}
\hline Case & Description & $k_{e f f} \pm \sigma$ & $k_{e f f}+2 \sigma$ \\
\hline $16 \mathrm{~b}-1$ & $\begin{array}{l}\text { Optimally moderated package with } 12-\text { in. }(30-\mathrm{cm}) \mathrm{H}_{2} \mathrm{O} \\
\text { reflection. Fuel positioned in } \mathrm{MO}-1 \text { as shown in } \\
\text { Fig. 3.9. Spacing between fuel assemblies is } \\
\text { maintained. Temp }=483.15 \mathrm{~K}\end{array}$ & $0.7021 \pm 0.0013$ & 0.7047 \\
\hline $16 \mathrm{~b}-2$ & $\begin{array}{l}\text { Optimally moderated package with } 12-\mathrm{in} .(30-\mathrm{cm}) \mathrm{H}_{2} \mathrm{O} \\
\text { reflection. Fuel positioned in } \mathrm{MO}-1 \text { as shown in } \\
\text { Fig. 3.9. Spacing between fuel assemblies is } \\
\text { removed. Temp }=483.15 \mathrm{~K}\end{array}$ & $0.7517 \pm 0.0014$ & 0.7545 \\
\hline $16 b-3$ & $\begin{array}{l}\text { Case } 16 \mathrm{~b}-2 \text { with carbon steel wall thickness }=0.028 \mathrm{in} . \\
(0.071 \mathrm{~cm}) \text { and no polyurethane foam. Spacing between } \\
\text { fuel assemblies is removed. Temp }=483.15 \mathrm{~K}\end{array}$ & $0.7582 \pm 0.0015$ & 0.7612 \\
\hline
\end{tabular}


Table 7.7. Calculated results for the damaged single package with $4.4 \mathrm{wt} \%$ and $3.03 \mathrm{wt} \%$ $\mathrm{PuO}_{2} \mathrm{MOX}$ fuel pins

\begin{tabular}{|c|c|c|c|}
\hline Case & Description & $k_{e f f} \pm \sigma$ & $k_{e f f}+2 \sigma$ \\
\hline $14 c-2$ & $\begin{array}{l}\text { Optimally moderated package with } 12-\mathrm{in} .(30-\mathrm{cm}) \mathrm{H}_{2} \mathrm{O} \\
\text { reflection. Fuel }\left(4.4 \mathrm{wt} \% \mathrm{PuO}_{2} \mathrm{MOX}\right) \text { positioned in } \\
\mathrm{MO}-1 \text {, as shown in Fig. } 3.7 . \text { Package has carbon-steel- } \\
\text { wall thickness }=0.028 \mathrm{in} .(0.071 \mathrm{~cm}) \text { with no } \\
\text { polyurethane foam. Spacing between fuel assemblies is } \\
\text { removed. Temp }=483.15 \mathrm{~K}\end{array}$ & $0.7452 \pm 0.0014$ & 0.7480 \\
\hline $14 a-3$ & $\begin{array}{l}\left.\text { Fuel ( } 4.4 \mathrm{wt} \% \mathrm{PuO}_{2} \mathrm{MOX}\right) \text { positioned in } \mathrm{MO}-1 \text {, as shown } \\
\text { in Fig. } 3.8 . \text { Carbon-steel-wall thickness }=0.028 \text { in. } \\
(0.071 \mathrm{~cm}) \text { and no polyurethane foam. Spacing between } \\
\text { fuel assemblies is removed. Temp }=483.15 \mathrm{~K}\end{array}$ & $0.7450 \pm 0.0014$ & 0.7478 \\
\hline $14 b-3$ & $\begin{array}{l}\text { Fuel }\left(4.4 \mathrm{wt} \% \mathrm{PuO}_{2} \mathrm{MOX}\right) \text { positioned in } \mathrm{MO}-1 \text {, as shown } \\
\text { in Fig. } 3.9 . \text { Carbon-steel-wall thickness }=0.028 \text { in. } \\
(0.071 \mathrm{~cm}) \text { and no polyurethane foam. Spacing between } \\
\text { fuel assemblies is removed. Temp }=483.15 \mathrm{~K}\end{array}$ & $0.7421 \pm 0.0013$ & 0.7447 \\
\hline $13 c-2$ & $\begin{array}{l}\text { Optimally moderated package with } 12-\mathrm{in} .(30-\mathrm{cm}) \mathrm{H}_{2} \mathrm{O} \\
\text { reflection. Fuel }\left(3.03 \mathrm{wt} \% \mathrm{PuO}_{2} \mathrm{MOX}\right) \text { positioned in } \\
\mathrm{MO}-1 \text {, as shown in Fig. } 3.7 . \text { Package has carbon-steel- } \\
\text { wall thickness }=0.028 \text { in. }(0.071 \mathrm{~cm}) \text { with no } \\
\text { polyurethane foam. Spacing between fuel assemblies is } \\
\text { removed. Temp }=483.15 \mathrm{~K}\end{array}$ & $0.7345 \pm 0.0014$ & 0.7373 \\
\hline $13 a-3$ & $\begin{array}{l}\text { Fuel ( }\left(3.03 \mathrm{wt} \% \mathrm{PuO}_{2} \mathrm{MOX}\right) \text { positioned in } \mathrm{MO}-1 \text {, as } \\
\text { shown in Fig. } 3.8 . \text { Carbon-steel-wall thickness }= \\
0.028 \mathrm{in} .(0.071 \mathrm{~cm}) \text { and no polyurethane foam. Spacing } \\
\text { between fuel assemblies is removed. Temp }=483.15 \mathrm{~K}\end{array}$ & $0.7342 \pm 0.0015$ & 0.7372 \\
\hline $13 b-3$ & $\begin{array}{l}\left.\text { Fuel ( } 3.03 \mathrm{wt} \% \mathrm{PuO}_{2} \mathrm{MOX}\right) \text { positioned in } \mathrm{MO}-1 \text {, as } \\
\text { shown in Fig. } 3.9 . \text { Carbon-steel-wall thickness }= \\
0.028 \mathrm{in} .(0.071 \mathrm{~cm}) \text { and no polyurethane foam. Spacing } \\
\text { between fuel assemblies is removed. Temp }=483.15 \mathrm{~K}\end{array}$ & $0.7321 \pm 0.0015$ & 0.7351 \\
\hline
\end{tabular}




\subsubsection{Weapons-Grade MOX Fuel}

\subsubsection{Undamaged Package Configurations}

The WG MOX fuel is 4.803 wt $\% \mathrm{Pu}$ with a Pu fissile fraction of $94 \mathrm{wt} \%$, as discussed in Sect. 2.1.2. The calculated results presented in Fig. 7.2 and Table 7.4 reveal that the WG MOX fuel pins are undermoderated for a triangular pitch less than $0.75 \mathrm{in} .(1.90 \mathrm{~cm})$. Using the constraints presented in Sect. 7.1 and the results of Table 7.4, the maximum triangular pitch considered for shipment of the WG MOX fuel pins is $0.43 \mathrm{in}$. $(1.10 \mathrm{~cm})$. In the following single-package analysis, the evaluation considers the shipment of at most two boxes of WG MOX fuel pins in the MO-1.

As with the previously certified MOX fuel pins, the inleakage of water must be considered during normal conditions of transport. Since the fuel is undermoderated for a pitch less than $0.75 \mathrm{in} .(1.90 \mathrm{~cm})$, full-density-water flooding is optimum for the pins arranged on a $0.43-\mathrm{in} .(1.10-\mathrm{cm})$ pitch. The undamaged single-package cases are presented in Table 7.8 for the WG MOX fuel pins. The calculated multiplication factor for the water flooded and reflected MO-1 loaded with two boxes of fuel pins (i.e., Case lwm-10) is $0.7667 \pm 0.0015$, which is acceptably below the calculational USL. In addition, the water-reflected singlecontainment model is presented as case lsc-wg in Table 7.8. Results are also presented in Table 7.8 to assess the undamaged package with 12 -in. $(30-\mathrm{cm})$ carbon-steel reflection (Case $1 w r-1)$ and $12 \mathrm{in.}(30 \mathrm{~cm})$ polyurethane foam reflection (Case lwr-2). The system multiplication factor for the single-containment model, as well as the carbon steel and polyurethane-foam-reflected cases are statistically the same as the water flooded and reflected undamaged package. As noted previously, the single package could be exposed to higher temperatures under normal transport conditions. Specifically, the internal package temperature could reach $232.0^{\circ} \mathrm{F}(384.3 \mathrm{~K})$. In Table 7.8 , Case lwt- 1 assesses the temperature increase, and the calculated $k_{e f f}$ for the package at $384.3 \mathrm{~K}$ is $0.7764 \pm 0.0015$, which is $\sim 1.3 \%$ higher relative to the package at $293 \mathrm{~K}$. Despite the increase in system multiplication under normal conditions of transport, the single MO-1 package with two boxes of WG MOX fuel pins is acceptably subcritical relative to the calculational USL.

Table 7.8. Calculated results for single package under normal conditions with WG MOX fuel pins

\begin{tabular}{cccc}
\hline Case & \multicolumn{1}{c}{ Description } & $k_{\text {eff }} \pm \sigma$ & $k_{\text {eff }}+2 \sigma$ \\
\hline lwm-10 & $\begin{array}{c}\text { Optimally moderated undamaged package with } \\
\text { 12-in. (30-cm) } \mathrm{H}_{2} \mathrm{O} \text { reflection. }\end{array}$ & $0.7667 \pm 0.0015$ & 0.7697 \\
lsc-wg & $\begin{array}{c}\text { Optimally moderated single containment with } \\
\text { 12-in. (30-cm) } \mathrm{H}_{2} \mathrm{O} \text { reflection. }\end{array}$ & $0.7656 \pm 0.0017$ & 0.7690 \\
lwr-1 & $\begin{array}{c}\text { Optimally moderated undamaged package with } \\
\text { 12-in. (30-cm) carbon-steel reflection. }\end{array}$ & $0.7668 \pm 0.0015$ & 0.7698 \\
lwr-2 & $\begin{array}{l}\text { Optimally moderated undamaged package with } \\
\text { 12-in. (30-cm) polyurethane-foam reflection. }\end{array}$ & $0.7671 \pm 0.0016$ & 0.7703 \\
lwt-1 & $\begin{array}{c}\text { Optimally moderated undamaged package at } \\
384.3 \mathrm{~K} \text { with 12-in. (30-cm) } \mathrm{H}_{2} \mathrm{O} \text { reflection. }\end{array}$ & $0.7764 \pm 0.0015$ & 0.7794 \\
\hline
\end{tabular}




\subsubsection{Damaged Package Configurations}

The calculational models for the damaged MO-1 package are presented in Sect. 3.3. Using the models of Sect. 3.3, the damaged single-package evaluation is presented in Sect. 6.1.2.2 for the shipment of WG MOX fuel assemblies. The upset cases presented in Sect. 6.1.2.2 are used to evaluate the shipment of WG MOX fuel assemblies; however, the evaluation presented for the loose pins considers two boxes of fuel pins in a single package. Table 7.9 presents the damaged single-package results for the WG MOX fuel. As with the shipment of MOX assemblies, Cases lwf-1 through lwf-3 evaluate the package under fire conditions. Moreover, these cases evaluate the polyurethane-foam decomposition during a fire scenario. In Case lwf-1, the region between the inner- and outer-steel shell is full-density polyurethane foam; however, Cases lwf-1a through lwf-3 consider various stages of foam charring. The calculated results for the single package under fire conditions with various stages of foam decomposition are statistically the same. Therefore, foam charring does not lead to a significant increase in system multiplication relative to the full-density-polyurethane foam model (i.e., Case lwf-1). The remaining damaged package cases consider full-density-polyurethane foam in the calculational model unless the model is specifically evaluated without foam.

The remaining cases in Table 7.9 assess the MO-1 under different impact conditions. Both Case lwc-1 and lwc-2 evaluate the MO-1 with crushed exterior walls, as shown in Fig. 3.7; however, Case lwc-2 evaluates the loss of box spacing within the damaged package. Although both configurations are subcritical relative to the USL, the loss of box spacing in Case lwc-2 leads to an $\sim 7.1 \%$ increase in system multiplication. The vertical displacement of the entire fuel package is evaluated in Cases lwa-1, lwa-2 and lwa-3, as shown in Fig. 3.8. In Cases lwa-1 and lwa-2, the exterior containment is not crushed, and polyurethane foam is present between the inner- and outer-steel shells. Note that the spacing between the boxes of pins is removed in Case lwa-2. Impact conditions would most likely damage the exterior containment thereby reducing the exterior wall thickness. Consequently, Case lwa-2 is re-evaluated with a $0.028 \mathrm{in} .(0.071 \mathrm{~cm})$ wall thickness in Case lwa-3. The calculated results for the damaged package in Cases lwa-1 through lwa-3 are acceptably below the USL. Therefore, the vertical displacement of the fuel package in the MO-1 does not lead to a critical configuration. During a corner or edge impact, the fuel package could shift to an interior corner of the MO-1, as shown in Fig. 3.9. Cases lwb-1, lwb-2 and lwb-3 assess the change in reactivity due to a corner or edge impact. In Cases lwb-1 and lwb-2, the containment is not damaged; however, the box spacing is removed in Case lb-2. Moreover, Case lwb-3 is the same as Case lwb-2, except the exterior containment is reduced to $0.028 \mathrm{in} .(0.071 \mathrm{~cm})$ of carbon steel. During a corner or edge impact, the most reactive configuration leads to a calculated $k_{\text {eff }}$ of $0.8326 \pm 0.0017$, which is acceptably subcritical. 
Table 7.9. Calculated results for the damaged single package with WG MOX fuel pins

\begin{tabular}{|c|c|c|c|}
\hline Case & Description & $k_{e f f} \pm \sigma$ & $k_{e f f}+2 \sigma$ \\
\hline lwf-1 & $\begin{array}{l}\text { Optimally moderated package with } 12 \mathrm{in} .(30 \mathrm{~cm}) \mathrm{H}_{2} \mathrm{O} \\
\text { reflection during fire conditions. Temp }=483.15 \mathrm{~K}\end{array}$ & $0.7844 \pm 0.0015$ & 0.7874 \\
\hline lwf-la & Case lwf- 1 with foam content $10 \% \mathrm{H}_{2} \mathrm{O}$ & $0.7826 \pm 0.0015$ & 0.7856 \\
\hline $\operatorname{lwf}-1 b$ & Case lwf- 1 with foam content $30 \% \mathrm{H}_{2} \mathrm{O}$ & $0.7813 \pm 0.0017$ & 0.7847 \\
\hline lwf-1c & Case lwf- 1 with foam content $50 \% \mathrm{H}_{2} \mathrm{O}$ & $0.7838 \pm 0.0018$ & 0.7874 \\
\hline lwf-1d & Case lwf- 1 with foam content $70 \% \mathrm{H}_{2} \mathrm{O}$ & $0.7855 \pm 0.0016$ & 0.7887 \\
\hline lwf-1e & Case lwf- 1 with foam content $90 \% \mathrm{H}_{2} \mathrm{O}$ & $0.7851 \pm 0.0016$ & 0.7883 \\
\hline lwf-2 & Case lwf- 1 with foam content $100 \% \mathrm{H}_{2} \mathrm{O}$ & $0.7875 \pm 0.0016$ & 0.7907 \\
\hline lwf-3 & Case lwf- 1 with foam replaced by void & $0.7834 \pm 0.0015$ & 0.7864 \\
\hline lwc-1 & $\begin{array}{l}\text { Optimally moderated package with } 12-\mathrm{in} .(30-\mathrm{cm}) \mathrm{H}_{2} \mathrm{O} \\
\text { reflection. Fuel positioned in } \mathrm{MO}-1 \text {, as shown in Fig. } 3.7 \text {. } \\
\text { Package has carbon-steel-wall thickness }=0.028 \mathrm{in} \text {. } \\
(0.071) \text { with no polyurethane foam. Spacing between fuel } \\
\text { assemblies is maintained. Temp }=483.15 \mathrm{~K}\end{array}$ & $0.7779 \pm 0.0015$ & 0.7809 \\
\hline lwc-2 & $\begin{array}{l}\text { Optimally moderated package with } 12-\text { in. }(30-\mathrm{cm}) \mathrm{H}_{2} \mathrm{O} \\
\text { reflection. Fuel positioned in MO-1, as shown in Fig. } 3.7 \text {. } \\
\text { Package has carbon-steel-wall thickness }=0.028 \text { in. } \\
(0.071 \mathrm{~cm}) \text { with no polyurethane foam. Spacing between } \\
\text { fuel assemblies is removed. Temp }=483.15 \mathrm{~K}\end{array}$ & $0.8332 \pm 0.0017$ & 0.8366 \\
\hline lwa-1 & $\begin{array}{l}\text { Optimally moderated package with } 12-\text { in. }(30-\mathrm{cm}) \mathrm{H}_{2} \mathrm{O} \\
\text { reflection. Fuel positioned in } \mathrm{MO}-1 \text {, as shown in Fig. } 3.8 \text {. } \\
\text { Spacing between fuel assemblies is maintained. Temp = } \\
483.15 \mathrm{~K}\end{array}$ & $0.7677 \pm 0.0017$ & 0.7711 \\
\hline lwa-2 & $\begin{array}{l}\text { Optimally moderated package with } 12-\text { in. }(30-\mathrm{cm}) \mathrm{H}_{2} \mathrm{O} \\
\text { reflection. Fuel positioned in MO-1, as shown in Fig. } 3.8 \text {. } \\
\text { Spacing between fuel assemblies is removed. Temp }= \\
483.15 \mathrm{~K}\end{array}$ & $0.8156 \pm 0.0017$ & 0.8190 \\
\hline lwa-3 & $\begin{array}{l}\text { Case lwa- } 2 \text { with carbon-steel-wall thickness }=0.028 \text { in. } \\
(0.071 \mathrm{~cm}) \text { and no polyurethane foam. Spacing between } \\
\text { fuel assemblies is removed. Temp }=483.15 \mathrm{~K}\end{array}$ & $0.8350 \pm 0.0016$ & 0.8382 \\
\hline
\end{tabular}


Table 7.9 (continued)

\begin{tabular}{|c|c|c|c|}
\hline Case & Description & $k_{e f f} \pm \sigma$ & $k_{e f f}+2 \sigma$ \\
\hline lwb-1 & $\begin{array}{l}\text { Optimally moderated package with } 12 \text {-in. }(30-\mathrm{cm}) \mathrm{H}_{2} \mathrm{O} \\
\text { reflection. Fuel positioned in } \mathrm{MO}-1 \text {, as shown in Fig. } 3.9 \text {. } \\
\text { Spacing between fuel assemblies is maintained. Temp }= \\
483.15 \mathrm{~K}\end{array}$ & $0.7551 \pm 0.0017$ & 0.7585 \\
\hline lwb-2 & $\begin{array}{l}\text { Optimally moderated package with } 12 \text {-in. }(30-\mathrm{cm}) \mathrm{H}_{2} \mathrm{O} \\
\text { reflection. Fuel positioned in } \mathrm{MO}-1 \text {, as shown in Fig. } 3.9 \text {. } \\
\text { Spacing between fuel assemblies is removed. Temp }= \\
483.15 \mathrm{~K}\end{array}$ & $0.8131 \pm 0.0016$ & 0.8163 \\
\hline lwb-3 & $\begin{array}{l}\text { Case lwb- } 2 \text { with carbon-steel-wall thickness }=0.028 \text { in. } \\
(0.071 \mathrm{~cm}) \text { and no polyurethane foam. Spacing between } \\
\text { fuel assemblies is removed. Temp }=483.15 \mathrm{~K}\end{array}$ & $0.8326 \pm 0.0017$ & 0.8360 \\
\hline
\end{tabular}

\subsection{PACKAGE ARRAYS}

To complete the criticality safety evaluation for the shipment of loose fuel pins, the TI must be determined by evaluating the undamaged and damaged package in array configurations. Due to the different loading configurations, the array of packages evaluation is provided separately for the previously approved MOX fuel and WG MOX fuel.

\subsubsection{Previously Certified MOX Fuel}

\subsubsection{Undamaged Package Configurations}

Because of the relatively large internal cavity of the MO-1, complete water flooding could neutronically isolate the packages in an array configuration. Consequently, the interaction between units in the array could be reduced. Therefore, the internal package moderation for the undamaged MO-1 in an array configuration must be reevaluated. Calculated results are presented in Table 7.10 for an infinite array of undamaged MO-1s with $6 \mathrm{wt} \% \mathrm{PuO}_{2} \mathrm{MOX}$ fuel pins. Note that there is no spacing between the MO-1 packages within the array. In the undamaged array configurations, the infinite-array calculations are presented as a matter of convenience. From a calculational perspective, modeling an infinite array is less involved relative to a finite-array model. If an infinite array can be demonstrated to be subcritical, a finite array of packages with the same spacing and moderation conditions will also be subcritical. Each package is loaded with two boxes of fuel pins arranged on a $0.47-\mathrm{in} .(1.20-\mathrm{cm})$ pitch, as described in Sect. 7.2.1. The optimum internal moderation conditions in the array configuration occur with little or no internal moderation. As the package flooding increases to full-density-water moderation, the calculated $k_{\infty}$ for the infinite array is $0.7017 \pm 0.0015$, which is statistically the same as the fully reflected and flooded single package case (i.e., 16t-1). These results demonstrate that an infinite number of undamaged MO-1s with two boxes of fuel pins ( $6 \mathrm{wt} \% \mathrm{PuO}_{2} \mathrm{MOX}$ ) is acceptably subcritical during normal conditions of transport. Similar calculations are presented in Tables 7.11 and 7.12, respectively, for the $4.4 \mathrm{wt} \%$ and $3.03 \mathrm{wt} \%$ 
Table 7.10. Calculated system multiplication for an infinite array of undamaged MO-1s with $6 \mathrm{wt} \% \mathrm{PuO}_{2} \mathrm{MOX}$ fuel pins

\begin{tabular}{cccc}
\hline Case & $\begin{array}{c}\text { Internal } \mathrm{H}_{2} \mathrm{O} \text { volume } \\
\text { fraction }\end{array}$ & $k_{\infty} \pm \sigma$ & $k_{\infty}+2 \sigma$ \\
\hline $16 \mathrm{i}-1$ & 0.0 & $0.7992 \pm 0.0012$ & 0.8016 \\
$16 \mathrm{i}-2$ & 0.001 & $0.7936 \pm 0.0010$ & 0.7956 \\
$16 \mathrm{i}-3$ & 0.003 & $0.7872 \pm 0.0011$ & 0.7894 \\
$16 \mathrm{i}-4$ & 0.05 & $0.6836 \pm 0.0012$ & 0.6860 \\
$16 \mathrm{i}-5$ & 0.1 & $0.6179 \pm 0.0013$ & 0.6205 \\
$16 \mathrm{i}-6$ & 0.4 & $0.5912 \pm 0.0012$ & 0.5936 \\
$16 \mathrm{i}-7$ & 0.6 & $0.6310 \pm 0.0013$ & 0.6336 \\
$16 \mathrm{i}-8$ & 0.8 & $0.6641 \pm 0.0013$ & 0.6667 \\
$16 \mathrm{i}-9$ & 0.9 & $0.6836 \pm 0.0015$ & 0.6866 \\
$16 \mathrm{i}-10$ & 0.95 & $0.6918 \pm 0.0013$ & 0.6944 \\
$16 \mathrm{i}-11$ & 1.0 & $0.7017 \pm 0.0015$ & 0.7047 \\
\hline
\end{tabular}

${ }^{\circ}$ Volume fraction applies to void locations that are within the first containment boundary (i.e., inner-containment shell). 
Table 7.11. Calculated system multiplication for an infinite array of undamaged MO-1s with 4.4 wt $\% \mathrm{PuO}_{2}$ MOX fuel pins

\begin{tabular}{cccc}
\hline Case & $\begin{array}{c}\text { Internal } \mathrm{H}_{2} \mathrm{O} \text { volume } \\
\text { fraction }^{a}\end{array}$ & $k_{\infty} \pm \sigma$ & $k_{\infty}+2 \sigma$ \\
\hline $14 \mathrm{i}-1$ & 0.0 & $0.7278 \pm 0.0011$ & 0.7300 \\
$14 \mathrm{i}-2$ & 0.001 & $0.7255 \pm 0.0011$ & 0.7277 \\
$14 \mathrm{i}-3$ & 0.003 & $0.7208 \pm 0.0012$ & 0.7232 \\
$14 \mathrm{i}-4$ & 0.05 & $0.6432 \pm 0.0013$ & 0.6458 \\
$14 \mathrm{i}-5$ & 0.1 & $0.5865 \pm 0.0012$ & 0.5889 \\
$14 \mathrm{i}-6$ & 0.4 & $0.5685 \pm 0.0012$ & 0.5709 \\
$14 \mathrm{i}-7$ & 0.6 & $0.6118 \pm 0.0013$ & 0.6144 \\
$14 \mathrm{i}-8$ & 0.8 & $0.6513 \pm 0.0013$ & 0.6539 \\
$14 \mathrm{i}-9$ & 0.9 & $0.6705 \pm 0.0016$ & 0.6737 \\
$14 \mathrm{i}-10$ & 0.95 & $0.6799 \pm 0.0013$ & 0.6825 \\
$14 \mathrm{i}-11$ & 1.0 & $0.6861 \pm 0.0016$ & 0.6893 \\
\hline
\end{tabular}

${ }^{a}$ Volume fraction applies to void locations which are within the first containment boundary (i.e., inner-containment shell). 
Table 7.12. Calculated system multiplication for an infinite array of undamaged MO-1s with 3.03 wt $\% \mathrm{PuO}_{2}$ MOX fuel pins

\begin{tabular}{cccc}
\hline Case & $\begin{array}{c}\text { Internal } \mathrm{H}_{2} \mathrm{O} \text { volume } \\
\text { fraction }\end{array}$ & $k_{\infty} \pm \sigma$ & $k_{\infty}+2 \sigma$ \\
\hline $13 \mathrm{i}-1$ & 0.0 & $0.6842 \pm 0.0012$ & 0.6866 \\
$13 \mathrm{i}-2$ & 0.001 & $0.6809 \pm 0.0011$ & 0.6831 \\
$13 \mathrm{i}-3$ & 0.003 & $0.6786 \pm 0.0011$ & 0.6808 \\
$13 \mathrm{i}-4$ & 0.05 & $0.6169 \pm 0.0013$ & 0.6195 \\
$13 \mathrm{i}-5$ & 0.1 & $0.5635 \pm 0.0012$ & 0.5659 \\
$13 \mathrm{i}-6$ & 0.4 & $0.5477 \pm 0.0013$ & 0.5503 \\
$13 \mathrm{i}-7$ & 0.6 & $0.5939 \pm 0.0013$ & 0.5965 \\
$13 \mathrm{i}-8$ & 0.8 & $0.6368 \pm 0.0015$ & 0.6398 \\
$13 \mathrm{i}-9$ & 0.9 & $0.6570 \pm 0.0014$ & 0.6598 \\
$13 \mathrm{i}-10$ & 0.95 & $0.6686 \pm 0.0016$ & 0.6718 \\
$13 \mathrm{i}-11$ & 1.0 & $0.6792 \pm 0.0013$ & 0.6818 \\
\hline
\end{tabular}

"Volume fraction applies to void locations which are within the first containment boundary (i.e., inner containment shell).

$\mathrm{PuO}_{2} \mathrm{MOX}$ loadings. For the other possible loadings, the optimum internal moderation conditions also occur with little or no moderation in the array configuration. At full-density-water flooding, the system multiplication for the infinite array is statistically the same as the fully flooded and reflected single-package cases (i.e., Cases 14t-1 and 13t-1). These results further demonstrate that an infinite number of undamaged packages with $4.4 \mathrm{wt} \% \mathrm{PuO}_{2}$ or $3.03 \mathrm{wt} \% \mathrm{PuO}_{2} \mathrm{MOX}$ fuel pins are also subcritical during normal conditions of transport.

\subsubsection{Damaged Package Configurations}

The calculations presented in Sect. 6.2.1.1 demonstrate that two damaged MO-1s with two $6 \mathrm{wt} \%$ $\mathrm{PuO}_{2} \mathrm{MOX}$ Fuel assemblies are not subcritical. Consequently, the array calculations for the loose pin configuration initially consider two damaged MO-1s. Since the objective of the array calculation is to determine the most reactive arrangement of packages, the configurations that optimize interaction between packages should be considered. In Fig. 3.11, the fuel contents of two damaged packages are shifted to neighboring interior corners. Moreover, both fuel regions are rotated $90^{\circ}$, thereby allowing greater interaction between packages. For a $2 \times 1 \times 1$ array of damaged packages, the configuration presented in Fig. 3.11 should provide the most interaction between the two MO-1s. Calculations are presented in Table 7.13 which evaluate two damaged MO-1s, as shown in Fig. 3.11. Each MO-1 is loaded with two boxes of $6 \mathrm{wt} \% \mathrm{PuO}_{2} \mathrm{MOX}$ fuel pins arranged on a $0.47-\mathrm{in} .(1.20-\mathrm{cm})$ pitch. The results presented in 
Table 7.13. Calculated $k_{e f f}$ values for two unspaced MO-1s (damaged) with 6 wt \% $\mathrm{PuO}_{2}$ MOX fuel pins

\begin{tabular}{cccc}
\hline Case & $\begin{array}{c}\text { Internal } \mathrm{H}_{2} \mathrm{O} \\
\text { volume fraction }\end{array}$ & $k_{\text {eff }} \pm \sigma$ & $k_{\text {eff }}+2 \sigma$ \\
\hline $16 \mathrm{ar}-00-1$ & 0.0 & $0.5455 \pm 0.0012$ & 0.5479 \\
$16 \mathrm{ar}-00-2$ & 0.001 & $0.5456 \pm 0.0012$ & 0.5480 \\
$16 \mathrm{ar}-00-3$ & 0.003 & $0.5436 \pm 0.0015$ & 0.5466 \\
$16 \mathrm{ar}-00-4$ & 0.05 & $0.5655 \pm 0.0013$ & 0.5681 \\
$16 \mathrm{ar}-00-5$ & 0.1 & $0.5989 \pm 0.0012$ & 0.6013 \\
$16 \mathrm{ar}-00-6$ & 0.4 & $0.7300 \pm 0.0013$ & 0.7326 \\
$16 \mathrm{ar}-00-7$ & 0.6 & $0.7849 \pm 0.0016$ & 0.7881 \\
$16 \mathrm{ar}-00-8$ & 0.8 & $0.8356 \pm 0.0013$ & 0.8382 \\
$16 \mathrm{ar}-00-9$ & 0.9 & $0.8546 \pm 0.0015$ & 0.8576 \\
$16 \mathrm{ar}-00-10$ & 0.95 & $0.8672 \pm 0.0015$ & 0.8702 \\
$16 \mathrm{ar}-00-11$ & 1.0 & $0.8755 \pm 0.0014$ & 0.8783 \\
\hline
\end{tabular}

Table 7.13 consider the array with varying degrees of internal moderation. As the internal moderation increases for each damaged package, the reactivity increases and is optimum at full-density- water moderation. At full-density-water moderation, the calculated $k_{\text {eff }}+2 \sigma$ for the $2 \times 1 \times 1$ array of damaged packages is 0.8783 , which is acceptably below the USL. Based on guidance provided in NUREG/CR-5661 (ref. 7), the evaluation of damaged packages must consider moderation between packages (i.e., interspersed moderation). For the results presented in Table 7.13, there is no spacing between the damaged MO-1s; however, the system reactivity is also a function of interspersed moderation and package spacing. Therefore, additional calculations are presented to assess varying degrees of interspersed water moderation for different package spacings.

Increasing the horizontal package spacing and adding interspersed water moderation will provide additional water reflection for each package. The objective is to determine the package spacing with optimum interspersed moderation conditions which provide the most reactive array configuration. Based on the results in Table 7.13, optimum internal moderation conditions occur with full-density water. Therefore, calculations are presented in Table 7.14 which evaluate the two damaged MO-1s (flooded with full-density water) separated by $0.5 \mathrm{in}$. $(1.27 \mathrm{~cm})$ of water. Moreover, the results in Table 7.14 also consider various degrees of interspersed moderation. As the interspersed water density increases, the system reactivity also increases. The system reactivity reaches a plateau at $\sim 80 \%$ water density. As the water density increases above $80 \%$ of full density, the system multiplication is statistically the same. 
Table 7.14. Calculated $k_{e f f}$ values for two 0.5 -in.-spaced MO-1s (damaged) with $6 \mathrm{wt} \% \mathrm{PuO}_{2} \mathrm{MOX}$ fuel pins

\begin{tabular}{|c|c|c|c|c|}
\hline Case & $\begin{array}{c}\text { Interspersed } \mathrm{H}_{2} \mathrm{O} \\
\text { volume fraction }\end{array}$ & $\begin{array}{c}\text { Internal } \mathrm{H}_{2} \mathrm{O} \\
\text { volume fraction }\end{array}$ & $k_{e f f} \pm \sigma$ & $k_{e f f}+2 \sigma$ \\
\hline l6ar-00-hf1 & 0.0 & 1.0 & $0.8692 \pm 0.0013$ & 0.8718 \\
\hline $16 \mathrm{ar}-00-\mathrm{hf} 2$ & 0.001 & 1.0 & $0.8694 \pm 0.0015$ & 0.8724 \\
\hline 16ar-00-hf3 & 0.003 & 1.0 & $0.8710 \pm 0.0014$ & 0.8738 \\
\hline 16ar-00-hf4 & 0.05 & 1.0 & $0.8728 \pm 0.0013$ & 0.8754 \\
\hline 16 ar-00-hf5 & 0.1 & 1.0 & $0.8750 \pm 0.0015$ & 0.8780 \\
\hline 16ar-00-hf6 & 0.4 & 1.0 & $0.8843 \pm 0.0016$ & 0.8875 \\
\hline 16ar-00-hf7 & 0.6 & 1.0 & $0.8908 \pm 0.0016$ & 0.8940 \\
\hline 16ar-00-hf8 & 0.8 & 1.0 & $0.8943 \pm 0.0016$ & 0.8975 \\
\hline 16ar-00-hf9 & 0.9 & 1.0 & $0.8975 \pm 0.0015$ & 0.9005 \\
\hline 16 ar-00-hf10 & 0.95 & 1.0 & $0.8980 \pm 0.0015$ & 0.9010 \\
\hline 16ar-00-hf1 1 & 1.0 & 1.0 & $0.8979 \pm 0.0013$ & 0.9005 \\
\hline
\end{tabular}

For a spacing of 0.5 in. $(1.27 \mathrm{~cm})$, the maximum calculated $k_{e f f}+2 \sigma$ is 0.9010 , which is $\sim 2.6 \%$ higher relative to the unspaced packages. Results are also presented in Table 7.15 for the two damaged MO-1s with 1.0 -in. $(2.54-\mathrm{cm})$ spacing. For a 1.0 -in. $(2.54-\mathrm{cm})$ separation, the system reactivity plateaus at $\sim 80 \%$ water density, and the maximum $k_{\text {eff }}+2 \sigma$ is 0.9128 , which is acceptably subcritical. In the next series of calculations, the packages are separated by 2 in. $(5.08 \mathrm{~cm})$ of water, and the results are presented in Table 7.16. Based on the results in Table 7.16, the system reactivity peaks at $60 \%$ of full-water density and decreases with increasing interspersed water density. For a $2-i n .(5.08-\mathrm{cm})$ separation, the maximum calculated $k_{e f f}+2 \sigma$ is 0.9011 . As the package spacing increases to 3 in. $(7.62 \mathrm{~cm})$, the system reactivity in Table 7.17 reaches a maximum at $40 \%$ full-water density, and the corresponding calculated $k_{e f f}+2 \sigma$ is 0.8889 which is $\sim 2.7 \%$ below the system multiplication for a 1.0 -in. $(2.54-\mathrm{cm})$ separation. Adding more spacing between the packages will only provide additional water reflection for each package and will not increase the array multiplication. Therefore, the array reactivity is a maximum for a $1.0-\mathrm{in} .(2.54-\mathrm{cm})$ horizontal separation distance between the two damaged MO-1s. Based on these results, two damaged MO-1s with two boxes of $6 \mathrm{wt} \% \mathrm{PuO}_{2} \mathrm{MOX}$ Fuel pins are acceptably subcritical. 
Table 7.15. Calculated $k_{\text {eff }}$ values for two 1.0-in.-spaced MO-1s (damaged) with $6 \mathrm{wt} \% \mathrm{PuO}_{2} \mathrm{MOX}$ fuel pins

\begin{tabular}{ccccc}
\hline Case & $\begin{array}{c}\text { Interspersed } \mathrm{H}_{2} \mathrm{O} \\
\text { volume fraction }\end{array}$ & $\begin{array}{c}\text { Internal } \mathrm{H}_{2} \mathrm{O} \\
\text { volume fraction }\end{array}$ & $k_{\text {eff }} \pm \sigma$ & $k_{\text {eff }}+2 \sigma$ \\
\hline $16 \mathrm{ar}-00-11$ & 0.0 & 1.0 & $0.8661 \pm 0.0013$ & 0.8687 \\
$16 \mathrm{ar}-00-12$ & 0.001 & 1.0 & $0.8625 \pm 0.0013$ & 0.8651 \\
$16 \mathrm{ar}-00-13$ & 0.003 & 1.0 & $0.8655 \pm 0.0014$ & 0.8683 \\
$16 \mathrm{ar}-00-14$ & 0.05 & 1.0 & $0.8681 \pm 0.0015$ & 0.8711 \\
$16 \mathrm{ar}-00-15$ & 0.1 & 1.0 & $0.8706 \pm 0.0015$ & 0.8736 \\
$16 \mathrm{ar}-00-16$ & 0.4 & 1.0 & $0.8898 \pm 0.0014$ & 0.8926 \\
$16 \mathrm{ar}-00-17$ & 0.6 & 1.0 & $0.8972 \pm 0.0015$ & 0.9002 \\
$16 \mathrm{ar}-00-18$ & 0.8 & 1.0 & $0.9046 \pm 0.0015$ & 0.9076 \\
$16 \mathrm{ar}-00-19$ & 0.9 & 1.0 & $0.9060 \pm 0.0015$ & 0.9090 \\
$16 \mathrm{ar}-00-110$ & 0.95 & 1.0 & $0.9098 \pm 0.0015$ & 0.9128 \\
$16 \mathrm{ar}-00-111$ & 1.0 & 1.0 & $0.9075 \pm 0.0014$ & 0.9103 \\
\hline
\end{tabular}

Table 7.16. Calculated $k_{\text {eff }}$ values for two 2.0-in.-spaced MO-1s (damaged) with $6 \mathrm{wt} \% \mathrm{PuO}_{2} \mathrm{MOX}$ fuel pins

\begin{tabular}{ccccc}
\hline Case & $\begin{array}{c}\text { Interspersed } \mathrm{H}_{2} \mathrm{O} \\
\text { volume fraction }\end{array}$ & $\begin{array}{c}\text { Internal } \mathrm{H}_{2} \mathrm{O} \\
\text { volume fraction }\end{array}$ & $k_{\text {eff }} \pm \sigma$ & $k_{\text {eff }}+2 \sigma$ \\
\hline $16 \mathrm{ar}-00-21$ & 0.0 & 1.0 & $0.8556 \pm 0.0015$ & 0.8586 \\
$16 \mathrm{ar}-00-22$ & 0.001 & 1.0 & $0.8563 \pm 0.0018$ & 0.8599 \\
$16 \mathrm{ar}-00-23$ & 0.003 & 1.0 & $0.8510 \pm 0.0014$ & 0.8538 \\
$16 \mathrm{ar}-00-24$ & 0.05 & 1.0 & $0.8583 \pm 0.0015$ & 0.8613 \\
$16 \mathrm{ar}-00-25$ & 0.1 & 1.0 & $0.8657 \pm 0.0014$ & 0.8685 \\
$16 \mathrm{ar}-00-26$ & 0.4 & 1.0 & $0.8908 \pm 0.0015$ & 0.8938 \\
$16 \mathrm{ar}-00-27$ & 0.6 & 1.0 & $0.8983 \pm 0.0014$ & 0.9011 \\
$16 \mathrm{ar}-00-28$ & 0.8 & 1.0 & $0.8932 \pm 0.0014$ & 0.8960 \\
$16 \mathrm{ar}-00-29$ & 0.9 & 1.0 & $0.8874 \pm 0.0014$ & 0.8902 \\
$16 \mathrm{ar}-00-210$ & 0.95 & 1.0 & $0.8854 \pm 0.0014$ & 0.8882 \\
$16 \mathrm{ar}-00-211$ & 1.0 & 1.0 & $0.8869 \pm 0.0015$ & 0.8899 \\
\hline
\end{tabular}


Table 7.17. Calculated $k_{\text {eff }}$ values for two 3.0-in.-spaced MO-1s (damaged) with $6 \mathrm{wt} \% \mathrm{PuO}_{2} \mathrm{MOX}$ fuel pins

\begin{tabular}{ccccc}
\hline Case & $\begin{array}{c}\text { Interspersed } \mathrm{H}_{2} \mathrm{O} \\
\text { volume fraction }\end{array}$ & $\begin{array}{c}\text { Internal } \mathrm{H}_{2} \mathrm{O} \\
\text { volume fraction }\end{array}$ & $k_{\text {eff }} \pm \sigma$ & $k_{\text {eff }}+2 \sigma$ \\
\hline $16 \mathrm{ar}-00-31$ & 0.0 & 1.0 & $0.8382 \pm 0.0013$ & 0.8408 \\
$16 \mathrm{ar}-00-32$ & 0.001 & 1.0 & $0.8426 \pm 0.0015$ & 0.8456 \\
$16 \mathrm{ar}-00-33$ & 0.003 & 1.0 & $0.8405 \pm 0.0014$ & 0.8433 \\
$16 \mathrm{ar}-00-34$ & 0.05 & 1.0 & $0.8478 \pm 0.0016$ & 0.8510 \\
$16 \mathrm{ar}-00-35$ & 0.1 & 1.0 & $0.8567 \pm 0.0015$ & 0.8597 \\
$16 \mathrm{ar}-00-36$ & 0.4 & 1.0 & $0.8859 \pm 0.0015$ & 0.8889 \\
$16 \mathrm{ar}-00-37$ & 0.6 & 1.0 & $0.8817 \pm 0.0014$ & 0.8845 \\
$16 \mathrm{ar}-00-38$ & 0.8 & 1.0 & $0.8585 \pm 0.0013$ & 0.8611 \\
$16 \mathrm{ar}-00-39$ & 0.9 & 1.0 & $0.8521 \pm 0.0015$ & 0.8551 \\
$16 \mathrm{ar}-00-310$ & 0.95 & 1.0 & $0.8460 \pm 0.0014$ & 0.8488 \\
$16 \mathrm{ar}-00-311$ & 1.0 & 1.0 & $0.8396 \pm 0.0014$ & 0.8424 \\
\hline
\end{tabular}

To assess the array reactivity for the alternative fuel loadings, damaged package calculations are also provided for the 4.4 and $3.03 \mathrm{wt} \% \mathrm{PuO}_{2} \mathrm{MOX}$ fuel pins arranged on a $0.47-\mathrm{in}$. $(1.20-\mathrm{cm})$ pitch. The $2 \times 1 \times 1$ array models presented for the $6 \mathrm{wt} \% \mathrm{PuO}_{2} \mathrm{MOX}$ cases were also used to evaluate the alternative fuel loadings. With regard to the $4.4 \mathrm{wt} \% \mathrm{PuO}_{2} \mathrm{MOX}$ fuel pins, results are presented in Tables 7.18-7.21 for package spacings of $0,0.5,1.0$ and $2.0 \mathrm{in}$. (i.e., $0,1.27,2.54$ and $5.08 \mathrm{~cm}$ ), respectively. As observed for the $6 \mathrm{wt} \% \mathrm{PuO}_{2} \mathrm{MOX}$ cases, the optimum horizontal package spacing is $1.0 \mathrm{in}$. $(2.54 \mathrm{~cm})$. The corresponding maximum calculated $k_{\text {eff }}+2 \sigma$ occurs at full interspersed water density and is 0.8963 . As the package spacing increases beyond $1.0 \mathrm{in}$, the system multiplication does not increase. Since the maximum system multiplication is acceptably below the calculational USL, a $2 \times 1 \times 1$ array of damaged MO-1s with $4.4 \mathrm{wt} \% \mathrm{PuO}_{2} \mathrm{MOX}$ fuel is acceptably subcritical.

For the $3.03 \mathrm{wt} \% \mathrm{PuO}_{2}$ MOX fuel pins, calculated results are presented in Tables 7.22-7.25 for the same package spacings used in the $4.4 \mathrm{wt} \%$ cases. With no package spacing in Table 7.22, the system multiplication is a maximum at full-density-water-moderation conditions; however, there is an upward trend in $k_{e f f}$ as the water fraction approaches 1 . These results indicate that the peak value of $k_{\text {eff }}$ has not been reached in the calculations for the $3.03 \mathrm{wt} \%$ cases in Table 7.22 . Consequently, the package spacing must be increased, and interspersed water moderation needs to be considered between the packages. The calculated results for horizontal spacings of $0.5,1.0$ and $2.0 \mathrm{in} .(1.27,2.54$ and $5.08 \mathrm{~cm})$ are presented in Tables $7.23,7.24$ and 7.25 , respectively. When the spacing increases to $1.0 \mathrm{in}$. $(2.54 \mathrm{~cm})$, the system multiplication reaches a plateau at $\sim 80 \%$ full-water density, and the maximum calculated $k_{\text {eff }}+2 \sigma$ is 0.8872 . As the package spacing increases beyond $1.0 \mathrm{in} .(2.54 \mathrm{~cm})$, the system multiplication does not increase, as shown in Table 7.25. Based on the results for the $3.03 \mathrm{wt} \% \mathrm{PuO}_{2} \mathrm{MOX}_{\text {fuel, }} \mathrm{a} 2 \times 1 \times 1$ array of damaged MO-1s with two boxes of fuel pins is subcritical relative to the calculational USL. 
Table 7.18. Calculated $k_{\text {eff }}$ values for two unspaced MO-1s (damaged) with $4.4 \mathrm{wt} \% \mathrm{PuO}_{2} \mathrm{MOX}$ fuel pins

\begin{tabular}{cccc}
\hline Case & $\begin{array}{c}\text { Internal } \mathrm{H}_{2} \mathrm{O} \\
\text { volume fraction }\end{array}$ & $k_{\text {eff }} \pm \sigma$ & $k_{\text {eff }}+2 \sigma$ \\
\hline $14 \mathrm{ar}-00-1$ & 0.0 & $0.5193 \pm 0.0012$ & 0.5217 \\
$14 \mathrm{ar}-00-2$ & 0.001 & $0.5194 \pm 0.0012$ & 0.5218 \\
$14 \mathrm{ar}-00-3$ & 0.003 & $0.5165 \pm 0.0015$ & 0.5195 \\
$14 \mathrm{ar}-00-4$ & 0.05 & $0.5358 \pm 0.0012$ & 0.5382 \\
$14 \mathrm{ar}-00-5$ & 0.1 & $0.5661 \pm 0.0012$ & 0.5685 \\
$14 \mathrm{ar}-00-6$ & 0.4 & $0.6922 \pm 0.0013$ & 0.6948 \\
$14 \mathrm{ar}-00-7$ & 0.6 & $0.7551 \pm 0.0013$ & 0.7577 \\
$14 \mathrm{ar}-00-8$ & 0.8 & $0.8097 \pm 0.0014$ & 0.8125 \\
$14 \mathrm{ar}-00-9$ & 0.9 & $0.8362 \pm 0.0014$ & 0.8390 \\
$14 \mathrm{ar}-00-10$ & 0.95 & $0.8485 \pm 0.0016$ & 0.8517 \\
$14 \mathrm{ar}-00-11$ & 1.0 & $0.8635 \pm 0.0015$ & 0.8665 \\
\hline
\end{tabular}

Table 7.19. Calculated $k_{\text {eff }}$ values for two 0.5-in.-spaced MO-1s (damaged) with 4.4 wt $\% \mathrm{PuO}_{2} \mathrm{MOX}$ fuel pins

\begin{tabular}{ccccc}
\hline Case & $\begin{array}{c}\text { Interspersed } \mathrm{H}_{2} \mathrm{O} \\
\text { volume fraction }\end{array}$ & $\begin{array}{c}\text { Internal } \mathrm{H}_{2} \mathrm{O} \\
\text { volume fraction }\end{array}$ & $k_{\text {eff }} \pm \sigma$ & $k_{\text {eff }}+2 \sigma$ \\
\hline 14ar-00-hf1 & 0.0 & 1.0 & $0.8536 \pm 0.0014$ & 0.8564 \\
14ar-00-hf2 & 0.001 & 1.0 & $0.8555 \pm 0.0014$ & 0.8583 \\
14ar-00-hf3 & 0.003 & 1.0 & $0.8551 \pm 0.0015$ & 0.8581 \\
14ar-00-hf4 & 0.05 & 1.0 & $0.8549 \pm 0.0015$ & 0.8579 \\
14ar-00-hf5 & 0.1 & 1.0 & $0.8593 \pm 0.0014$ & 0.8621 \\
14ar-00-hf6 & 0.4 & 1.0 & $0.8692 \pm 0.0014$ & 0.8720 \\
14ar-00-hf7 & 0.6 & 1.0 & $0.8734 \pm 0.0016$ & 0.8766 \\
14ar-00-hf8 & 0.8 & 1.0 & $0.8805 \pm 0.0014$ & 0.8833 \\
14ar-00-hf9 & 0.9 & 1.0 & $0.8836 \pm 0.0015$ & 0.8866 \\
14ar-00-hf10 & 0.95 & 1.0 & $0.8862 \pm 0.0016$ & 0.8878 \\
14ar-00-hf11 & 1.0 & 1.0 & $0.8863 \pm 0.0016$ & 0.8895 \\
\hline
\end{tabular}


Table 7.20. Calculated $k_{\text {eff }}$ values for two 1.0 -in.-spaced MO-1s (damaged) with 4.4 wt $\% \mathrm{PuO}_{2} \mathrm{MOX}$ fuel pins

\begin{tabular}{ccccc}
\hline Case & $\begin{array}{c}\text { Interspersed } \mathrm{H}_{2} \mathrm{O} \\
\text { volume fraction }\end{array}$ & $\begin{array}{c}\text { Internal } \mathrm{H}_{2} \mathrm{O} \\
\text { volume fraction }\end{array}$ & $k_{\text {eff }} \pm \sigma$ & $k_{\text {eff }}+2 \sigma$ \\
\hline $14 \mathrm{ar}-00-11$ & 0.0 & 1.0 & $0.8478 \pm 0.0018$ & 0.8514 \\
$14 \mathrm{ar}-00-12$ & 0.001 & 1.0 & $0.8463 \pm 0.0014$ & 0.8491 \\
$14 \mathrm{ar}-00-13$ & 0.003 & 1.0 & $0.8470 \pm 0.0016$ & 0.8502 \\
$14 \mathrm{ar}-00-14$ & 0.05 & 1.0 & $0.8493 \pm 0.0014$ & 0.8521 \\
$14 \mathrm{ar}-00-15$ & 0.1 & 1.0 & $0.8559 \pm 0.0014$ & 0.8587 \\
$14 \mathrm{ar}-00-16$ & 0.4 & 1.0 & $0.8742 \pm 0.0014$ & 0.8770 \\
$14 \mathrm{ar}-00-17$ & 0.6 & 1.0 & $0.8817 \pm 0.0013$ & 0.8843 \\
$14 \mathrm{ar}-00-18$ & 0.8 & 1.0 & $0.8885 \pm 0.0015$ & 0.8915 \\
$14 \mathrm{ar}-00-19$ & 0.9 & 1.0 & $0.8906 \pm 0.0014$ & 0.8934 \\
$14 \mathrm{ar}-00-110$ & 0.95 & 1.0 & $0.8923 \pm 0.0016$ & 0.8955 \\
$14 \mathrm{ar}-00-111$ & 1.0 & 1.0 & $0.8933 \pm 0.0015$ & 0.8963 \\
\hline
\end{tabular}

Table 7.21. Calculated $k_{\text {eff }}$ values for two 2.0-in.-spaced MO-1s (damaged) with 4.4 wt $\% \mathrm{PuO}_{2} \mathrm{MOX}$ fuel pins

\begin{tabular}{ccccc}
\hline Case & $\begin{array}{c}\text { Interspersed } \mathrm{H}_{2} \mathrm{O} \\
\text { volume fraction }\end{array}$ & $\begin{array}{c}\text { Internal } \mathrm{H}_{2} \mathrm{O} \\
\text { volume fraction }\end{array}$ & $k_{\text {eff }} \pm \sigma$ & $k_{\text {eff }}+2 \sigma$ \\
\hline $14 \mathrm{ar}-00-21$ & 0.0 & 1.0 & $0.8350 \pm 0.0014$ & 0.8378 \\
$14 \mathrm{ar}-00-22$ & 0.001 & 1.0 & $0.8341 \pm 0.0014$ & 0.8369 \\
$14 \mathrm{ar}-00-23$ & 0.003 & 1.0 & $0.8348 \pm 0.0015$ & 0.8378 \\
$14 \mathrm{ar}-00-24$ & 0.05 & 1.0 & $0.8406 \pm 0.0014$ & 0.8434 \\
$14 \mathrm{ar}-00-25$ & 0.1 & 1.0 & $0.8481 \pm 0.0015$ & 0.8511 \\
$14 \mathrm{ar}-00-26$ & 0.4 & 1.0 & $0.8766 \pm 0.0014$ & 0.8794 \\
$14 \mathrm{ar}-00-27$ & 0.6 & 1.0 & $0.8818 \pm 0.0015$ & 0.8848 \\
$14 \mathrm{ar}-00-28$ & 0.8 & 1.0 & $0.8767 \pm 0.0015$ & 0.8797 \\
$14 \mathrm{ar}-00-29$ & 0.9 & 1.0 & $0.8743 \pm 0.0016$ & 0.8775 \\
$14 \mathrm{ar}-00-210$ & 0.95 & 1.0 & $0.8698 \pm 0.0014$ & 0.8726 \\
$14 \mathrm{ar}-00-211$ & 1.0 & 1.0 & $0.8683 \pm 0.0015$ & 0.8713 \\
\hline
\end{tabular}


Table 7.22. Calculated $k_{e f f}$ values for two unspaced MO-1s (damaged) with 3.03 wt $\% \mathrm{PuO}_{2} \mathrm{MOX}$ fuel pins

\begin{tabular}{cccc}
\hline Case & $\begin{array}{c}\text { Internal } \mathrm{H}_{2} \mathrm{O} \\
\text { volume fraction }\end{array}$ & $k_{\text {eff }} \pm \sigma$ & $k_{\text {eff }}+2 \sigma$ \\
\hline 13ar-00-1 & 0.0 & $0.4895 \pm 0.0013$ & 0.4921 \\
$13 \mathrm{ar}-00-2$ & 0.001 & $0.4894 \pm 0.0013$ & 0.4920 \\
13ar-00-3 & 0.003 & $0.4900 \pm 0.0011$ & 0.4922 \\
13ar-00-4 & 0.05 & $0.5051 \pm 0.0013$ & 0.5077 \\
13ar-00-5 & 0.1 & $0.5362 \pm 0.0013$ & 0.5388 \\
13ar-00-6 & 0.4 & $0.6675 \pm 0.0012$ & 0.6699 \\
13ar-00-7 & 0.6 & $0.7361 \pm 0.0014$ & 0.7389 \\
13ar-00-8 & 0.8 & $0.7986 \pm 0.0014$ & 0.8014 \\
13ar-00-9 & 0.9 & $0.8299 \pm 0.0013$ & 0.8325 \\
13ar-00-10 & 0.95 & $0.8382 \pm 0.0016$ & 0.8414 \\
13ar-00-11 & 1.0 & $0.8565 \pm 0.0014$ & 0.8593 \\
\hline
\end{tabular}

Table 7.23. Calculated $k_{\text {eff }}$ values for two 0.5 -in.-spaced MO-1s (damaged) with 3.03 wt $\% \mathrm{PuO}_{2} \mathrm{MOX}$ fuel pins

\begin{tabular}{ccccc}
\hline Case & $\begin{array}{c}\text { Interspersed } \mathrm{H}_{2} \mathrm{O} \\
\text { volume fraction }\end{array}$ & $\begin{array}{c}\text { Internal } \mathrm{H}_{2} \mathrm{O} \\
\text { volume fraction }\end{array}$ & $k_{\text {eff }} \pm \sigma$ & $k_{\text {eff }}+2 \sigma$ \\
\hline 13ar-00-hf1 & 0.0 & 1.0 & $0.8450 \pm 0.0015$ & 0.8480 \\
13ar-00-hf2 & 0.001 & 1.0 & $0.8451 \pm 0.0015$ & 0.8481 \\
13ar-00-hf3 & 0.003 & 1.0 & $0.8467 \pm 0.0017$ & 0.8501 \\
13ar-00-hf4 & 0.05 & 1.0 & $0.8490 \pm 0.0015$ & 0.8520 \\
13ar-00-hf5 & 0.1 & 1.0 & $0.8516 \pm 0.0013$ & 0.8542 \\
13ar-00-hf6 & 0.4 & 1.0 & $0.8614 \pm 0.0015$ & 0.8644 \\
13ar-00-hf7 & 0.6 & 1.0 & $0.8649 \pm 0.0014$ & 0.8677 \\
13ar-00-hf8 & 0.8 & 1.0 & $0.8705 \pm 0.0015$ & 0.8735 \\
13ar-00-hf9 & 0.9 & 1.0 & $0.8724 \pm 0.0014$ & 0.8752 \\
13ar-00-hf10 & 0.95 & 1.0 & $0.8742 \pm 0.0017$ & 0.8776 \\
13ar-00-hf11 & 1.0 & 1.0 & $0.8781 \pm 0.0016$ & 0.8813 \\
\hline
\end{tabular}


Table 7.24. Calculated $k_{\text {eff }}$ values for two 1.0-in.-spaced MO-1s (damaged) with $3.03 \mathrm{wt} \% \mathrm{PuO}_{2} \mathrm{MOX}$ fuel pins

\begin{tabular}{ccccc}
\hline Case & $\begin{array}{c}\text { Interspersed } \mathrm{H}_{2} \mathrm{O} \\
\text { volume fraction }\end{array}$ & $\begin{array}{c}\text { Internal } \mathrm{H}_{2} \mathrm{O} \\
\text { volume fraction }\end{array}$ & $k_{\text {eff }} \pm \sigma$ & $k_{\text {eff }}+2 \sigma$ \\
\hline $13 \mathrm{ar}-00-11$ & 0.0 & 1.0 & $0.8391 \pm 0.0014$ & 0.8419 \\
$13 \mathrm{ar}-00-12$ & 0.001 & 1.0 & $0.8366 \pm 0.0015$ & 0.8396 \\
$13 \mathrm{ar}-00-13$ & 0.003 & 1.0 & $0.8394 \pm 0.0014$ & 0.8422 \\
$13 \mathrm{ar}-00-14$ & 0.05 & 1.0 & $0.8442 \pm 0.0014$ & 0.8470 \\
$13 \mathrm{ar}-00-15$ & 0.1 & 1.0 & $0.8471 \pm 0.0014$ & 0.8499 \\
$13 \mathrm{ar}-00-16$ & 0.4 & 1.0 & $0.8654 \pm 0.0015$ & 0.8684 \\
$13 \mathrm{ar}-00-17$ & 0.6 & 1.0 & $0.8755 \pm 0.0015$ & 0.8785 \\
$13 \mathrm{ar}-00-18$ & 0.8 & 1.0 & $0.8816 \pm 0.0016$ & 0.8848 \\
$13 \mathrm{ar}-00-19$ & 0.9 & 1.0 & $0.8809 \pm 0.0015$ & 0.8839 \\
$13 \mathrm{ar}-00-110$ & 0.95 & 1.0 & $0.8818 \pm 0.0017$ & 0.8852 \\
$13 \mathrm{ar}-00-111$ & 1.0 & 1.0 & $0.8842 \pm 0.0015$ & 0.8872 \\
\hline
\end{tabular}

Table 7.25. Calculated $k_{\text {eff }}$ values for two 2.0-in.-spaced MO-1s (damaged) with 3.03 wt $\% \mathrm{PuO}_{2} \mathrm{MOX}$ fuel pins

\begin{tabular}{ccccc}
\hline Case & $\begin{array}{c}\text { Interspersed } \mathrm{H}_{2} \mathrm{O} \\
\text { volume fraction }\end{array}$ & $\begin{array}{c}\text { Internal } \mathrm{H}_{2} \mathrm{O} \\
\text { volume fraction }\end{array}$ & $k_{\text {eff }} \pm \sigma$ & $k_{\text {eff }}+2 \sigma$ \\
\hline $13 \mathrm{ar}-00-21$ & 0.0 & 1.0 & $0.8244 \pm 0.0014$ & 0.8272 \\
$13 \mathrm{ar}-00-22$ & 0.001 & 1.0 & $0.8267 \pm 0.0014$ & 0.8295 \\
$13 \mathrm{ar}-00-23$ & 0.003 & 1.0 & $0.8256 \pm 0.0014$ & 0.8284 \\
$13 \mathrm{ar}-00-24$ & 0.05 & 1.0 & $0.8303 \pm 0.0015$ & 0.8333 \\
$13 \mathrm{ar}-00-25$ & 0.1 & 1.0 & $0.8413 \pm 0.0018$ & 0.8449 \\
$13 \mathrm{ar}-00-26$ & 0.4 & 1.0 & $0.8647 \pm 0.0015$ & 0.8677 \\
$13 \mathrm{ar}-00-27$ & 0.6 & 1.0 & $0.8723 \pm 0.0015$ & 0.8753 \\
$13 \mathrm{ar}-00-28$ & 0.8 & 1.0 & $0.8643 \pm 0.0016$ & 0.8675 \\
$13 \mathrm{ar}-00-29$ & 0.9 & 1.0 & $0.8629 \pm 0.0013$ & 0.8655 \\
$13 \mathrm{ar}-00-210$ & 0.95 & 1.0 & $0.8583 \pm 0.0014$ & 0.8611 \\
$13 \mathrm{ar}-00-211$ & 1.0 & 1.0 & $0.8537 \pm 0.0013$ & 0.8563 \\
\hline
\end{tabular}


The results that are presented in Tables 7.13-7.25 demonstrate that two damaged MO-1s with two boxes of the previously certified MOX fuel pins are subcritical. As noted in Sect. 1.1, only two MO-1 packages exist. Therefore, analyzing a finite array of damaged packages with more than two units is not realistic. For the purposes of determining a transport index, the maximum number of damaged packages that are acceptably subcritical is two.

\subsubsection{Weapons-Grade MOX Fuel}

\subsubsection{Undamaged Package Configurations}

As shown in Sect. 7.3.1, an array of undamaged MO-1s may be neutronically isolated at fulldensity internal water flooding. Table 7.26 presents calculated results for an infinite array of undamaged MO-1s at progressive states of water flooding. For each case, the MO-1 is loaded with two boxes of WG MOX fuel pins arranged on a 0.43-in. $(1.10-\mathrm{cm})$ pitch, as described in Sect. 7.2.2. The calculated results in Table 7.26 demonstrate that the optimum moderation conditions for the infinite array is at full-density-water flooding. The maximum calculated $k_{\infty}$ for the infinite array of undamaged packages is $0.7746 \pm 0.0016$ which is acceptably below the USL. Moreover, the multiplication factor for the infinite array is statistically the same as the fully water-reflected and flooded-single-unit case (i.e., lwt-1). Under full-density-water flooding conditions, the undamaged packages in the array are neutronically isolated.

Table 7.26. Calculated system multiplication for an infinite array of undamaged MO-1s with WG MOX fuel pins

\begin{tabular}{cccc}
\hline Case & $\begin{array}{c}\text { Internal } \mathrm{H}_{2} \mathrm{O} \\
\text { volume fraction }\end{array}$ & $k_{\infty} \pm \sigma$ & $k_{\infty}+2 \sigma$ \\
\hline lwi-1 & 0.0 & $0.7633 \pm 0.0013$ & 0.7659 \\
lwi-2 & 0.001 & $0.7602 \pm 0.0012$ & 0.7626 \\
lwi-3 & 0.003 & $0.7547 \pm 0.0012$ & 0.7571 \\
lwi-4 & 0.05 & $0.6687 \pm 0.0014$ & 0.6715 \\
lwi-5 & 0.1 & $0.6047 \pm 0.0014$ & 0.6075 \\
lwi-6 & 0.4 & $0.6053 \pm 0.0014$ & 0.6081 \\
lwi-7 & 0.6 & $0.6649 \pm 0.0015$ & 0.6679 \\
lwi-8 & 0.8 & $0.7226 \pm 0.0016$ & 0.7258 \\
lwi-9 & 0.9 & $0.7488 \pm 0.0014$ & 0.7516 \\
lwi-10 & 0.95 & $0.7618 \pm 0.0016$ & 0.7650 \\
lwi-11 & 1.0 & $0.7746 \pm 0.0016$ & 0.7778 \\
\hline
\end{tabular}




\subsubsection{Damaged Package Configurations}

In the preceding array analyses of damaged packages, configurations that optimize package interaction lead to a higher system multiplication for the overall array. Based on the results in Sect. 6.2.2.2 for the WG MOX fuel assemblies, a $2 \times 1 \times 1$ configuration of damaged MO-1s is not subcritical. The fuel contents of each package are shifted to neighboring corners with the internal MO-1 cavity, as shown in Fig. 3.10. Initially, this configuration is reevaluated with two boxes of WG MOX fuel pins in each package. In both $\mathrm{MO}-1 \mathrm{~s}$, the crushed exterior containment is 0.028 -in. $(0.071-\mathrm{cm})$-thick carbon steel with no polyurethane foam insulation. As in the previous case, both packages are completely flooded, and the array is fully reflected with 12 -in. $(30-\mathrm{cm})$ of water. The calculated multiplication factor for the $2 \times 1 \times 1$ array is provided in Table 7.27 as Case lwar-0. In addition, the calculated result for the damaged single-package case with fuel contents shifted to the internal corner (i.e., Case lwb-3) is also provided in Table 7.27. The calculated result for the two-unit array of packages is $0.9136 \pm 0.0017$, which is acceptably below the calculational USL. Although the array of two damaged packages is subcritical, the array presented in Fig. 3.9 is not the most reactive configuration. If the fuel contents in each MO-1 are rotated $90^{\circ}$ as shown in Fig. 3.11, the interaction between packages would increase. An additional calculation is provided in Table 7.27 as Case lwar-00 for the configuration presented in Fig. 3.11. Both units are completely flooded, and the array is fully reflected with water. The calculated $k_{e f f}+2 \sigma$ for the

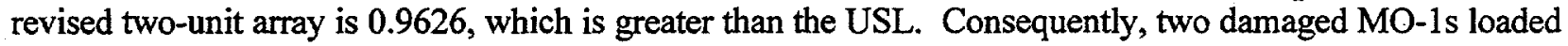
with two boxes of WG MOX pins are not subcritical.

Table 7.27. Calculated $k_{\text {eff }}$ values for finite array of damaged MO-1s with WG MOX fuel pins

\begin{tabular}{|c|c|c|c|c|}
\hline Case & $\begin{array}{l}\text { Internal } \\
\mathrm{H}_{2} \mathrm{O} \\
\text { volume } \\
\text { fraction }\end{array}$ & Description & $k_{e f f} \pm \sigma$ & $k_{e f f}+2 \sigma$ \\
\hline lwb-3 & 1.0 & $\begin{array}{l}1 \times 1 \times 1 \text { array, damaged package with shifted } \\
\text { fuel contents (Fig. 3.9). Temp }=483.15 \mathrm{~K}\end{array}$ & $0.8326 \pm 0.0017$ & 0.8360 \\
\hline lwar-0 & 1.0 & $\begin{array}{l}2 \times 1 \times 1 \text { array, damaged packages with shifted } \\
\text { fuel contents (Fig. } 3.10) . \text { Crushed wall } \\
\text { thickness }=0.028 \text { in. }(0.071 \mathrm{~cm}) . \text { Temp }= \\
483.15 \mathrm{~K}\end{array}$ & $0.9136 \pm 0.0017$ & 0.9170 \\
\hline lwar-00 & 1.0 & $\begin{array}{l}2 \times 1 \times 1 \text { array, damaged packages with shifted } \\
\text { fuel contents (Fig. } 3.11) . \text { Crushed wall } \\
\text { thickness }=0.028 \text { in. }(0.071 \mathrm{~cm}) . \text { Temp }= \\
483.15 \mathrm{~K}\end{array}$ & $0.9596 \pm 0.0015$ & 0.9626 \\
\hline
\end{tabular}




\subsection{TRANSPORT INDEX}

\subsubsection{Previously Certified MOX Fuel}

Table 7.28 summarizes the results for the number of packages that are subcritical under normal and hypothetical accident conditions. For normal conditions of transport, an infinite array of packages is subcritical. As discussed in Sect. 7.3.1, two damaged packages with two boxes of the previously certified MOX fuel pins are subcritical. In accordance with 10 CFR $\S 71.59$, the maximum number of packages for an exclusive use shipment is $2(\mathrm{~N}=1)$, and the corresponding $T$ is 50 .

The TI determination for the shipment of the previously certified MOX fuel pins is based on the evaluation constraints that are specified in Sect. 7.1. As noted in Sect. 7.2.1.1, the maximum triangular pitch that is considered in the loose pin evaluation is $1.20 \mathrm{~cm}$, which limits the number of pins to 340 per box. If a smaller pitch is used (i.e., $<1.20 \mathrm{~cm}$ ), more pins can be shipped within a box. Note that fewer pins may be shipped in a box provided the constraints of Sect. 7.1 are satisfied and the pitch does not exceed $1.20 \mathrm{~cm}$. In particular, no vacant rod positions are present in the fuel-pin array within the box, and the box is filled from the bottom, leaving no vacant pin locations in the array.

The evaluation also assumes the fuel pins are arranged in a triangular-pitch configuration. However, a square-pitch configuration may be needed for shipment of the fuel pins. A triangular-lattice configuration will typically be more reactive than a square lattice, provided the lattice has the same pitch dimensions and the same number of pins. Therefore, the $T I$ in Table 7.28 should be applicable for the shipment of loose pins arranged on a maximum square pitch of $1.20 \mathrm{~cm}$. The specific loose pin configuration should be evaluated in the final criticality safety analysis report for the MO-1 transportation package.

Table 7.28. Parameters used for TI determination of previously certified MOX fuel pins

\begin{tabular}{cc}
\hline Case & Number of subcritical packages \\
\hline Undamaged & $\infty$ \\
Damaged & 2 \\
\hline
\end{tabular}

\subsubsection{Weapons-Grade MOX Fuel}

Table 7.29 summarizes the results for the number of packages that are subcritical under normal and hypothetical accident conditions. For normal conditions of transport, an infinite array of packages is subcritical. As discussed in Sect. 7.3.2, one damaged package with two boxes of WG MOX fuel pins is subcritical. In accordance with $10 \mathrm{CFR} \S 71.59$, the maximum number of packages for an exclusive-use shipment is $1(\mathrm{~N}=0.5)$, and the corresponding $T I$ is 100 .

The TI determination for the shipment of WG MOX fuel pins is based on the evaluation constraints that are specified in Sect. 7.1. As noted in Sect. 7.2.2.1, the maximum triangular pitch that is considered in the loose-pin evaluation is $1.10 \mathrm{~cm}$, which limits the number of pins to 407 per box. If a smaller pitch is used (i.e., $<1.10 \mathrm{~cm}$ ), more pins can be shipped within a box. Note that fewer pins may be shipped in a box provided the constraints of Sect. 7.1 are satisfied and the pitch does not exceed $1.10 \mathrm{~cm}$. In particular, no 
vacant rod positions are present in the fuel-pin array within the box, and the box is filled from the bottom, leaving no vacant pin locations in the array.

The evaluation also assumes the fuel pins are arranged in a triangular-pitch configuration. However, a square-pitch configuration may be needed for shipment of the fuel pins. A triangular-lattice configuration will typically be more reactive than a square lattice, provided the lattice has the same pitch dimensions and the same number of pins. Therefore, the $T I$ in Table 7.29 should be applicable for the shipment of loose pins arranged on a maximum square pitch of $1.10 \mathrm{~cm}$. The specific loose-pin configuration should be evaluated in the final criticality safety analysis report for the MO-1 transportation package.

Table 7.29. Parameters used for TI determination of weapons-grade MOX fuel pins

\begin{tabular}{cc}
\hline Case & Number of subcritical packages \\
\hline Undamaged & $\infty$ \\
Damaged & 1 \\
\hline
\end{tabular}





\section{SUMMARY}

As part of the disposition objectives, the FMDP is exploring the option to modify CoC 9069 and obtain recertification for the shipment of MOX fuel using the MO-1 [USA/9069/B( )F] shipping package. Furthermore, the FMDP plans to extend the approved contents to include WG MOX lead test assemblies. To facilitate the FMDP objectives, this report provides example criticality safety evaluation information that should be included in the criticality safety section of the revised MO-1 certification application. The report addresses two different MOX loadings in the MO-1: Specifically, the evaluation addresses the shipment of non-weapons-grade MOX fuel as certified under $\mathrm{CoC} 9069$, Revision 10. In addition, the report evaluates the shipment of WG MOX fuel using a possible $17 \times 17$ Westinghouse fuel assembly design. All calculations in the report were performed in accordance with the guidance provided in NUREG/CR-5661 for satisfying the statutory requirements of 10 CFR $\S 71$.

Section 2 of the report discusses the MO-1 design information that should be included in the criticality safety section of the application. In particular, the fuel contents (e.g., form, composition, design, etc.) are provided for the previously certified MOX fuel, as well as the WG MOX fuel. Furthermore, Sect. 2 specifies the pertinent package information (e.g., internal configuration, materials, etc.) for the criticality safety evaluation. Using the design information, Sect. 3 describes the computational models used in the criticality safety evaluation. Specifically, the report provides the contents model as well as the single-package and package-array models that should be provided in accordance with the guidance of NUREG/CR-5661.

Section 4 discusses the method of analysis (i.e., computer code, cross sections, code input and calculation convergence) used in the package evaluation. Section 5 describes the validation information used in establishing the calculational USL for criticality safety applications. As part of the validation, 102 critical experiments that are directly applicable to the MO-1 package evaluation are presented and discussed. Based on the selected critical experiments, Sect. 5 also establishes the bias and uncertainties associated with the method of analysis. Using the bias and uncertainties, a calculational USL of 0.9245 is established for the criticality calculations presented in Sect. 6. Note that the USL includes the NRC-required $0.05 \Delta k$ minimum margin of subcriticality for transportation packages.

Using the information presented in Sects. $2-5$, the criticality safety analysis information is provided in Sects. 6 and 7 to demonstrate that the requirements of 10 CFR $\S 71.55$ and 71.59 are satisfied. In particular, the calculations and results provided in Sect. 6 address the shipment of fuel assemblies in the MO-1 package, and the information presented in Sect. 7 considers the transportation of fuel pins in the package. In Sects. 6 and 7, the MO-1 is evaluated under normal and hypothetical accident conditions of transport. Moreover, the damaged and undamaged MO-1 package is evaluated in array configurations that optimize package interaction. Using the array analysis information, a TI for criticality control is established for the shipment of non-weapons-grade MOX fuel. In addition, a separate TI is provided for the shipment of WG MOX fuel.

Based on the array analysis information in Sect. 6, a maximum of one damaged MO-1 is subcritical with two non-weapons-grade MOX assemblies (i.e., assemblies that are described in CoC 9069, Revision 10). As a result, the criticality safety $T I$ for the shipment of two non-weapons-grade MOX fuel assemblies in the MO-1 is 100 . With regard to WG MOX fuel, a maximum of one damaged MO-1 is subcritical with a single $17 \times 17$ Westinghouse WG MOX assembly. Consequently, the criticality safety $\mathrm{TI}$ for the shipment of 1 WG MOX fuel assembly in the MO-1 is 100. Regarding the shipment of individual fuel pins, the evaluation presented in Sect. 7 outlines the constraints used in the calculations for individual fuel pins. Under the constraints specified in Sect. 7, two damaged MO-1s are subcritical with two boxes of non-weapons-grade fuel pins with a maximum pitch of $0.47 \mathrm{in} .(1.20 \mathrm{~cm})$. As a result, the criticality safety 
TI for the shipment of non-weapons-grade MOX fuel pins in the MO-1 is 50. For the WG MOX fuel, a maximum of one damaged MO-1 is subcritical with two boxes of fuel pins with a maximum pitch of 0.43 in. $(1.10 \mathrm{~cm})$. As a result, the criticality safety TI for the shipment of WG MOX fuel pins in the MO-1 is 100 .

Note that this report is considered to be a scoping evaluation and is not intended to substitute for the final criticality safety analysis of the MO-1 shipping package. However, the evaluation presented in this report demonstrates the feasibility of obtaining certification for the transport of WG MOX lead test assemblies using the MO-1 shipping package. 


\section{REFERENCES}

1. S. B. Ludwig et. al., Programmatic and Technical Requirements for the FMDP Fresh MOX Fuel Transport Package, ORNL/TM-13526, Lockheed Martin Energy Research Corp., Oak Ridge Natl. Lab., December 1997.

2. Compatibility with the International Atomic Energy Agency (LAEA); Final Rule, Part II, 10 CFR Part 71 of Federal Register 60 (188), 50248-50289 (September 28, 1995).

3. R. B. Pope and S. B. Ludwig, Certification History of the MO-1 Fresh Fuel Package [Certificate USA/9069/B()] and Consideration for Application of the MO-1 within the DOE FMDP Program Rev. 0, White Paper (DRAFT), January 13, 1998.

4. Certificate of Compliance for Radioactive Materials Packages No. 9069, Revision 11, Docket Number 71-9069, U.S. Nuclear Regulatory Commission, December 16, 1997.

5. Certificate of Compliance for Radioactive Materials Packages No. 9069, Revision 10, Docket Number 71-9069, U.S. Nuclear Regulatory Commission, Expiration January 31, 1997.

6. NRC Letter Correspondence, Cass R. Chappell to Michael E. Wangler, April 7, 1997.

7. H. R. Dyer and C. V. Parks, Recommendations for Preparing the Criticality Safety Evaluation of Transportation Packages, NUREG/CR-5661 (ORNL/TM-11936), U. S. Nuclear Regulatory Commission, 1997.

8. SCALE: A Modular Code System for Performing Standardized Computer Analyses for Licensing Evaluation, NUREG/CR-0200, Rev. 5 (ORNL/NUREG/CSD-2/R5), Vols. I, II, and III, March 1997. Available from Radiation Safety Information Computational Center at Oak Ridge National Laboratory as CCC-545.

9. B. D. Murphy, Characteristics of Spent Fuel from Plutonium Disposition Reactors Vol. 4:

Westinghouse Pressurized-Water-Reactor Fuel Cycle Without Integral Absorber, ORNL/TM13170/V4, Lockheed Martin Energy Research Corp., Oak Ridge Natl. Lab., April 1998.

10. Application for Renewal of Certificate of Compliance No. 9069 Revision 10 Docket 71-9069, Westinghouse Electric Corporation, October 30, 1981.

11. "General Requirements for Fissile Material Packages," Title 10 Code of Federal Regulations, Part 71, Sect. 55, (10 CFR 71.55).

12. "Standards for Arrays of Fissile Material Packages," Title 10 Code of Federal Regulations, Part 71, Sect. 59 ( 10 CFR 71.59).

13. "Hypothetical Accident Conditions," Title 10 Code of Federal Regulations, Part 71, Sect. 73 (10 CFR 71.73). 
14. KENOView 2.1 User's Guide, Netherlands Energy Research Foundation ECN, 1995.

15. American National Standard for Nuclear Criticality Safety in Operations with Fissionable Materials Outside Reactors, ANSI/ANS-8.1-1983 (Revision of ANSI N16.1-1975), American Nuclear Society, La Group, Illinois, 1983.

16. Neutronics Benchmarks for the Utilization of Mixed-Oxide Fuel: Joint U. S./Russian Progress Report for Fiscal Year 1997 Volume 2 - Calculations Performed in the United States, ORNL/TM13603/V2, Lockheed Martin Energy Research Corp., Oak Ridge Natl. Lab., in press.

17. J. J. Lichtenwalter, S. M. Bowman, M. D. DeHart and C. M. Hopper, Criticality Benchmark Guide for Light-Water-Reactor Fuel in Transportation and Storage Packages, NUREG/CR-6361 (ORNL/TM-13211), U.S. Nuclear Regulatory Commission, 1997.

18. American National Standard for Nuclear Criticality Safety Criteria for the Handling, Storage, and Transportation of LWR Fuel Outside Reactors, ANSI/ANS-8.17-1984 (Reaffirmed August 1989). 
APPENDIX A

SAMPLE CSAS25 INPUT FILES 



\section{APPENDIX A}

\section{SAMPLE CSAS25 INPUT FILES}

In the following sections, CSAS25 input files are provided for selected calculational models. Sect. A.1 provides selected input cases from Sect. 6 of the evaluation. In particular, the single-package and array cases that yield the highest calculated multiplication factor are presented in the following sections for the weapons-grade and non-weapons-grade MOX loadings. In Sect. A.2, similar input files from Sect. 7 are also provided for the weapons-grade and non-weapons-grade MOX loadings.

\section{A.1 FUEL ASSEMBLY CALCULATIONS}

\section{A.1.1 Previonsly Certified MOX Fuel}

\section{A.1.1.1 Single-Package Model}

Case: $6 c-2$

$=$ csas 25 parm $=s i z e=140000$

case $\mathrm{fl}$ : fuel temp $483.15 \mathrm{~K}$

238group latticecell

pu-238 $\quad 10.02 .2509 \mathrm{e}-5483.15$ end

pu-239 $10.08 .416 \mathrm{e}-4 \quad 483.15$ end

pu-240 $\quad 10.03 .277 \mathrm{e}-4 \quad 483.15$ end

pu-241 $\quad 10.01 .967 \mathrm{e}-4 \quad 483.15$ end

pu-242 $\quad 10.07 .310 \mathrm{e}-5 \quad 483.15$ end

u-234 $\quad 10.01 .2441$ e-6 483.15 end

u-235 $\quad 10.01 .638 \mathrm{e}-4 \quad 483.15$ end

u-238 $\quad 10.02 .287 \mathrm{e}-2 \quad 483.15$ end

o $\quad 10.02 .5962 \mathrm{e}-2483.15$ end

zirc2 21.0483 .15 end

carbonsteel 31.0483 .15 end

h2o $\quad 41.0483 .15$ end

h2o $\quad 51.0483 .15$ end

h $\quad 60.01 .9621 \mathrm{e}-3483.15$ end

c $\quad 60.02 .1847 e-3483.15$ end

n $\quad 60.04 .167 \mathrm{e}-4 \quad 483.15$ end

o $\quad 60.08 .864 \mathrm{e}-4 \quad 483.15$ end

arbm-boronss3047.74 51015000.9752600068 .82

2400018.81280009 .41120001 .9871 .0483 .15 end

polyethylene 81.0483 .15 end

h2o 91.0483 .15 end

end comp

squarepitch 1.41220 .9272191 .071920 .954 end

case fl: fuel temp $483.15 \mathrm{~K}$

read parm nub-yes npg $=600$ gen $=400$ tme $=100$ nsk $=20$ plt-yes end parm

read geom

unit 1 com $=$ 'fuel unit cell h2o flooded gap'

ycylinder 110.4636365 .80 .0

ycylinder 410.475365 .80 .0

ycylinder 210.536365 .80 .0

cuboid $912 \mathrm{p} 0.7061365 .80 .02 \mathrm{p} 0.7061$

unit 2 com='guide tube $h 20$ flooded"

ycylinder 410.475365 .80 .0

ycylinder 210.536365 .80 .0

cuboid $912 \mathrm{p} 0.7061365 .80 .02 \mathrm{p} 0.7061$

unit 3 com $=$ 'instrumentation h20 flooded'

ycylinder 410.475365 .80 .0

ycylinder 210.536365 .80 .0

cuboid $912 \mathrm{p} 0.7061365 .80 .02 \mathrm{p} 0.7061$

unit 4 com=' $14 \times 14$ assembly'

array $\quad 1-9.8854-182.9-9.8854$

unit 41

com $=19$ in $\mathrm{x}$-thick strongback plate'

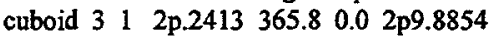

unit 42

com $=.25$ in $x$-thick $h 20$ (cork)

$\begin{array}{llllll}\text { cuboid } 5 & 1 & 2 \mathrm{p} .3175 & 365.8 & 0.0 & 2 \mathrm{p} 9.8854\end{array}$

unit 5 com=' 0.188 in $x$-thick neutron poison plate'

cuboid $712 \mathrm{p} 0.23876365 .80 .08 .34-9.8854$

cuboid $\quad 312 p .23876365 .8 \quad 0.02 p 9.8854$

unit 51

com $=1.5$ in. $x$-space between assemblies'

cuboid $512 \mathrm{pl} .905365 .80 .02 \mathrm{p} 9.8854$

unit 6

com $=2$ assemblies with poison plates'array

$-9.8854$

unit 7

com='strong back plate for assemblies'

cuboid $5110.5204-9.88542 \mathrm{p} 182.92 \mathrm{p} 0.3175$

cuboid $3111.003 \quad-9.88542 \mathrm{p} 182.92 \mathrm{p} 0.3175$

cuboid $7111.48052-9.88542 \mathrm{p} 182.92 \mathrm{p} 0.3175$

cuboid $7111.95804-9.88542 \mathrm{p} 182.92 \mathrm{p} 0.3175$

cuboid $\quad 3112.44064-9.88542 \mathrm{p} 182.92 \mathrm{p} 0.3175$

cuboid $5132.84644-9.88542 \mathrm{p} 182.92 \mathrm{p} 0.3175$

unit 71

cuboid $\quad 3111.003-9.88542 \mathrm{p} 182.92 \mathrm{p} 0.2413$

cuboid $7111.48052-9.88542 \mathrm{p} 182.92 \mathrm{p} 0.2413$

cuboid $7111.95804-9.88542 \mathrm{p} 182.92 \mathrm{p} 0.2413$

cuboid $\quad 3132.84644-9.88542 \mathrm{p} 182.92 \mathrm{p} 0.2413$

global unit 8

com='assemblies in mo-l'

array $\quad 3-20.249-182.9-10.3617$

cuboid $512 \mathrm{p} 46.992 \mathrm{p} 236.229840 .64-53.34$

cuboid 312 p47.06112 2p236.30092 40.71112 -53.41112

replicate $526 * 3.010$

end geom

read array

ara $=1$ nux $=14$ nuy $=1$ nuz $=14$

com $=14 \times 14$ assembly'

loop

111411111141

231231113129 
251051115105

23129111693

3771111881

end loop

ara $=2$ nux $=8$ nuy $=1$ nuz $=1$

com $=2$ assemblies with poison plates'

fill $442415 \quad 541424$ end fill

ara $=3$ nux=1 nuy=1 nuz=3

com='assemblies on strongback'

fill 7176 end fill

end array

read bias id $=500211$ end bias

read plot

$\mathrm{tt}={ }^{\prime} \mathrm{xz}$ slice at $\mathrm{y}=0^{\circ}$

$\mathrm{xul}=91.0 \mathrm{yul}=0.0 \mathrm{zul}=95.0$

$\mathrm{xl}=91.0 \mathrm{ylr}=0.0 \mathrm{zl}=95.0$

$\mathrm{uax}=1.0$ vax $=0.0$ wax $=0.0$

$\mathrm{udn}=0.0 \mathrm{vdn}=0.0 \mathrm{wdn}=1.0$

nax $=120$

end plot

end data

end 


\section{A.1.1.2 Package-Array Model}

Case: 6 ar-0

$=$ csas 25 parm $=s i z e=140000$

case f1: 6 wt $\%$ fuel temp 483.15 accident conf. B crushed-case 5

238group latticecell

pu-238 $10.02 .2509 \mathrm{e}-5483.15$ end

pu-239 $10.08 .416 \mathrm{e}-4483.15$ end

pu-240 $10.03 .277 \mathrm{e}-4 \quad 483.15$ end

$\mathrm{pu}-241 \quad 10.01 .967 \mathrm{e}-4 \quad 483.15$ end

pu-242 $10.07 .310 \mathrm{e}-5 \quad 483.15$ end

$\mathrm{u}-234 \quad 10.01 .2441 \mathrm{e}-6483.15$ end

$\mathrm{u}-235 \quad 10.01 .638 \mathrm{e}-4 \quad 483.15$ end

$\mathrm{u}-238 \quad 10.02 .287 \mathrm{e}-2 \quad 483.15$ end

o $\quad 10.02 .5962 \mathrm{e}-2483.15$ end

zirc2 21.0483 .15 end

carbonsteel 31.0483 .15 end

h2o $\quad 41.0483 .15$ end

h20 $\quad 51.0483 .15$ end

h $\quad 60.01 .9621 \mathrm{e}-3483.15$ end

c $\quad 60.02 .1847 \mathrm{e}-3483.15$ end

n $\quad 60.04 .167 \mathrm{e}-4 \quad 483.15$ end

- $\quad 60.08 .864 \mathrm{e}-4483.15$ end

arbm-boronss3047.7451015000 9752600068.82

2400018.81280009 .41120001 .9871 .0483 .15 end

polyethylene 81.0483 .15 end

h20 91.0483 .15 end

end comp

squarepitch $1.41220 .9272191 .07192 \quad 0.954$ end

case $\mathrm{fl}$ : fuel temp 483.15 accident conf $B$

read parm nub $=y$ es npg $=600$ gen $=400$ tme $=100$ nsk $=20$ plt-yes end parm

read geom

unit l com='fuel unit cell h2o flooded gap'

ycylinder 110.4636365 .80 .0

ycylinder 410.475365 .80 .0

ycylinder 210.536365 .80 .0

cuboid $912 \mathrm{p} 0.7061365 .80 .02 \mathrm{p} 0.7061$

unit 2 com='guide tube $h 20$ flooded'

ycylinder $410.475 \quad 365.80 .0$

ycylinder 210.536365 .80 .0

cuboid $912 \mathrm{p} 0.7061365 .80 .02 \mathrm{p} 0.7061$

unit 3 com='instrumentation h2o flooded'

ycylinder 410.475365 .80 .0

ycylinder 210.536365 .80 .0

cuboid $912 \mathrm{p} 0.7061365 .80 .02 \mathrm{p} 0.7061$

unit 4 com='14x14 assembly'

array $\quad 1-9.8854-182.9-9.8854$

unit 41

com $=$ ' 19 in $\mathrm{x}$-thick strongback plate'

$\begin{array}{llllll}\text { cuboid } 31 & 2 p .2413 & 365.8 & 0.0 & 2 p 9.8854\end{array}$

unit 42

com ${ }^{\prime} .25$ in $\mathrm{x}$-thick $\mathrm{h} 2 \mathrm{o}$ (cork)

$\begin{array}{llllll}\text { cuboid } 5 & 1 & 2 \mathrm{p} .3175 & 365.8 & 0.0 & 2 \mathrm{p} 9.8854\end{array}$

unit 5 com $=0.188$ in $x$-thick neutron poison plate'

cuboid $712 \mathrm{p} 0.23876365 .80 .08 .34-9.8854$

cuboid $312 \mathrm{p} .23876365 .8 \quad 0.0 \quad 2 \mathrm{p} 9.8854$

unit 6

com $=2$ assemblies with poison plates'

array $\quad 2-21.36592-182.9-9.884$

unit 7

com 'strong back plate for assemblies'

cuboid $5110.5204-9.88542 \mathrm{p} 182.92 \mathrm{p} 0.3175$

cuboid $3111.003 \quad-9.88542 \mathrm{p} 182.92 \mathrm{p} 0.3175$

cuboid $7111.48052-9.88542 \mathrm{p} 182.92 \mathrm{p} 0.3175$

cuboid $\quad 5115.29052-9.88542 \mathrm{p} 182.92 \mathrm{p} 0.3175$ cuboid $\quad 7115.76804-9.88542 \mathrm{p} 182.92 \mathrm{p} 0.3175$

cuboid $3116.25064-9.88542 \mathrm{p} 182.92 \mathrm{p} 0.3175$

cuboid $5132.84644-9.88542 \mathrm{p} 182.92 \mathrm{p} 0.3175$

unit 71 cuboid $3111.003-9.88542 \mathrm{p} 182.92 \mathrm{p} 0.2413$

cuboid 7111.48052 -9.8854 2p182.92p0.2413

cuboid $5115.29052-9.88542 \mathrm{p} 182.92 \mathrm{p} 0.2413$

cuboid $7115.76804-9.88542 \mathrm{p} 182.92 \mathrm{p} 0.2413$

cuboid $3132.84644-9.88542 \mathrm{p} 182.92 \mathrm{p} 0.2413$

unit 8

com='assemblies in mo- 1 '

array $\quad 3-21.36592-182.9-10.3617$

cuboid $5172.6141-21.365922 \mathrm{p} 236.229883 .6183-10.3617$

cuboid $\quad 3172.8191-21.570922$ p236.30092 $83.8233-10.5667$

unit 9

array $3-21.36592-182.9-10.3617$

cuboid $5121.36592-72.61412$ 2p236.2298 $83.6183-10.3617$

cuboid $3121.57092-72.81912$ p236.30092 83.8233-10.5667

global unit 10

array $4-94.39-182.9-10.3617$

replicate $526 * 3.010$

end geom

read array

ara $=1$ nux $=14$ nuy $=1$ nuz $=14$

com $=14 \times 14$ assembly'

loop

111411111141

2312311113129

251051115105

23129111693

3771111881

end loop

ara $=2$ nux $=8$ nuy $=1$ nuz $=1$

com $\rightleftharpoons 2$ assemblies with poison plates'

fill 442415541424 end fill

ara $=3$ nux $=1$ nuy $=1$ nuz $=3$

com 'assemblies on strongback'

fill 7176 end fill

ara $=4$ nux $=2$ nuy=1 nuz $=1$

fill 98 end fill

end array

read bias id=5002 11 end bias

read plot

$\mathfrak{t t l}=' x z$ slice at $y=0$ '

$\mathrm{xul}=91.0$ yul $=0.0 \mathrm{zul}=95.0$

$\mathrm{x} \mid \mathrm{r}=91.0 \mathrm{yl}=0.0 \mathrm{zlr}=95.0$

uax $=1.0$ vax $=0.0$ wax $=0.0$

$\mathrm{udn}=0.0 \mathrm{vdn}=0.0 \mathrm{wdn}=1.0$

nax $=120$

end plot

end data

end

$=$ csas 25 parm $=$ size $=140000$

case f1: $4.4 \mathrm{wt} \%$ fuel temp 483.15 accident conf. B crushed-case 5

238group infhommedium

pu-238 $10.09 .6525 \mathrm{e}-7483.15$ end

pu-239 $\quad 10.08 .388 \mathrm{e}-4 \quad 483.15$ end

$\mathrm{pu}-240 \quad 10.01 .953 \mathrm{e}-4 \quad 483.15$ end

pu-241 $10.03 .25 \mathrm{e}-5 \quad 483.15$ end

pu-242 $\quad 10.04 .9 \mathrm{e} 6 \quad 483.15$ end

u-234 10.01 .2641 e-5 483.15 end

u-235 $\quad 10.01 .664 \mathrm{e}-4 \quad 483.15$ end

$\mathrm{u}-238 \quad 10.02 .324 \mathrm{e}-2 \quad 483.15$ end 
- $\quad 10.04 .8965 \mathrm{e}-2483.15$ end

zirc2 21.0483 .15 end

carbonsteel 31.0483 .15 end

h2o $\quad 41.0483 .15$ end

h2o $\quad 51.0483 .15$ end

h $\quad 60.01 .9621 \mathrm{e}-3483.15$ end

c $\quad 60.02 .1847 \mathrm{e}-3483.15$ end

n $\quad 60.04 .167 e-4483.15$ end

o $\quad 60.08 .864 \mathrm{e}-4 \quad 483.15$ end

arbm-boronss304 7.69510150001.32600068.6

2400018.75280009 .38120001 .9771 .0483 .15 end

polyethylene 81.0483 .15 end

end comp

case f1: fuel temp 483.15 accident conf $B$

read parm nub-yes npg $=600$ gen $=400$ tme $=100 \mathrm{nsk}=20$ plt-yes end parm

read geom

unit l com 'fuel unit cell h2o flooded gap'

ycylinder 110.4636365 .80 .0

ycylinder 410.475365 .80 .0

ycylinder 210.536365 .80 .0

cuboid $512 \mathrm{p} 0.7061365 .80 .02 \mathrm{p} 0.7061$

unit 2 com $=$ 'guide tube h2o flooded'

ycylinder 410.475365 .80 .0

ycylinder 210.536365 .80 .0

cuboid $512 \mathrm{p} 0.7061365 .80 .02 \mathrm{p} 0.7061$

unit 3 com='instrumentation h2o flooded'

ycylinder 410.475365 .80 .0

ycylinder 210.536365 .80 .0

cuboid 512p0.7061 365.8 $0.02 \mathrm{p} 0.7061$

unit 4 com ='14x14 assembly'

array $\quad 1-9.8854-182.9-9.8854$

unit 41

com $=^{\prime} .19$ in $x$-thick strongback plate'

$\begin{array}{llllllllllllllll}\text { cuboid } 3 & 1 & 2 \mathrm{p} .2413 & 365.8 & 0.0 & 2 p 9.8854\end{array}$

unit 42

com $=.25$ in $x$-thick h2o(cork)'

cuboid 51 2p.3175 $365.8 \quad 0.0 \quad 2 p 9.8854$

unit 5 com $=$ ' 0.188 in $\mathrm{x}$-thick neutron poison plate'

cuboid $712 \mathrm{p} 0.23876365 .80 .08 .34-9.8854$

cuboid $\quad 312 \mathrm{p} .23876365 .8 \quad 0.02 \mathrm{p} 9.8854$

unit 6

com $=2$ assemblies with poison plates'

array $\quad 2-21.36592-182.9-9.8854$

unit 7

com='strong back plate for assemblies'

cuboid $5110.5204-9.8854$ 2p182.92p0.3175

cuboid $3111.003-9.88542 \mathrm{p} 182.92 \mathrm{p} 0.3175$

cuboid $7111.48052-9.88542 \mathrm{p} 182.92 \mathrm{p} 0.3175$

cuboid $\quad 5115.29052-9.88542 \mathrm{p} 182.92 \mathrm{p} 0.3175$

cuboid $7115.76804-9.88542 \mathrm{p} 182.92 \mathrm{p} 0.3175$

cuboid $3116.25064-9.88542 \mathrm{p} 182.92 \mathrm{p} 0.3175$

cuboid $5132.84644-9.88542 \mathrm{pl} 82.2 \mathrm{p} 0.3175$

unit 71

cuboid $3111.003-9.88542 \mathrm{p} 182.92 \mathrm{p} 0.2413$

cuboid $7111.48052-9.88542 \mathrm{p} 182.92 \mathrm{p} 0.2413$

cuboid $5115.29052-9.88542 \mathrm{p} 182.92 \mathrm{p} 0.2413$

cuboid $7115.76804-9.88542 \mathrm{p} 182.92 \mathrm{p} 0.2413$

cuboid $\quad 3132.84644-9.88542 \mathrm{p} 182.92 \mathrm{p} 0.2413$

unit 8

com='assemblies in mo-1'

array $\quad 3-21.36592-182.9-10.3617$

cuboid $5172.6141-21.365922 \mathrm{p} 236.229883 .6183-10.3617$

cuboid $3172.8191-21.57092$ 2p236.30092 83.8233-10.5667

unit 9

array $3-21.36592-182.9-10.3617$

cuboid $\quad 5121.36592-72.61412 p 236.2298 \quad 83.6183-10.3617$

cuboid $\quad 3121.57092-72.81912$ p236.30092 $83.8233-10.5667$ global unit 10

array $4-94.39-182.9-10.3617$

replicate $526 * 3.010$

end geom

read array

ara $=1$ nux $=14$ nuy $=1$ nuz $=14$

com $=14 \times 14$ assembly'

loop

111411111141

231231113129

251051115105

23129111693

3771111881

end loop

ara $=2$ nux $=8$ nuy $=1$ nuz $=1$

com $=2$ assemblies with poison plates'

fill 442415541424 end fill

$a r a=3$ nux $=1$ nuy $=1$ nuz $=3$

com='assemblies on strongback'

fill 7176 end fill

ara $=4$ nux $=2$ nuy $=1$ nuz $=1$

fill 98 end fill

end array

read bias id $=500211$ end bias

read plot

$\mathrm{t} \mathrm{t}]={ }^{\prime} \mathrm{xz}$ slice at $\mathrm{y}=0^{\prime}$

$\mathrm{xul}=91.0 \mathrm{yul}=0.0 \mathrm{zul}=95.0$

$\mathrm{xl}=91.0 \mathrm{yl}=0.0 \mathrm{zl}=95.0$

uax $=1.0$ vax $=0.0$ wax $=0.0$

$\mathrm{udn}=0.0 \mathrm{vdn}=0.0 \mathrm{wdn}=1.0$

nax $=120$

end plot

end data

end

$=\operatorname{csas} 25$ parm $=$ size $=140000$

case fl: $3.03 \mathrm{wt} \%$ fuel temp 483.15 accident conf. B crushed-case 5

238group infhommedium

pu-238 $10.01 .6884 \mathrm{e}-6483.15$ end

pu-239 $\quad 10.06 .04 \mathrm{e}-4 \quad 483.15$ end

pu-240 $10.09 .98 \mathrm{e}-5 \quad 483.15$ end

pu-241 $10.02 .76 \mathrm{e}-5 \quad 483.15$ end

pu-242 $10.04 .30 \mathrm{e}-6 \quad 483.15$ end

u-234 $\quad 10.01 .2809 \mathrm{e}-5483.15$ end

$u-235 \quad 10.01 .686 \mathrm{e}-4 \quad 483.15$ end

u-238 $\quad 10.02 .355 \mathrm{e}-2 \quad 483.15$ end

o $\quad 10.04 .8926 \mathrm{e}-2483.15$ end

zirc2 21.0483 .15 end

carbonsteel 31.0483 .15 end

h20 $\quad 41.0483 .15$ end

h2o $\quad 51.0483 .15$ end

h $\quad 60.01 .9621 \mathrm{e}-3483.15$ end

c $\quad 60.02 .1847 \mathrm{e}-3483.15$ end

n $\quad 60.04 .167 e 4483.15$ end

o $\quad 60.08 .864 \mathrm{e}-4483.15$ end

arbm-boronss3047.69510150001.32600068.6

2400018.75280009 .38120001 .9771 .0483 .15 end

polyethylene 81.0483 .15 end

end comp

case $f 1$ : fuel temp 483.15 accident conf $B$

read parm nub $=y e s$ npg $=600$ gen $=400$ tme $=100$ nsk $=20$ pltt=yes end parm

read geom

unit 1 com=fuel unit cell h2o flooded gap'

ycylinder 110.4636365 .80 .0

ycylinder 410.475365 .80 .0

ycylinder 210.536365 .80 .0

cuboid $512 \mathrm{p} 0.7061365 .80 .02 \mathrm{p} 0.7061$

unit 2 com $=$ 'guide tube $h 20$ flooded' 
ycylinder $410.475 \quad 365.80 .0$

ycylinder 210.536365 .80 .0

cuboid $512 \mathrm{p} 0.7061365 .80 .02 \mathrm{p} 0.7061$

unit 3 com='instrumentation h2o flooded'

ycylinder $410.475 \quad 365.80 .0$

ycylinder 210.536365 .80 .0

cuboid $512 \mathrm{p} 0.7061365 .80 .02 \mathrm{p} 0.7061$

unit 4 com $=14 \times 14$ assembly'

array $\quad 1-9.8854-182.9-9.8854$

unit 41

com $=^{\prime} .19$ in $\mathrm{x}$-thick strongback plate'

$\begin{array}{llllll}\text { cuboid } 3 & \text { I } & 2 \mathrm{p} .2413 & 365.8 & 0.0 & 2 \mathrm{p} 9.8854\end{array}$

unit 42

com $=^{\prime} .25$ in $x$-thick h2o(cork)

cuboid 51 2p.3175 $365.8 \quad 0.02$ p9.8854

unit 5 com $=0.188$ in $\mathrm{x}$-thick neutron poison plate'

cuboid $712 \mathrm{p} 0.23876365 .80 .08 .34-9.8854$

cuboid $\quad 312 \mathrm{p} .23876365 .8 \quad 0.02 \mathrm{p} 9.8854$

unit 6

com $=2$ assemblies with poison plates'

array $\quad 2-21.36592-182.9-9.8854$

unit 7

com='strong back plate for assemblies'

cuboid $5110.5204-9.88542 \mathrm{p} 182.92 \mathrm{p} 0.3175$

cuboid $3111.003 \quad-9.88542 \mathrm{pl} 182.92 \mathrm{p} 0.3175$

cuboid $7111.48052-9.88542 \mathrm{p} 182.92 \mathrm{p} 0.3175$

cuboid $5115.29052-9.88542 \mathrm{p} 182.92 \mathrm{p} 0.3175$

cuboid $7115.76804-9.88542 \mathrm{p} 182.92 \mathrm{p} 0.3175$

cuboid $3116.25064-9.88542 \mathrm{p} 182.92 \mathrm{p} 0.3175$

cuboid $5132.84644-9.88542 \mathrm{p} 182.92 \mathrm{p} 0.3175$

unit 71

cuboid $3111.003-9.88542 \mathrm{p} 182.92 \mathrm{p} 0.2413$

cuboid $7111.48052-9.88542 \mathrm{p} 182.92 \mathrm{p} 0.2413$

cuboid $5115.29052-9.88542 \mathrm{p} 182.92 \mathrm{p} 0.2413$

cuboid $7115.76804-9.88542 \mathrm{p} 182.92 \mathrm{p} 0.2413$

cuboid $3132.84644-9.88542 \mathrm{p} 182.92 \mathrm{p} 0.2413$

unit 8

com='assemblies in mo-l'

array $\quad 3-21.36592-182.9-10.3617$

cuboid $5172.6141-21.365922 \mathrm{p} 236.2298836183-10.3617$

cuboid $3172.8191-21.57092$ 2p236.30092 83.8233-10.5667

unit 9

array $3-21.36592-182.9-10.3617$

cuboid $5121.36592-72.61412$ p236.2298 $83.6183-10.3617$

cuboid $3121.57092-72.81912$ p236.30092 83.8233-10.5667

global unit 10

array $4-94.39-182.9-10.3617$

replicate $526 * 3.010$

end geom

read array

ara $=1$ nux $=14$ nuy=1 nuz $=14$

com $=14 \times 14$ assembly'

loop

111411111141

231231113129

251051115105

23129111693

3771111881

end loop

ara $=2$ nux $=8$ nuy $=1$ nuz $=1$

com $=2$ assemblies with poison plates'

fill 442415541424 end fill

ara $=3$ nux $=1$ nuy $=1$ nuz $=3$

com 'assemblies on strongback'

fill 7176 end fill

ara $=4$ nux $=2$ nuy $=1$ nuz $=1$

fill 98 end fill

end array read bias id $=500211$ end bias

read plot

$\mathrm{ttl}=\mathbf{x}^{\mathrm{x} z}$ slice at $\mathrm{y}=0^{\prime}$

$\mathrm{xul}=91.0 \mathrm{yul}=0.0 \mathrm{zul}=95.0$

$x l r=91.0$ y $l r=0.0$ zl $=95.0$

uax $=1.0$ vax $=0.0$ wax $=0.0$

$\mathrm{udn}=0.0 \mathrm{vdn}=0.0 \mathrm{wdn}=1.0$

nax $=120$

end plot

end data

end 


\section{A.1.2 Weapons-Grade MOX Fuel}

\section{A.1.2.1 Single-Package Model}

Case: wc-1

$=\operatorname{csas} 25$ parm $=s i z e=140000$

case wspf-9: 17x17 assembly; fire- laam centered-crushed; h20 refl, $\bmod =1.0$

'run at fire temp-483.15'

238group latticecell

$\mathrm{pu}-239 \quad 10.01 .162 \mathrm{e}-3 \quad 483.15$ end

pu-240 $10.07 .297 \mathrm{e}-5483.15$ end

pu-241 $10.04 .964 \mathrm{e}-6483.15$ end

pu-242 $10.01 .241 \mathrm{e}-6483.15$ end

u-234 $10.04 .326 \mathrm{e}-6483.15$ end

$\mathrm{u}-235 \quad 10.04 .391 \mathrm{e}-5483.15$ end

u-236 $\quad 10.02 .163 e-6483.15$ end

u-238 $10.02 .159 \mathrm{e}-2483.15$ end

$0 \quad 10.04 .575 \mathrm{e}-2483.15$ end

zirc2 21.0483 .15 end

carbonsteel 31.0483 .15 end

h2o $\quad 41.0483 .15$ end

h2o $\quad 51.0483 .15$ end

h $\quad 60.01 .9621 \mathrm{e}-3483.15$ end

c $\quad 60.02 .1847 \mathrm{e}-3483.15$ end

n $\quad 60.04 .167 e-4483.15$ end

o $\quad 60.08 .864 \mathrm{e}-4483.15$ end

arbm-boronss 3047.74510150000 .9752600068 .82

2400018.81280009 .41120001 .9871 .0483 .15 end

polyethylene 81.0483 .15 end

h2o 91.0483 .15 end

h2o $\quad 101.0483 .15$ end

end comp

squarepitch 1.260 .7844140 .91442 end

case wspf-9: $17 \times 17$ assembly; fire- laam centered-crushed; th20 refl, $\bmod =1.0$

read parm nub $=$ yes npg $=600$ gen $=400$ tme $=100$ nsk $=20$ pltzyes end parm

read geom

unit 1 com='fuel unit cell'

ycylinder 110.3922365 .80 .0

ycylinder 210.4572365 .80 .0

cuboid $412 \mathrm{p} 0.63365 .80 .02 \mathrm{p} 0.63$

unit 2 com='guide tube'

ycylinder 510.3922365 .80 .0

ycylinder 210.4572365 .80 .0

cuboid $412 \mathrm{p} 0.63365 .80 .02 \mathrm{p} 0.63$

unit 3 com='instrumentation tube'

ycylinder 510.3922365 .80 .0

ycylinder 210.4572365 .80 .0

cuboid $412 \mathrm{p} 0.63365 .80 .02 \mathrm{p} 0.63$

unit 4 com $=17 \times 17$ assembly'

array $\quad 1-10.71-182.9-10.71$

unit $40 \mathrm{com}=$ 'water box to replace assembly'

cuboid 912 2p10.71 2p182.90 2pl0.71

unit 41

com $=.19$ in $x$-thick strongback plate'

cuboid 312 2p.2413 $365.8 \quad 0.02$ pl0.71

unit 42

com $=.25$ in $\mathrm{x}$-thick h 2 (cork)

$\begin{array}{llllll}\text { cuboid } 9 & 1 & 2 \mathrm{p} .3175 & 365.8 & 0.0 & 2 \mathrm{p} 10.71\end{array}$

unit 5 com $=0.188$ in $x$-thick neutron poison plate'

cuboid $712 \mathrm{p} 0.239365 .80 .08 .34-10.71$

cuboid $312 \mathrm{p} .239365 .8 \quad 0.02 \mathrm{p} 10.71$

unit 51

com $=15$ in. $x$-space between assemblies' cuboid $912 \mathrm{p} 1.905365 .80 .02 \mathrm{p} 10.71$

unit 6 com $=2$ assemblies with poison plates, $x$-strong back plates and spacing array $2-24.9206-182.9-10.71$

unit 7

com='strong back plate for assemblies'

cuboid $9111.345-10.712 \mathrm{p} 182.92 \mathrm{p} 0.3175$

cuboid $3111.8276-10.712 \mathrm{p} 182.92 \mathrm{p} 0.3175$

cuboid $7112.3056-10.712 \mathrm{p} 182.92 \mathrm{p} 0.3175$

cuboid $9116.1156-10.712 \mathrm{p} 182.92 \mathrm{p} 0.3175$

cuboid $7116.5936-10.712 \mathrm{p} 182.92 \mathrm{p} 0.3175$

cuboid $\quad 3117.0762-10.712 \mathrm{p} 182.92 \mathrm{p} 0.3175$

cuboid $\quad 9139.1312-10.712 \mathrm{p} 182.92 \mathrm{p} 0.3175$

unit 71

cuboid $\quad 3111.8276-10.712 \mathrm{p} 182.92 \mathrm{p} 0.2413$

cuboid $\quad 7112.3056-10.712 \mathrm{p} 182.92 \mathrm{p} 0.2413$

cuboid $\quad 9116.1156-10.712 \mathrm{p} 182.92 \mathrm{p} 0.2413$

cuboid $7116.5936-10.712 \mathrm{p} 182.92 \mathrm{p} 0.2413$

cuboid $\quad 3139.1312-10.712 \mathrm{p} 182.92 \mathrm{p} 0.2413$

global unit 8

com='assemblies in mo-1'

array $\quad 3-24.9206-182.9-11.186$

cuboid $\quad 912 \mathrm{p} 46.992 \mathrm{p} 236.229840 .64-53.34$

cuboid $\quad 312 \mathrm{p} 47.061122 \mathrm{p} 236.3009240 .71112-53.41112$

replicate $1026^{*} 3.010$

end geom

read array

ara $=1$ nux $=17$ nuy $=1$ nuz $=17$

com $=14 \times 14$ assembly'

loop

111711111171

2612311131512

24141011141410

231531116123

3991111991

end loop

ara $=2$ nux $=9$ nuy $=1$ nuz $=1$

com $=2$ assemblies with poison plates'

fill $40 \quad 42415 \quad 51541424$ end fill

ara $=3$ nux $=1$ nuy $=1$ nuz $=3$

com=assemblies on strongback

fill 7176 end fill

end array

read bias id $=500211$ end bias

end data

end 


\section{A.1.2.2 Package-Array Model}

Case: war-0

$=\operatorname{csas} 25$ parm $=$ size $=140000$

case wspf-9: $17 \times 17$ assembly; accident 1 assm on bottom- pushed together

238group latticecell

pu-239 $10.01 .162 \mathrm{e}-3483.15$ end

pu-240 $10.07 .297 \mathrm{e}-5483.15$ end

pu-241 $10.04 .964 e-6483.15$ end

pu-242 $10.01 .241 \mathrm{e}-6483.15$ end

u-234 $10.04 .326 \mathrm{e}-6483.15$ end

u-235 $10.04 .391 \mathrm{e}-5483.15$ end

u-236 $10.02 .163 \mathrm{e}-6483.15$ end

u-238 $\quad 10.02 .159 \mathrm{e}-2483.15$ end

o $\quad 10.04 .575 \mathrm{e}-2483.15$ end

zirc2 21.0483 .15 end

carbonsteel 31.0483 .15 end

h2o $\quad 41.0483 .15$ end

h2o 51.0483 .15 end

h $\quad 60.01 .9621 \mathrm{e}-3483.15$ end

c $\quad 60.02 .1847 \mathrm{e}-3483.15$ end

n $\quad 60.04 .167 e-4483.15$ end

o $\quad 60.08 .864 \mathrm{e}-4483.15$ end

arbm-boronss3047.7451015000 0.9752600068 .82

2400018.81280009 .41120001 .9871 .0483 .15 end

polyethylene 81.0483 .15 end

h20 $\quad 91.0483 .15$ end

h2o $\quad 101.0483 .15$ end

end comp

squarepitch 1.260 .7844140 .91442 end

case wspf-9: $17 \times 17$ assembly; accident 1 assm on bottom- pushed together

read parm nub=yes npg $=600$ gen $=400$ tme $=100$ nsk $=20$ plt=yes end parm

read geom

unit 1 com '='fuel unit cell'

ycylinder 110.3922365 .80 .0

ycylinder 210.4572365 .80 .0

cuboid $412 \mathrm{p} 0.63365 .80 .02 \mathrm{p} 0.63$

unit 2 com $=$ 'guide tube'

ycylinder 510.3922365 .80 .0

ycylinder 210.4572365 .80 .0

cuboid $412 \mathrm{p} 0.63365 .80 .02 \mathrm{p} 0.63$

unit 3 com='instrumentation tube'

ycylinder 510.3922365 .80 .0

ycylinder 210.4572365 .80 .0

cuboid $412 \mathrm{p} 0.63365 .80 .02 \mathrm{p} 0.63$

unit 4 com $=17 \times 17$ assembly'

array $\quad 1-10.71-182.9-10.71$

unit 40 com='water box to replace assembly'

cuboid 912 2p10.71 2p182.90 2p10.71

unit 41

com $=1.19$ in $\mathrm{x}$-thick strongback plate'

$\begin{array}{lllllll}\text { cuboid } 3 & 1 & 2 \mathrm{p} .2413 & 365.8 & 0.0 & 2 \mathrm{p} 10.71\end{array}$

unit 42

com $=^{\prime} .25$ in $x$-thick $h 20$ (cork)

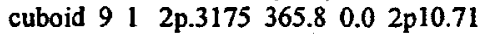

unit 5 com $=0.188$ in $\mathrm{x}$-thick neutron poison plate'

cuboid $712 \mathrm{p} 0.239365 .80 .08 .34-10.71$

cuboid $312 \mathrm{p} .239365 .8 \quad 0.02 \mathrm{p} 10.71$

unit 51

com='1.5 in. $x$-space between assemblies'cuboid $912 \mathrm{p} 1.905365 .8$ $0.02 \mathrm{p} 10.71$

unit 6

com $=1$ assembly with poison plates, $x$-strong back plates and spacing' array $2-24.9206-182.9-10.71$

unit 61 com=' 1 assembly with poison plates, $x$-strong back plates and spacing' array $5-24.9206-182.9-10.71$

unit 7

com='strong back plate for assemblies'

cuboid $9111.345-10.712 \mathrm{p} 182.92 \mathrm{p} 0.3175$

cuboid $3111.8276-10.712 \mathrm{p} 182.92 \mathrm{p} 0.3175$

cuboid $7112.3056-10.712 \mathrm{p} 182.92 \mathrm{p} 0.3175$

cuboid $\quad 9116.1156-10.712 \mathrm{p} 182.92 \mathrm{p} 0.3175$

cuboid $7116.5936-10.712 \mathrm{p} 182.92 \mathrm{p} 0.3175$

cuboid $3117.0762-10.712 \mathrm{p} 182.92 \mathrm{p} 0.3175$

cuboid $\quad 9139.1312-10.712 \mathrm{p} 182.92 \mathrm{p} 0.3175$

unit 71

cuboid $3111.8276-10.712 \mathrm{p} 182.92 \mathrm{p} 0.2413$

cuboid $7112.3056-10.712 \mathrm{p} 182.92 \mathrm{p} 0.2413$

cuboid $\quad 9116.1156-10.712 \mathrm{p} 182.92 \mathrm{p} 0.2413$

cuboid $7116.5936-10.712 p 182.92 \mathrm{p} 0.2413$

cuboid $\quad 3139.1312-10.712 \mathrm{p} 182.92 \mathrm{p} 0.2413$

unit 8

com='assemblies in mo- $1^{\prime}$

array $\quad 3-24.9206-182.9-11.186$

cuboid $\quad 9124.9206-69.05942 \mathrm{p} 236.229882 .7944-11.186$

cuboid $3124.99172-69.13052$ 2p236.435 82.86552-11.391

unit 9

com='assemblies in mo-1'

array $\quad 31-24.9206-182.9-11.186$

cuboid $9169.0594-24.9206$ 2p236.2298 82.7944-11.186

cuboid $\quad 3169.13052-24.99172$ 2p236.435 82.86552-11.391 global unit 10

array $4-49.8412-182.9-11.186$

replicate $1026 * 3.010$

end geom

read bias id $=500211$ end bias

read array

ara $=1$ nux $=17$ nuy=1 nuz $=17$

com $=14 x 14$ assembly'

loop

111711111171

2612311131512

24141011141410

231531116123

3991111991

end loop

ara $=2$ nux $=9$ nuy $=1$ nuz $=1$

com ' 2 assemblies with poison plates'

fill $40 \quad 42415 \quad 51541424$ end fill

ara $=3$ nux $=1$ nuy $=1$ nuz $=3$

com='assemblies on strongback'

fill 7176 end fill

ara $=31$ nux $=1$ nuy $=1$ nuz $=3$

com ''assemblies on strongback'

fill 71761 end fill

ara $=4$ nux $=2$ nuy $=1$ nuz $=1$

fill 89 end fill

ara $=5$ nux $=9$ nuy $=1$ nuz $=1$

com $=2$ a assemblies with poison plates'

fill $4 \quad 4241551 \quad 5414240$ end fill

end array

rad bias id $=500211$ end bias

end data

end 


\section{A.2 FUEL-PIN CALCULATIONS}

\section{A.2.1 Previously Certified MOX Fuel}

\section{A.2.1.1 Single-Package Model}

Case: $16 \mathrm{c}-2$

$=\operatorname{csas} 25$ parm $=s i z e=140000$

case: $16 \mathrm{c}-2$; config $\mathrm{c} d t=0.028$ in 2 unspaced boxes 1.20 pitch, foam $=100 \%$

238group latticecell

pu-238 $\quad 10.02 .2509 \mathrm{e}-5483.15$ end

pu-239 $10.08 .416 \mathrm{e}-4 \quad 483.15$ end

pu-240 $10.03 .277 \mathrm{e}-4 \quad 483.15$ end

pu-241 $10.01 .967 \mathrm{e}-4 \quad 483.15$ end

pu-242 $10.07 .310 \mathrm{e}-5 \quad 483.15$ end

u-234 $\quad 10.01 .2441 \mathrm{e}-6483.15$ end

$\mathrm{u}-235 \quad 10.01 .638 \mathrm{e}-4 \quad 483.15$ end

$\mathrm{u}-238 \quad 10.02 .287 \mathrm{e}-2 \quad 483.15$ end

o $\quad 10.02 .5962 \mathrm{e}-2483.15$ end

zirc2 21.0483 .15 end

carbonsteel 31.0483 .15 end

h2o 41.0483 .15 end

h2o 51.0483 .15 end

arbmmfoam 0.8004400010014 .1601254 .4

$701412.1801629 .461 .0 \quad 483.15$ end

arbm-boronss304 7.74 51015000.9752600068 .82

$2400018.81280009 .41 \quad 120001.9871 .0483 .15$ end

polyethylene 81.0483 .15 end

h2o $9 \quad 1.0483 .15$ end

h2o $10 \quad 1.0 \quad 483.15$ end

end comp

triangpitch 1.200 .9272151 .0722 .954 end

case: $16 \mathrm{c}-2$; config $\mathrm{c} d t=0.028$ in 2 unspaced boxes 1.20 pitch, foam $=100 \%$

read parm nub $=$ yes npg $=600$ gen $=400$ tme $=100 \mathrm{nsk}=20$ plt $=$ yes end parm

read geom

unit 1 com $=$-x hemicyl fuel unit cell'

yhemicyl-z 110.4636365 .80 .0

yhemicyl-z $410.475365 .8 \quad 0.0$

yhemicyl-z 210.536365 .80 .0

unit 2 com $=-x$ hemicyl fuel unit cell'

yhemicyltz 110.4636365 .80 .0

yhemicyl $+z \quad 4 \quad 0.475 \quad 365.8 \quad 0.0$

yhemicyl+z 210.536365 .80 .0

unit 3 com $=-x$ hemicyl fuel unit cell'

yhemicyl+x 110.4636365 .80 .0

yhemicylt $x \quad 410.475 \quad 365.8 \quad 0.0$

yhemicyltx 210.536365 .80 .0

unit 4 com $^{\prime \prime}-x$ hemicyl fuel unit cell

yhemicyl-x 110.4636365 .80 .0

yhemicyl-x $410.475 \quad 365.8 \quad 0.0$

yhemicyl-x 210.536365 .80 .0

unit 5

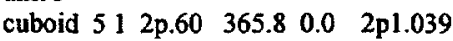

hole $1 \quad 0.0 \quad 0.01 .039$

hole $20.0 \quad 0.0-1.039$

hole $3-.600 .0 \quad 0.0$

bole $4 \quad .60 \quad 0.0 \quad 0.0$

unit 6

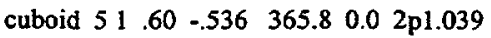

hole 10.00 .01 .039

hole $2 \quad 0.0 \quad 0.0 \quad-1.039$

hole 4.600 .00 .0

unit 7

cuboid $51 \quad 6430.0 \quad 365.8 \quad 0.0 \quad 2 p 1.039$

hole $3 \quad 0.00 .0 \quad 0.0$

unit 8

cuboid $51.60 \quad-.536 \quad 365.8 \quad 0.0 \quad 0.0 \quad-536$

hole 10.00 .00 .0

unit 9

cuboid $512 \mathrm{p} .60365 .8 \quad 0.0 \quad 0.0 \quad-.536$

hole 10.00 .00 .0

unit 10

cuboid $51.643 \quad 0.0 \quad 365.8 \quad 0.0 \quad 0.0 \quad-.536$

unit 11

cuboid $51.60-.536 \quad 365.8 \quad 0.0 \quad .702-1.039$

hole $20.00 .0-1.039$

hole $4.600 .0 \quad 0.0$

unit 12

$\begin{array}{llllll}\text { cuboid } 512 \mathrm{p} .60 & 365.8 & 0.0 & .702 & -1.039\end{array}$

hole $2 \quad 0.0 \quad 0.0 \quad-1.039$

hole $3 \quad \cdot .600 .00 .0$

hole $4 \quad .60 \quad 0.0 \quad 0.0$

unit 13

cuboid $51.643 \quad 0.0 \quad 365.8 \quad 0.0 \quad 702 \quad-1.039$

hole $3 \quad 0.00 .00 .0$

unit 20

com 'right box with pins'

array $1-10.4895-182.9-10.4895$

cuboid $9110.9305-10.48952$ p182.9 $10.9305-10.4895$ unit 21

com='revised unit 6 for left box'

$\begin{array}{llllll}\text { cuboid } 51 & 1.60 & -.643 & 365.8 & 0.0 & 2 \mathrm{p} 1.039\end{array}$

hole 10.00 .01 .039

hole $20.00 .0-1.039$

hole 4.600 .00 .0

unit 22

com='revised unit 8 for left box'

cuboid $51.60-.643 \quad 365.8 \quad 0.0 \quad 0.0 \quad-.536$

hole 10.00 .00 .0

unit 23

com='revised unit 11 for left box

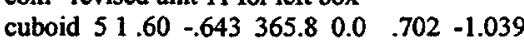

hole $2 \quad 0.0 \quad 0.0-1.039$

hole $4 \quad .60 \quad 0.0 \quad 0.0$

unit 24

com='revised unit 7 for left box'

cuboid $51.5360 .0 \quad 365.8 \quad 0.02 \mathrm{p} 1.039$

hole 30.00 .00 .0

unit 25

com='revised unit 10 for left box'

$\begin{array}{lllllll}\text { cuboid } 5 & 1.536 & 0.0 & 365.8 & 0.0 & 0.0 & -.536\end{array}$

unit 26

com='revised unit 13 for left box'

$\begin{array}{lllllll}\text { cuboid } 5 & 1.536 & 0.0 & 365.8 & 0.0 & 702 & -1.039\end{array}$

hole 30.00 .00 .0

unit 27

com='left box with pins'

array $2-10.4895-182.9-10.4895$

cuboid $9110.4895-10.93052 p 182.910 .9305-10.4895$

unit $104 \mathrm{com}=$ 'right box with pins for placement' 
array $\quad 110-10.71-182.9-10.71$

unit $140 \mathrm{com}=$ 'left box with pins for placement'

array $111-10.71-182.9-10.71$

unit 141

com $=.19$ in $x$-thick strongback plate

cuboid 31 2p.2413 $365.8 \quad 0.0 \quad 2 p 10.71$

unit 142

com $=.25$ in $x$-thick h2o(cork)

cuboid 912 2p.3175 $365.8 \quad 0.02$ 2p10.71

unit 105 com $=0.188$ in $x$-thick neutron poison plate'

cuboid $712 \mathrm{p} 0.239365 .80 .08 .34-10.71$

cuboid $\quad 312 \mathrm{p} .239365 .8 \quad 0.02 \mathrm{2pl0.71}$

unit 151

com='1.5 in. water block'

cuboid 912 p.9525 $365.80 .0 \quad 2 p 10.71$

unit 106

com $=2$ assemblies with poison pltes, $x$-strong back plates and spacing'

array $102-24.9206-182.9-10.7$

unit 107

com='strong back plate for assemblies'

cuboid $9113.25-10.712 \mathrm{p} 182.92 \mathrm{p} 0.3175$

cuboid $\quad 3113.7326-10.712 \mathrm{p} 182.92 \mathrm{p} 0.3175$

cuboid $7114.2106-10.712 \mathrm{p} 182.92 \mathrm{p} 0.3175$

cuboid $7114.6886-10.712 \mathrm{p} 182.92 \mathrm{p} 0.3175$

cuboid $3115.1712-10.712 \mathrm{pl} 182.92 \mathrm{p} 0.3175$

cuboid $9139.1312-10.712 \mathrm{p} 182.92 \mathrm{p} 0.3175$

unit 17

cuboid $3113.7326-10.712 \mathrm{pl} 182.92 \mathrm{p} 0.2413$

cuboid $7114.2106-10.712 p 182.92 p 0.2413$

cuboid $7114.6886-10.712 \mathrm{p} 182.92 \mathrm{p} 0.2413$

cuboid $\quad 3139.1312-10.712$ p182.92p0.2413

global unit 108

com $=$ assemblies in mo- 1

array $\quad 103-24.9206-182.9-11.186$

cuboid $912 \mathrm{p} 46.992 \mathrm{p} 236.229840 .64-53.34$

cuboid $\quad 312 \mathrm{p} 47.061122 \mathrm{p} 236.3009240 .71112-53.41112$

replicate $1026 * 3.010$

end geom

read array

ara $=1$ nux=18 nuy $=1$ nuz $=11$

fill

$816 \mathrm{r} 910$

$616 \mathrm{r} 57$

$616 \mathrm{r} 57$

$616 r 57$

$616 \mathrm{r} 57$

$616 \mathrm{r} 57$

$6 \quad 16 r 57$

$616 r 57$

$616 \mathrm{r} 57$

$6 \cdot 16 \mathrm{r} 57$

$1116 \mathrm{r} 1213$

end fill

ara $=2$ nux $=18$ nuy $=1$ nuz $=11$

fill

$2216 r 925$

$2116 r 524$

$2116 r 524$

$2116 \mathrm{r} 524$

$2116 \mathrm{r} 524$

$2116 \mathrm{r} 524$

$2116 \times 524$

2116 r5 24

$2116 r 524$

$2116 \mathrm{r} 524$

$2316 \mathrm{r} 1226$

end fill

ara $=110$ nux=1 nuy $=1$ nuz=1 fill

20

end fill

ara $=111$ nux=1 nuy=1 nuz=1

fill

27

end fill

ara $=102$ nux $=10$ nuy $=1$ nuz $=1$

$\operatorname{com}=2$ boxes with poison plates'

fill

$151140142141105 \quad 105141142104151$

end fill

ara=103 nux=1 nuy=1 nuz=3

com='boxes on strongback'

fill

171107106

end fill

end array

end data

end 


\section{A.2.1.2 Package-Array Model}

Case: 16 ar -00

$=\operatorname{csas} 25$ parm $=$ size $=140000$

case: $16 \mathrm{ar}-00 ; 2 \times 1 \times 1 \mathrm{dt}=0.028$ in 2 unspaced boxes 1.20 pitch, foam $=100 \%$

238group latticecell

pu-238 $\quad 10.02 .2509 \mathrm{e}-5483.15$ end

pu-239 $10.08 .416 \mathrm{e}-4483.15$ end

pu-240 $\quad 10.03 .277 \mathrm{e}-4 \quad 483.15$ end

pu-241 $10.01 .967 e-4 \quad 483.15$ end

pu-242 $10.07 .310 \mathrm{e}-5 \quad 483.15$ end

u-234 $10.01 .2441 \mathrm{e}-6483.15$ end

u-235 $10.01 .638 \mathrm{e}-4 \quad 483.15$ end

u-238 10.02 .287 e-2 483.15 end

o $\quad 10.02 .5962 \mathrm{e}-2483.15$ end

zirc2 21.0483 .15 end

carbonsteel 31.0483 .15 end

h2o 41.0483 .15 end

h2o $\quad 51.0483 .15$ end

arbmmfoam 0.8004400010014 .1601254 .4

701412.1801629 .461 .0483 .15 end

arbm-boronss304 7.74 51015000.9752600068 .82

2400018.81280009 .41120001 .9871 .0483 .15 end

polyethyiene 81.0483 .15 end

h2o $91.0 \quad 483.15$ end

h2o $10 \quad 1.0 \quad 483.15$ end

end comp

triangpitch 1.200 .9272151 .0722 .954 end

case: $16 \mathrm{ar}-00 ; 2 \times 1 \times 1 \mathrm{dt}=0.028$ in 2 unspaced boxes 1.20 pitch, foam $=100 \%$

read parm nub $=$ yes npg $=600$ gen $=400$ tme $=100$ nsk $=20$ plt $=$ yes end parm

read geom

unit 1 com $=-x$ hemicyl fuel unit cell'

yhemicyl-z 110.4636365 .80 .0

yhemicyl-z $410.475 \quad 365.8 \quad 0.0$

yhemicyl-z 210.536365 .80 .0

unit 2 com $=-x$ hemicyl fuel unit cell'

yhemicyltz 110.4636365 .80 .0

yhemicyltz $410.475 \quad 365.8 \quad 0.0$

yhemicyltz 210.536365 .80 .0

unit 3 com $=-x$ hemicyl fuel unit cell'

yhemicyltx 110.4636365 .80 .0

yhemicyl+x $410.475365 .8 \quad 0.0$

yhemicyl+x 210.536365 .80 .0

unit 4 com $=$ '- $x$ hemicyl fuel unit cell'

yhemicyl-x 110.4636365 .80 .0

yhemicyl-x $410.475365 .8 \quad 0.0$

yhemicyl-x 210.536365 .80 .0

unit 5

cuboid 512 2p1.039 365.80 .02 p.60

hole $1 \quad 0.0 \quad 0.0 \quad 0.6$

hole $2 \quad 0.0 \quad 0.0-0.6$

hole $3-1.0390 .0 \quad 0.0$

hole $4 \quad 1.039 \quad 0.0 \quad 0.0$

unit 6

cuboid $512 \mathrm{pl} .039365 .80 .0 .60-.536$

hole 10.00 .00 .6

hole $3-1.0390 .00 .0$

hole $4 \quad 1.0390 .00 .0$

unit $?$

cuboid $512 \mathrm{pl} .039365 .80 .0 .6430 .0$

hole 20.00 .00 .0

unit 8

cuboid $51.5360 .0365 .80 .0 \quad 60-.536$ hole $3 \quad 0.00 .00$.0unit 9

cuboid 51.5360 .0365 .80 .02 p. 60

hole 30.00 .00 .0

unit 10

cuboid $51.5360 .0365 .80 .0 .643 \quad 0.0$

unit 11

cuboid $511.039-.702365 .80 .0 .60-.536$

hole $1 \quad 0.0 \quad 0.00 .6$

hole $4 \quad 1.0390 .0 \quad 0.0$

unit 12

cuboid $511.039-.702365 .80 .02 p .60$

hole $2 \quad 0.0 \quad 0.0 \quad-60$

hole 10.00 .0 .60

hole 41.0390 .00 .0

unit 13

cuboid $511.039-.702365 .80 .0 .643 \quad 0.0$

hole 20.00 .00 .0

unit 20

com $=$ 'right box with pins'

array $1-10.4895-182.9-10.4895$

cuboid $9110.4895-10.9305$ 2p182.9 $10.9305-10.4895$

unit 21

com='revised unit 6 for left box'

cuboid $512 \mathrm{p} 1.039365 .80 .0 .60-.643$

hole 10.00 .00 .6

hole $3-1.0390 .00 .0$

hole $4 \quad 1.0390 .00 .0$

unit 22

com='revised unit 8 for left box'

cuboid $51.5360 .0365 .80 .0 .60-.643$

hole $3 \quad 0.00 .00 .0$

unit 23

com='revised unit 11 for left box'

cuboid $511.039-.702365 .80 .0 .60-.643$

hole $1 \quad 0.0 \quad 0.00 .6$

hole 41.0390 .00 .0

unit 24

com 'revised unit 7 for left box'

cuboid $512 \mathrm{pl} 1.039365 .80 .0 .5360 .0$

hole 20.00 .00 .0

unit 25

com='revised unit 10 for left box'

$\begin{array}{lllllll}\text { cuboid } 51.536 & 0.0 & 365.8 & 0.0 & 0.0 & -.536\end{array}$

unit 26

com='revised unit 13 for left box'

cuboid $511.039-.702365 .80 .0 .5360 .0$

hole $2 \quad 0.00 .00 .0$

unit 27

com='left box with pins'

array $2-10.4895-182.9-10.4895$

cuboid $9110.4895-10.9305$ 2p182.9 10.4895-10.9305

unit 104 com='right box with pins for placement'

array $\quad 110-10.71-182.9-10.71$

unit $140 \mathrm{com}=$ 'left box with pins for placement'

array $111-10.71-182.9-10.71$

unit 141

com $=.19$ in z-thick strongback plate'

cuboid 312 pl0.71 365.8 0.02p.2413

unit 142

com $=^{\circ} .25$ in z-thick h2o(cork)'

cuboid 912 2p10.71 365.80 .02 p.3175

unit $105 \mathrm{com}={ }^{\prime} 0.188$ in z-thick neutron poison plate'

cuboid $7110.71-8.34365 .80 .02$ p0.239 
cuboid $\quad 312 \mathrm{pl} 10.71365 .80 .02 \mathrm{2p} .239$

unit 151

com='water block outside of box'

cuboid $912 \mathrm{p} 10.71365 .80 .02 \mathrm{p} 1.905$

unit 106

com $=2$ assemblies with poison plates, $\mathrm{x}$-strong back plates and spacing' array $\quad 102-10.71-182.9-24.9206$

unit 107

com='srong back plate for assemblies'

cuboid $912 \mathrm{p} 0.31752 \mathrm{p} 182.911 .345-10.71$

cuboid $312 \mathrm{p} 0.31752 \mathrm{p} 182.911 .8276-10.71$

cuboid $712 \mathrm{p} 0.31752 \mathrm{p} 182.912 .3056-10.71$

cuboid $712 \mathrm{p} 0.31752 \mathrm{p} 182.912 .7836-10.71$

cuboid $312 \mathrm{p} 0.31752 \mathrm{p} 182.913 .2662-10.71$

cuboid $912 \mathrm{p} 0.31752 \mathrm{p} 182.939 .1312-10.71$

unit 1070

com='strong back plate for assemblies in left mo-l'

cuboid $912 \mathrm{p} 0.31752 \mathrm{p} 182.915 .155-10.71$

cuboid $312 \mathrm{p} 0.31752 \mathrm{p} 182.915 .6376-10.71$

cuboid $712 \mathrm{p} 0.31752 \mathrm{p} 182.916 .1156-10.71$

cuboid $712 \mathrm{p} 0.31752 \mathrm{p} 182.916 .5936-10.71$

cuboid $312 \mathrm{p} 0.31752 \mathrm{p} 182.917 .0762-10.71$

cuboid $912 \mathrm{p} 0.31752 \mathrm{p} 182.939 .1312-10.71$

unit 171

cuboid $312 \mathrm{p} 0.24132 \mathrm{p} 182.911 .8276-10.71$

cuboid $712 \mathrm{p} 0.24132 \mathrm{p} 182.912 .3056-10.71$

cuboid $712 \mathrm{p} 0.24132 \mathrm{p} 182.912 .7836-10.71$

cuboid $312 \mathrm{p} 0.24132 \mathrm{p} 182.939 .1312-10.71$

unit 1710

cuboid $\quad 312 \mathrm{p} 0.24132 \mathrm{p} 182.915 .6376-10.71$

cuboid $712 \mathrm{p} 0.24132 \mathrm{p} 182.916 .1156-10.71$

cuboid $712 \mathrm{p} 0.24132 \mathrm{p} 182.916 .5936-10.71$

cuboid $312 \mathrm{p} 0.24132 \mathrm{p} 182.939 .1312-10.71$

unit 108

com='mo-1 with fuel shifted to lower left comer'

array $103-11.186-182.9-24.9206$

cuboid $\quad 9182.7941-11.1862 \mathrm{p} 236.229869 .0594-24.9206$

cuboid $3182.86522-11.25712$ 2p236.30092 69.13052 -24.99172

unit 109

com='revised unit 11 for second mo-1'

cuboid $51.702-1.039365 .80 .0 .536-.60$

hole $2 \quad 0.0 \quad 0.0-.6$

hole $3-1.0390 .0 \quad 0.0$

unit 110

com 'revised unit 12 for second mo- $1^{\prime}$

cuboid $51.702-1.039365 .80 .02$ p.60

hole $2 \quad 0.0 \quad 0.0 \quad-.60$

hole 10.00 .0 .60

hole $3-1.0390 .00 .0$

unit 111

com='revised unit 8 for second mo- 1 '

cuboid $510.0-.536365 .80 .0 .536-.60$

hole $4 \quad 0.00 .00 .0$

unit 112

com='revised unit 9 for second mo- 1 '

cuboid $510.0-.536365 .80 .02$ p.60

hole 40.00 .00 .0

unit 113

com $=$ 'revised unit 13 for second mo-1'

cuboid $51.702-1.039365 .80 .00 .0-.643$

hole 10.00 .00 .0

unit 114

com='revised unit 10 for second mo-1'

cuboid $510.0-.536365 .80 .00 .0-.643$

unit 115

com='revised unt 6 for second mo-1'

cuboid $512 \mathrm{p} 1.039365 .80 .0 .536-.60$

hole $2 \quad 0.00 .0-0.6$ hole 3-1.039 0.00 .0

hole $4 \quad 1.0390 .00 .0$

unit 116

com=revised unit 7 for second mo- 1 '

cuboid $512 \mathrm{p} 1.039365 .80 .00 .0-.643$

hole 10.00 .00 .0

unit 117

com $=$ 'revised unit 23 for second mo- $1^{\prime}$

cuboid $51.702-1.039365 .80 .0 .643-.60$

hole $2 \quad 0.0 \quad 0.0-6$

hole $3-1.0390 .0 \quad 0.0$

unit 118

com $=$ 'revised unit 21 for second mo-1'

cuboid $512 \mathrm{pl} .039365 .80 .0 .643-.60$

hole $20.00 .0-0.6$

hole $3-1.0390 .00 .0$

hole 41.0390 .00 .0

unit 119

com='revised unit 22 for second mo- 1

cuboid $510.0-.536365 .80 .0 .643-.60$

hole 40.00 .00 .0

unit 120

com='revised unit 24 for second mo-1'

cuboid $512 \mathrm{pl} .039365 .80 .00 .0-.536$

hole $10.00 .0 \quad 0.0$

unit 121

com='revised unit 25 for second mo- 1 '

cuboid $510.0-.536365 .80 .00 .0-.536$

unit 122

com='revised unit 26 for second mo-1

cuboid $51.702-1.039365 .80 .00 .0-.536$

hole 10.00 .00 .0

unit 123

com='bottom box with pins for second mo- 1 "

array $104-10.4895-182.9-10.4895$

cuboid $9110.9305-10.48952$ p182.9 $10.4895-10.9305$

unit 124

com ='top box with pins for second mo-l'

array $105-10.4895-182.9-10.4895$

cuboid $9110.9305-10.48952 \mathrm{p} 182.910 .9305-10.4895$

unit 125

com $=0.188$ in $\mathrm{z}$-thick neutron poison plate for second mo- ${ }^{\prime}$

cuboid $718.34-10.71365 .80 .02 \mathrm{p} 0.239$

cuboid $312 \mathrm{p} 10.71365 .80 .02 \mathrm{p} .239$

unit 126

com $=2$ boxes with poison plates, $h 20$ block on top'

array $\quad 107-10.71-182.9-24.9206$

unit 127

com 'second mo-1 with fuel in lower right corner

array $\quad 108-11.2688-182.9-24.9206$

cuboid $9111.2688-82.71132 \mathrm{p} 236.229869 .0594-24.9206$

cuboid $3111.33992-82.78242$ 2p236.30092 69.13052-24.99172

global unit 128

com $=2 \times 1 \times 1$ array of damaged mo-1s'

array $\quad 109-94.12234-236.30092-47.06112$

replicate $1026 * 3.010$

end geom

read array

ara $=1$ nux $=11$ nuy=1 nuz=18

fill

$119 \mathrm{r} 68$

$129 \mathrm{r} 59$

129 r5 9

129 r5 9

129 r5 9

$129 \mathrm{r} 59$

$129 \mathrm{r} 59$

129 r5 9 
12959

$129 \mathrm{r} 59$

$129 \mathrm{r} 59$

$129 r 59$

$129+59$

$129 \mathrm{r} 59$

12 ז59

$129 \mathrm{r} 59$

$129+59$

1395710

end fill

ara $=2$ nux $=11$ nuy=1 nuz=18

fill

239 r21 22

$129 r 59$

$129 \mathrm{r} 59$

$129 \mathrm{r} 59$

$129 \mathrm{r} 59$

129559

$129 \mathrm{r} 59$

$129 \mathrm{r} 59$

$129 \mathrm{r} 59$

$129 \mathrm{r} 59$

129.59

$129 \mathrm{r} 59$

$129 r 59$

$129 \mathrm{r} 59$

$129 r 59$

129 r5 9

129 r5 9

$269 \mathrm{r} 2425$

end fill

ara $=110$ nux $=1$ nuy $=1$ nuz $=1$

fill

20

end fill

ara $=111$ nux $=1$ nuy $=1$ nuz $=1$

fill

27

end fill

ara $=102$ nux $=1$ nury $=1$ nuz $=9$

com $=2$ boxes with poison plates h2o block on right side fill

$140142141105 \quad 105141142104151$

end fill

ara $=103$ nux $=3$ nuy $=1$ nuz $=1$

com $=$ 'boxes on strongback'

fill

106107171

end fill

ara $=104$ nux=11 nuy=1 nuzz=18

fill

1149 r116113

1129 r5 110

1129 r 5110

1129 r5 110

$1129 \mathrm{r} 5110$

$1129+5110$

$1129 \mathrm{r} 5110$

$1129 \mathrm{r} 5110$

1129 r5 110

1129 r5 110

$1129 \mathrm{r} 5110$

$1129 \mathrm{r} 5110$

$1129 \mathrm{r} 5110$

$1129 \mathrm{r} 5110$

$1129 \mathrm{r} 5110$

$1129 \mathrm{r} 5110$
$1129 \mathrm{r} 5110$

$1119 \mathrm{r} 115109$

end fill

ara $=105$ nux=11 nuy=1 nuz=18

fill

$1219 \mathrm{r} 120122$

$1129 r 5110$

1129 r5 110

1129 r5 110

$1129 \mathrm{r} 5110$

$1129 r 5110$

$1129 \mathrm{r} 5110$

112955110

1129 r5 110

$1129 \mathrm{r} 5110$

$1129 \mathrm{r} 5110$

$1129 \mathrm{r} 5110$

$1129 \mathrm{r} 5110$

$1129 \mathrm{r} 5110$

$1129 \mathrm{r} 5110$

$1129 \times 5110$

$1129 \mathrm{r} 5110$

$1199 \mathrm{r} 118117$

end fill

ara $=107$ nux $=1$ nuy=1 nuz $=9$ fill

123142141125125141142124151 end fill

ara $=108$ nux=3 nuy=1 nuz $=1$

com $=$ boxes on strongback in second $\mathrm{mo}^{-1} \mathrm{l}^{+}$

fill

171107126

end fill

ara $=109$ nux $=2$ nuy=1 nuz $=1$

fill

127108

end fill

end array

end data

end 


\section{A.2.2 Weapons-Grade MOX Fuel}

\section{A.2.2.1 Single-Package Model}

Case: lwc-2

$=\operatorname{csas} 25$ parm $=\operatorname{size}=140000$

case: lwc-2; 2 unspaced boxes of wg mox pins 1.10 pitch, wall $\mathrm{dt}=0.028$ in

238group latticecell

pu-239 $10.01 .162 \mathrm{e}-3483.15$ end

pu-240 $\quad 10.07 .297 \mathrm{e}-5483.15$ end

pu-241 $10.04 .964 \mathrm{e}-6483.15$ end

pu-242 $\quad 10.01 .241 \mathrm{e}-6483.15$ end

u-234 $10.04 .326 \mathrm{e}-6483.15$ end

u-235 $\quad 10.04 .391 \mathrm{e}-5483.15$ end

u-236 $10.02 .163 \mathrm{e}-6483.15$ end

$\mathrm{u}-238 \quad 10.02 .159 \mathrm{e}-2483.15$ end

$0 \quad 10.04 .575 \mathrm{e}-2483.15$ end

zirc2 21.0483 .15 end

carbonsteel 31.0483 .15 end

h2o $\quad 41.0483 .15$ end

h2o $\quad 51.0483 .15$ end

h $\quad 60.01 .9621 \mathrm{e}-3483.15$ end

c $\quad 60.02 .1847 \mathrm{e}-3483.15$ end

$60.04 .167 \mathrm{e}-4 \mathrm{483.15}$ end

$60.08 .864 \mathrm{e}-4483.15$ end

arbm-boronss304 7.74510150000.975 2600068.82

2400018.81280009 .41120001 .9871 .0483 .15 end

polyethylene 81.0483 .15 end

h2o $\quad 91.0483 .15$ end

h2o $\quad 101.0483 .15$ end

end comp

triangpitch 1.100 .7844140 .91442 end

case: lwc-2; 2 unspaced boxes of wg mox pins 1.10 pitch, wall $\mathrm{dt}=0.028 \mathrm{in}$

read parm nub $=y e s$ npg $=600$ gen $=400$ tme $=100$ nsk $=20$ plt-yes end parm

read geom

unit 1 com $=-x$ hemicyl fuel unit cell

yhemicyl-z 110.3922365 .80 .0

yhemicyl-z 210.4572365 .80 .0

unit 2 com $=-x$ hemicyl fuel unit cell'

yhemicyltz 110.3922365 .80 .0

yhemicyltz 210.4572365 .80 .0

unit 3 com $=-x$ hemicyl fuel unit cell'

yhemicyl $+x 110.3922365 .80 .0$

yhemicyltx 210.4572365 .80 .0

unit 4 com $=-x$ hemicyl fuel unit cell

yhemicyl-x 110.3922365 .80 .0

yhemicyl-x 210.4572365 .80 .0

unit 5

$\begin{array}{lllll}\text { cuboid } 41 & 2 p .55 & 365.8 & 0.0 & 2 p .9526\end{array}$

hole $1 \quad 0.0 \quad 0.0 .9526$

$\begin{array}{lllll}\text { hole } 2 & 0.0 & 0.0 & -.9526\end{array}$

hole $3 \quad-.55 \quad 0.0 \quad 0.0$

hole $4 \quad .55 \quad 0.0 \quad 0.0$

unit 6

cuboid $41.55 \quad-.4572 \quad 365.8 \quad 0.0 \quad 2 p .9526$

hole 10.00 .0 .9526

hole $2 \begin{array}{lllll}2 & 0.0 & 0.0 & -.9526\end{array}$

hole 4.550 .00 .0

unit 7

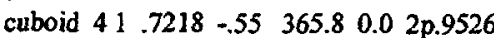

hole $1 \quad 0.0 \quad 0.0 .9526$

hole $2 \quad 0.0 \quad 0.0 \quad-.9526$

hole $3-55 \quad 0.000$ unit 8

$\begin{array}{lllllll}\text { cuboid } 4 & 1.55 & -.4572 & 365.8 & 0.0 & 0.0 & -.4572\end{array}$

hole 10.00 .00 .0

uni 9

cuboid $412 \mathrm{2p} .55365 .8 \quad 0.0 \quad 0.0 \quad-.4572$

hole 10.00 .00 .0

unit 10

cuboid $41.7218 \quad-.55365 .8 \quad 0.0 \quad 0.0 \quad-.4572$

hole 10.00 .00 .0

unit 11

cuboid $41.55 \quad-.4572 \quad 365.8 \quad 0.0 \quad .5172 \quad-.9526$

hole $20.00 .0-.9526$

hole 4.550 .00 .0

unit 12

cuboid 412 2p.55 $365.8 \quad 0.0 \quad .5172-.9526$

hole $2 \quad 0.0 \quad 0.0-.9526$

hole 4.550 .00 .0

hole $3-.550 .00 .0$

unit 13

cuboid $41.7218 \quad-.55 \quad 365.8 \quad 0.0 \quad .5172-.9526$

hole $20.00 .0-.9526$

hole $3-.550 .00 .0$

unit 20

com='right box with pins'

array $1-10.4895-182.9-10.4895$

cuboid $9110.9305-10.48952$ p182.9 $10.9305-10.4895$ unit 21

com='revised unit 6 for left box'

cuboid $41 \quad .55 \quad-.7218 \quad 365.8 \quad 0.0 \quad 2 p .9526$

hole 10.00 .09526

hole $2 \quad 0.0 \quad 0.0-.9526$

hole 4.550 .00 .0

unit 22

com='revised unit 8 for left box'

$\begin{array}{lllllll}\text { cuboid } 4 & 1.55 & -.7218 & 365.8 & 0.0 & 0.0 & -.4572\end{array}$

hole 10.00 .00 .0

unit 23

com ' 'revised unit 11 for left box'

cuboid $41.55 \quad-.7218 \quad 365.8 \quad 0.0 \quad .5172-.9526$

hole $2 \quad 0.0 \quad 0.0-.9526$

hole 4.550 .00 .0

unit 24

com='revised unit 7 for left box'

cuboid $41.4572 \quad-.55 \quad 365.8 \quad 0.0 \quad 2 p .9526$

hole $1 \quad 0.0 \quad 0.0 .9526$

hole $2 \quad 0.0 \quad 0.0 \quad-.9526$

hole $3-.55 \quad 0.00 .0$

unit 25

com='revised unit 10 for left box'

cuboid $41.4572 \quad-.55365 .8 \quad 0.0 \quad 0.0 \quad-.4572$

hole 10.00 .00 .0

unit 26

com='revised unit 13 for left box'

cuboid $41.4572 \quad-.55 \quad 365.8 \quad 0.0 \quad .5172-.9526$

hole $2 \quad 0.00 .0-.9526$

hole $3-.550 .00 .0$

unit 27

com=left box with pins'

array $2-10.4895-182.9-10.4895$

cuboid $9110.4895-10.9305$ 2pl $82.910 .9305-10.4895$

unit 104 com $\approx$ right box with pins for placement' 
array $\quad 110-10.71-182.9-10.71$

unit $140 \mathrm{com}=$ "left box with pins for placement'

array $111-10.71-182.9-10.71$

unit 141

com=' .19 in $\mathrm{x}$-thick strongback plate'

$\begin{array}{lllllll}\text { cuboid } 3 & 1 & 2 \mathrm{p} .2413 & 365.8 & 0.0 & 2 \mathrm{p} & 10.71\end{array}$

unit 142

com $=.25$ in $x$-thick h2o(cork)'

$\begin{array}{llllllll}\text { cuboid } 9 & 1 & 2 \mathrm{p} .3175 & 365.8 & 0.0 & 2 \mathrm{p} 10.71\end{array}$

unit $105 \mathrm{com}=0.188$ in $\mathrm{x}$-thick neutron poison plate'

cuboid $712 \mathrm{p} 0.239365 .80 .08 .34-10.71$

cuboid $312 \mathrm{p} .239365 .8 \quad 0.02 \mathrm{p} 10.71$

unit 151

$\mathrm{co}^{-}$'water block outside of box'

cuboid $912 \mathrm{p} 0.9525365 .80 .02 \mathrm{p} 10.71$

unit 106

com $=2$ assemblies with poison plates, $x$-strong back plates and spacing'

array $102-24.9206-182.9-10.71$

unit 107

com='strong back plate for assemblies'

cuboid $9111.345-10.712 \mathrm{p} 182.92 \mathrm{p} 0.3175$

cuboid $3111.8276-10.712 \mathrm{p} 182.92 \mathrm{p} 0.3175$

cuboid $7112.3056-10.712 \mathrm{p} 182.92 \mathrm{p} 0.3175$

cuboid $9116.1156-10.712 \mathrm{p} 182.92 \mathrm{p} 0.3175$

cuboid $7116.5936-10.712 \mathrm{p} 182.92 \mathrm{p} 0.3175$

cuboid $3117.0762-10.712 p 182.92 p 0.3175$

cuboid $9139.1312-10.712 \mathrm{p} 182.92 \mathrm{p} 0.3175$

unit 171

cuboid $3111.8276-10.712 \mathrm{p} 182.92 \mathrm{p} 0.2413$

cuboid $7112.3056-10.712 p 182.92 p 0.2413$

cuboid $9116.1156-10.712 \mathrm{p} 182.92 \mathrm{p} 0.2413$

cuboid $7116.5936-10.712 \mathrm{p} 182.92 \mathrm{p} 0.2413$

cuboid $3139.1312-10.712 \mathrm{p} 182.92 \mathrm{p} 0.2413$

global unit 108

com = assemblies in mo- $\mathrm{I}^{\prime}$

array $\quad 103-24.9206-182.9-11.186$

cuboid $912 \mathrm{p} 46.992 \mathrm{p} 236.229840 .64-53.34$

cuboid $\quad 312 \mathrm{p} 47.061122 \mathrm{p} 236.3009240 .71112 \quad .53 .41112$

replicate $1026 * 3.010$

end geom

read array

$a r a=1$ nux=19 nuy $=1$ nuz $=12$

fill

$817 \times 910$

$617 \mathrm{r} 57$

$6 \quad 17 \mathrm{r} 57$

$6 \quad 17 r 57$

$6 \quad 17 \mathrm{r} 57$

$617 \mathrm{r} 57$

$\begin{array}{lll}6 & 17 r 57\end{array}$

617157

$\begin{array}{lll}6 & 17 \mathrm{r} 57\end{array}$

$\begin{array}{lll}6 & 17 \mathrm{r} 57\end{array}$

$617 \mathrm{r} 57$

$1117 \mathrm{r} 1213$

end fill

ara $=2$ nux=19 nuy=1 nuz $=12$

fill

$2217 \mathrm{r} 925$

$2117 r 524$

$2117 \mathrm{r} 524$

$2117 \mathrm{r} 524$

$2117 \mathrm{r} 524$

$2117 \mathrm{r} 524$

$2117 \mathrm{r} 524$

$2117 \mathrm{r} 524$

$2117 \mathrm{r} 524$

$2117 \mathrm{r} 524$
$2117 r 524$

$2317 \times 1226$

end fill

ara $=110$ nux $=1$ nuy=1 nuz $z=1$

fill

20

end fill

ara $=111$ nux $=1$ nuy $=1$ nuz $=1$

fill

27

end fill

ara $=102$ nux $=10$ nuy=1 nuz $=1$

com $=2$ boxes with poison plates'

fill

$151140142141105 \quad 105141142104151$ end fill

ara $=103$ nux $=1$ nuy $=1$ nuz $z=3$

com='boxes on strongback'

fill

171107106

end fill

end array

end data

end 


\section{A.2.2.2 Package-Array Model}

Case: lwar-00

$=\operatorname{csas} 25$ parm $=s i z e=140000$

case: Iwar-00; $2 \times 1 \times 1$ damaged mo-1s wg mox pins fuel in corner, $\mathrm{dt}=0.028 \mathrm{in}$

238group latticecell

pu-239 $10.01 .162 \mathrm{e}-3483.15$ end

pu-240 $10.07 .297 \mathrm{e}-5483.15$ end

pu-241 $10.04 .964 \mathrm{e}-6483.15$ end

pu-242 $10.01 .241 \mathrm{e}-6483.15$ end

u-234 $10.04 .326 \mathrm{e}-6483.15$ end

u-235 $10.04 .391 \mathrm{e}-5483.15$ end

u-236 $10.02 .163 \mathrm{e}-6483.15$ end

u-238 $10.02 .159 \mathrm{e}-2483.15$ end

$0 \quad 10.04 .575 \mathrm{e}-2483.15$ end

zirc2 21.0483 .15 end

carbonsteel 31.0483 .15 end

h2o $\quad 41.0483 .15$ end

h20 51.0483 .15 end

h $\quad 60.01 .9621$ e-3 483.15 end

c $\quad 60.02 .1847 \mathrm{e}-3483.15$ end

n $\quad 60.04 .167 \mathrm{e}-4483.15$ end

o $\quad 60.08 .864 \mathrm{e}-4483.15$ end

arbm-boronss3047.7451015000 0.9752600068 .82

2400018.81280009 .41120001 .9871 .0483 .15 end

polyethylene 81.0483 .15 end

h2o $\quad 91.0483 .15$ end

h2o $\quad 101.0483 .15$ end

end comp

triangpitch 1.100 .7844140 .91442 end

case: lwar-00; $2 \times 1 \times 1$ damaged mo-1s wg mox pins fuel in comer, $\mathrm{dt}=0.028 \mathrm{in}$

read parm nub-yes npg $=600$ gen $=400$ tme $=100$ nsk $=20$ plt-yes end parm

read geom

unit 1 com=-x hemicyl fuel unit cell

yhemicyl-z 110.3922365 .80 .0

yhemicyl-z 210.4572365 .80 .0

unit 2 com $=-x$ hemicyl fuel unit cell

yhemicyltz 110.3922365 .80 .0

yhemicyltz 210.4572365 .80 .0

unit 3 com $=-x$ hemicyl fuel unit cell'

yhemicyltx 110.3922365 .80 .0

yhemicyltx 210.4572365 .80 .0

unit 4 com='-x hemicyl fuel unit cell'

yhemicyl-x 110.3922365 .80 .0

yhemicyl-x 210.4572365 .80 .0

unit 5

cuboid 41 2p.9526 $365.8 \quad 0.02$ p.55

hole 10.00 .0 .55

bole $20.00 .0-.55$

hole $3-.95260 .00 .0$

hole $4 \quad .9526 \quad 0.0 \quad 0.0$

unit 6

cuboid 412 2p.9526 $365.80 .0 .55-.4572$

hole 10.00 .0 .55

hole $3-.95260 .00 .0$

hole $4 \quad .95260 .00 .0$

unit 7

cuboid 412 p.9526 $365.80 .0 .7218-.55$

hole $20.00 .0-.55$

hole $3 \quad-.95260 .00 .0$

hole 4.95260 .00 .0

unit 8

cuboid $41.45720 .0365 .80 .0 .55-.4572$

hole 30.00 .00 .0 unit 9

cuboid 41.45720 .0365 .0 .02 p.55

hole $3 \quad 0.00 .00 .0$

unit 10

cuboid $41.45720 .0365 .80 .0 .7218-.55$

hole $3 \quad 0.00 .00 .0$

unit 11

cuboid 41 1.9526 $-.5172365 .80 .0 .55 \quad-.4572$

hole 10.00 .0 .55

hole 4.95260 .00 .0

unit 12

cuboid $41.9526-.5172365 .80 .02$ p.55

hole $20.00 .0-.55$

hole 10.00 .0 .55

hole 4.95260 .00 .0

unit 13

cuboid $41.9526-.5172365 .80 .0 .7218-.55$

hole $20.00 .0-.55$

hole 40.95260 .00 .0

unit 20

com='right box with pins'

array $1-10.4895-182.9-10.4895$

cuboid $9110.4895-10.93052 p 182.910 .9305-10.4895$

unit 21

com='revised unit 6 for left box'

cuboid 412 2p.9526 365.80 .0 .55 -.7218

hole 10.00 .0 .55

hole $3-.95260 .00 .0$

hole 4.95260 .00 .0

unit 22

com $=$ 'revised unit 8 for left box'

cuboid $41.45720 .0365 .80 .0 .55-.7218$

hole 30.00 .00 .0

unit 23

com 'revised unit 11 for left box'

cuboid $41.9526-.5172365 .80 .0 .55 \quad-.7218$

hole $1 \quad 0.0 \quad 0.0 .55$

hole 4.95260 .00 .0

unit 24

com='revised unit 7 for left box'

cuboid $412 \mathrm{2p} .9526365 .80 .0 .4572 \quad-.55$

hole $2 \quad 0.0 \quad 0.0-.55$

hole $3 \quad-.95260 .00 .0$

hole 4.95260 .00 .0

unit 25

com='revised unit 10 for left box'

cuboid $41.45720 .0365 .8 \quad 0.0 .4572-.55$

hole $3 \quad 0.00 .00 .0$

unit 26

com='revised unit 13 for left box'

cuboid $41.9526-.5172365 .80 .0 \quad 4572-.55$

hole $20.00 .0-.55$

hole 4.95260 .00 .0

unit 27

com=left box with pins'

array $2-10.4895-182.9-10.4895$

cuboid $9110.4895-10.93052$ p182.9 $10.4895-10.9305$

unit 104 com $=$ 'right box with pins for placement'

array $\quad 110-10.71-182.9-10.71$

unit $140 \mathrm{com}=$ 'left box with pins for placement

array $111-10.71-182.9-10.71$

unit 141

com $=19$ in z-thick strongback plate'

cuboid 312 p 10.71365 .80 .02 p.2413 
unit 142

com $=25$ in z-thick $\mathrm{h} 2 \mathrm{o}$ (cork)

cuboid 912 p10.71 $365.80 .02 p .3175$

unit 105 com=' 0.188 in $\mathrm{x}$-thick neutron poison plate'

cuboid $7110.71-8.34365 .80 .02 \mathrm{p} 0.239$

cuboid $312 \mathrm{p} 10.71365 .80 .02 \mathrm{p} .239$

unit 151

com='water block outside of box'

cuboid $912 \mathrm{p} 10.71365 .80 .02 \mathrm{p} 1.905$

unit 106

com='2 boxeswith poison plates, h2o block on right side'

array $\quad 102-10.71-182.9-24.9206$

unit 107

com='strong back plate for assemblies'

cuboid $312 \mathrm{p} 0.31752 \mathrm{p} 182.911 .8276-10.71$

cuboid $712 \mathrm{p} 0.31752 \mathrm{p} 182.912 .3056-10.71$

cuboid $712 \mathrm{p} 0.31752 \mathrm{p} 182.912 .7836-10.71$

cuboid $\quad 312 \mathrm{p} 0.31752 \mathrm{p} 182.939 .1312-10.71$

unit 171

cuboid $312 \mathrm{p} 0.24132 \mathrm{p} 182.911 .8276-10.71$

cuboid $712 \mathrm{p} 0.24132 \mathrm{p} 182.912 .3056-10.71$

cuboid $712 \mathrm{p} 0.24132 \mathrm{p} 182.912 .7836-10.71$

cuboid $312 \mathrm{p} 0.24132 \mathrm{p} 182.939 .1312-10.71$

unit 108

com=mo-1 with fuel shifted to lower left corner

array $\quad 103-11.2688-182.9-24.9206$

cuboid $\quad 9182.7113-11.26882 \mathrm{p} 236.229869 .0594-24.9206$

cuboid $3182.78242-11.339922$ 2p236.30092 69.13052-24.99172

unit 109

com='revised unit 11 for second mo- 1 '

cuboid $41.5172-.9526365 .80 .0 .55-.4572$

hole 10.00 .0 .55

hole $3 \quad-.95260 .00 .0$

unit 110

com='revised unit 12 for second mo-1'

cuboid $41.5172-.9526365 .80 .02 p .55$

hole $20.00 .0-.55$

hole 10.00 .0 .55

hole $3-.95260 .00 .0$

unit 111

com 'revised unit 8 for second mo- $1^{\prime}$

cuboid $410.0-.4572365 .80 .0 .55-.4572$

hole 40.00 .00 .0

unit 112

com $=$ 'revised unit 9 for second mo-1'

cuboid $410.0-.4572365 .80 .02$ p.55

hole 40.00 .00 .0

unit 113

com ' 'revised unit 13 for second mo- 1 '

cuboid $41.5172-.9526365 .80 .0 .7218-.55$

hole $20.00 .0-55$

hole $3-0.95260 .00 .0$

unit 114

com ='revised unit 10 for second mo-1'

cuboid $410.0-.4572365 .80 .0 .7218-.55$

hole 40.00 .00 .0

unit 115

com='revised unit 23 for second mo-1'

cuboid $41.5172-.9526365 .80 .0 .55 \quad-.7218$

hole $1 \quad 0.0 \quad 0.0 .55$

hole $3 \quad-.95260 .00 .0$

unit 116

com='revised unit 22 for second mo-1'

cuboid $410.0-.4572365 .80 .0 .55-.7218$

hole $4 \quad 0.00 .00 .0$

unit 117

com='revised unit 26 for second mo-1'

cuboid $41.5172-.9526365 .80 .0 .4572 \quad-.55$ hole $2 \quad 0.00 .0-.55$

hole $3-.95260 .00 .0$

unit 118

com='revised unit 25 for second mo- 1

cuboid $4110.0-.4572365 .8 \quad 0.0 .4572-.55$

hole 40.00 .00 .0

unit 119

com $=$ 'botom box with pins for second mo- 1 '

array $104-10.4895-182.9-10.4895$

cuboid $9110.9305-10.48952$ p182.9 $10.4895-10.9305$

unit 120

com='top box with pins for second mo-l'

array $105-10.4895-182.9-10.4895$

cuboid $9110.9305-10.48952 \mathrm{p} 182.910 .9305-10.4895$

unit 121

com $=0.188$ in $z$-thick neutron poison plate for second mo- $1^{*}$

cuboid $718.34-10.71365 .80 .02 \mathrm{p} 0.239$

cuboid $312 \mathrm{p} 10.71365 .80 .02 \mathrm{p} .239$

unit 122

com $=$ ' 2 boxes with poison plates, $h 20$ block on top'

array $\quad 107-10.71-182.9-24.9206$

unit 123

com 'second mo-1 with fuel in lower right comer'

array $\quad 108-11.2688-182.9-24.9206$

cuboid $9111.2688-82.71132$ 2p236.2298 $69.0594-24.9206$

cuboid $3111.33992-82.78242$ 2p236.30092 69.13052 -24.99172

global unit 124

com $=2 \times 1 \times 1$ array of damaged mo-1s'

array $\quad 109-94.12234-236.30092-47.06112$

replicate $1026 * 3.010$

end geom

read array

$a r a=1$ nux $=12$ nuy=1 nuz=19

fill

$1110 \mathrm{rr} 8$

$1210 \mathrm{r} 59$

$1210 r 59$

$1210 \mathrm{r} 59$

$1210 r 59$

$1210 r 59$

$1210 \mathrm{r} 59$

$1210 \mathrm{r} 59$

$1210 \mathrm{r} 59$

$1210 \mathrm{r} 59$

1210 r5 9

$1210 r 59$

$1210 \mathrm{r} 59$

$1210 \mathrm{r} 59$

$1210 \mathrm{r} 59$

$1210 r 59$

$1210 r 59$

$1210 \mathrm{r} 59$

$1310 \times 710$

end fill

ara $=2$ nux=12 nuy=1 nuz=19

fill

$2310 r 2122$

$1210 r 59$

$1210 \mathrm{r} 59$

$1210 \mathrm{r} 59$

$1210 r 59$

$1210 \mathrm{r} 59$

$1210 \mathrm{r} 59$

$1210 \mathrm{r} 59$

$1210 \mathrm{r} 59$

$1210 r 59$

$1210 \mathrm{r} 59$

$1210 r 59$ 
1210 r5 9

$1210 \mathrm{r} 59$

$1210 r 59$

1210559

$1210 r 59$

$1210 r 59$

$2610 \mathrm{r} 2425$

end fill

ara $=110$ nux $=1$ nuy $=1$ nuz $=1$

fill

20

end fill

ara $=111$ nux $=1$ nuy $=1$ nuz $=1$

fill

27

end fill

ara $=102$ nux $=1$ nuy $=1$ nuz $=9$

com $=2$ boxes with poison plates'

fill

$140142141105 \quad 105141142104151$

end fill

ara $=103$ nux $=3$ nuy $=1$ nuz $=1$

com='boxes on strongback'

fill

106107171

end fill

ara $=104$ nux $=12$ nuy= $=1$ nuz $=19$

fill

$11610 \mathrm{r} 21115$

$11210 \mathrm{r} 5110$

$11210 \mathrm{r} 5110$

$11210 r 5110$

$11210 r 5110$

$11210 \mathrm{r} 5110$

$11210 r 5110$

$11210 \mathrm{r} 5110$

$11210 \mathrm{r} 5110$

112 10r5 110

$11210 \mathrm{r} 5110$

$11210 \mathrm{r} 5110$

11210 r5 110

$11210 \mathrm{r} 5110$

$11210 \mathrm{r} 5110$

$11210 r 5110$

112 10r5 110

1121055110

$11810 r 24117$

end fill

ara=105 nux=12 nuy=1 nuz=19

fill

1111016109

$11210 \mathrm{r} 5110$

$11210 \mathrm{r} 5110$

$11210 \mathrm{r} 5110$

$11210 \mathrm{r} 511011210 \mathrm{r} 5110$

112 10r5 110

$11210 \mathrm{r} 5110$

$11210 r 5110$

$11210 \mathrm{r} 5110$

$11210 \mathrm{r} 5110$

$11210 \mathrm{r} 5110$

$11210 \mathrm{r} 5110$

$11210 \mathrm{r} 5110$

$11210 \mathrm{r} 5110$

$11210 \mathrm{r} 110$

$11210 \mathrm{r} 5110$

$11210 \mathrm{r} 5110$

$11410 \mathrm{r} 7113$ end fill

ara $=107$ nux $=1$ nuy $=1$ nuz $=9$

fill

$119142141121 \quad 121141142120151$

end fill

ara $=108$ nux $=3$ nuy $=1$ nuz $=1$

com='boxes on strongback in second $\mathrm{mo-1}^{\prime}$

fill

171107122

end fill

ara $=109$ nux $=2$ nuy $=1$ nuz $=1$

fill

123108

end fill

end array

end data

end 
APPENDIX B

VOLUME FRACTION CALCULATION FOR $\mathrm{H}_{2} \mathrm{O}$ 



\section{APPENDIX B}

\section{VOLUME FRACTION CALCULATION FOR $\mathrm{H}_{2} \mathrm{O}$}

Given the hydrogen atom density, the corresponding water volume fraction can be calculated as follows.

The atom density for water is given by the following the equation:

$$
N_{h_{2} \mathrm{O}}=\frac{\rho_{h_{2} \mathrm{O}} N_{A} C}{A_{h_{2} \mathrm{O}}} .
$$

where

$\rho_{\mathrm{h} 20}=$ density of water $(\mathrm{g} / \mathrm{cc})$,

$\mathrm{N}_{\mathrm{A}}=$ Avogadro's Number $=6.0221367 \times 10^{-23}$ atoms $/ \mathrm{mo}$,

$\mathrm{C}=$ constant multiplier $=1 \times 10^{-2} \mathrm{~cm}^{2} / \mathrm{barn}$,

$\mathrm{A}_{\mathrm{h} 2 \mathrm{o}}=$ atomic mass $(\mathrm{g} / \mathrm{mol})$.

Solving Eq. (B.1) for $\rho$, the density of water can be expressed as follows:

$$
\rho_{h_{2} \mathrm{O}}=\frac{N_{h_{2} \mathrm{o}} A_{h_{2} \mathrm{o}}}{N_{A} C} .
$$

Since there are two hydrogen atoms for each water molecule, the water density can be expressed in terms of the hydrogen atom density, $\mathrm{N}_{\mathrm{H}}$ :

$$
\rho_{h_{2} \mathrm{O}}=\frac{\frac{N_{h}}{2} A_{h_{2} \mathrm{o}}}{N_{A} C} .
$$

The volume fraction is the ratio of the actual water density to the theoretical water density, $\rho^{\text {th }}{ }_{\mathrm{h} 2}$ :

$$
V F=\frac{\rho_{h_{2} \circ}}{\rho_{h_{2} \circ}^{t h}} .
$$

The atomic mass and theoretical density for water is $18.0058 \mathrm{~g} / \mathrm{mol}\left(3.97 \times 10^{-2} \mathrm{lb} / \mathrm{mol}\right)$ and $0.9982 \mathrm{~g} / \mathrm{cc}$ $\left(0.036 \mathrm{lb} / \mathrm{in}^{3}{ }^{3}\right)$, respectively. For a hydrogen atom density of 0.031 atoms $/ \mathrm{b}-\mathrm{cm}$, the density of water is $0.463 \mathrm{~g} / \mathrm{cc}\left(0.017 \mathrm{lb} / \mathrm{in}^{3}\right)$, which corresponds to a volume fraction of 0.46 . 
ORNL/TM-13741

\section{INTERNAL DISTRIBUTION}

1. J. M. Begovich

2. B. B. Bevard

3. S. M. Bowman

4. B. L. Broadhead

5. S. L. Byerly

6-10. W. C. Carter

11. B. S. Cowell

12. A. G. Croff

13. M. D. DeHart

14. E. E. Duncan

15-19. M. E. Dunn

20. K. R. Elam

21. M. B. Emmett

22. S. E. Fisher

23. C. W. Forsberg

24. E. C. Fox

25. P. B. Fox

26. S. R. Greene

27. S. A. Hodge

28. R. F. Holdaway

29. D. F. Hollenbach

30. C. M. Hopper

31. T. W. Horning

32. J. D. James

33. W. C. Jordan

34. M. A. Kuliasha

35-39. S. B. Ludwig
40. G. T. Mays

41. S. D. McGhee

42. L. E. McNeese

43. G. E. Michaels

44. R. D. Michelhaugh

45. R. N. Morris

46. D. L. Moses

47. B. D. Murphy

48. D. G. O'Connor

49. C. V. Parks

50. L. M. Petrie

51. K. A. Pilcher

52. R. B. Pope

53. R. T. Primm III

54. B. T. Rearden

55. W. J. Reich

56. C. H. Shappert

57. L. B. Shappert

58-59. D. J. Spellman

60. R. M. Westfall

61. V.S. White

62. C. K. Williams

63. K. A. Williams

64. D. L. Williams, Jr.

65. Central Research Library

66. FMDP Library

67. ORNL Laboratory Records-RC

68-69. Laboratory Records -

for submission to OSTI

\section{EXTERNAL DISTRIBUTION}

70. J. E. Didlake, Jr., Sandia National Laboratories, MS-9014, 7011 E. Avenue, Livermore, CA 94551-0969

71-72. R. I. Elder, U. S. Department of Energy, CH, Argonne Area Office, Bldg. 201, 3H-01, 9800 South Cass Avenue, Argonne, IL 60439

73. J. V. Johnson, Office of Fissile Materials Disposition, U.S. Department of Energy, MD-4, Forrestal Bldg., 6G-050, 1000 Independence Avenue SW, Washington, DC 20585 
74. P. B. Lester, U.S. Department of Energy, Oak Ridge Operations Office, DOE/OR, 55 Jefferson, Rm. 114, Oak Ridge, TN 37831

75. J. J. Lichtenwalter, Bechtel Jacobs Company LLC, P. O. Box 4699, Bldg. K-1320, MS-7592, Oak Ridge, TN 37831-7592

76. J. D. Nulton, Office of Fissile Materials Disposition, U.S. Department of Energy, MD-4, Forrestal Bldg., 6G-050, 1000 Independence Avenue SW, Washington, DC 20585

77. D. Peko, Office of Fissile Materials Disposition, U.S. Department of Energy, MD-3, Forrestal Bldg., 6G-050, 1000 Independence Avenue SW, Washington, DC 20585

78. P. T. Rhoads, Office of Fissile Materials Disposition, U.S. Department of Energy, MD-3, Forrestal Bldg., 6G-050, 1000 Independence Avenue SW, Washington, DC 20585

79. R. C. Selby, U. S. Department of Energy, CH, Argonne Area Office, Bldg. 201, Rm. 362, 9800 South Cass Avenue, Argonne, IL 60439

80. P. Kasik, MPR Associates Inc., 320 King Street, Alexandria, VA 22314-3238

81. J. H. Thompson, Office of Fissile Materials Disposition, U.S. Department of Energy, MD-4, Forrestal Bldg., 6G-081, 1000 Independence Avenue SW, Washington, DC 20585

82. D. M. Willaford, U.S. Department of Energy, Oak Ridge Operations Office, DOE/OR, Federal Bldg., 200 Administration Road, Oak Ridge, TN 37831 